\title{
Orderly chaos
}

Citation for published version (APA):

Schalbroeck, R. (2021). Orderly chaos: social defeat as a risk factor for psychosis in autism. [Doctoral Thesis, Maastricht University]. Maastricht University. https://doi.org/10.26481/dis.20211105rs

Document status and date:

Published: 01/01/2021

DOI:

10.26481/dis.20211105rs

Document Version:

Publisher's PDF, also known as Version of record

\section{Please check the document version of this publication:}

- A submitted manuscript is the version of the article upon submission and before peer-review. There can be important differences between the submitted version and the official published version of record.

People interested in the research are advised to contact the author for the final version of the publication, or visit the DOI to the publisher's website.

- The final author version and the galley proof are versions of the publication after peer review.

- The final published version features the final layout of the paper including the volume, issue and page numbers.

Link to publication

\footnotetext{
General rights rights.

- You may freely distribute the URL identifying the publication in the public portal. please follow below link for the End User Agreement:

www.umlib.nl/taverne-license

Take down policy

If you believe that this document breaches copyright please contact us at:

repository@maastrichtuniversity.nl

providing details and we will investigate your claim.
}

Copyright and moral rights for the publications made accessible in the public portal are retained by the authors and/or other copyright owners and it is a condition of accessing publications that users recognise and abide by the legal requirements associated with these

- Users may download and print one copy of any publication from the public portal for the purpose of private study or research.

- You may not further distribute the material or use it for any profit-making activity or commercial gain

If the publication is distributed under the terms of Article $25 \mathrm{fa}$ of the Dutch Copyright Act, indicated by the "Taverne" license above, 


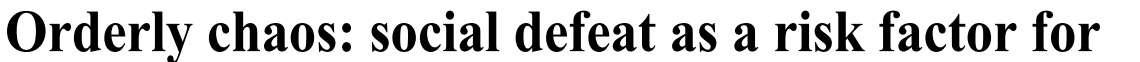

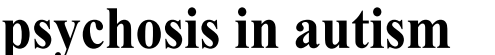

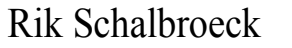


$\square$

पाण्य

पाणाणापणाएण

$\square$

पा11

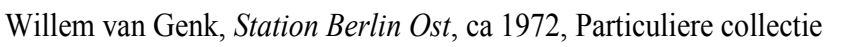

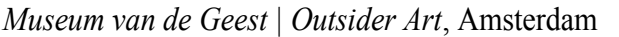

$\square$

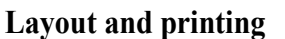

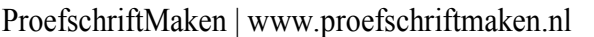

$\square$

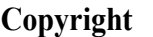

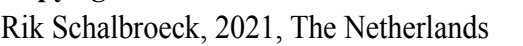




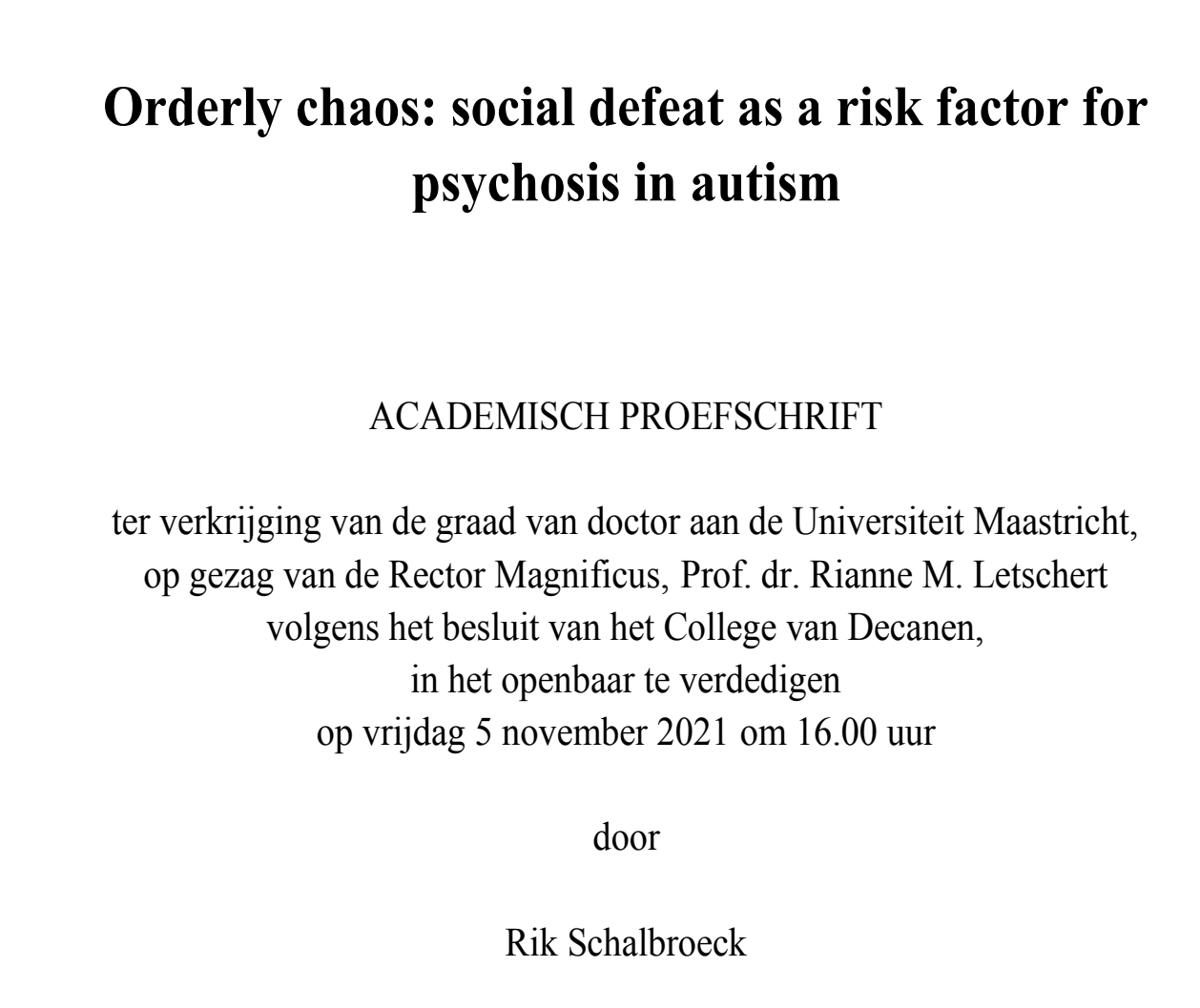


पणएवणाए

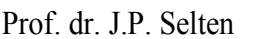

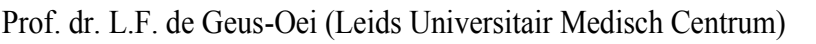

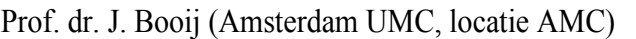

$\square$

$\square$

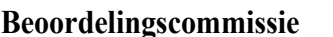

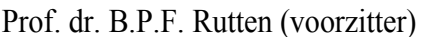

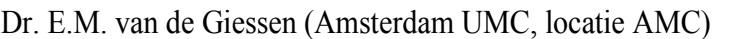

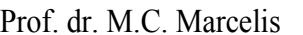

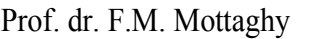

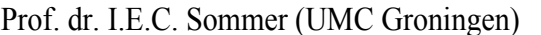



$\square$ 


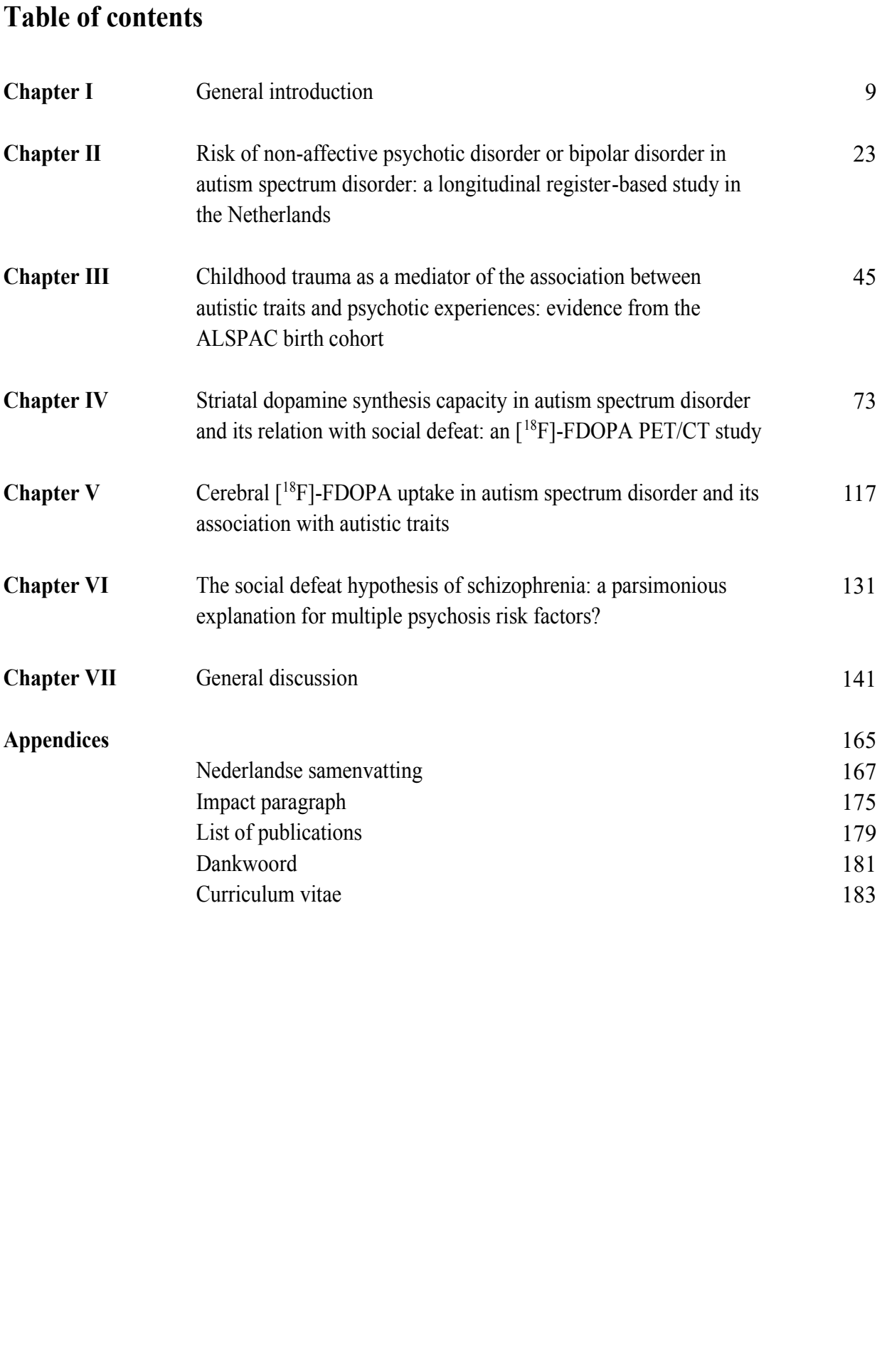




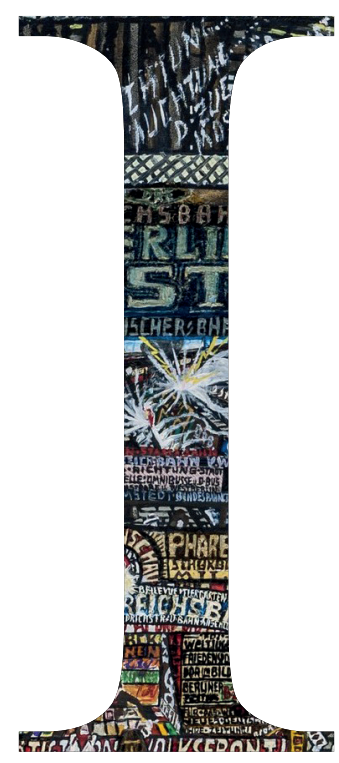


Chapter I

General introduction 
Chapter I

$\square$

$\square$ 


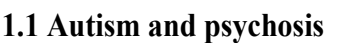

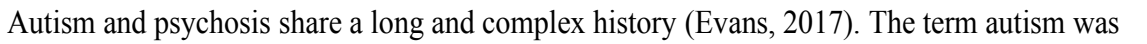

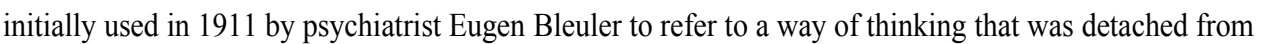

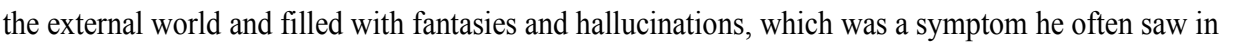

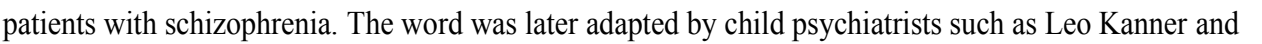

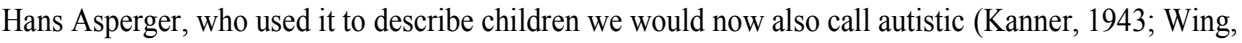

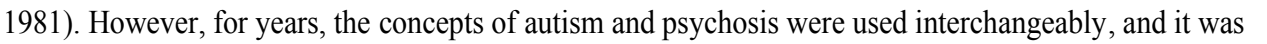

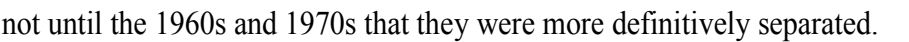

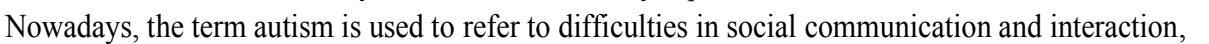

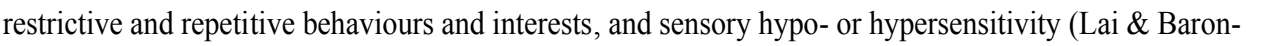

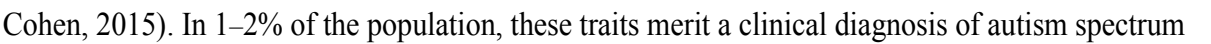

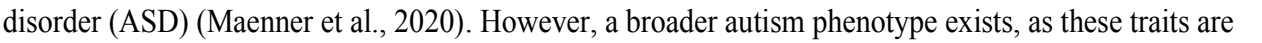

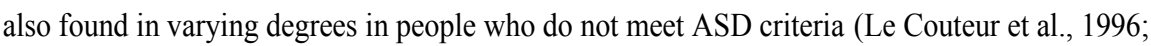

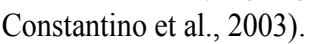

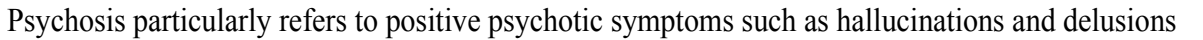

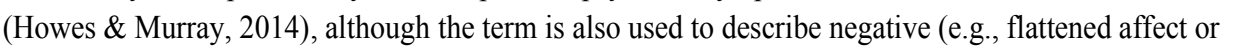

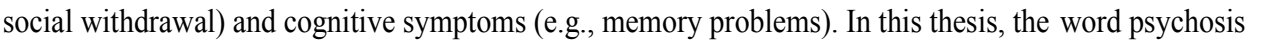

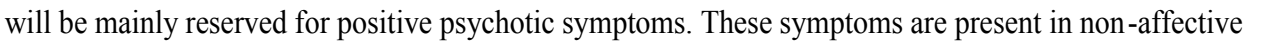

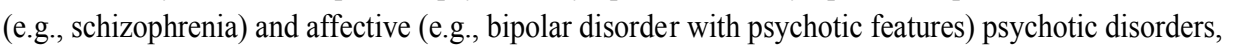

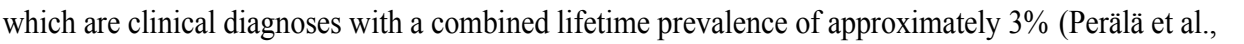

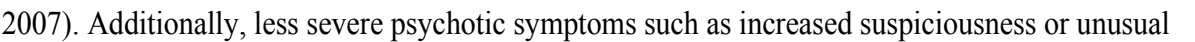

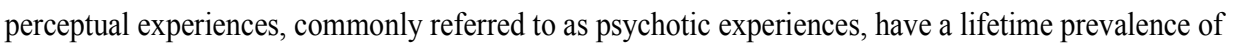

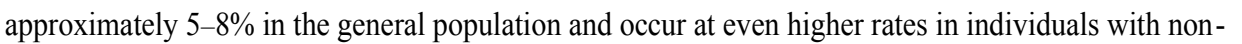

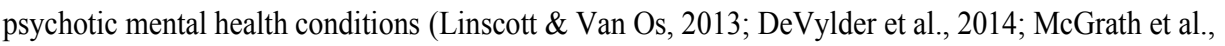

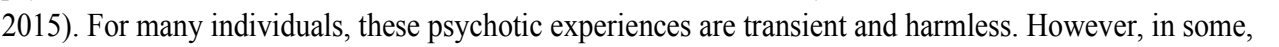

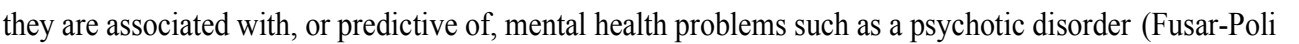
पाएाएाएाएणाए

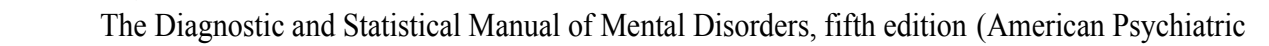

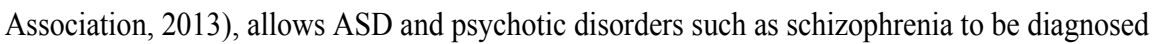

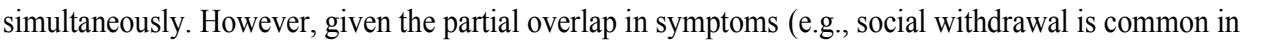

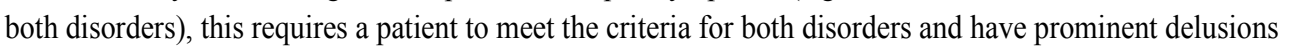

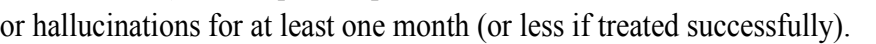

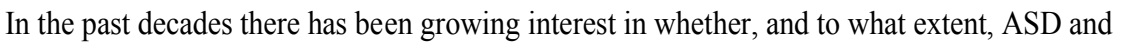

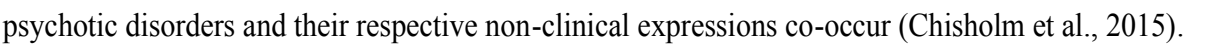

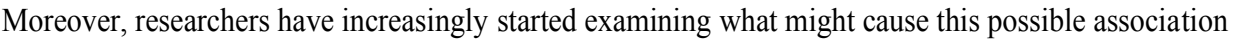
पाणाणए

$\square$

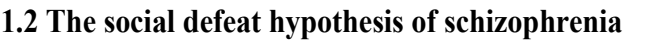

एणा

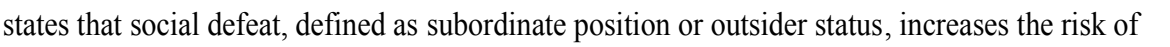

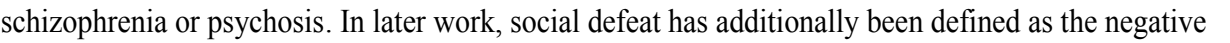

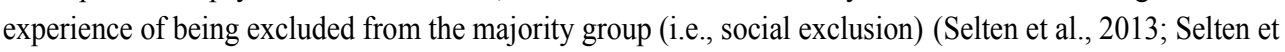

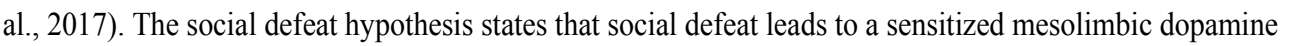


एव

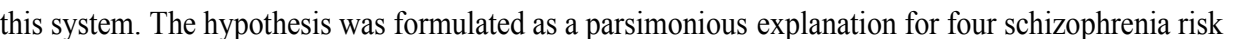

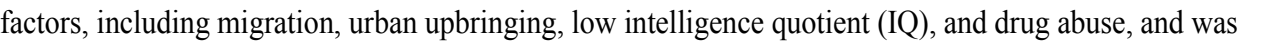

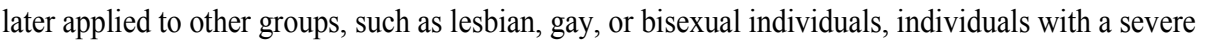

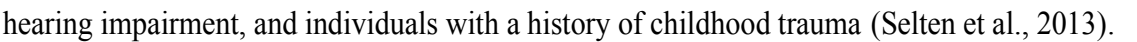

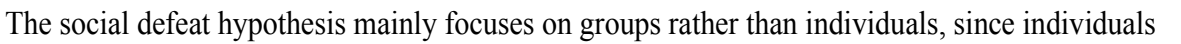

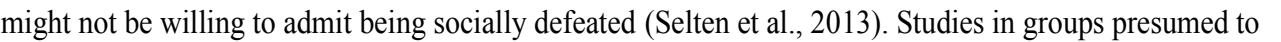

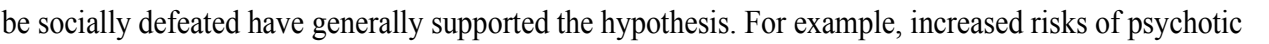

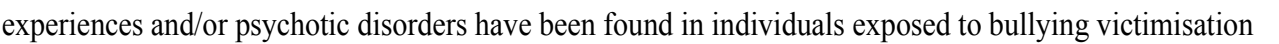

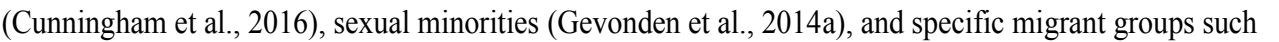

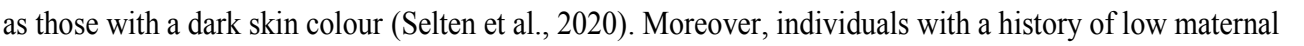

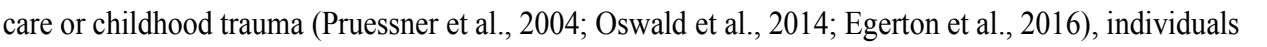

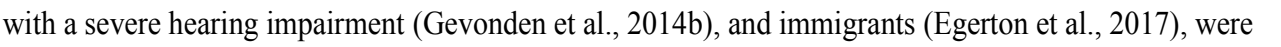

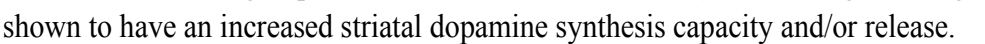

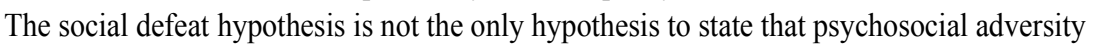

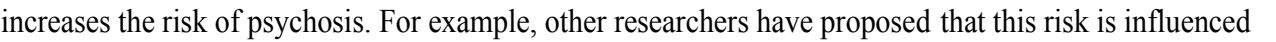

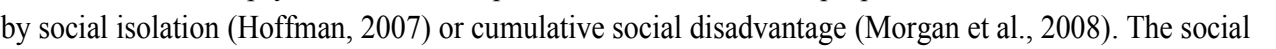
ए एव

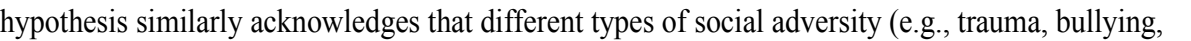

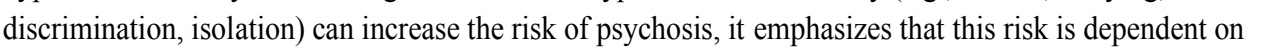

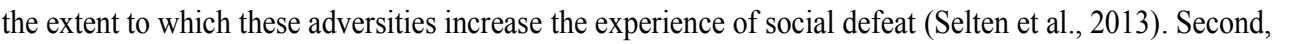

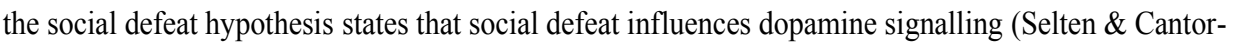
Grae, 2005; Selten et al., 2017)

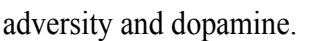

$\square$

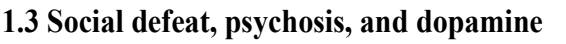

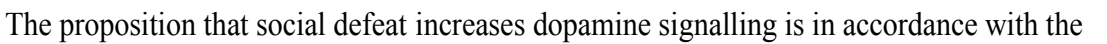

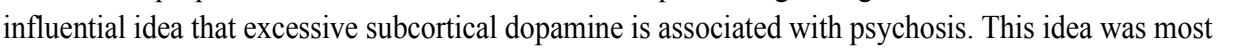

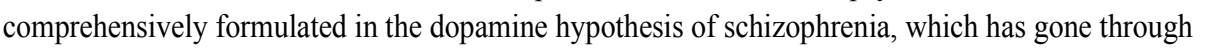
प प110ाण

Early versions of the dopamine hypothesis were mainly based on studies showing that dopamine

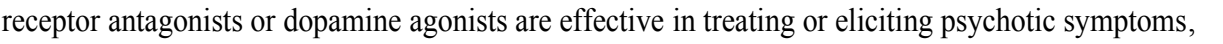

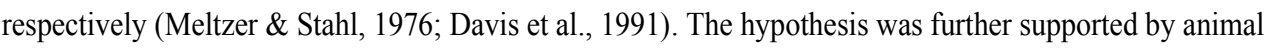

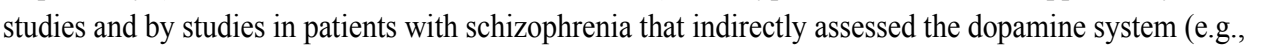

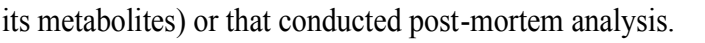

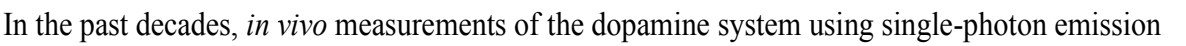
computed tomography (SPECT) and positron emission tomography (PET) have enabled researchers to

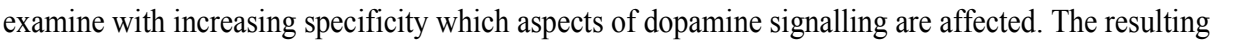

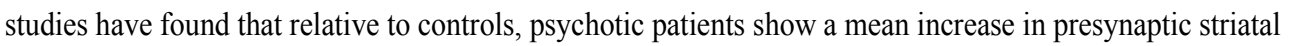

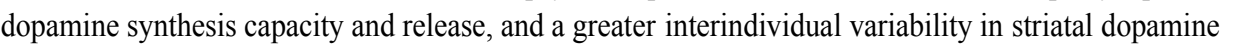
transporter (DAT) and dopamine $\mathrm{D}_{\text {m }}$

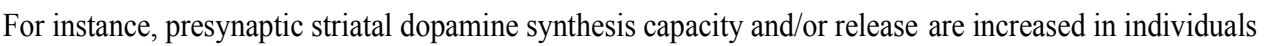

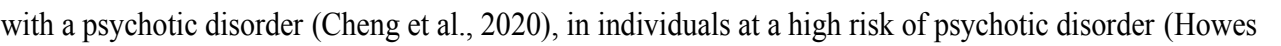




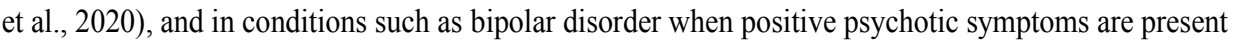

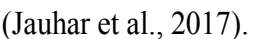

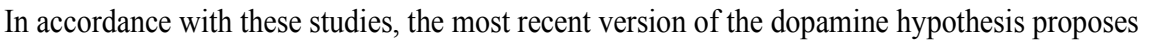
ए

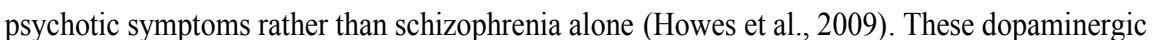

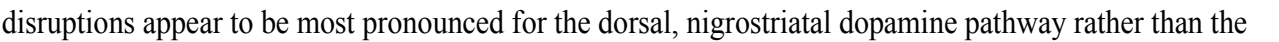

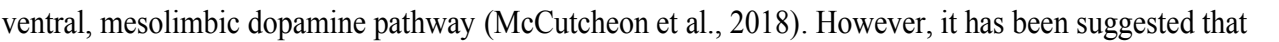

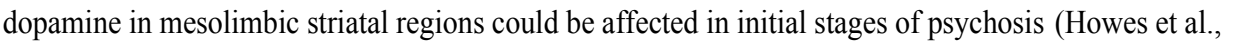

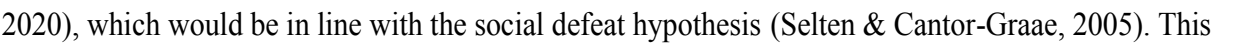

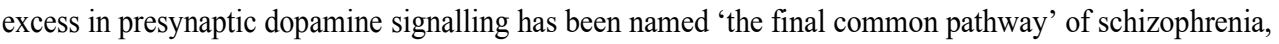

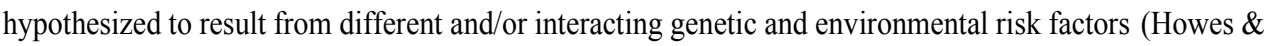

Kapur, 2009; Howes \& Murray, 2014) $\square$

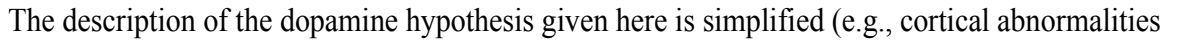

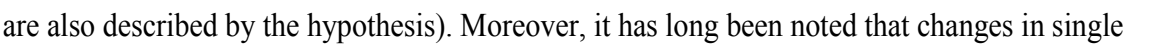

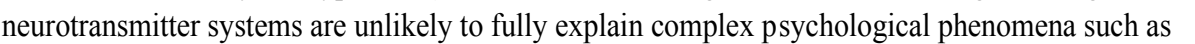

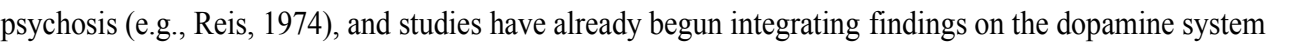

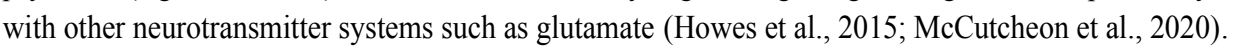

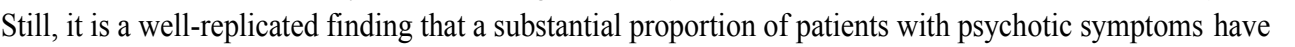

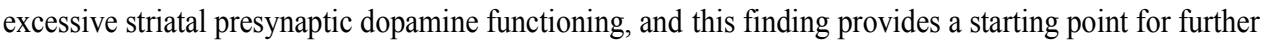

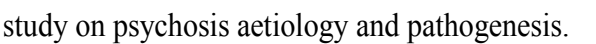
$\square$

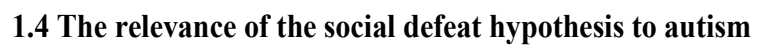

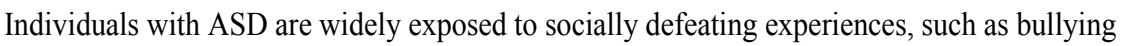

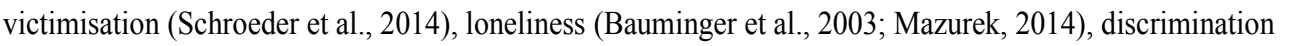

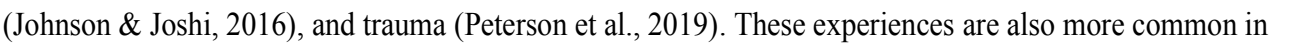
ए 2018; Han et al., 2019) $\square$

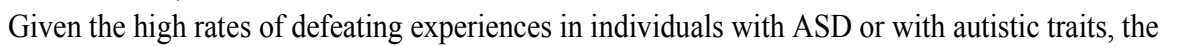

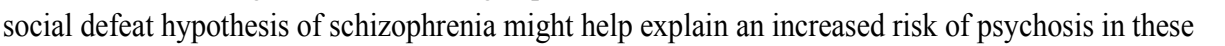

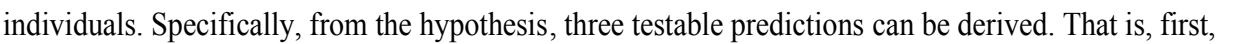

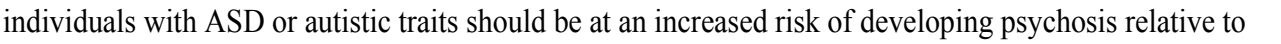

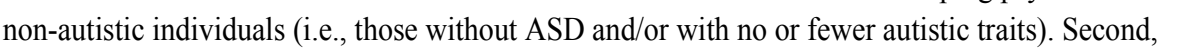

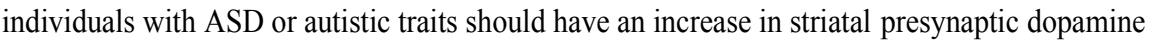

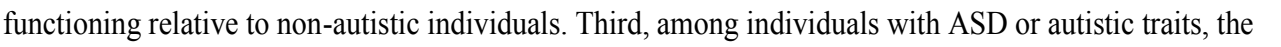

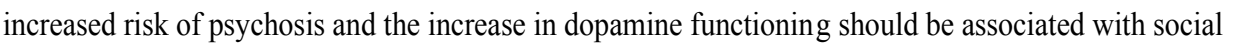

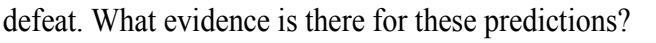

$\square$

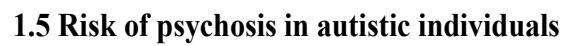

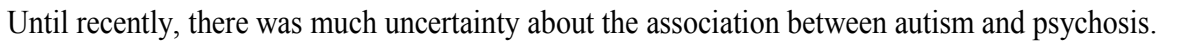

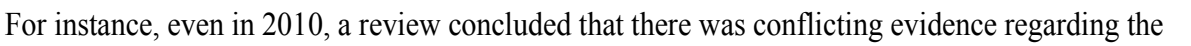

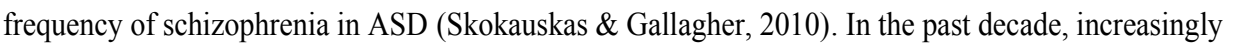
प

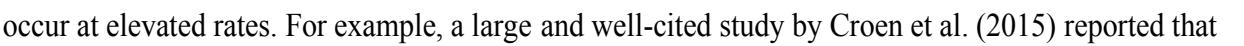

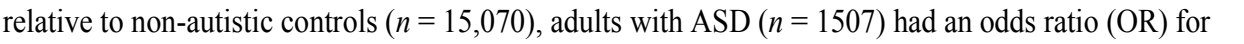




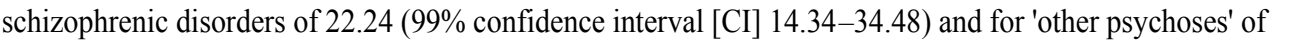

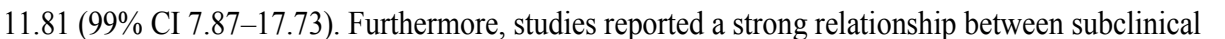

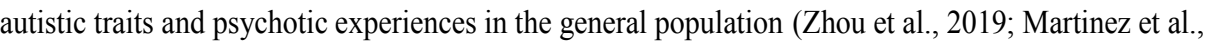

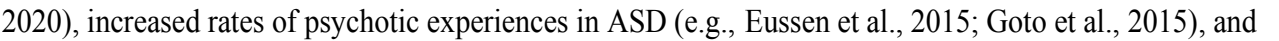

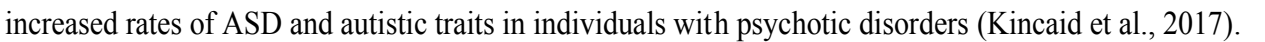

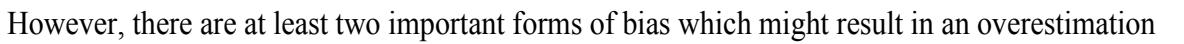

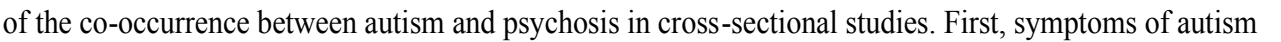

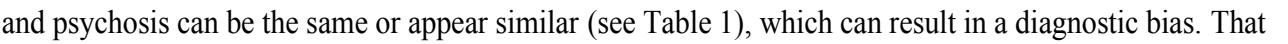

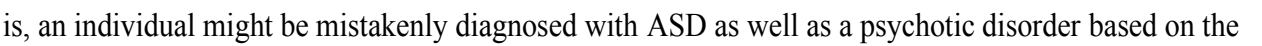

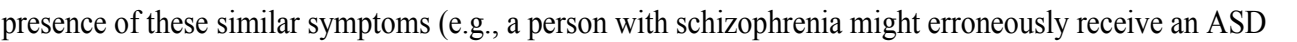

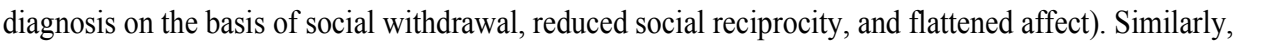

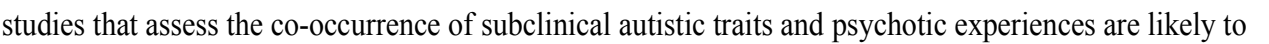

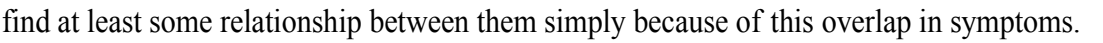

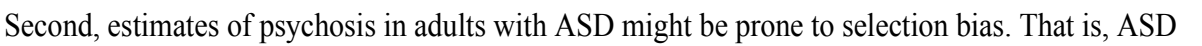

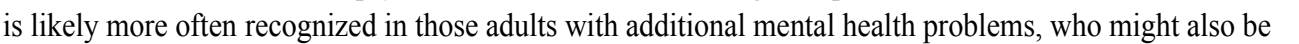

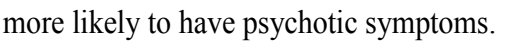

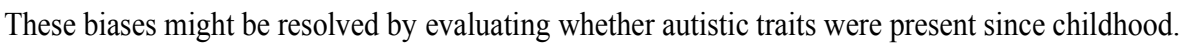

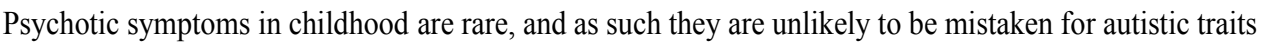

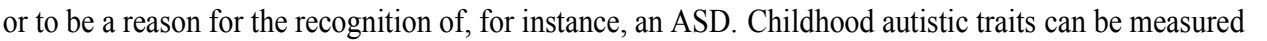

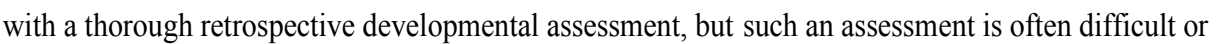

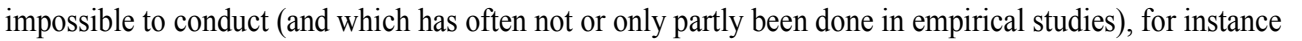

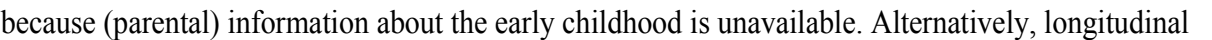

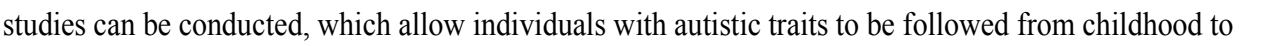
पा山ा山ा

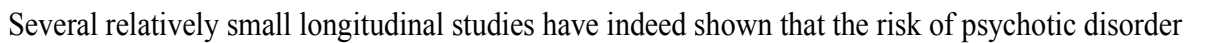

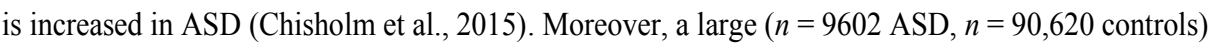

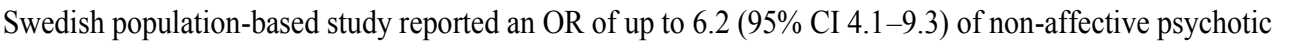

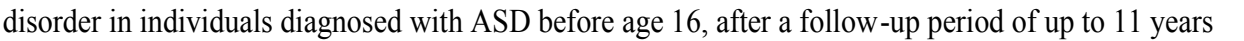

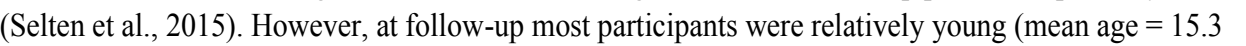

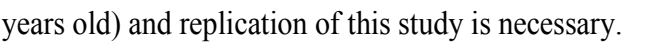

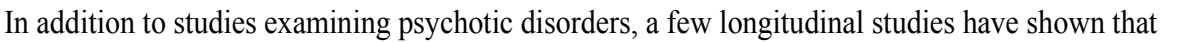

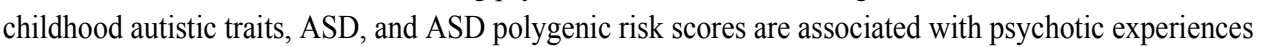

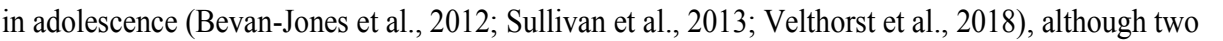

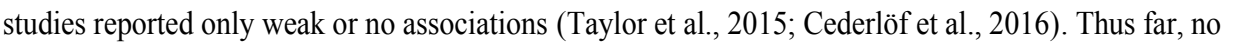

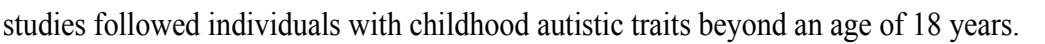

ए

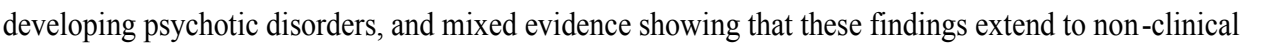

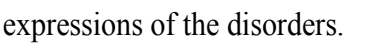
$\square$ 


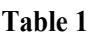

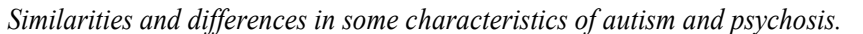

\begin{tabular}{|c|c|c|}
\hline$\square$ & 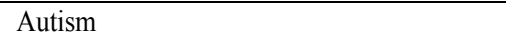 & 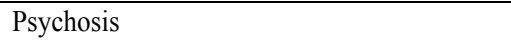 \\
\hline 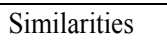 & 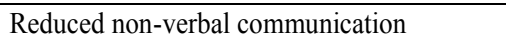 & 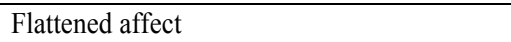 \\
\hline \multirow[t]{2}{*}{$\square$} & 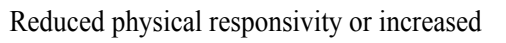 & 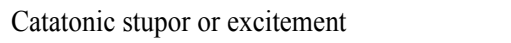 \\
\hline & 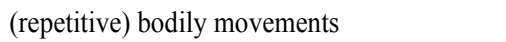 & \\
\hline \multirow[t]{2}{*}{$\square$} & 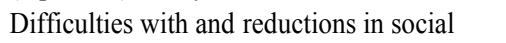 & 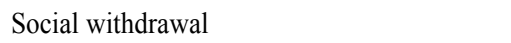 \\
\hline & 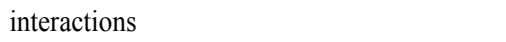 & \\
\hline$\square$ & 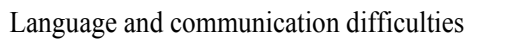 & 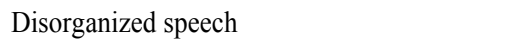 \\
\hline \multirow[t]{2}{*}{$\square$} & 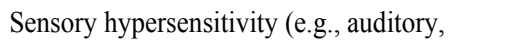 & 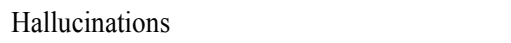 \\
\hline & 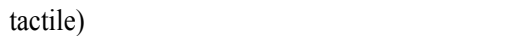 & \\
\hline \multirow[t]{2}{*}{$\square$} & 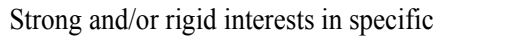 & 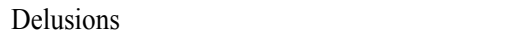 \\
\hline & एणाए & \\
\hline \multirow[t]{3}{*}{ 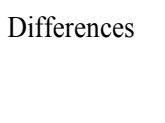 } & 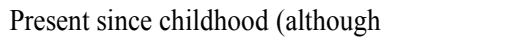 & 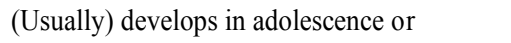 \\
\hline & 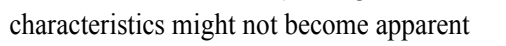 & 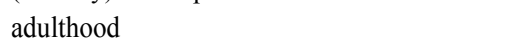 \\
\hline & 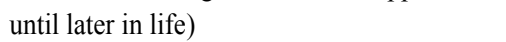 & \\
\hline \multirow[t]{4}{*}{$\square$} & 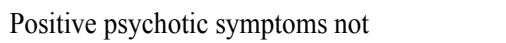 & 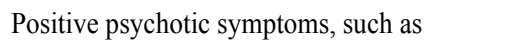 \\
\hline & 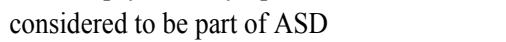 & 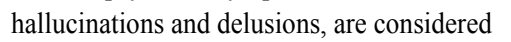 \\
\hline & & 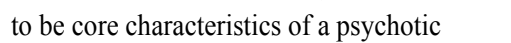 \\
\hline & & पण口णाए \\
\hline
\end{tabular}

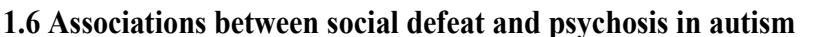

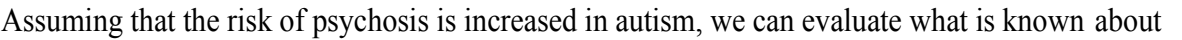

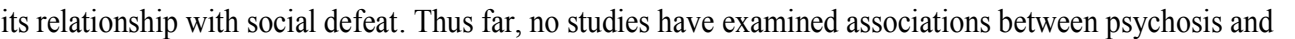

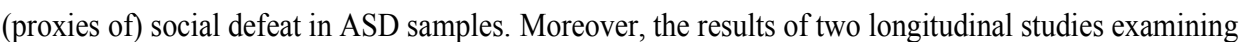
प

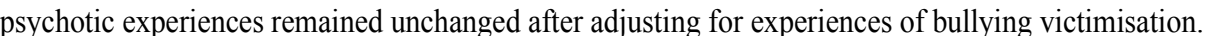

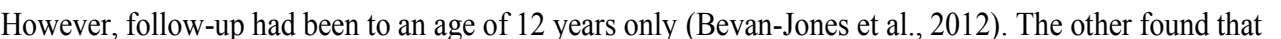

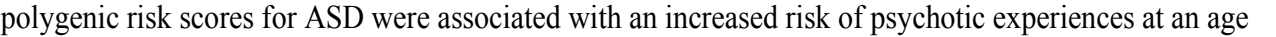

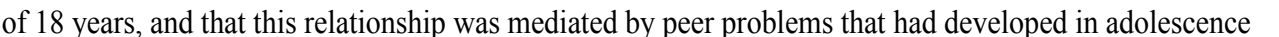

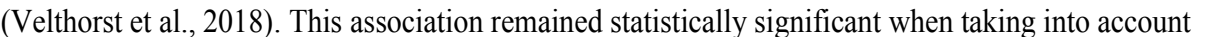

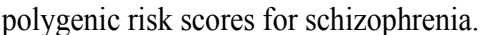

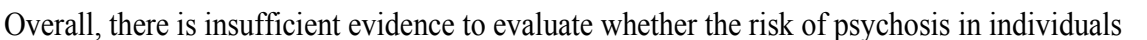

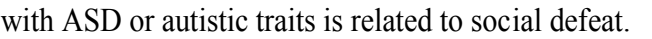

$\square$

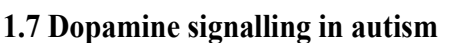

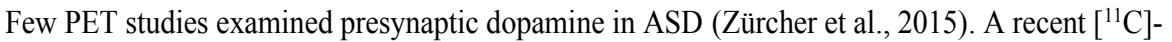
ए

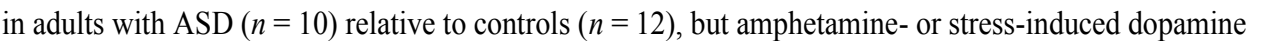

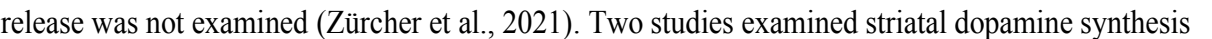

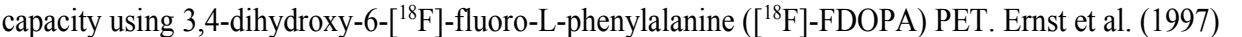

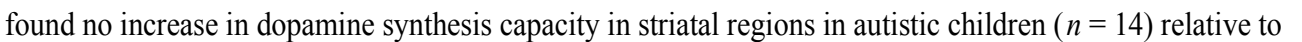

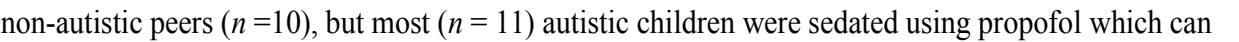

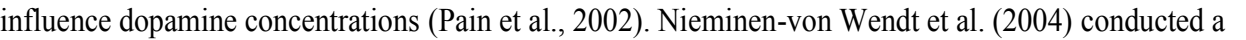

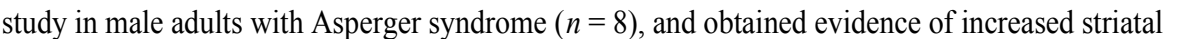




\section{Chapter I}

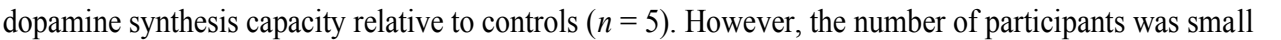

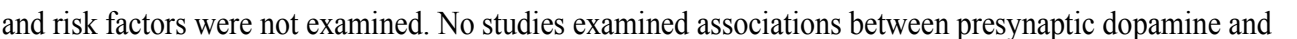

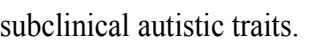

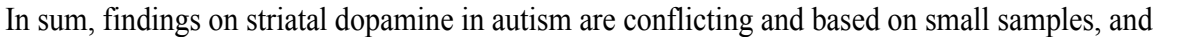

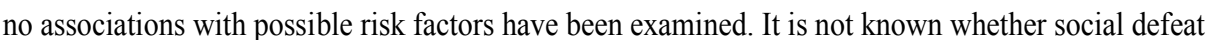

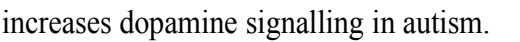

$\square$

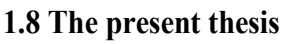

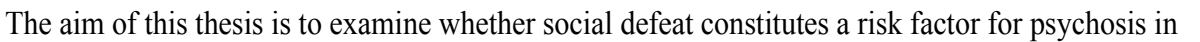

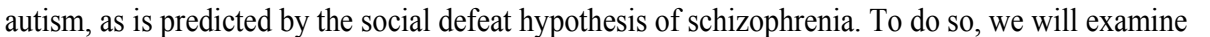

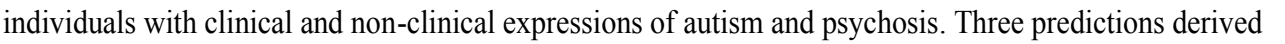

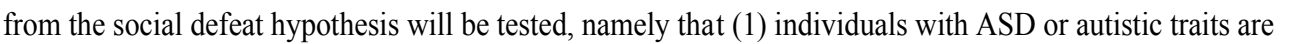

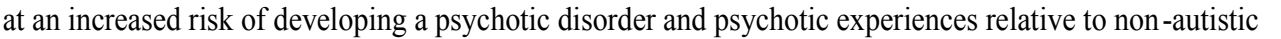

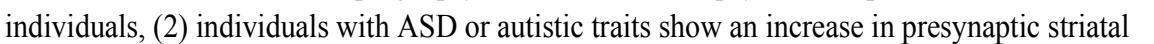

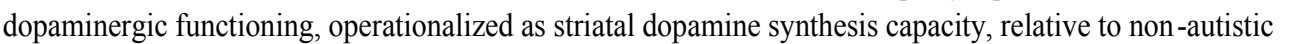
प

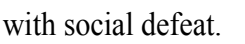

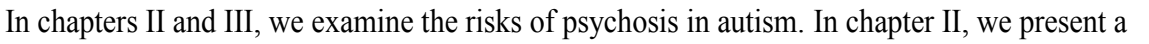
ए

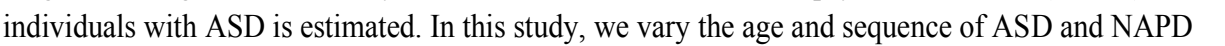

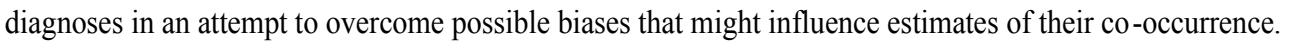

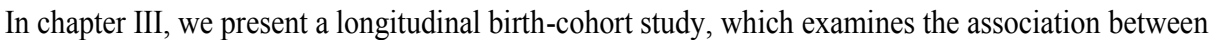

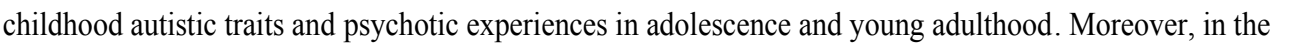

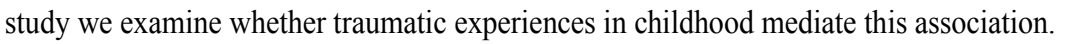

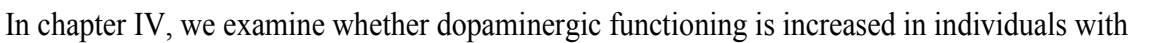

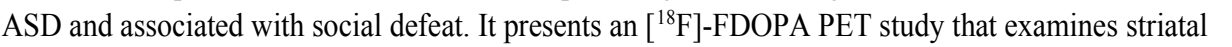

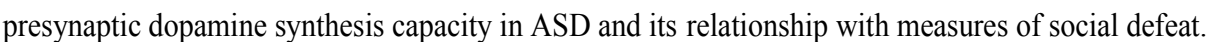

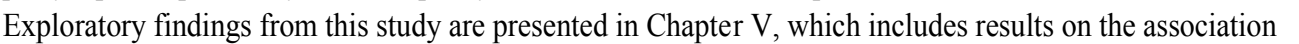

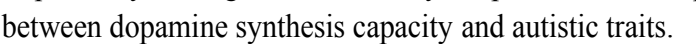

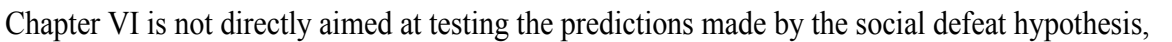

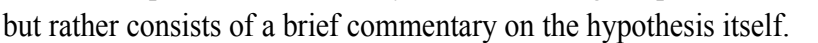

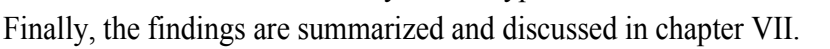

$\square$

$\square$ 


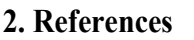

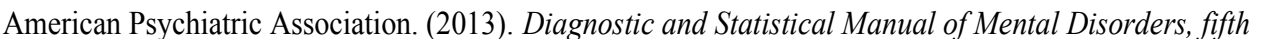

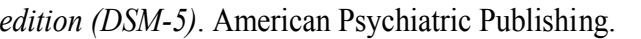

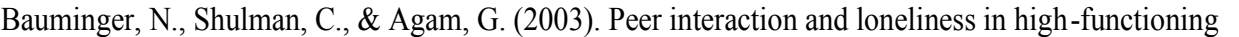

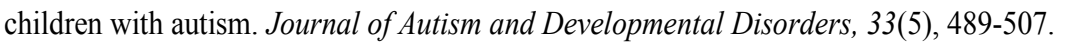

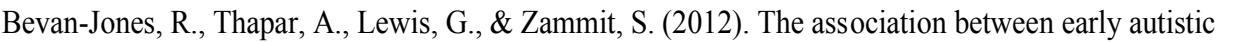

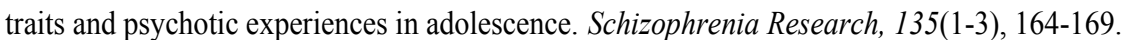

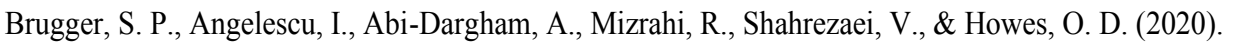

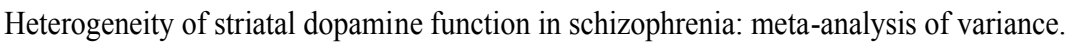

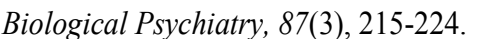

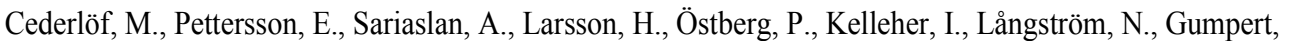

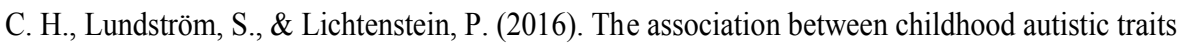

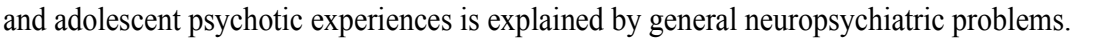

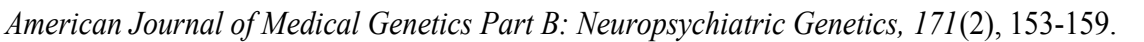

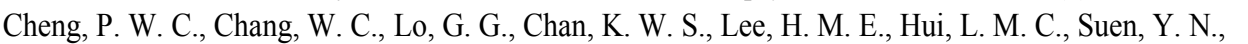

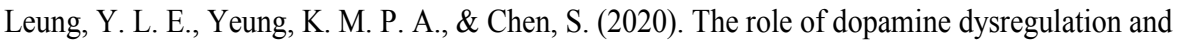

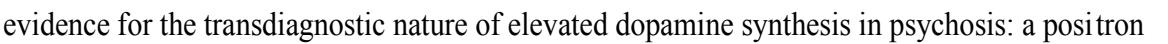

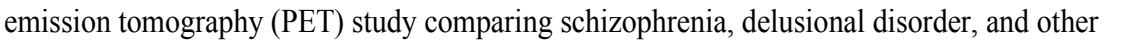

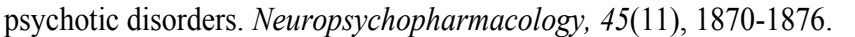

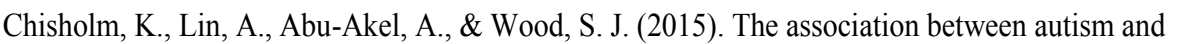
घh

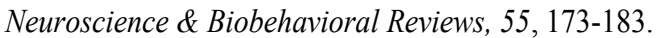

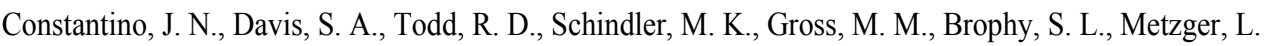

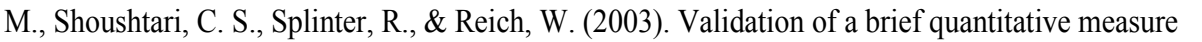

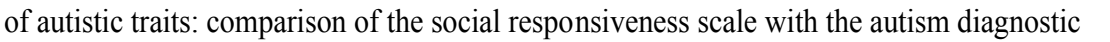

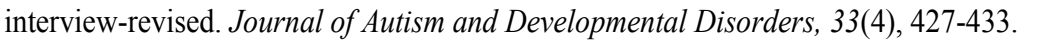

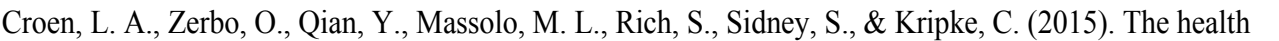

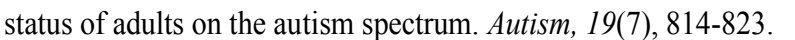

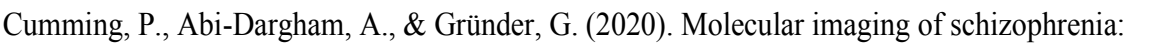

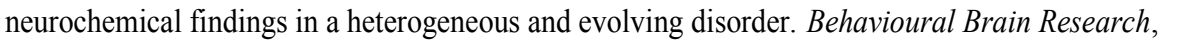
पणाण

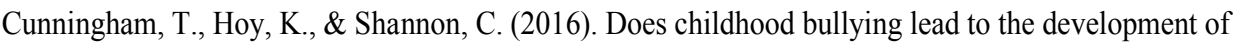

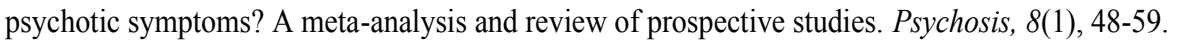

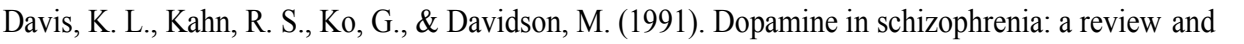

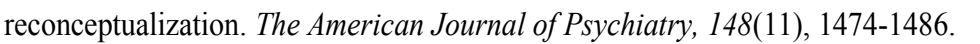

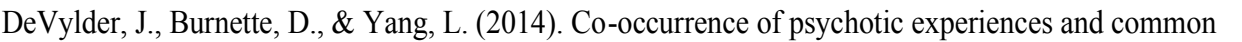

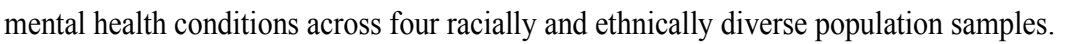

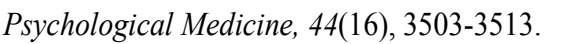

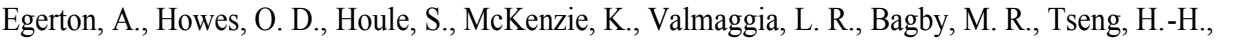

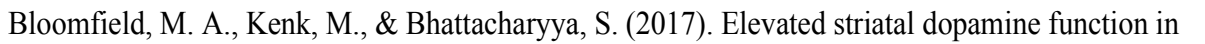

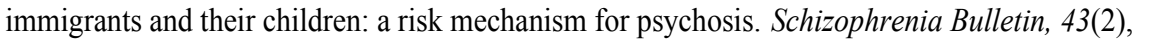
$\square 1\|1\|$ 


\section{Chapter I}

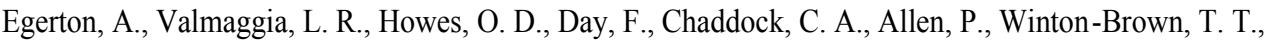

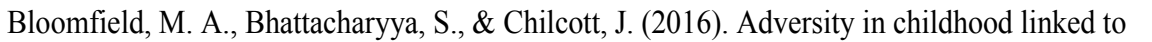

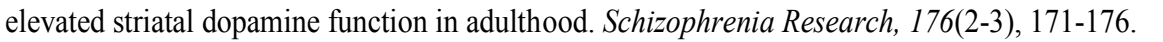

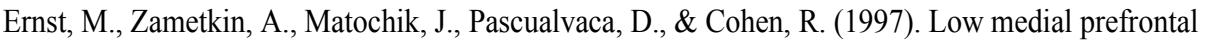

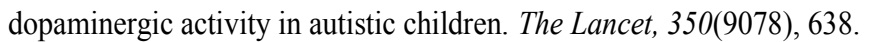

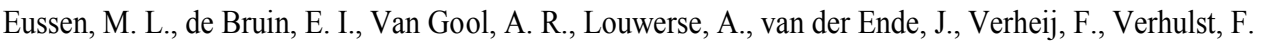

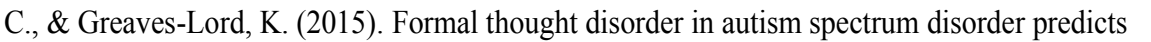

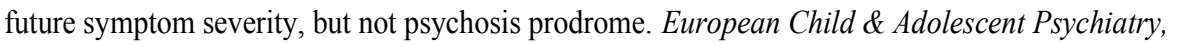

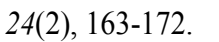

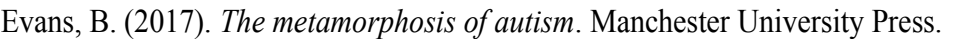

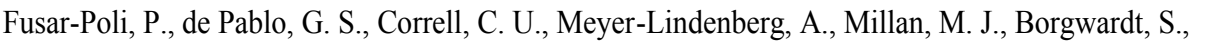

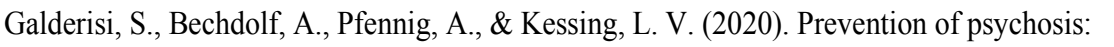

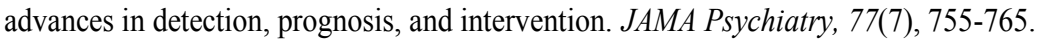

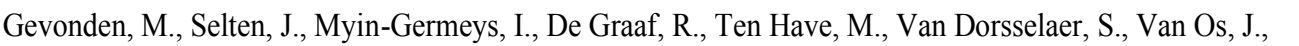

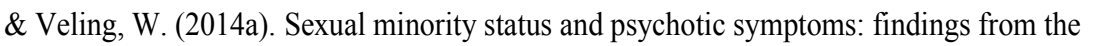

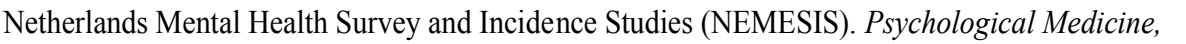
पाणाणमणाप

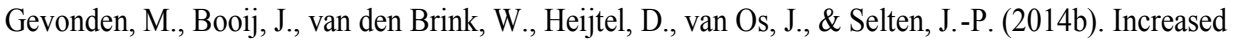

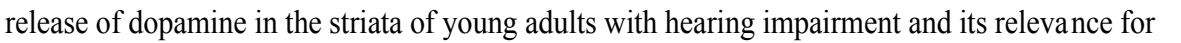

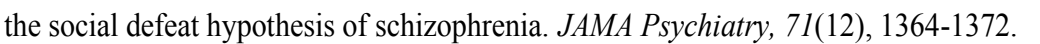

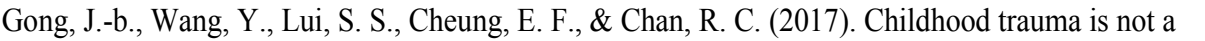

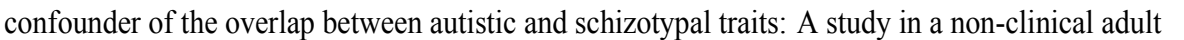

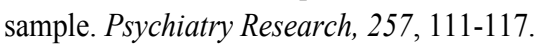

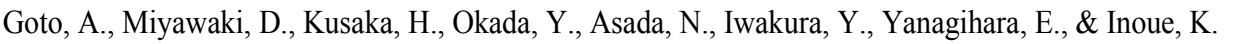

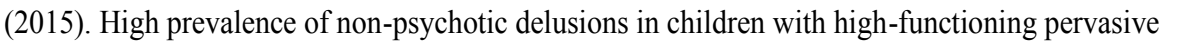

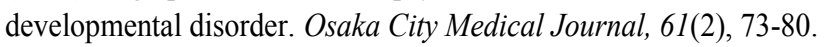

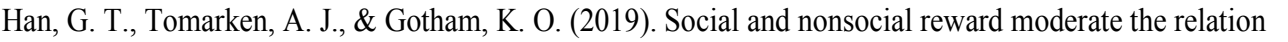

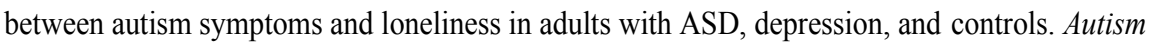

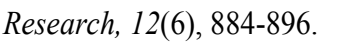

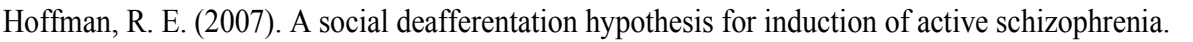

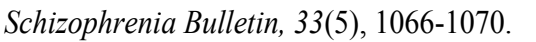

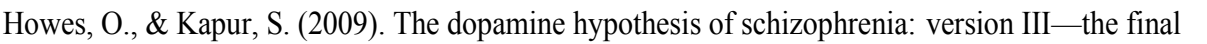

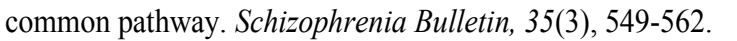

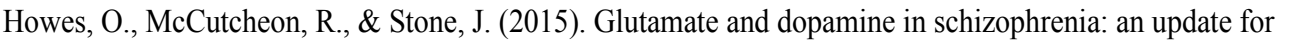

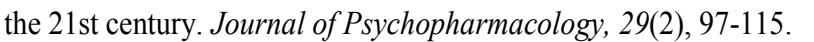

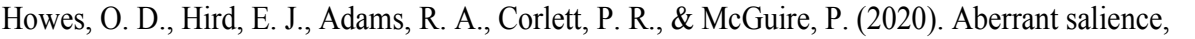

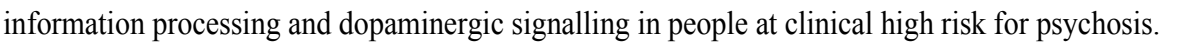

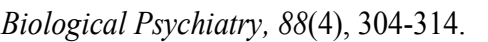

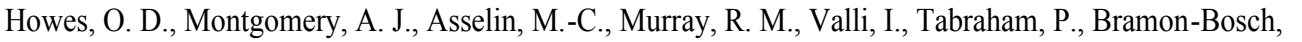

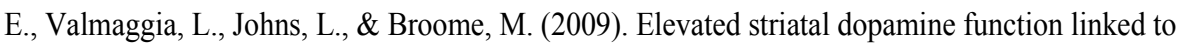

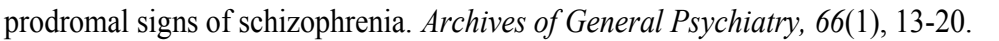

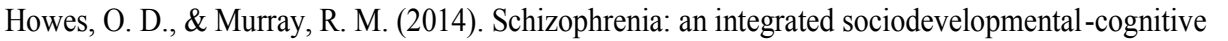

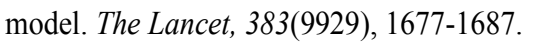




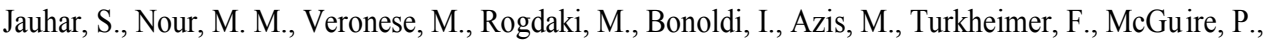

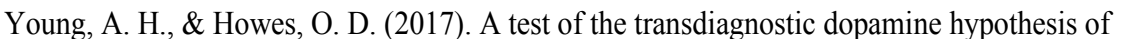

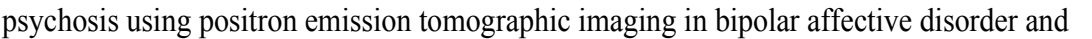

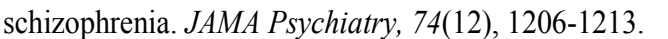

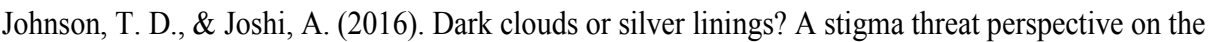

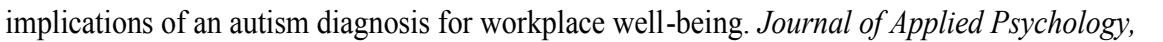

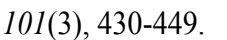

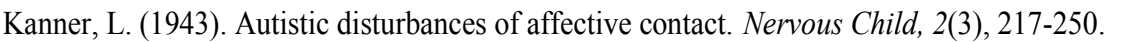

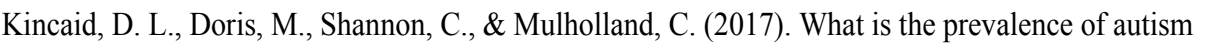

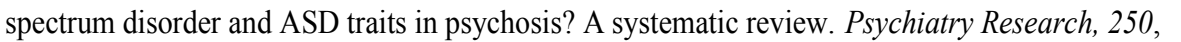
पाणापा

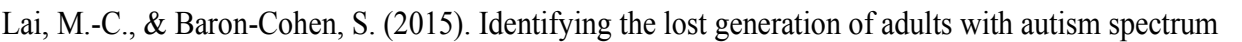

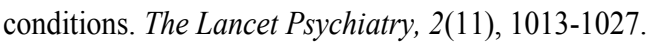

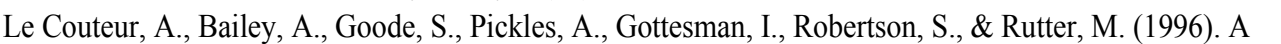

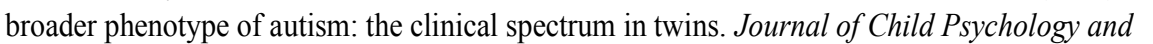

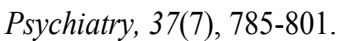

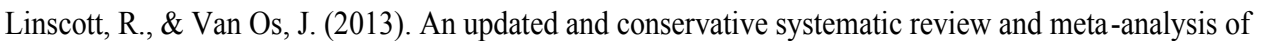

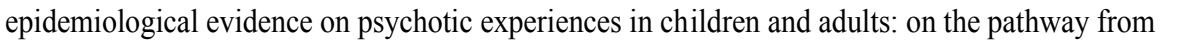

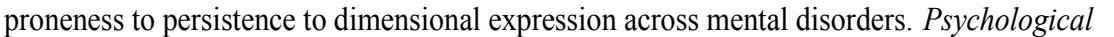

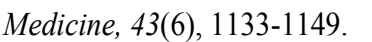

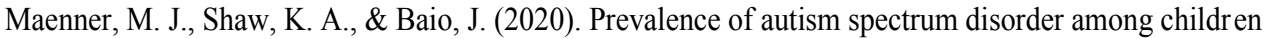

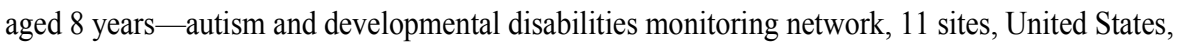

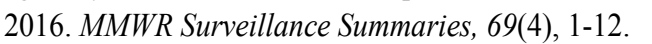

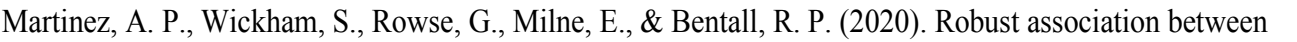

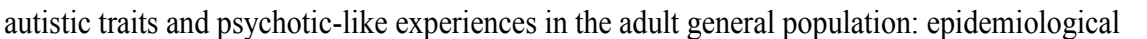

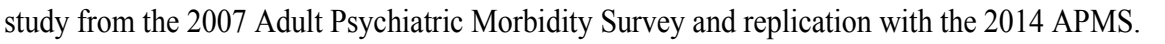

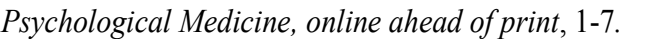

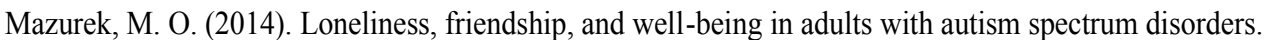

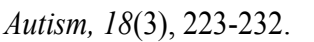

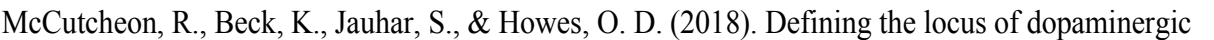

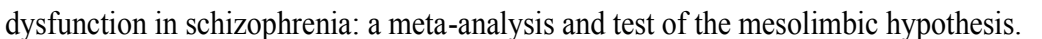

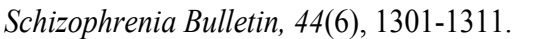

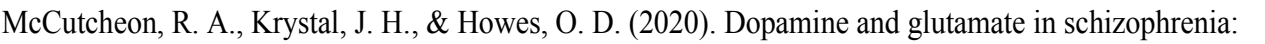

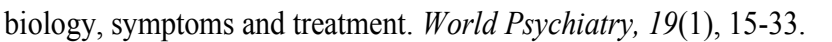

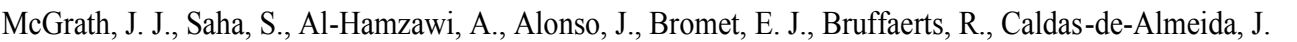

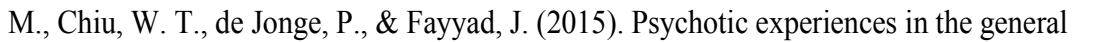

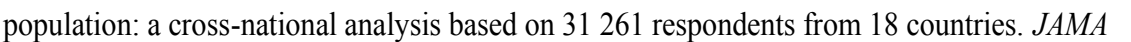

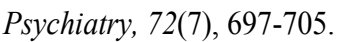

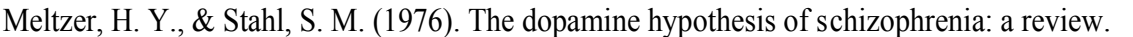

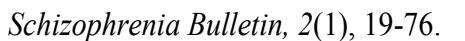

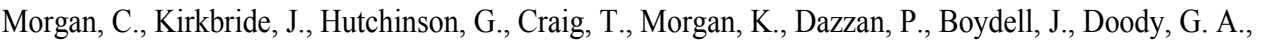

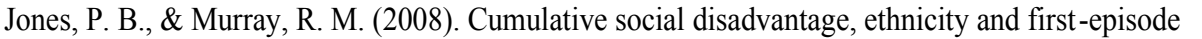
पणाए। 


\section{Chapter I}

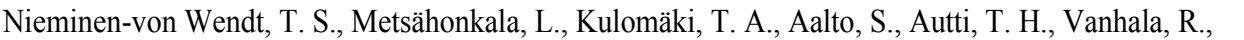

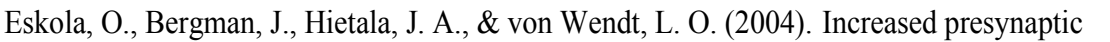

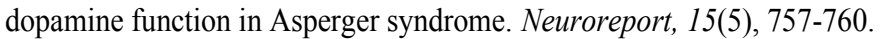

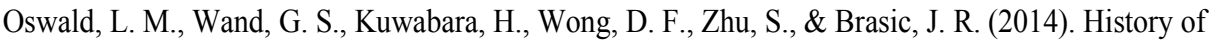

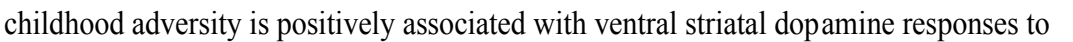

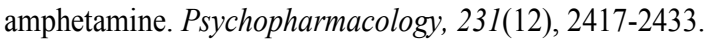

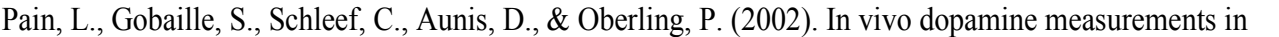

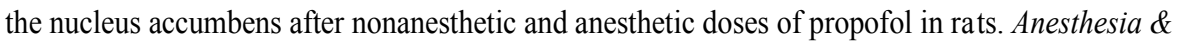

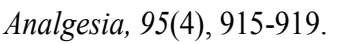

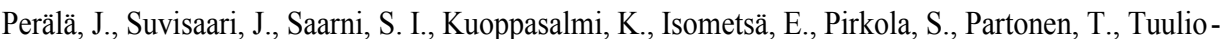

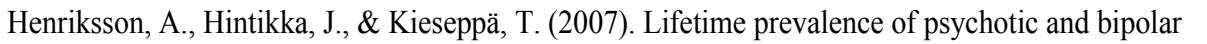

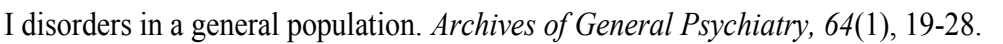

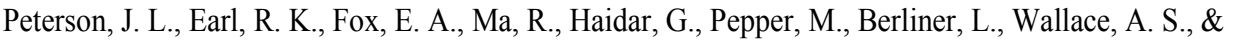

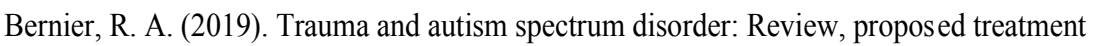

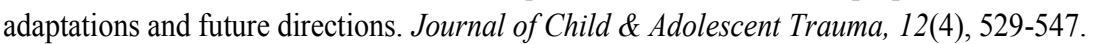

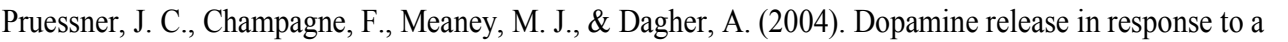

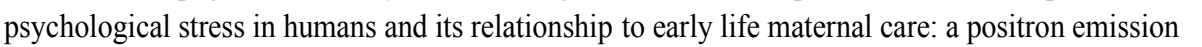

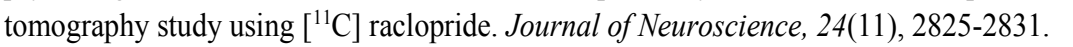

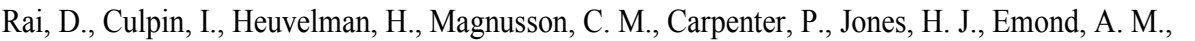

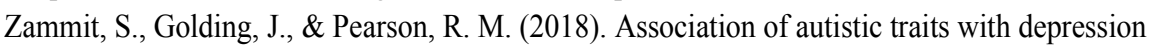

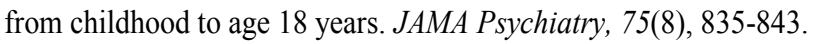

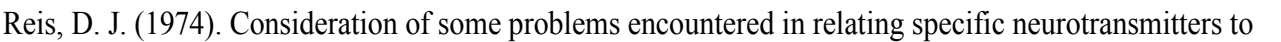

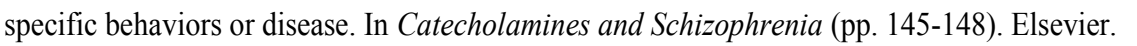

a

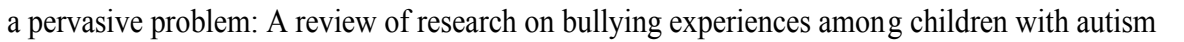

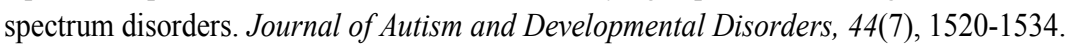

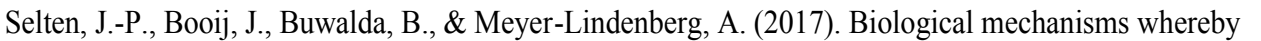

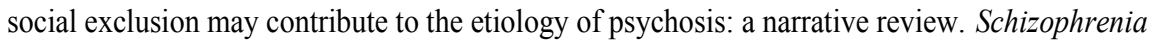

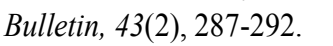

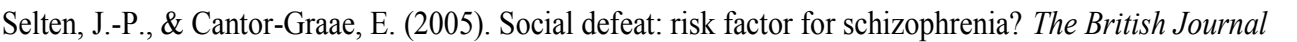

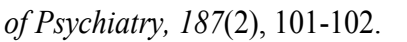

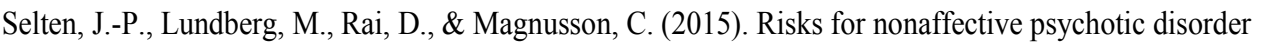

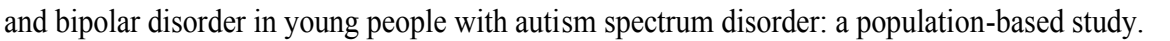

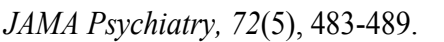

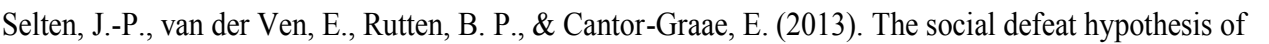

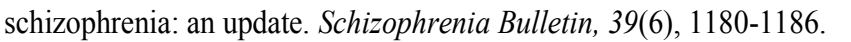

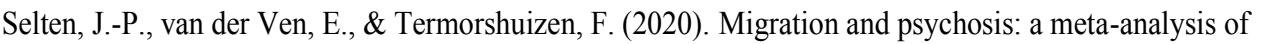

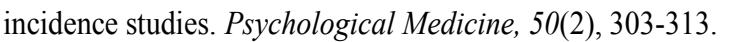

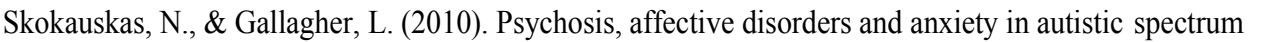

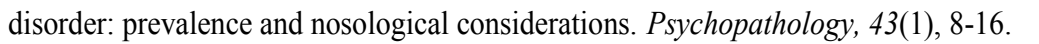

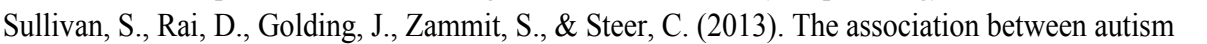

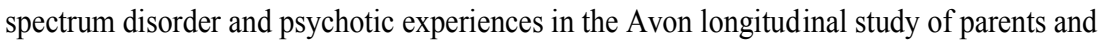

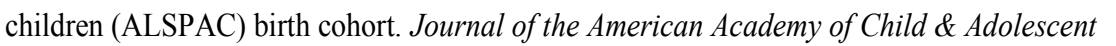

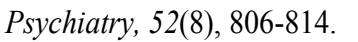




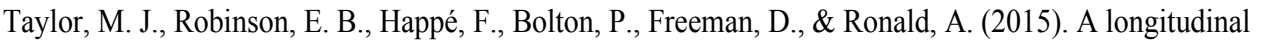

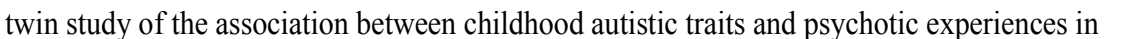

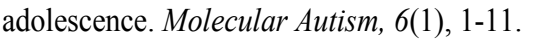

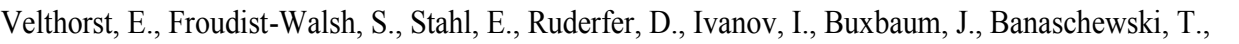

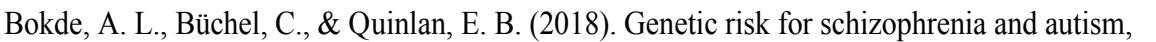

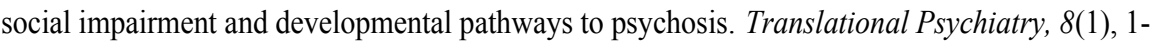
$\square$ पाI

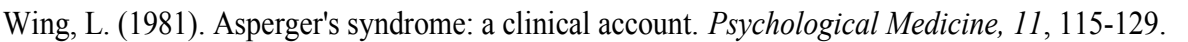

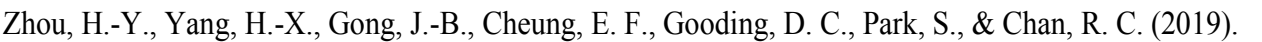

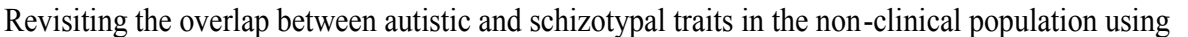

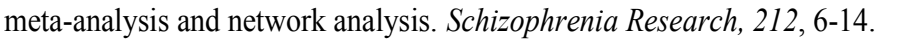

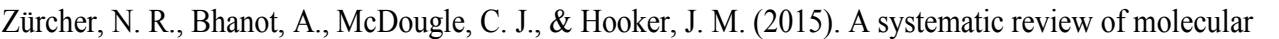

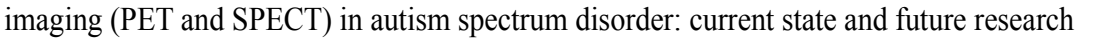

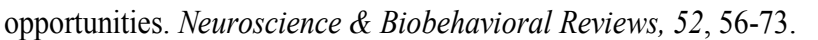

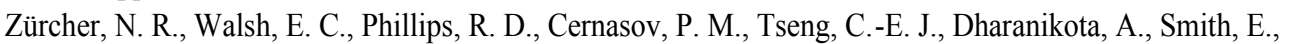

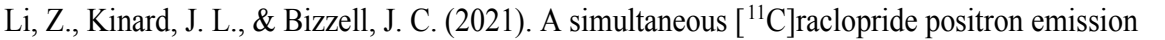

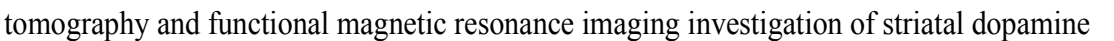

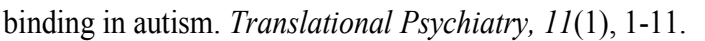

$\square$

$\square$ 


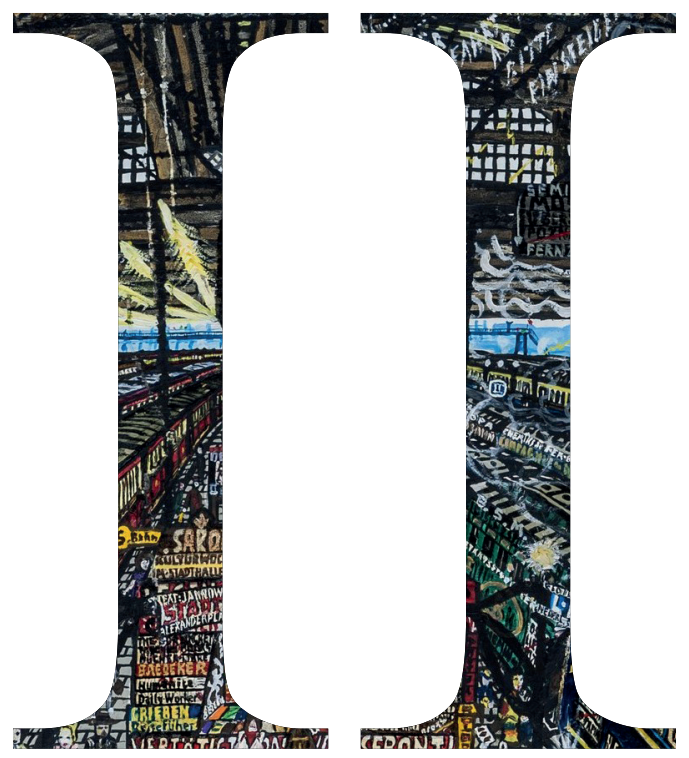




\section{Chapter II}

\section{Risk of non-affective psychotic disorder or bipolar disorder in autism spectrum disorder: a longitudinal register-based study in the Netherlands}

Schalbroeck, R., Termorshuizen, F., Visser, E., van Amelsvoort, T., Selten, J. P. Psychological Medicine (2019), 49(15), 2543-2550. 


\section{Chapter II}

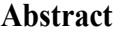

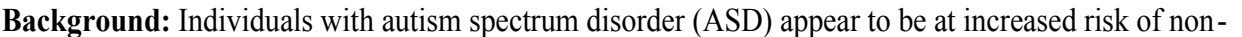

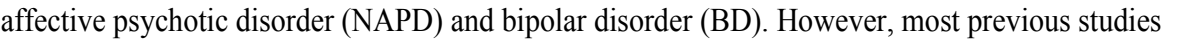

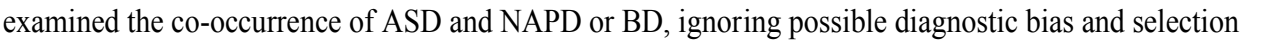

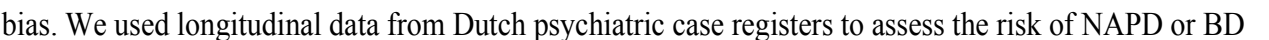

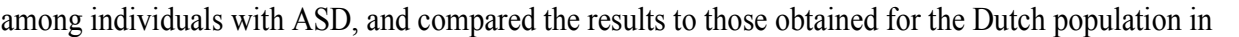

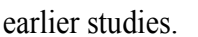

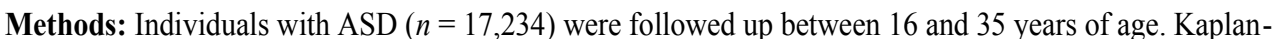

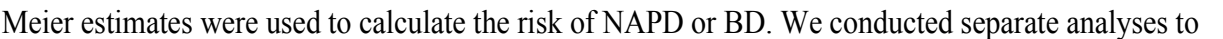
ए ए पाIIमाणा

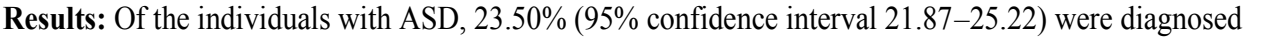

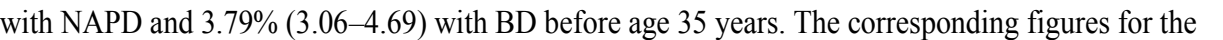

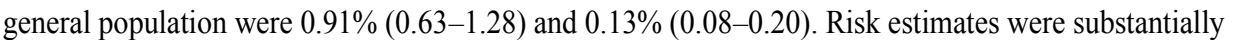

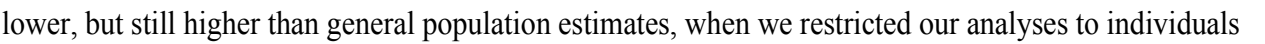

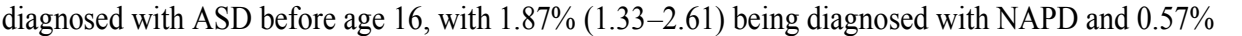

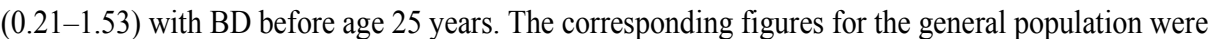

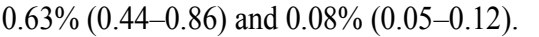

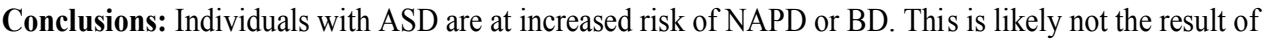

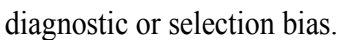




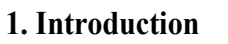

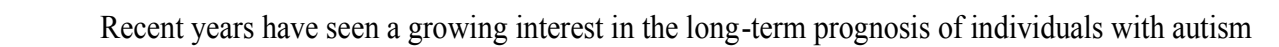

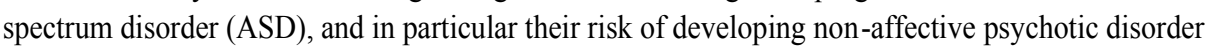

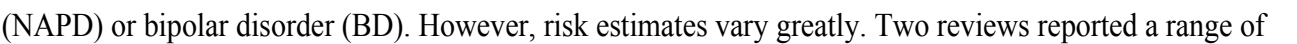

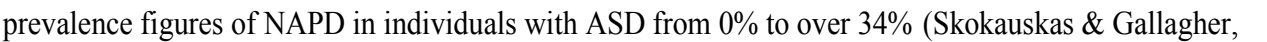

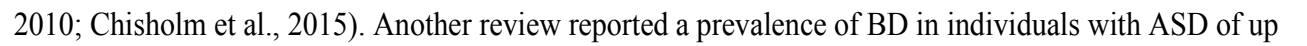

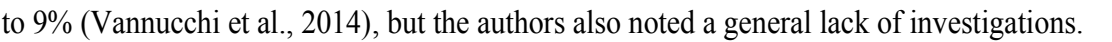

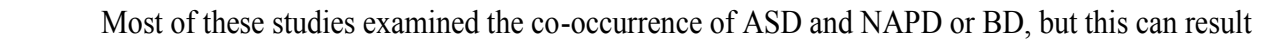

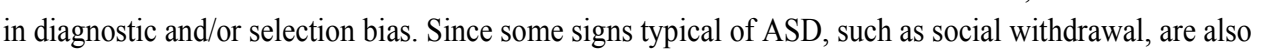

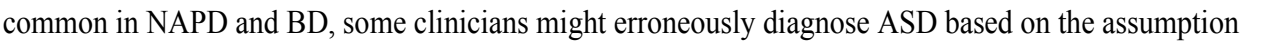

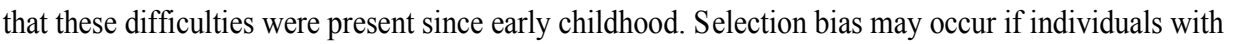

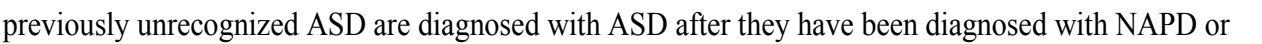

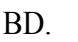

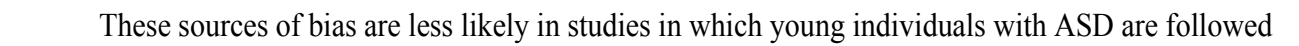

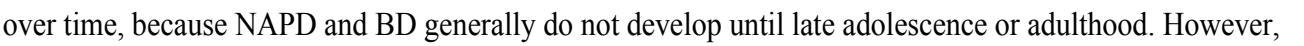

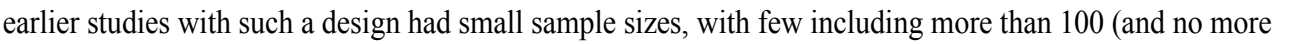

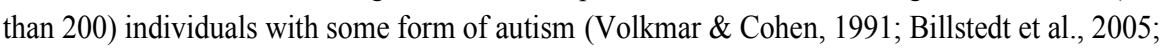

Cederlund et al., 2008; Hutton et al., 2008; Mouridsen et al., 2008)

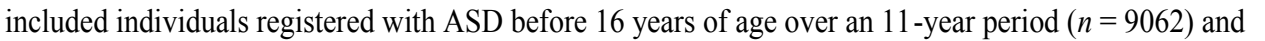

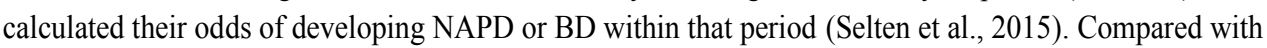

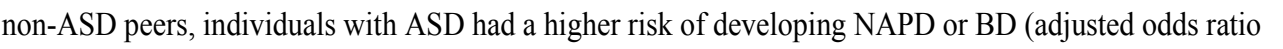
4.6 and 4.3, respectively); however, the study did not take into account

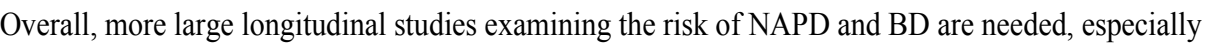

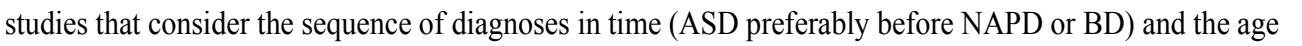

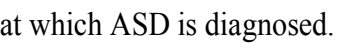

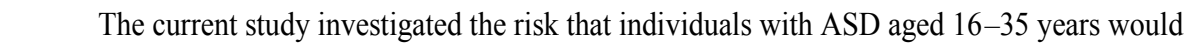
develop NAPD or BD, using longitudinal data from Dutch psychiatric case registers (PCRs). Several

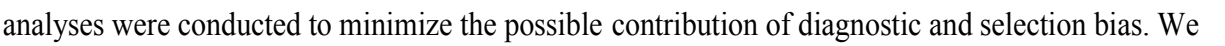

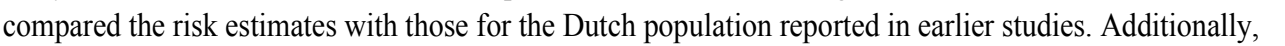

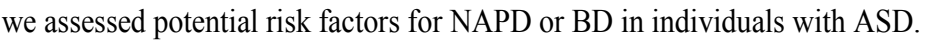
$\square$ 


\section{Chapter II}

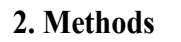

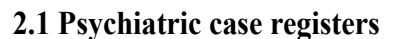

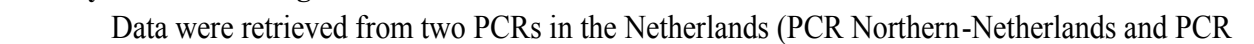

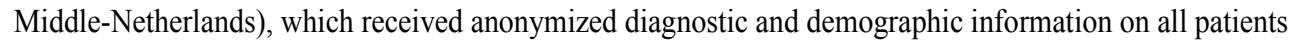

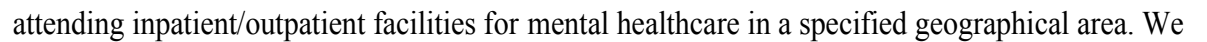

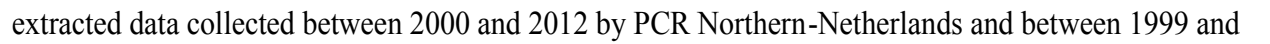

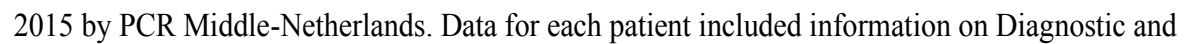

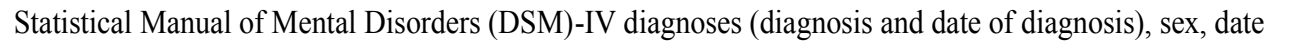

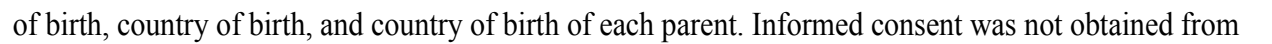
पा $\square$

\section{पणापणएण}

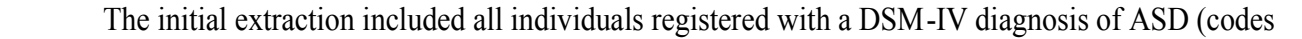

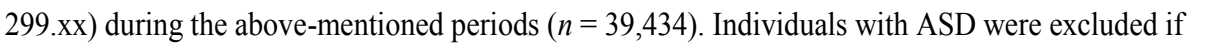

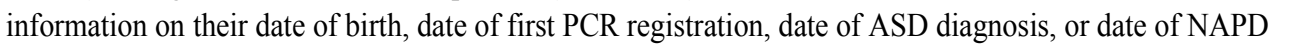

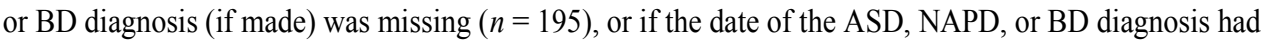

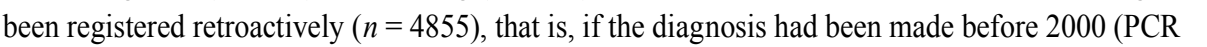

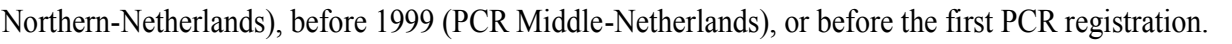

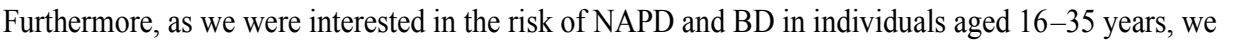

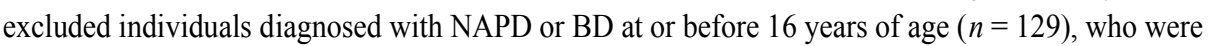

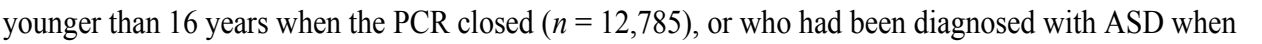

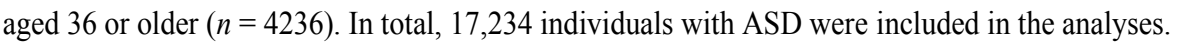
$\square$

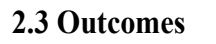

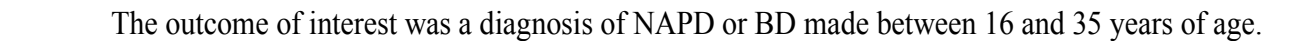

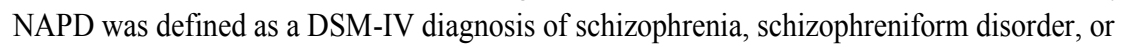

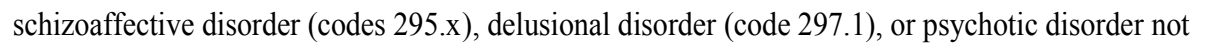

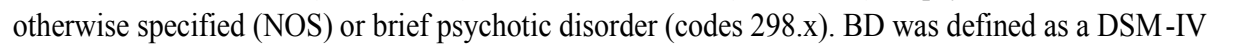

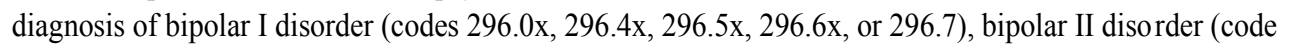

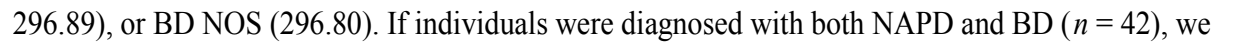

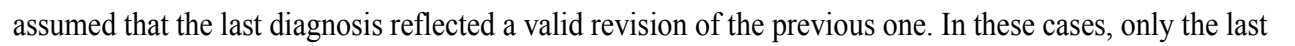

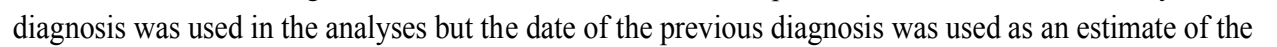

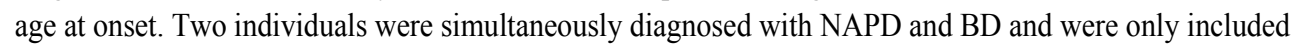
एயா

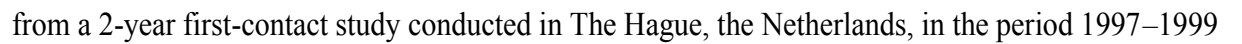

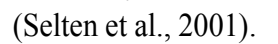

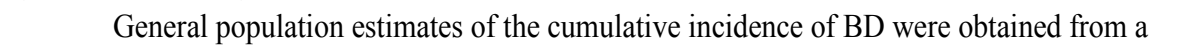

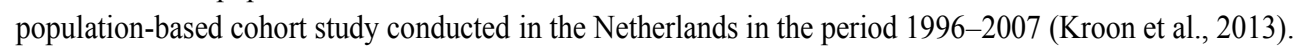

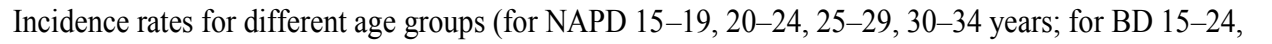

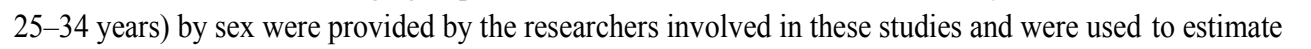

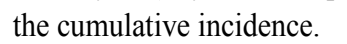

$\square$

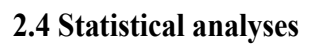

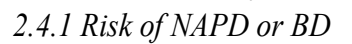




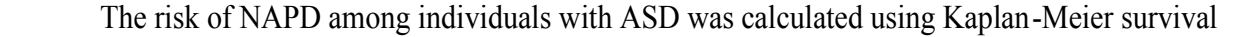

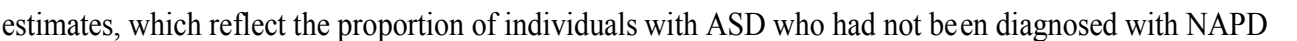

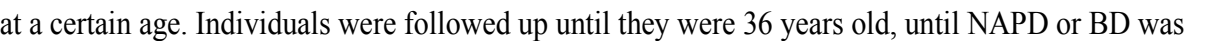

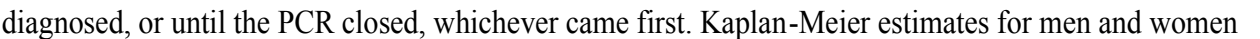
प्रा $\square$

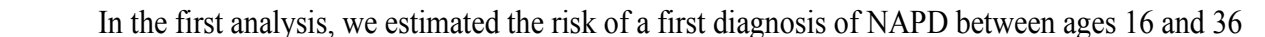

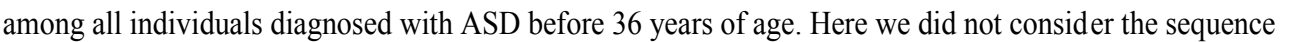

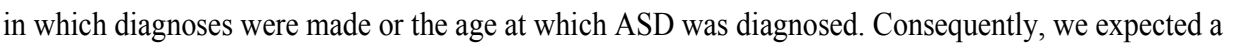

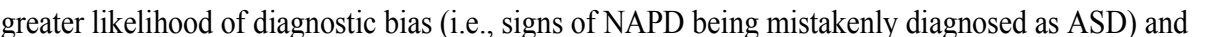

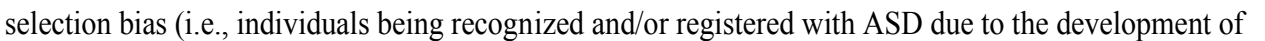

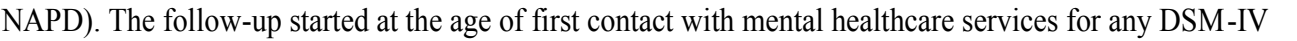

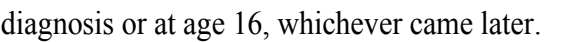

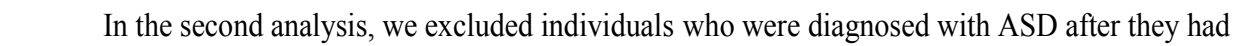

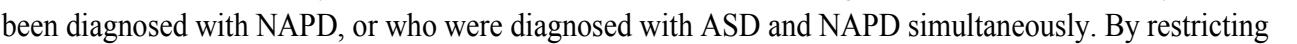
प

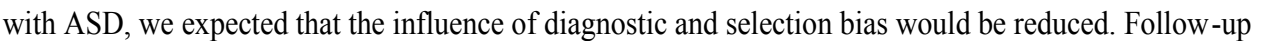

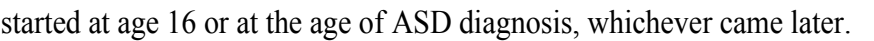

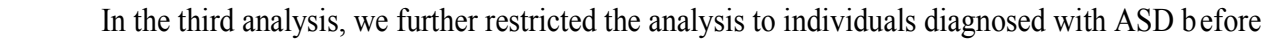

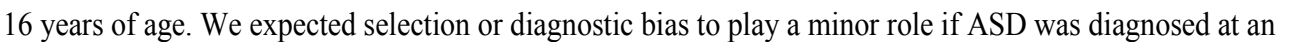

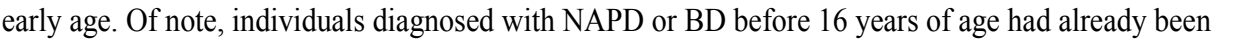
पाणाणाण

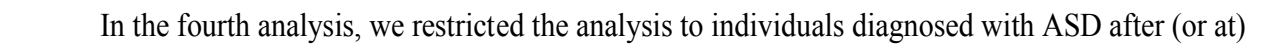

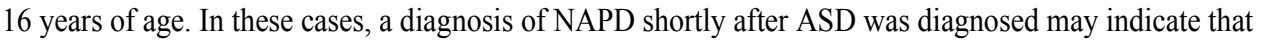

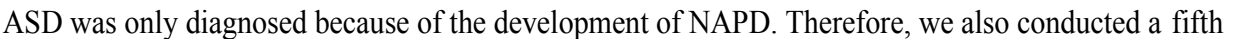

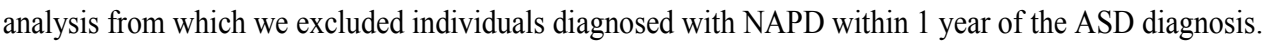

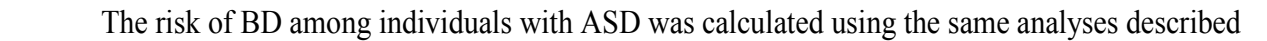

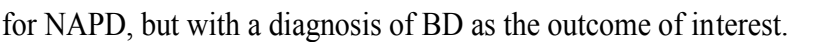

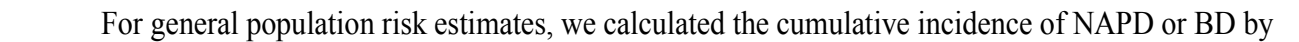

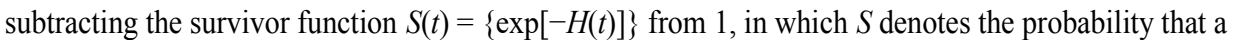

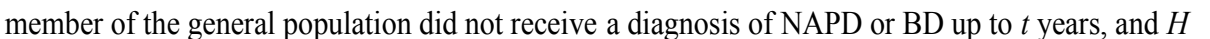

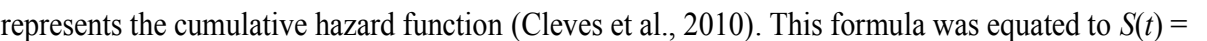

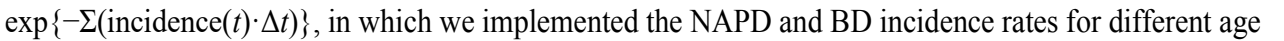

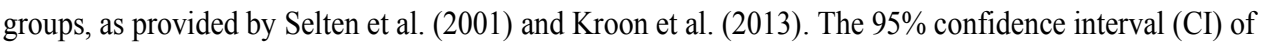

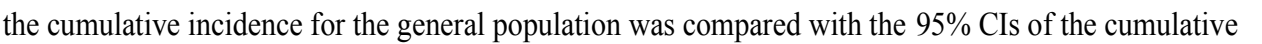

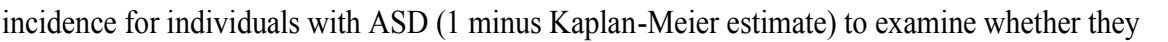

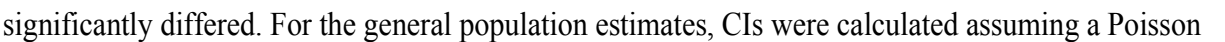

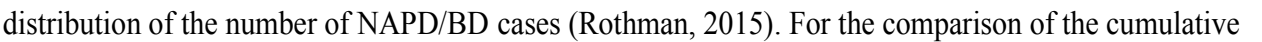

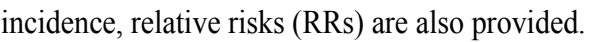

$\square$

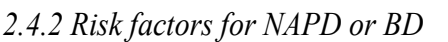

\begin{aligned} \hline \\ \hline\end{aligned}

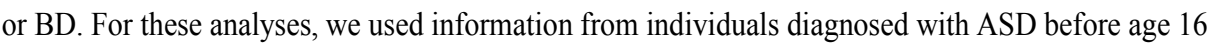

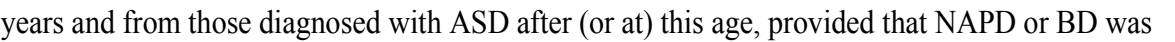




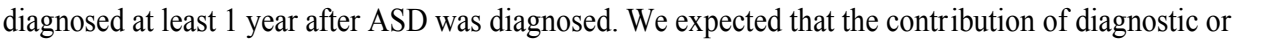

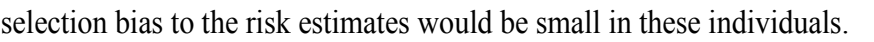

The following potential risk factors were evaluated: sex, intellectual disability (ID; DSM $\square \square$

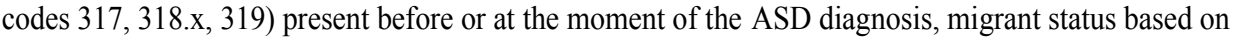

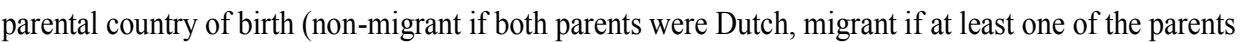

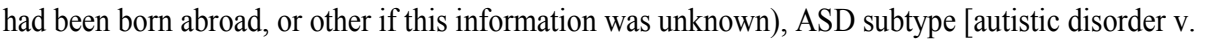

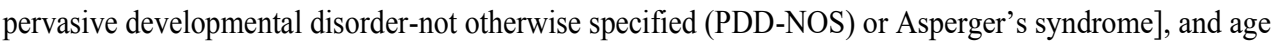

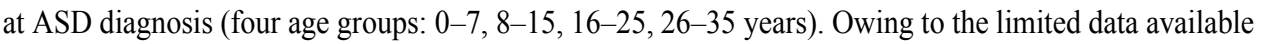

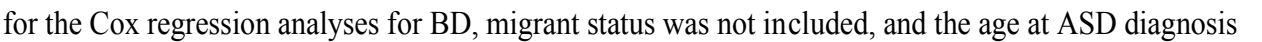

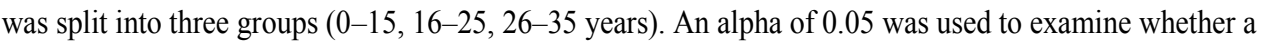

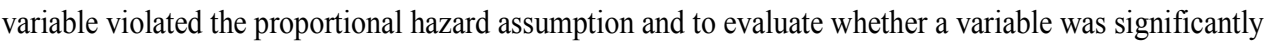

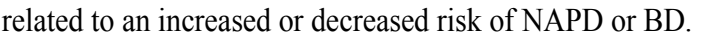

$\square$

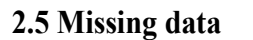

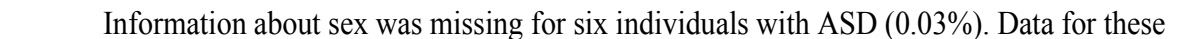

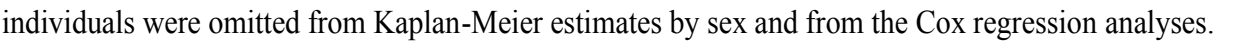
Migrant status could not be ascertained in 3019 individuals (17.5\%). As described above, in the Cox regression analyses the migrant status of these individuals was coded as 'other'. $\square$

$\square$

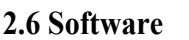

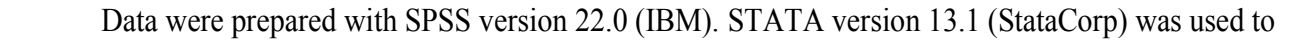

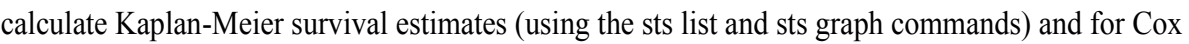

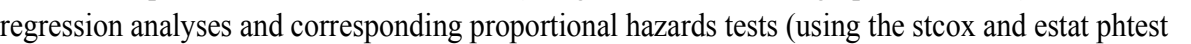
$\square \square \square\|\| ण \square$ 


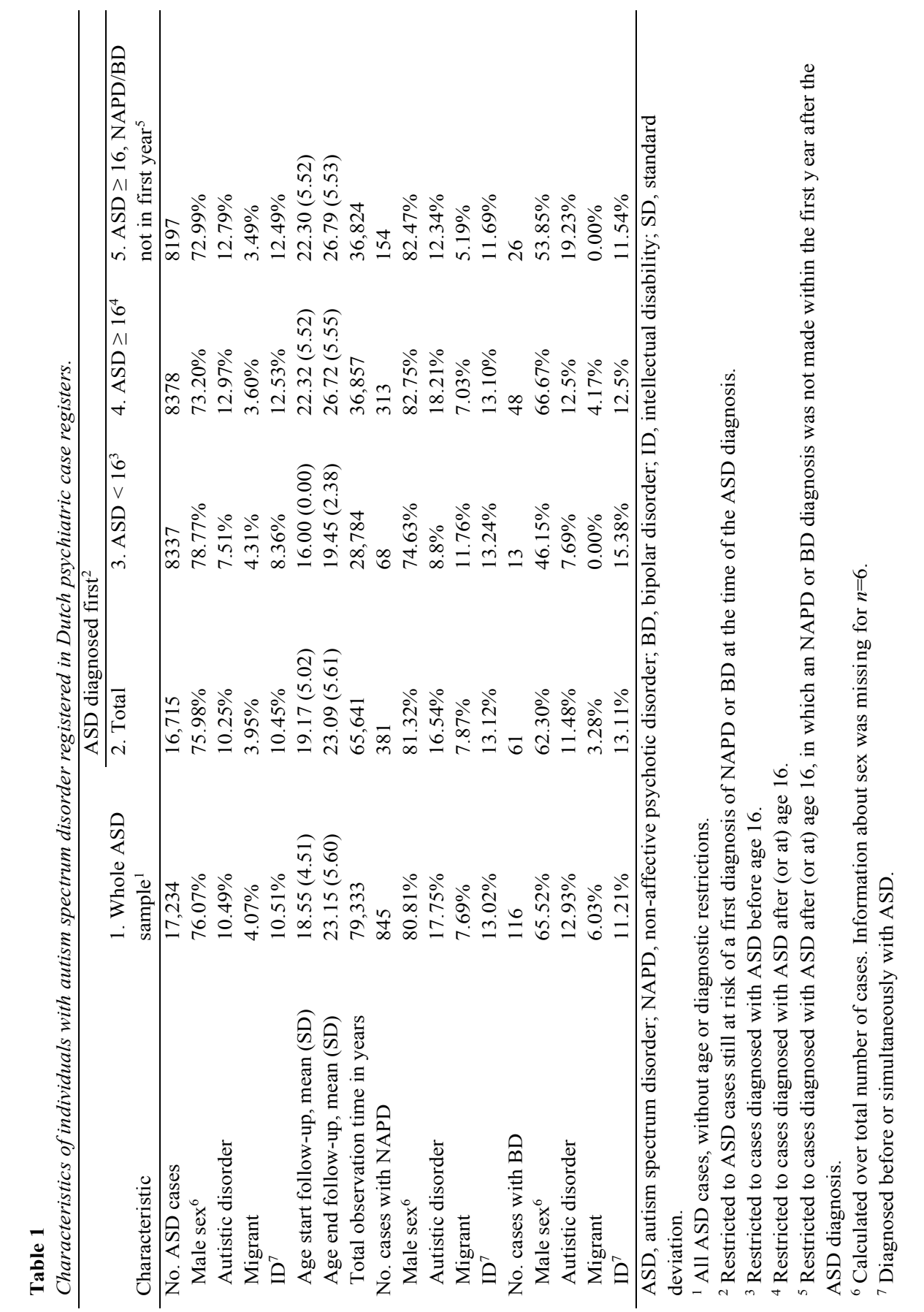




\section{Chapter II}

पा山ाणाण

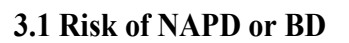

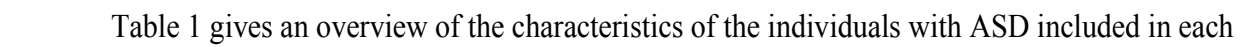

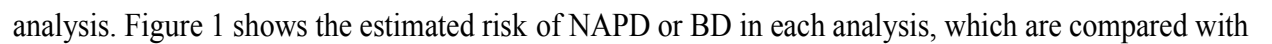

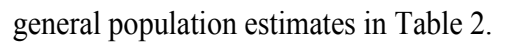

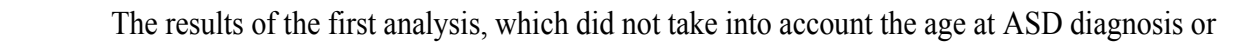

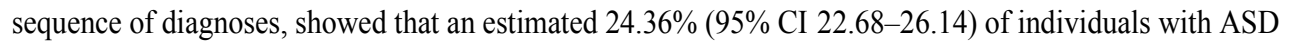

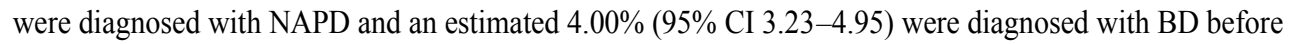

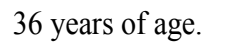

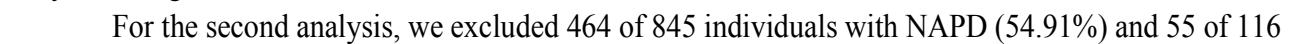
ए

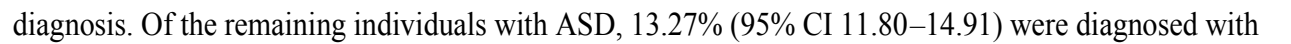

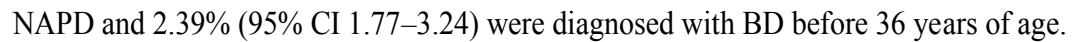

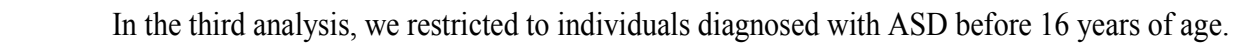

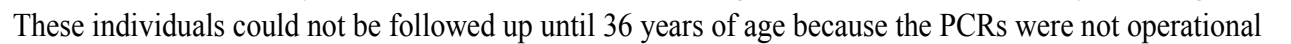

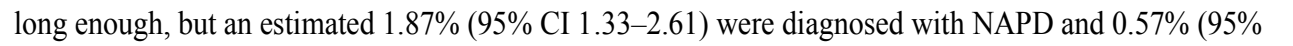

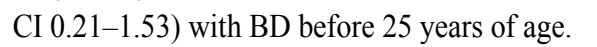

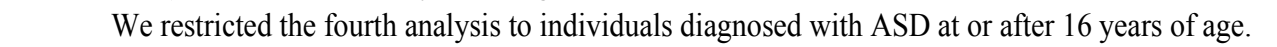

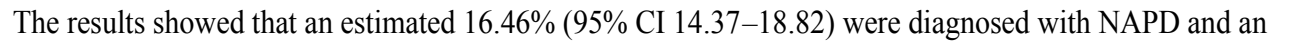

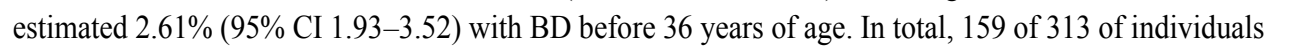

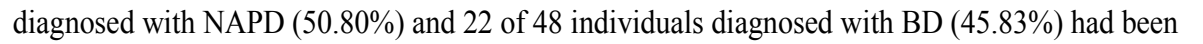

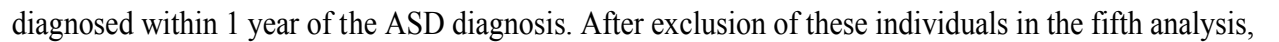

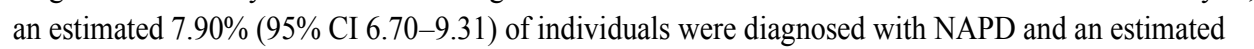

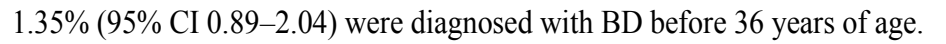

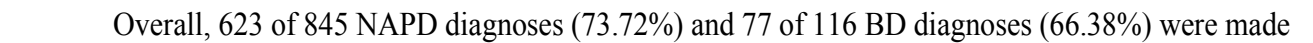

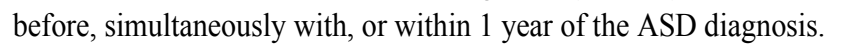

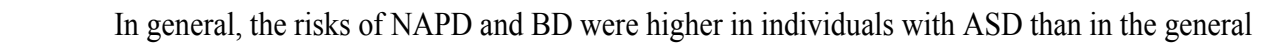

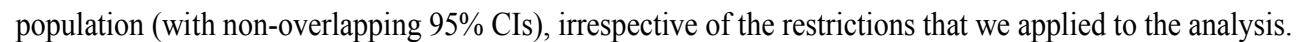

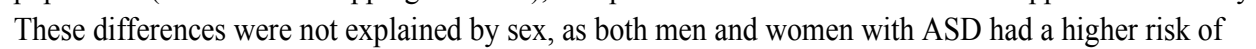

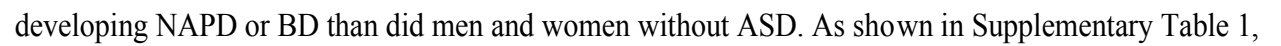
प

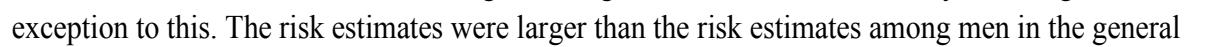

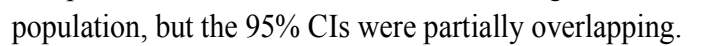

$\square$

$\square$

$\square$

$\square$

$\square$

$\square$

$\square$

$\square$

$\square$

$\square$

$\square$ 


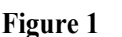

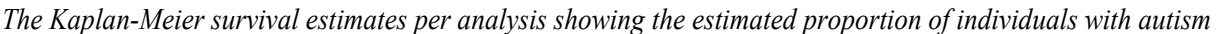

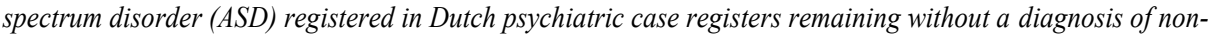

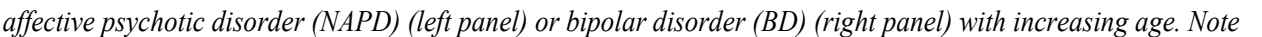

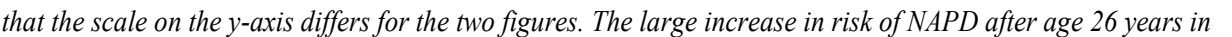

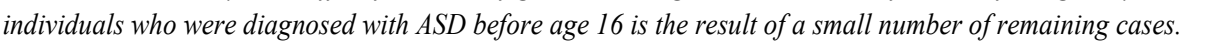
$\square$

NAPD

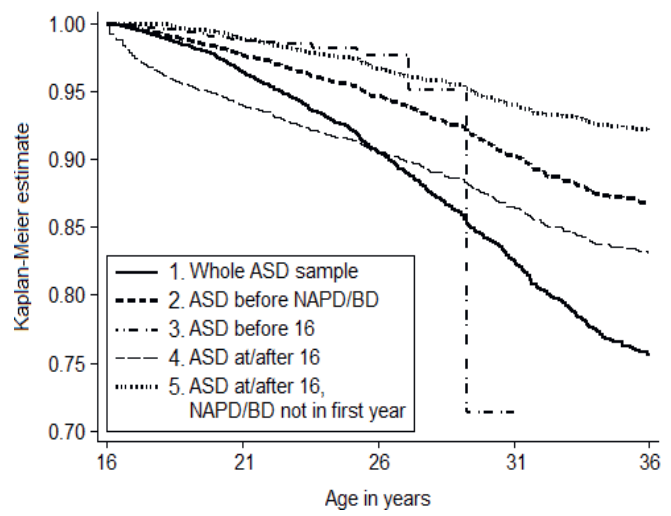

BD

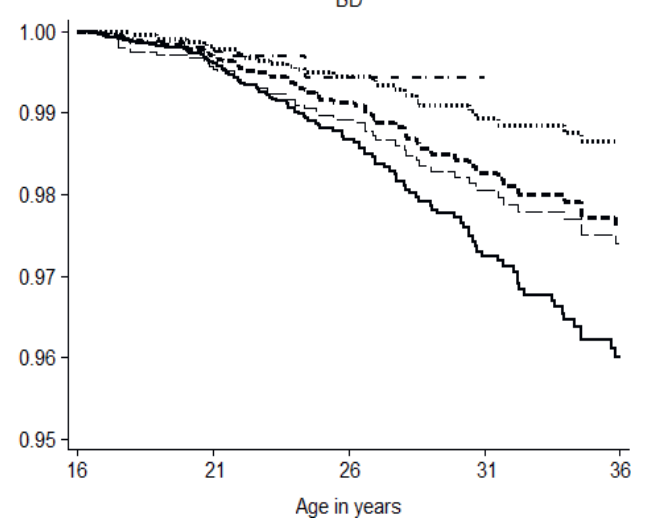




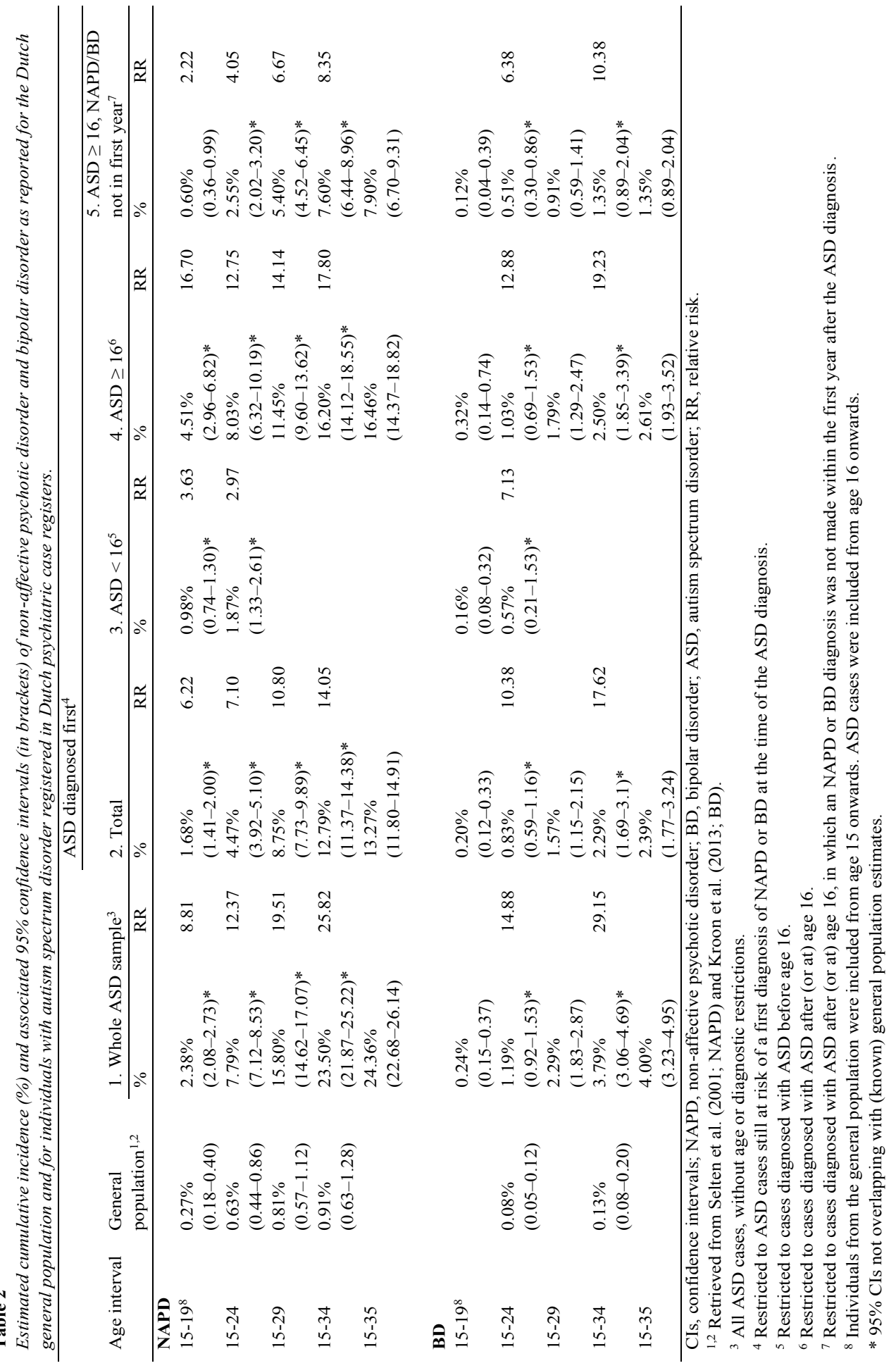


पाणm

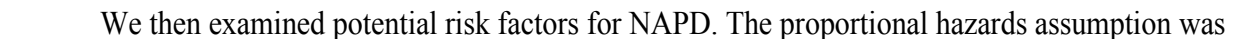

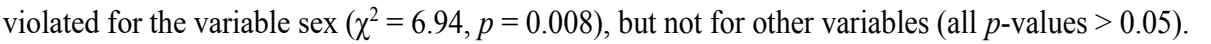

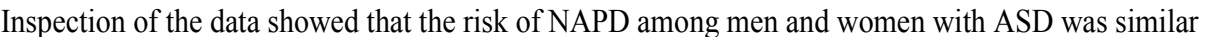

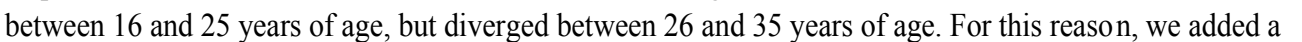

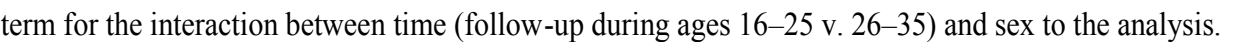

\begin{tabular}{l}
\hline \\
\hline
\end{tabular}

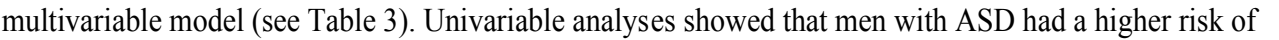

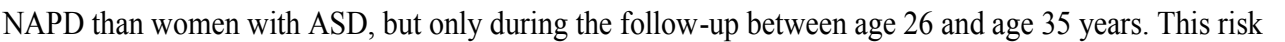

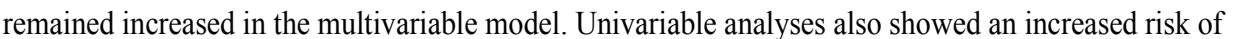

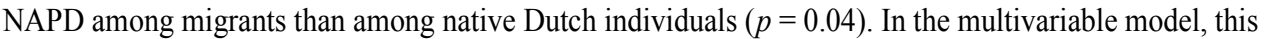

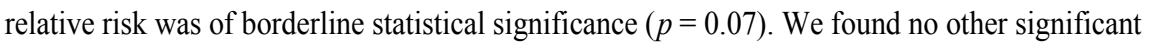

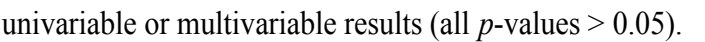

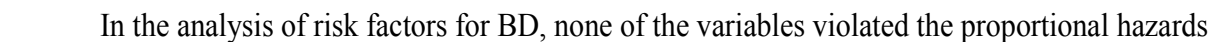

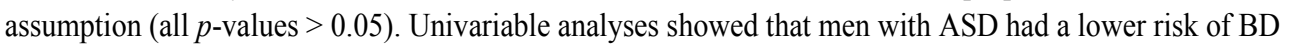
प

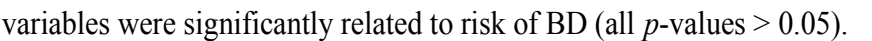
$\square$ 


\section{Chapter II}

पापाणा

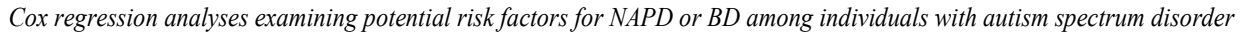

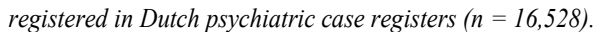

\begin{tabular}{|c|c|c|c|c|}
\hline \multirow{3}{*}{$\begin{array}{l}\square \\
\square \\
\square \square\|ा\| \square\end{array}$} & \multicolumn{4}{|c|}{ 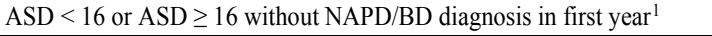 } \\
\hline & \multicolumn{4}{|c|}{ 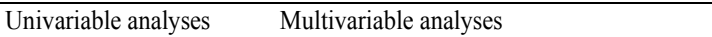 } \\
\hline & 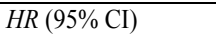 & 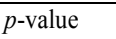 & 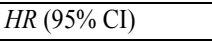 & पापापा \\
\hline 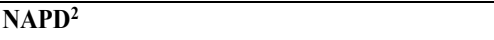 & $\square$ & $\square$ & $\square$ & $\square$ \\
\hline$\square \square$ & $\square$ & $\square$ & $\square$ & $\square$ \\
\hline 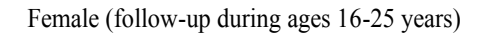 & पणणाणाप & $\square$ & पपणाणा & $\square$ \\
\hline 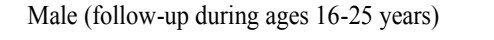 & 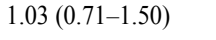 & पाए & 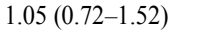 & पाए। \\
\hline 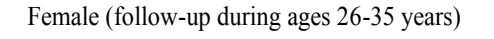 & पणाणाए & $\square$ & पएणाएा & $\square$ \\
\hline 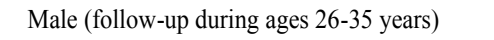 & 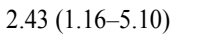 & पाए & 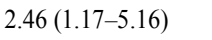 & एणए \\
\hline 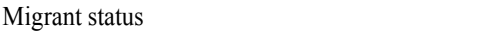 & $\square$ & $\square$ & $\square$ & $\square$ \\
\hline एणापाए & पणणाणा & $\square$ & पपणाणा & $\square$ \\
\hline 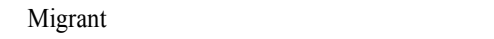 & 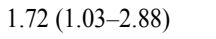 & एणाए & 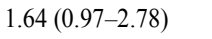 & $\square$ \\
\hline 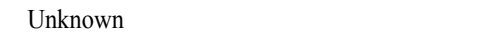 & 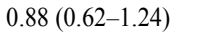 & पण & 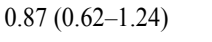 & पाए। \\
\hline $\mathbb{\square}$ & $\square$ & $\square$ & $\square$ & $\square$ \\
\hline 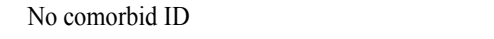 & पणणाणाए & $\square$ & पणाणाए & $\square$ \\
\hline 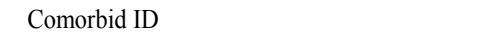 & 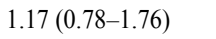 & $\square \amalg$ & 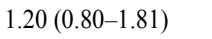 & $\square \square$ \\
\hline 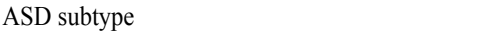 & $\square$ & $\square$ & $\square$ & $\square$ \\
\hline पAsperger's syndrome/PDD $\square \square \square \square$ & पणणाणाए & $\square$ & पपणाणा & $\square$ \\
\hline 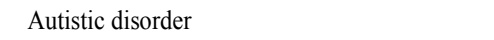 & 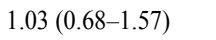 & $\square \square$ & 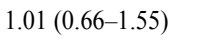 & पाए \\
\hline 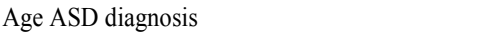 & $\square$ & $\square$ & $\square$ & $\square$ \\
\hline एाய冋 & पणणाएए & $\square$ & पपणाएण & $\square$ \\
\hline एणाएம & 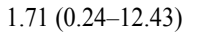 & पाए & 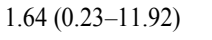 & पाए \\
\hline एणाएण & 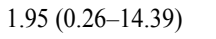 & 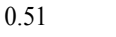 & 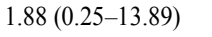 & 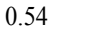 \\
\hline 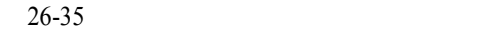 & 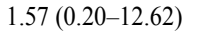 & पाए & 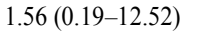 & पाए। \\
\hline$\square$ & $\square$ & $\square$ & $\square$ & $\square$ \\
\hline 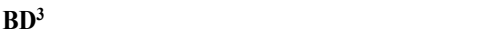 & $\square$ & $\square$ & $\square$ & $\square$ \\
\hline$\square \square$ & $\square$ & $\square$ & $\square$ & $\square$ \\
\hline யण口冋ாण & पणणाणए & $\square$ & पणमणाए & $\square$ \\
\hline एणा पण口 & 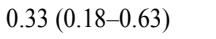 & पणाएम & 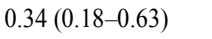 & एणाए \\
\hline $\mathbb{⿴ 囗 十 ~}$ & $\square$ & $\square$ & $\square$ & $\square$ \\
\hline 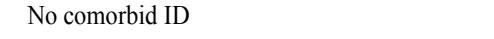 & पणणाणाए & $\square$ & पमाणाए & $\square$ \\
\hline 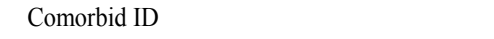 & 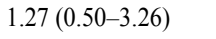 & पाए & 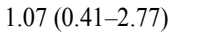 & $\square \square$ \\
\hline 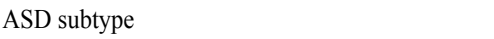 & $\square$ & $\square$ & $\square$ & $\square$ \\
\hline पAsperger's syndrome/PDD $\square \square \square \square$ & पणणाणाए & $\square$ & पणाणाए & $\square$ \\
\hline 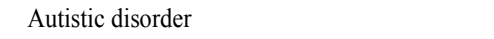 & 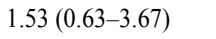 & $\square \square$ & 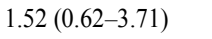 & $\square \square$ \\
\hline 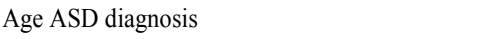 & $\square$ & $\square$ & $\square$ & $\square$ \\
\hline யாШ口 & पणणाणए & $\square$ & पपणाणए & $\square$ \\
\hline 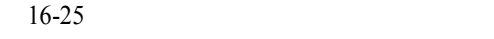 & 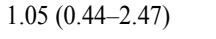 & पाए & 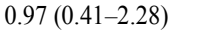 & पाए \\
\hline पाणा|ा & 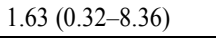 & $\square[11$ & 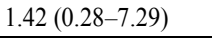 & 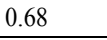 \\
\hline
\end{tabular}

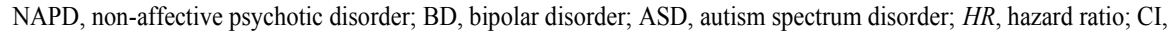
confidence interval; ID, intellectual disability $\mathbb{\square}$

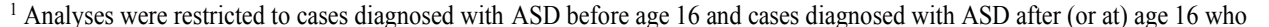

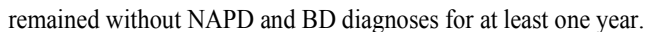

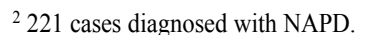

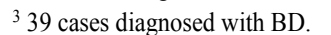

पाणाणाण

पाणापणाणा

$\square$ 


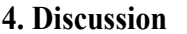

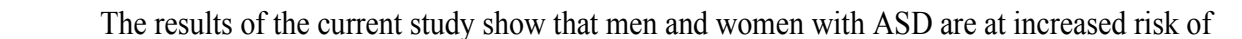

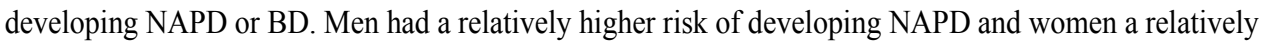

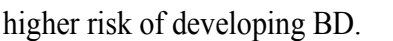

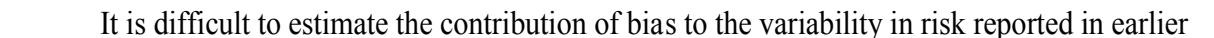

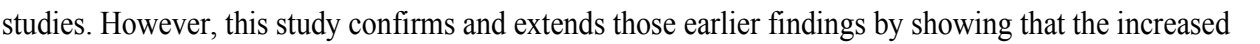

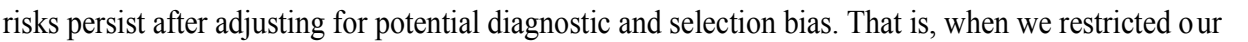

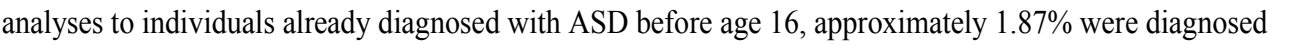

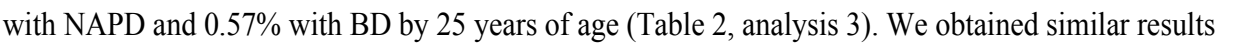

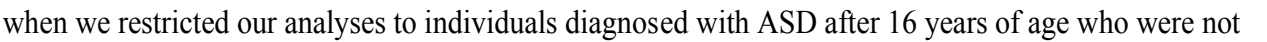

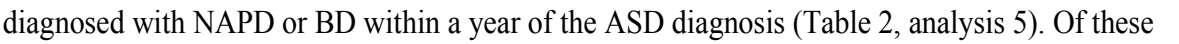

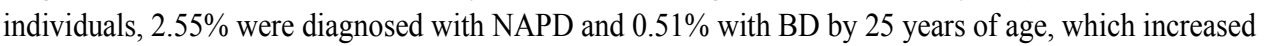

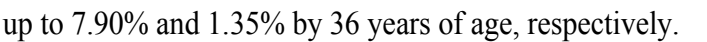

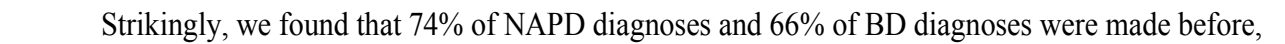

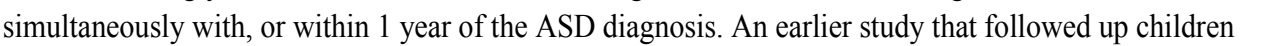

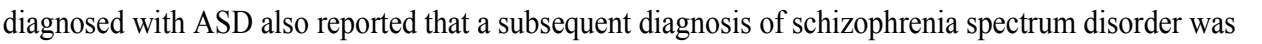

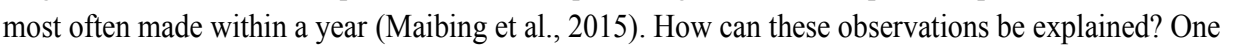

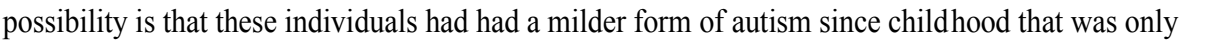

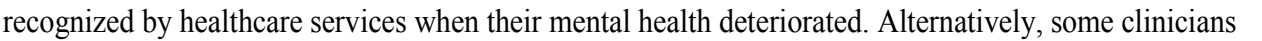

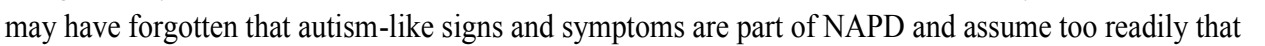

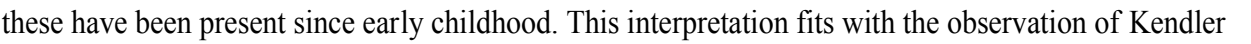
$\llbracket \amalg \amalg$ that some clinicians equate 'schizophrenia' with its DSM criteria only. It is less clear whether such

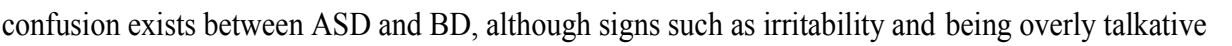

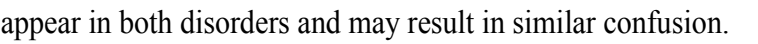

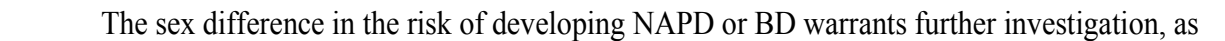
पणता Croen et al., 2015; Lugnegård et al., 2015)

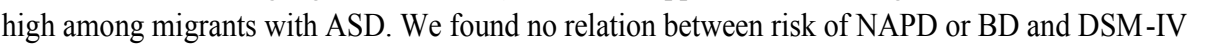

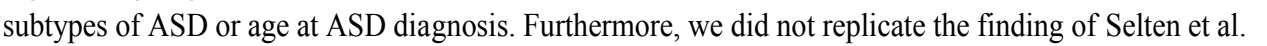

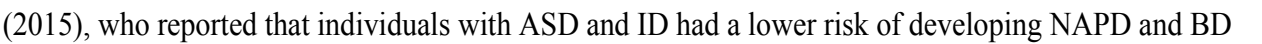

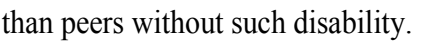

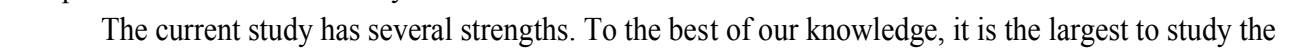

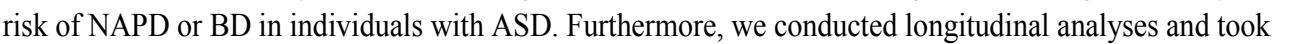

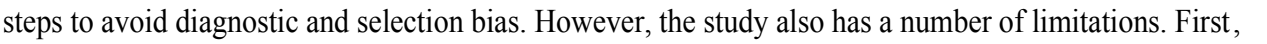

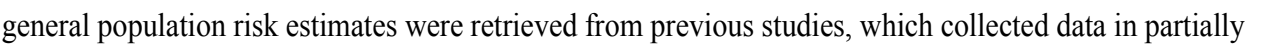

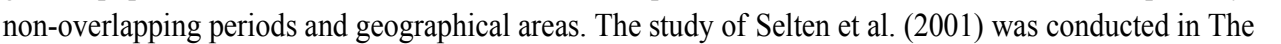

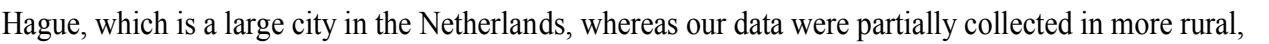

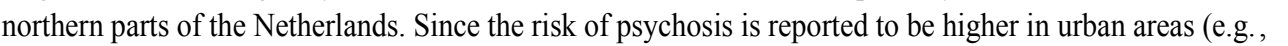

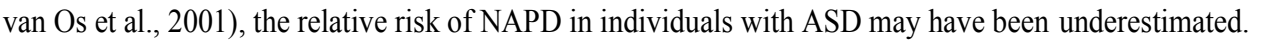

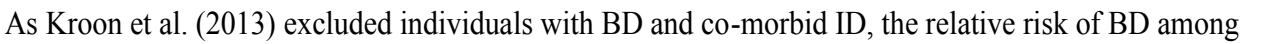

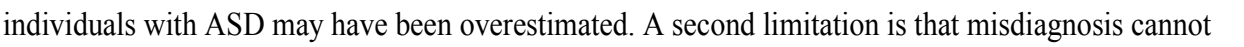

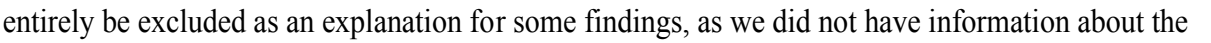

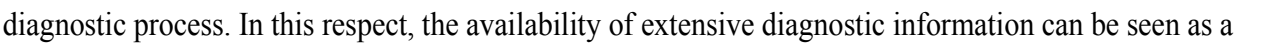




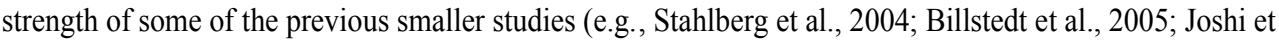
al., 2013; Lugnegård et al., 2015)

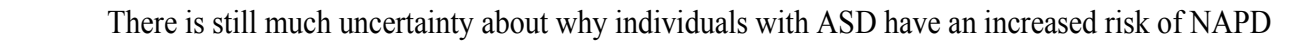
and BD (Padgett et al., 2010; Chisholm et al., 2015)

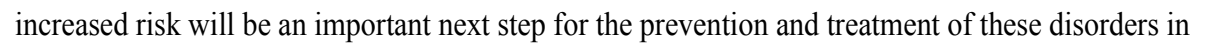
individuals with ASD. Shared risk factors, such as genetic overlap between ASD, NAPD, and BD

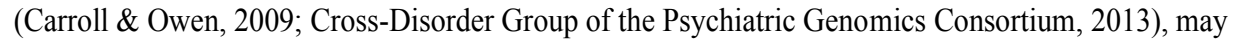

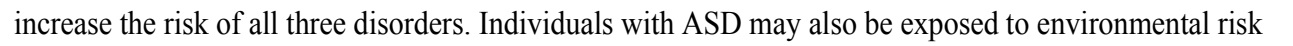

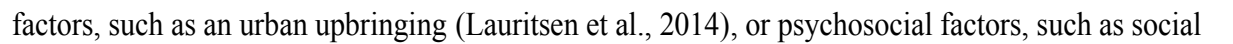

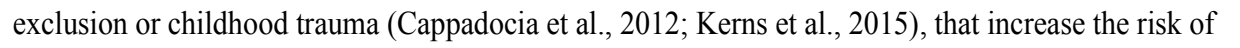
developing NAPD and/or BD (Read et al., 2005; Laursen et al., 2007; Van Dam et al., 2012; Selten et al.,

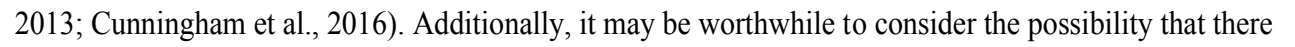

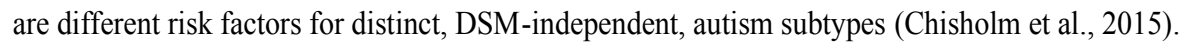

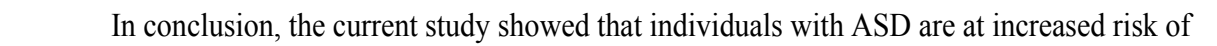
developing NAPD or BD. Thes

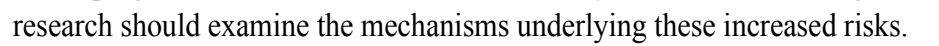




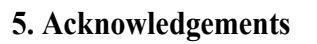

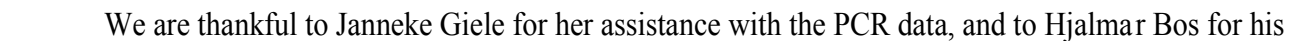

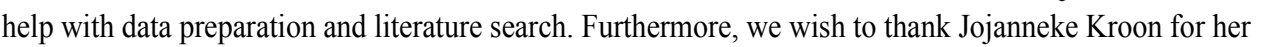

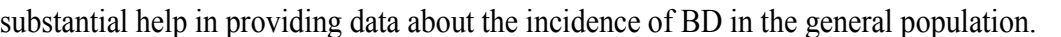
$\square$ 


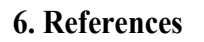

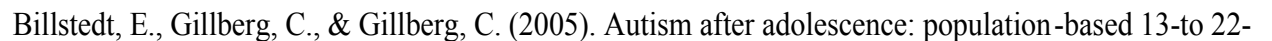

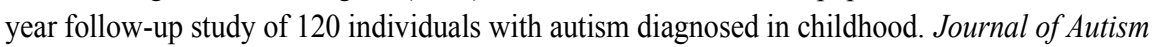

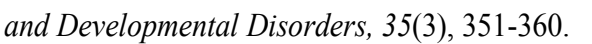

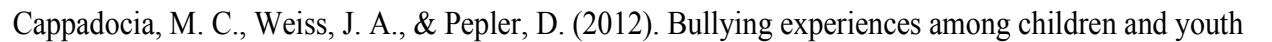

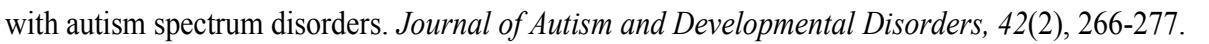

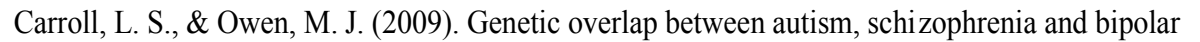

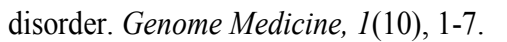

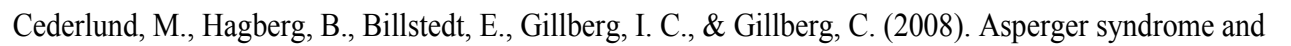

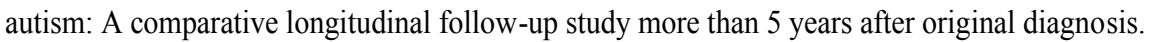

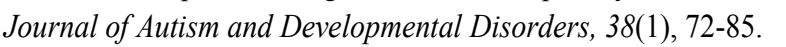

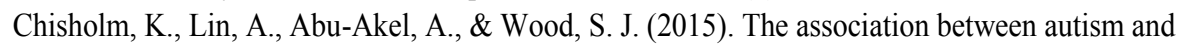

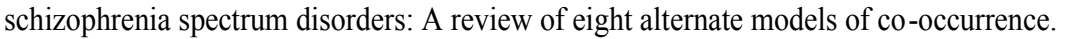

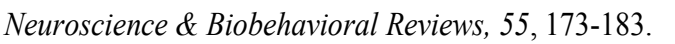

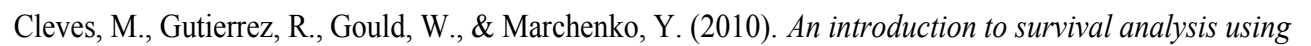

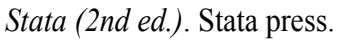

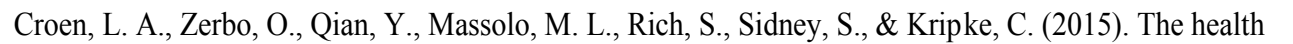

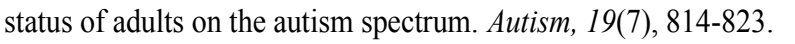

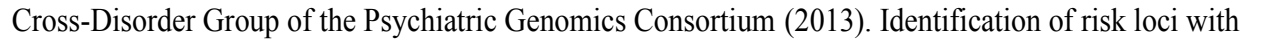

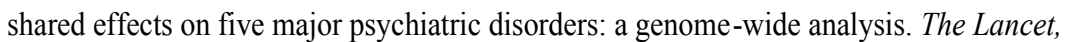

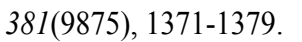

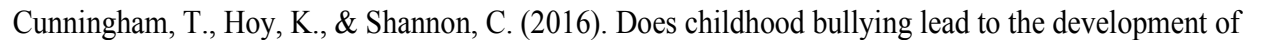

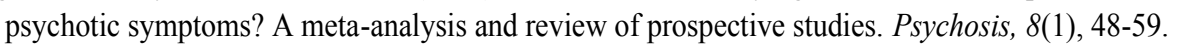

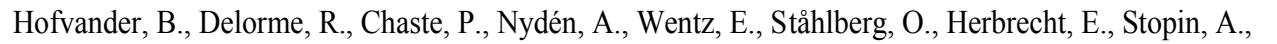

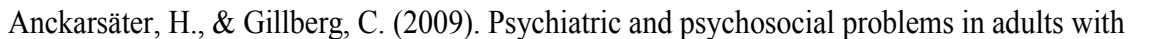

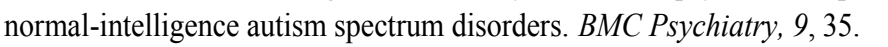

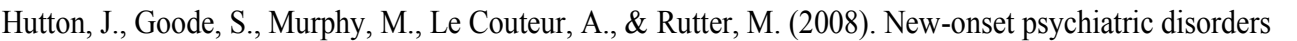

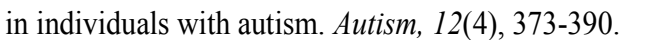

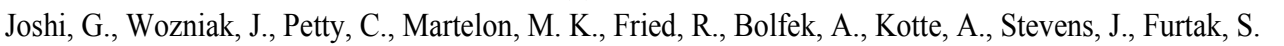

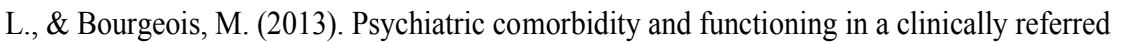

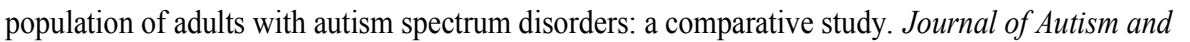

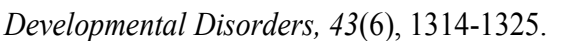

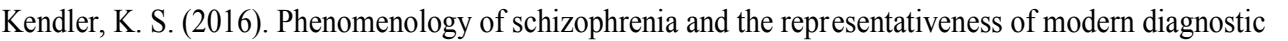

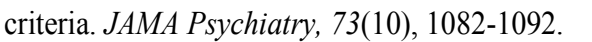

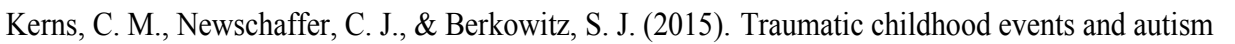

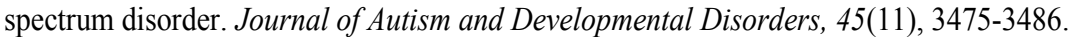

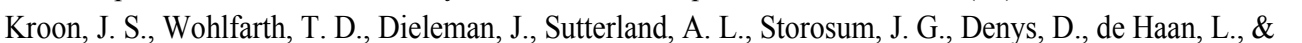

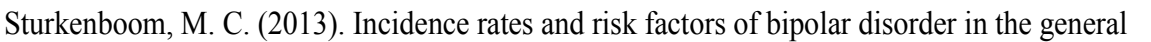

population: a population-based cohort study

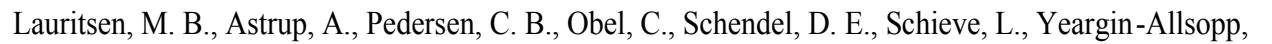

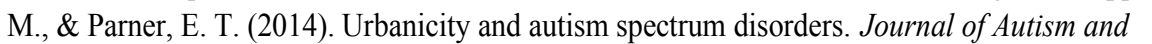

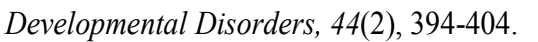

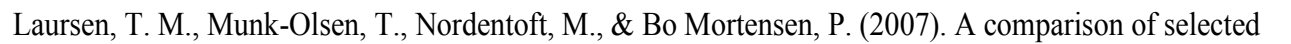

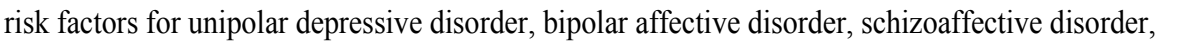




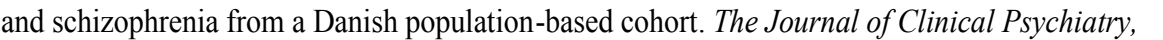

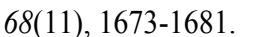

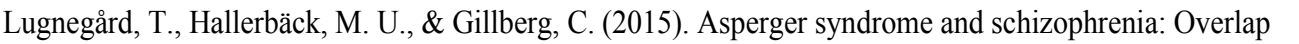

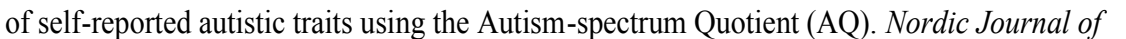

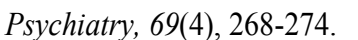

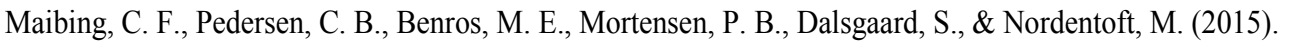

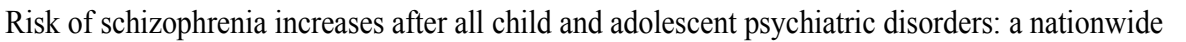

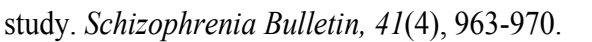

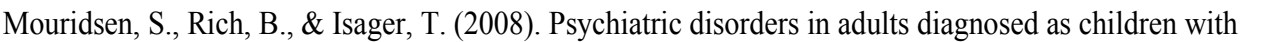

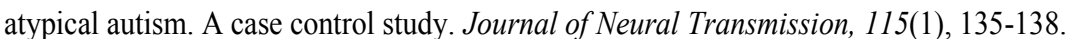

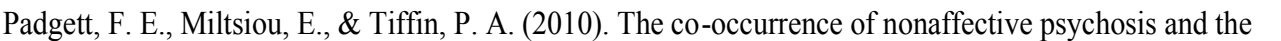

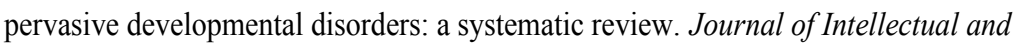

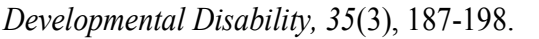

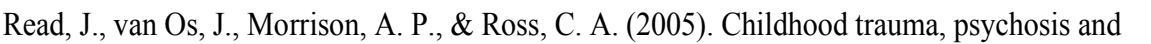

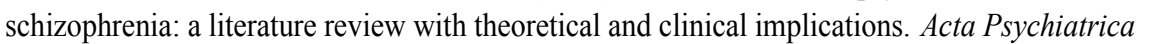

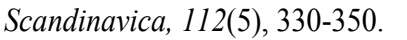

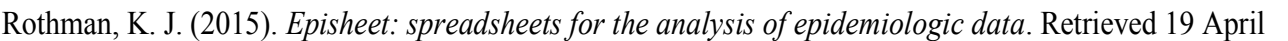

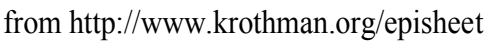

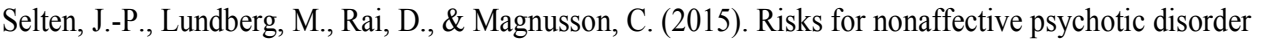

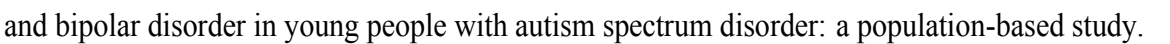

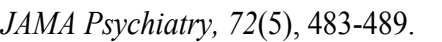

a

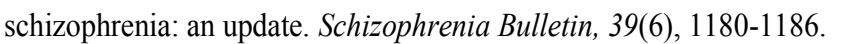

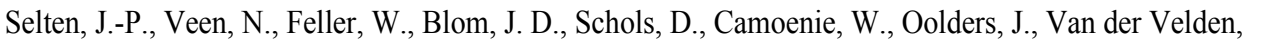

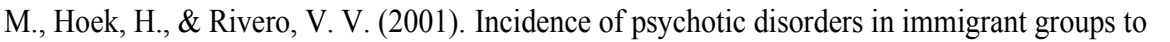

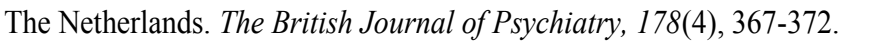

a

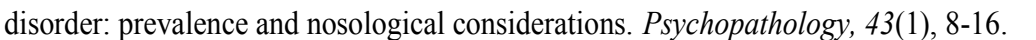

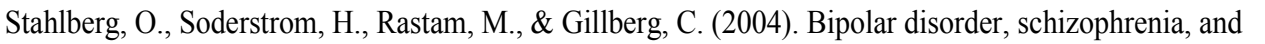

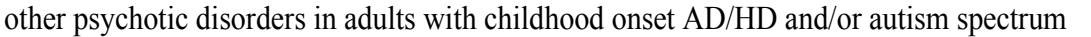

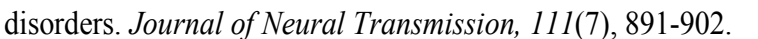

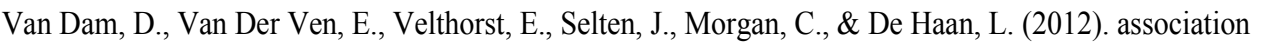

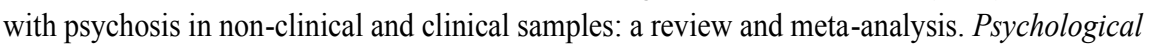

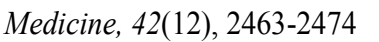

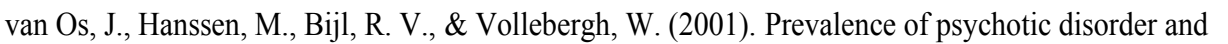
ए

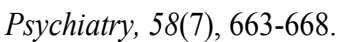

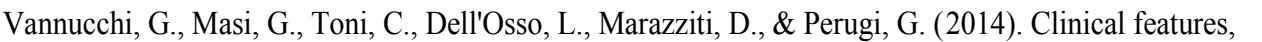

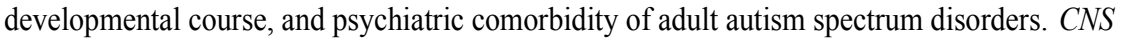

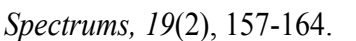

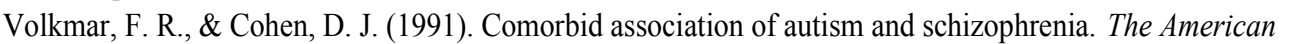

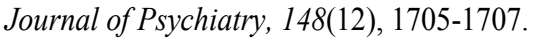


Chapter II

$\square$

प

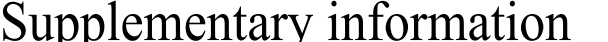

$\square$

$\square$

$\square$

$\square$

$\square$

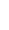

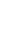

$\square$

$\square$

$\square$

$\square$ 


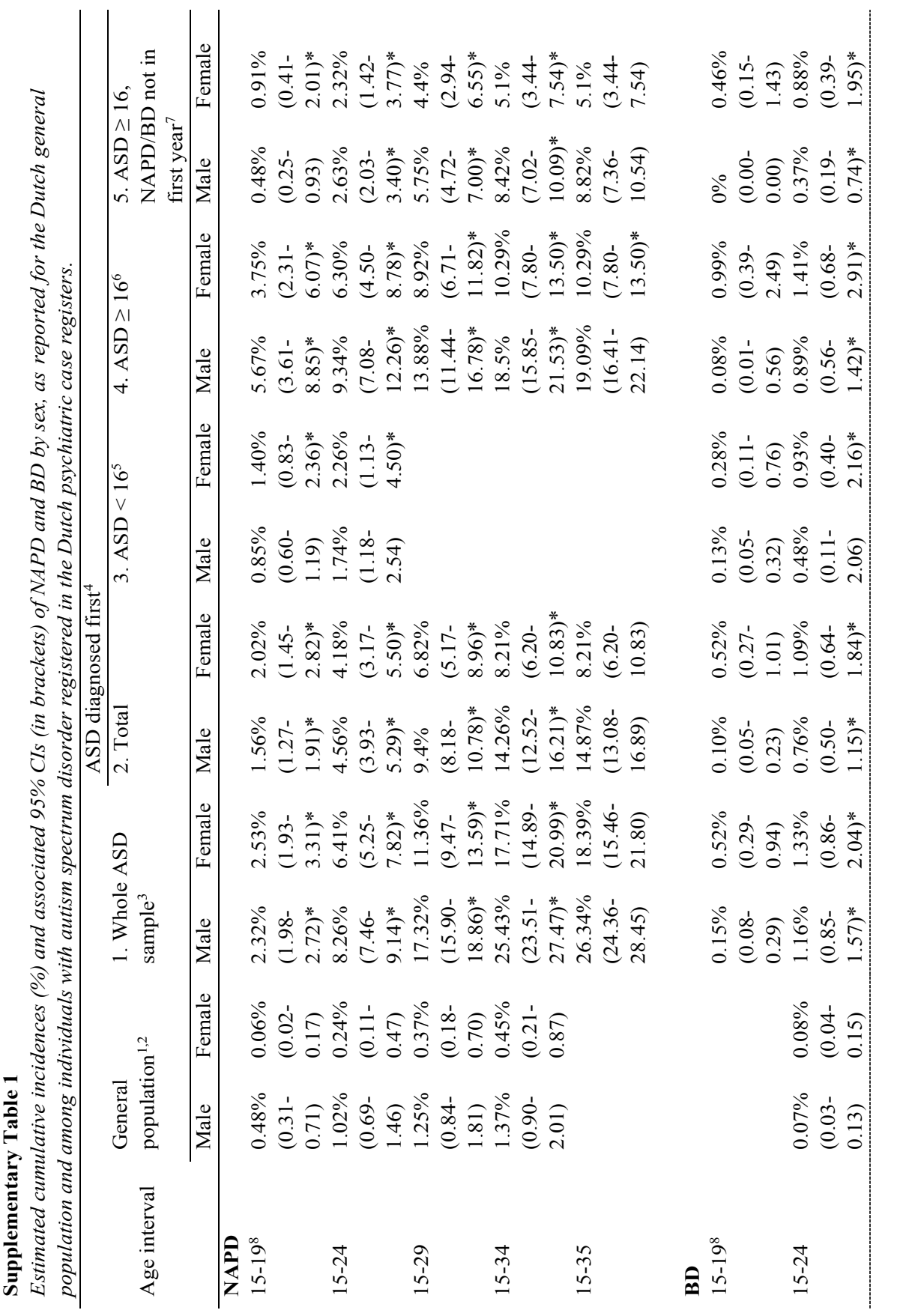




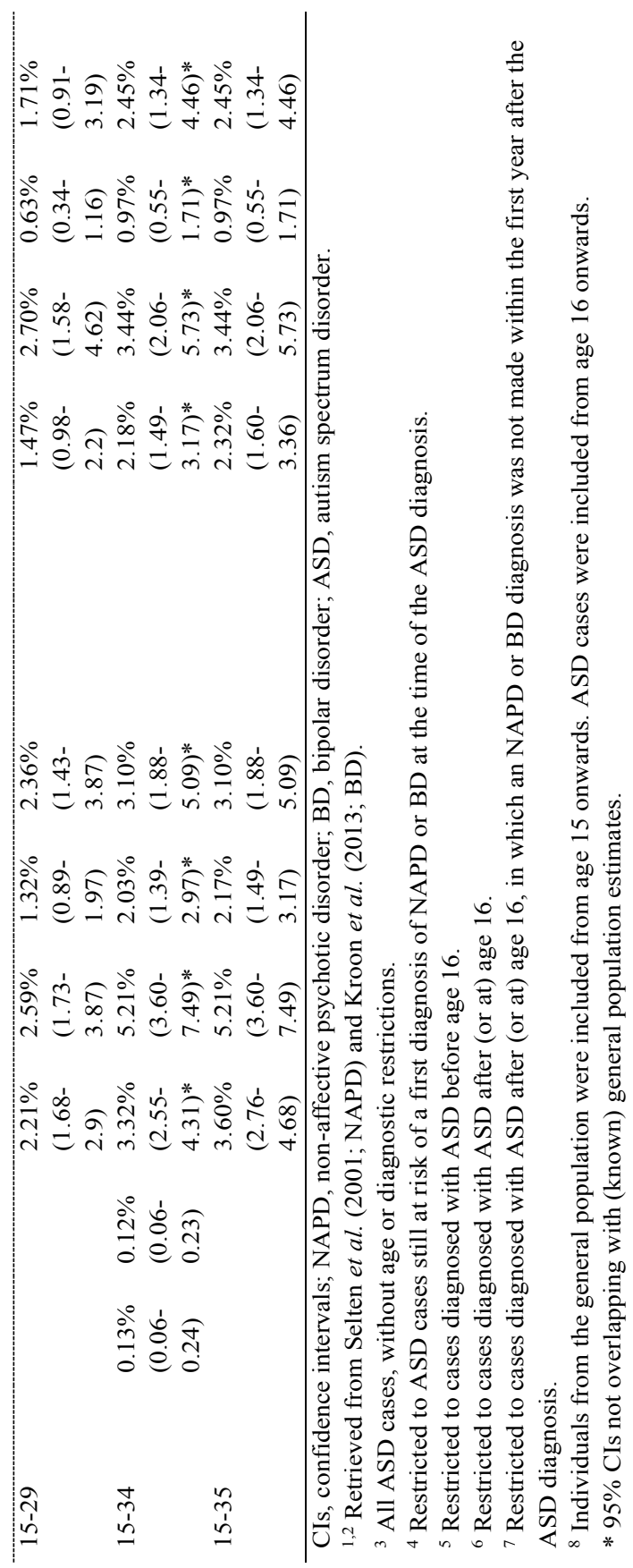




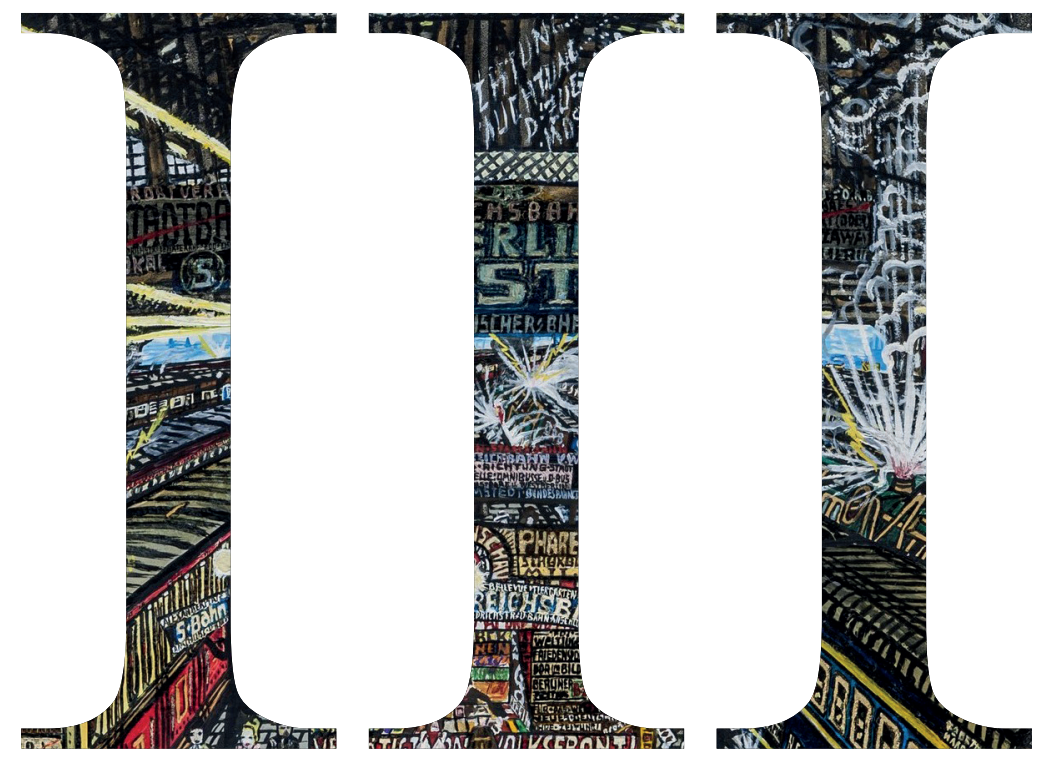




\title{
Chapter III
}

\section{Childhood trauma as a mediator of the association between autistic traits and psychotic experiences: evidence from the ALSPAC birth cohort}

Dardani, C.*, Schalbroeck, R.*, Jones, H., Hammerton, G., Croft, J., Madley-

Dowd, P., Sullivan, S., Zammit, S., Selten, J. P., \& Rai, D.

\author{
* Joint first authors
}

Manuscript submitted 


\section{Chapter III}

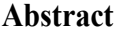

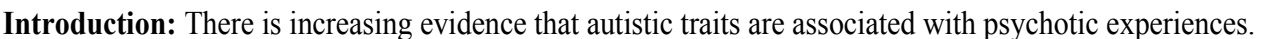

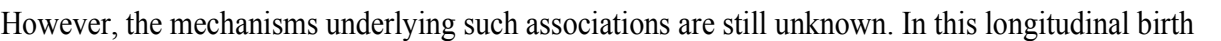

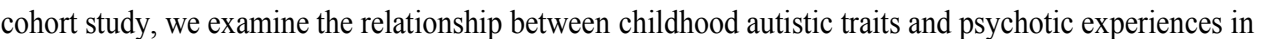

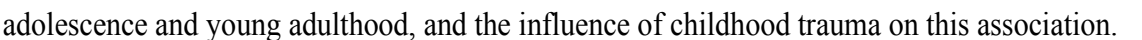

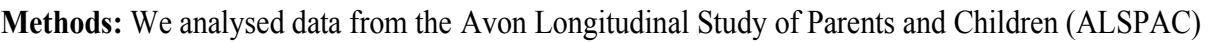

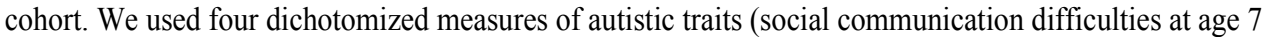

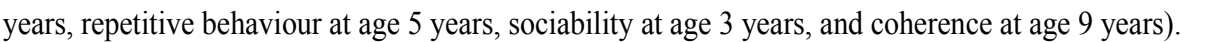

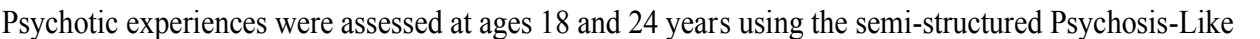

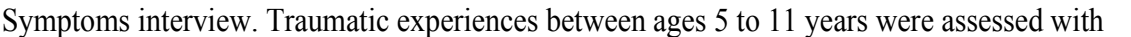

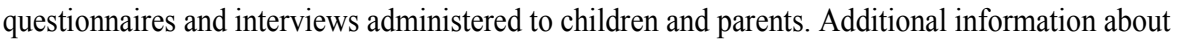

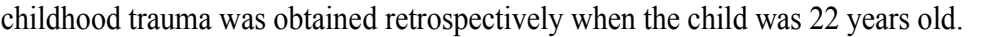

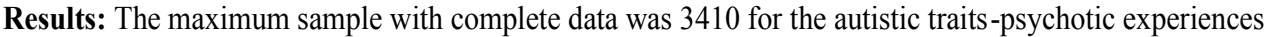

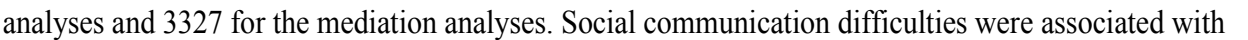

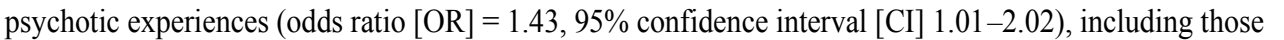
प

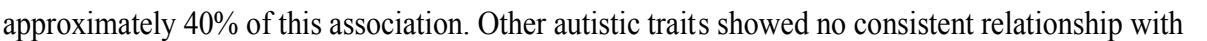

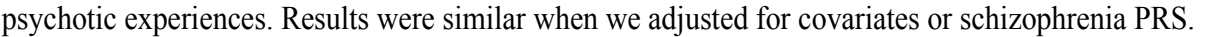

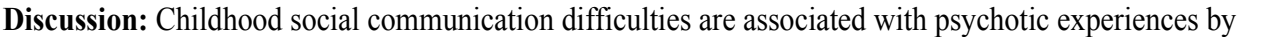

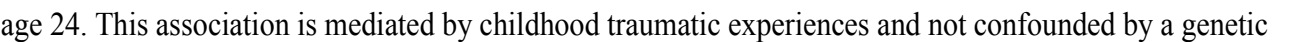
प

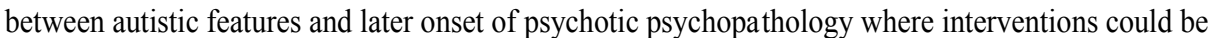
पाणाणाए

$\square$ 


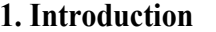

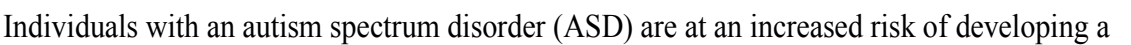

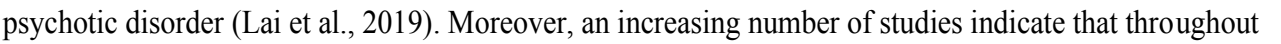
ए

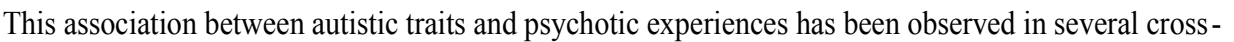

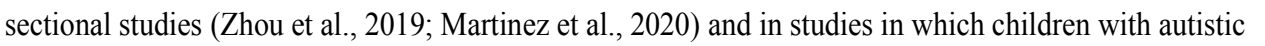

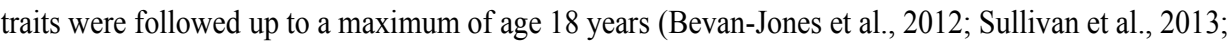
Taylor et al., 2015; Cederlöf et al., 2016) एण

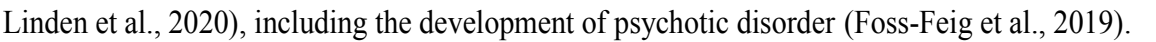

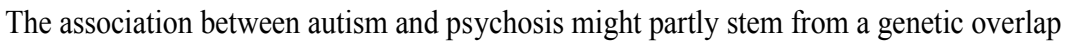

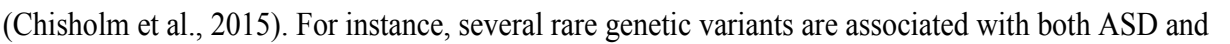

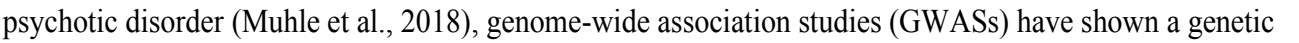

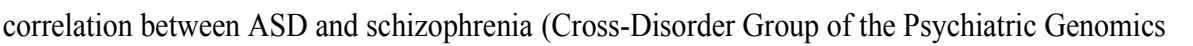
Consortium, 2019)

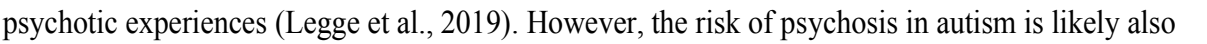

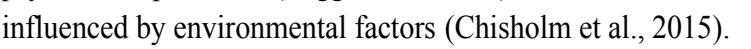

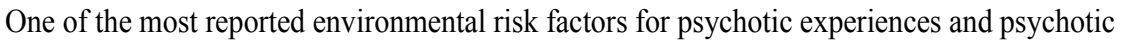

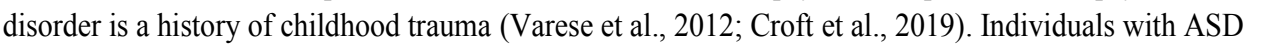

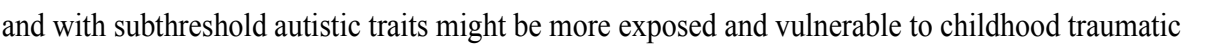

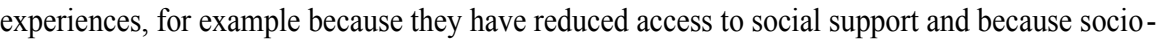

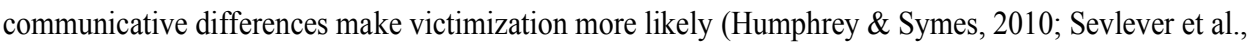

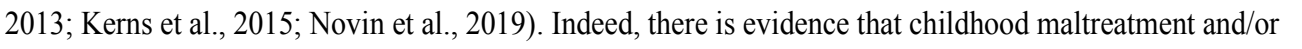

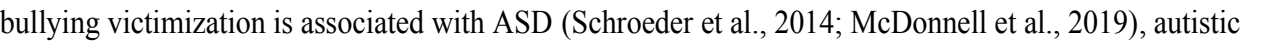

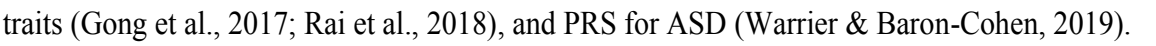

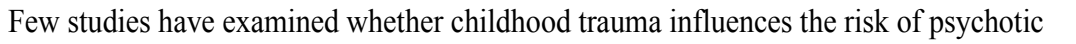

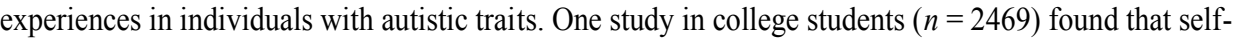
पम

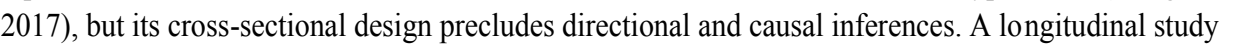

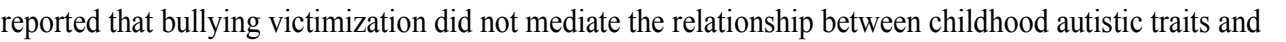

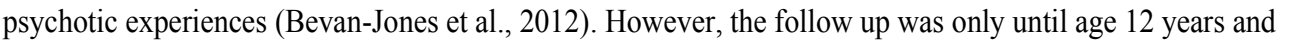

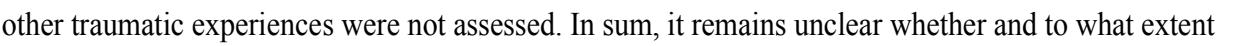
ए

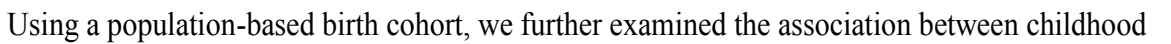

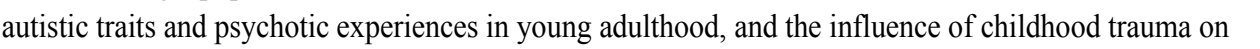
this association. We examined (1) whether autistic traits assessed between ages 3 and 9 were associated

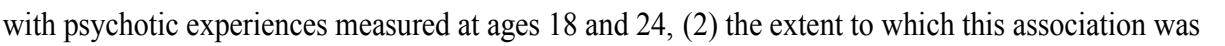
mediated by trauma experienced between ages 5 and 11, and (3) the possible confounding effects of

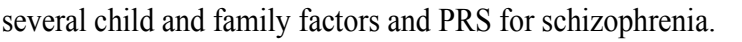
$\square$ 


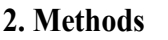

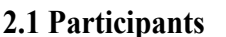

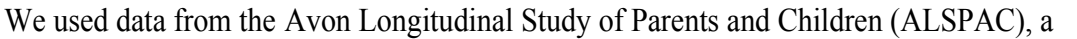

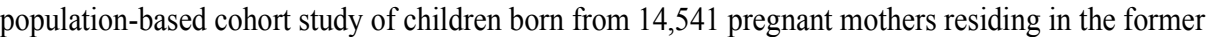

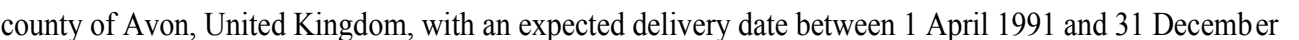

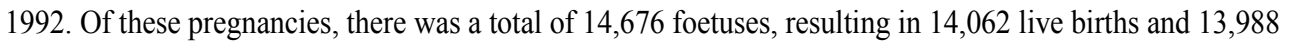

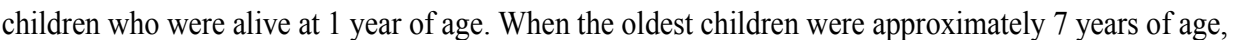

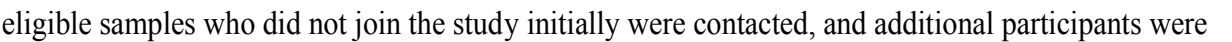

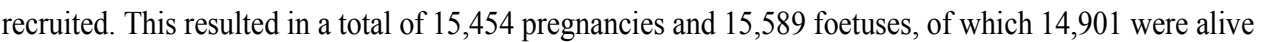

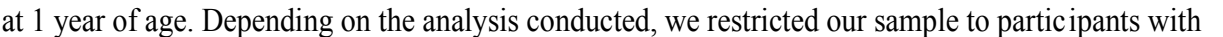

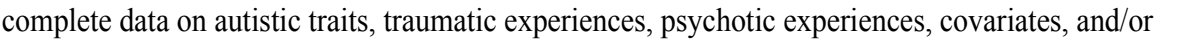

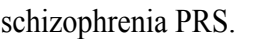

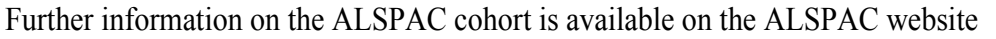

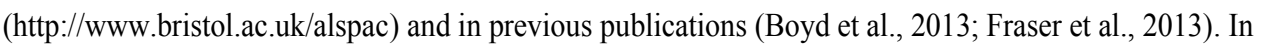

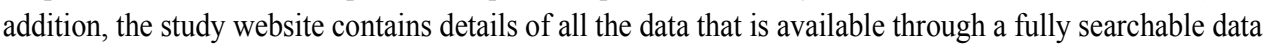

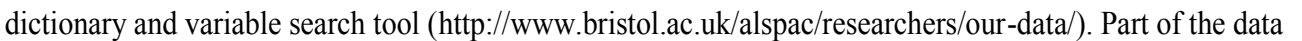

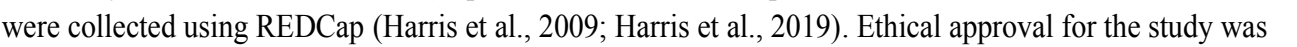

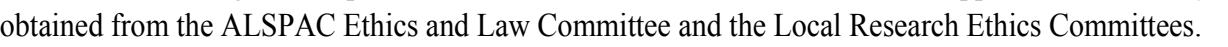
ए

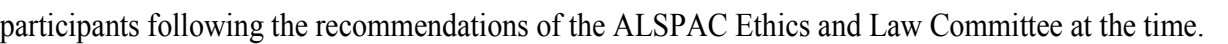
$\square$

पाणापापणा

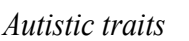

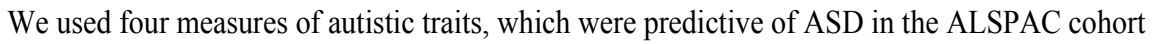

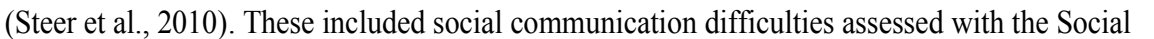

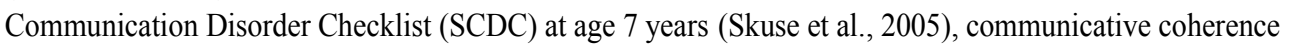

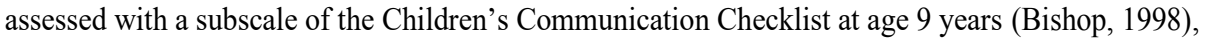

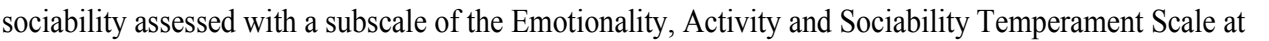

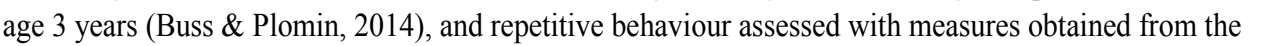

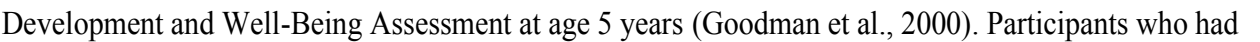

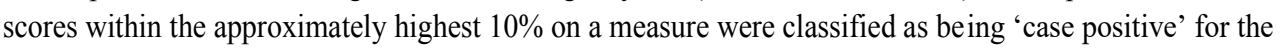

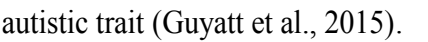

$\square$

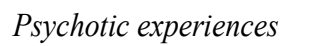

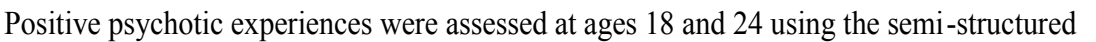

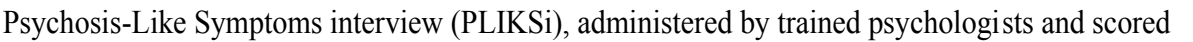

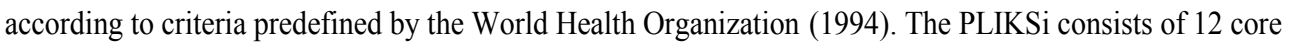

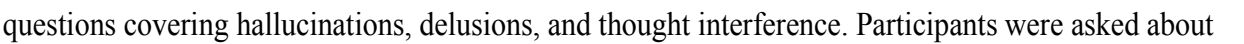

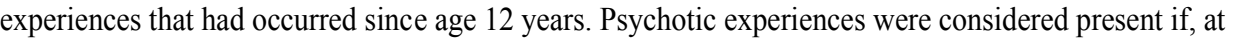

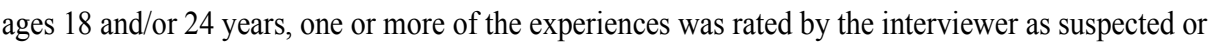

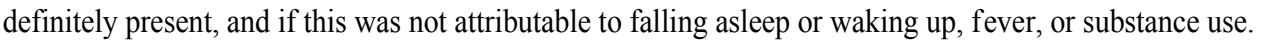

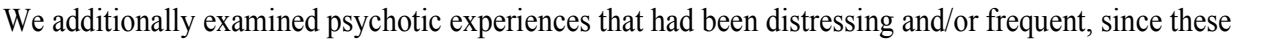

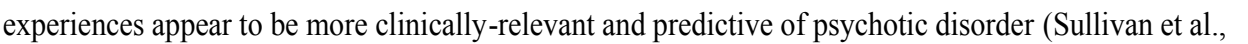
प11⿴囗十丁 


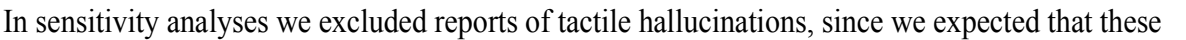

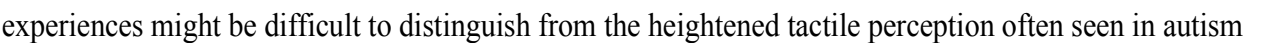

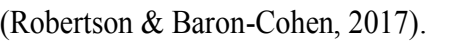

$\square$

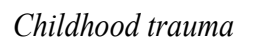

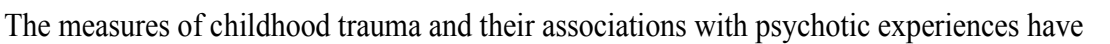

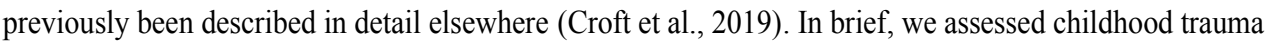

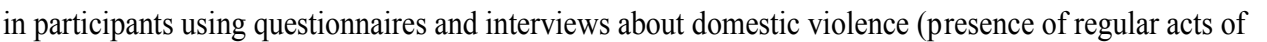

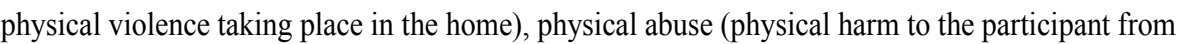

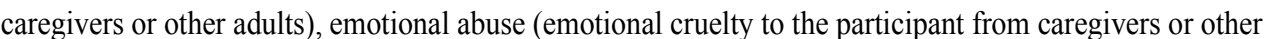

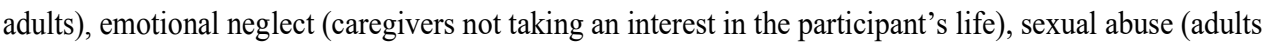

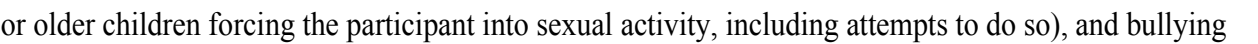

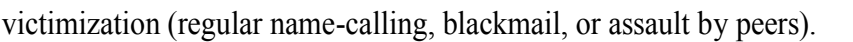

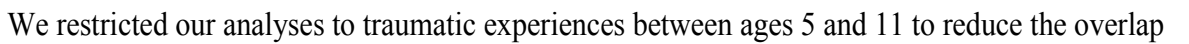

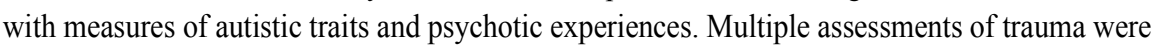

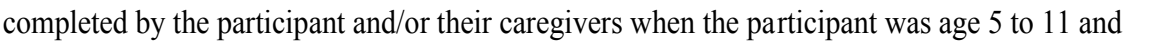

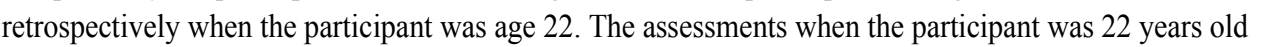

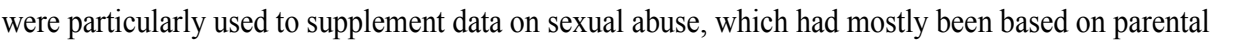

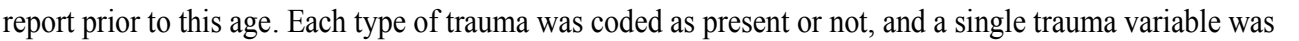

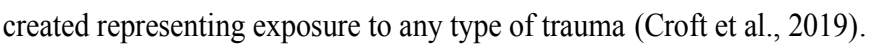
$\square$

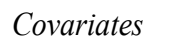

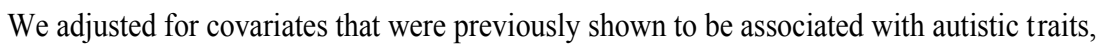

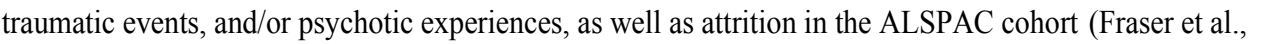
2013; Maclean et al., 2017; Rai et al., 2018). These included child sex (male/female), parity ( $\leq 1$ child

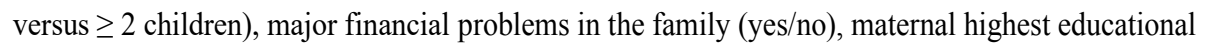
प

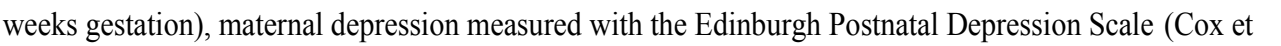
al., 1987)(EPDS; 18 weeks gestation scores $\geq 13$ ), and child IQ scores at age 8 assessed with the

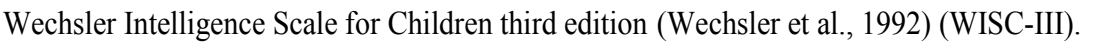
$\square$

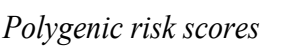

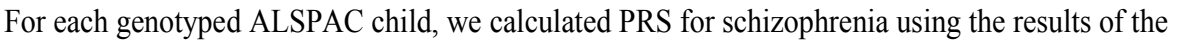

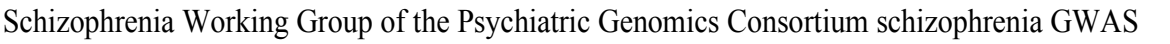

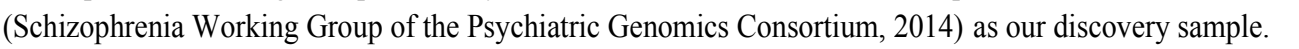

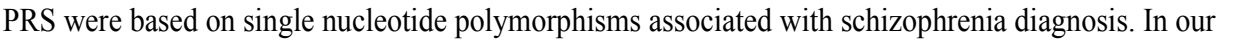

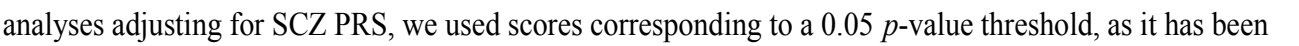

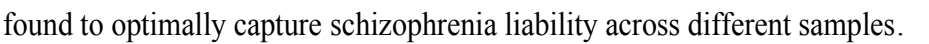

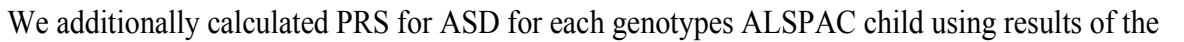

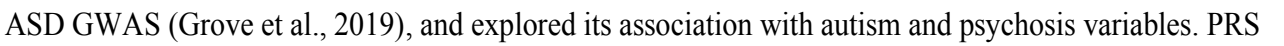

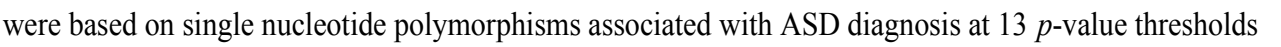

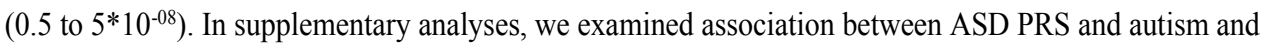

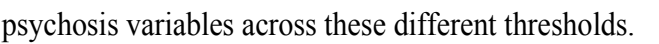

$\square$ 


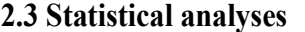

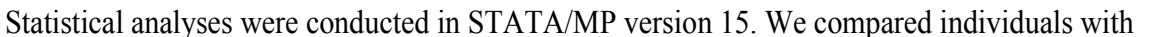

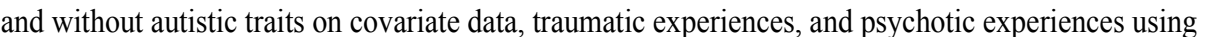

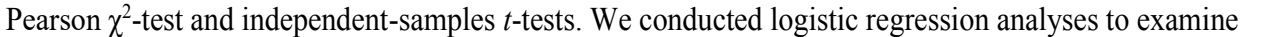

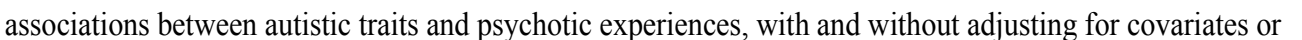

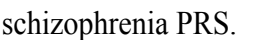

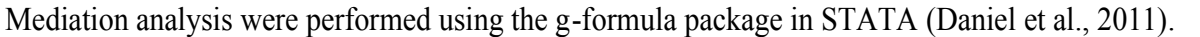

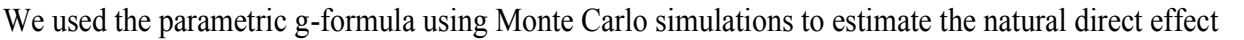

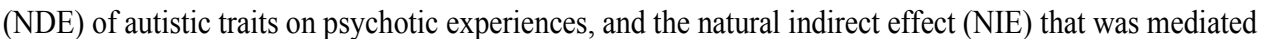

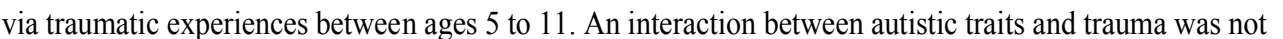

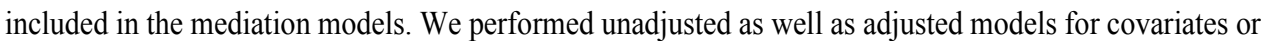

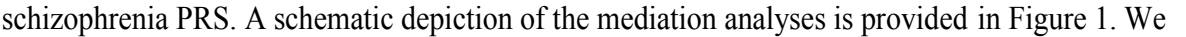

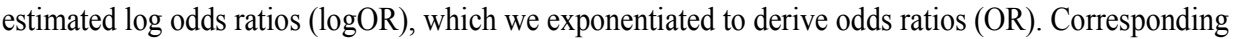

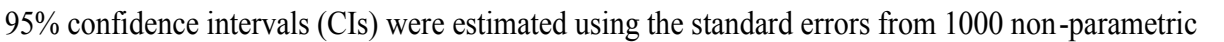

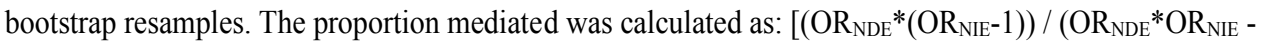

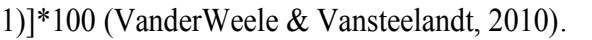

\section{प्णाप⿴囗十丁口卄}

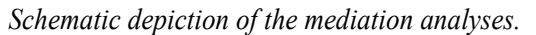

$\square$

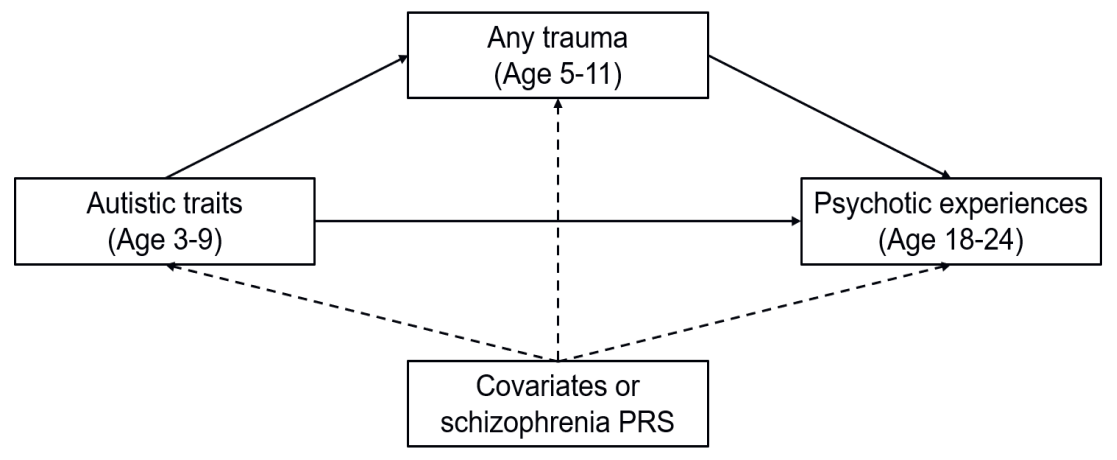

$\square$

$\square$ 


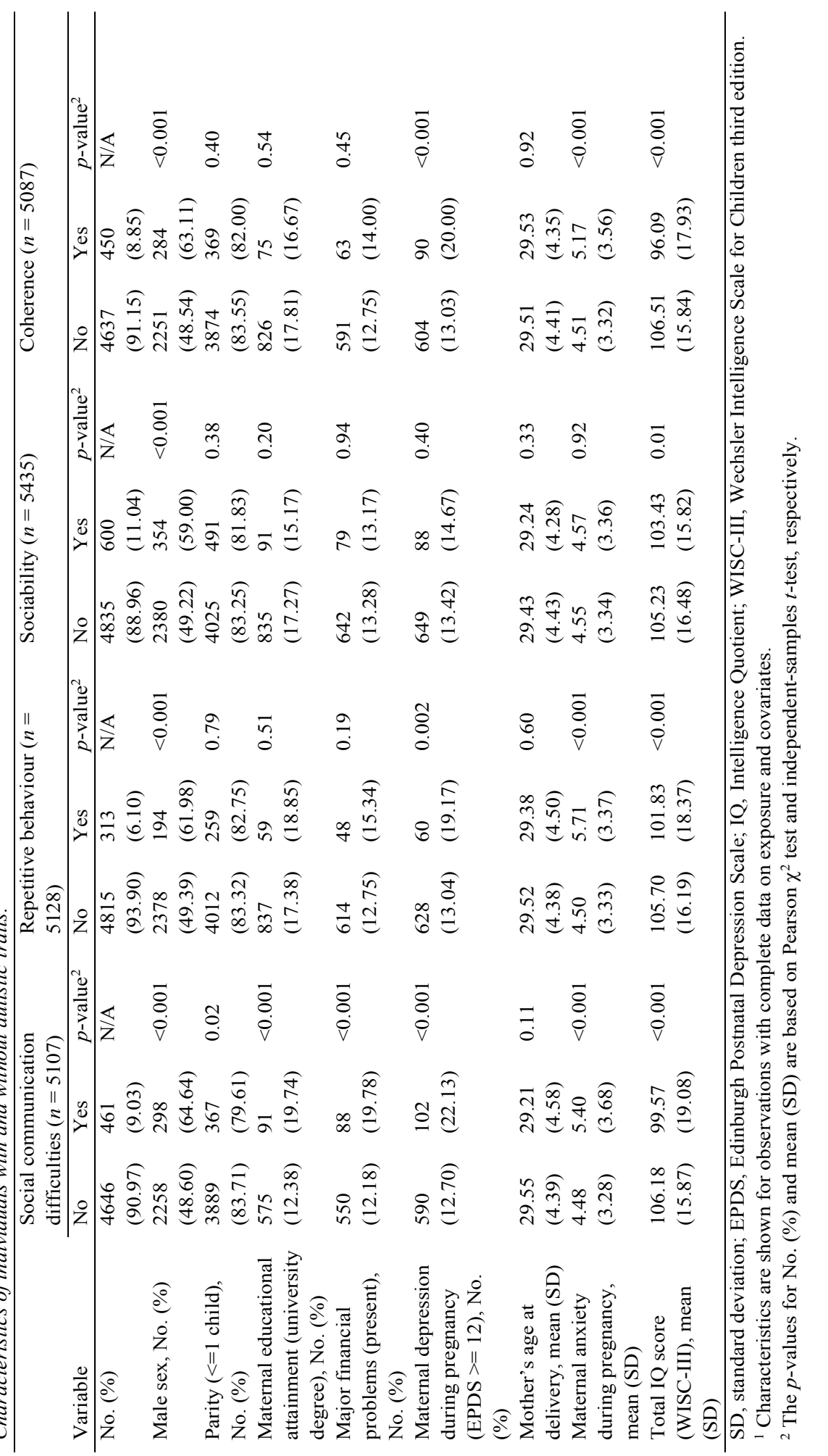


Chapter III

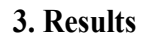

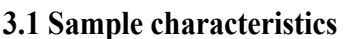

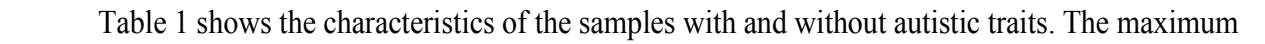

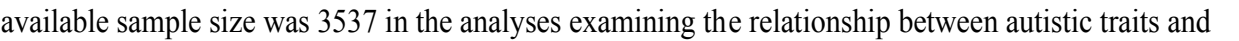

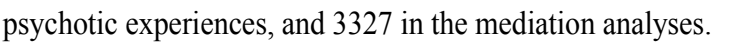

\begin{aligned} \hline \\ \hline\end{aligned}

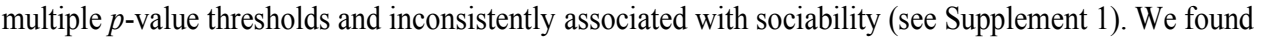

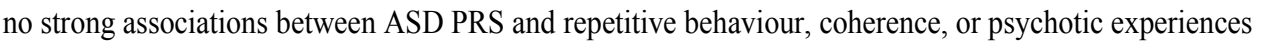

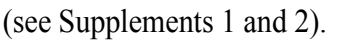

$\square$

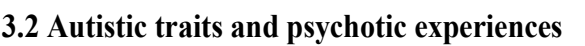

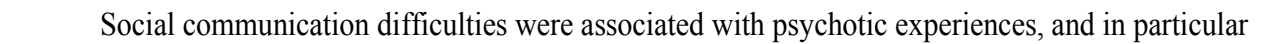
口

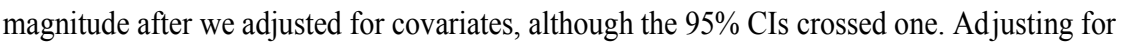

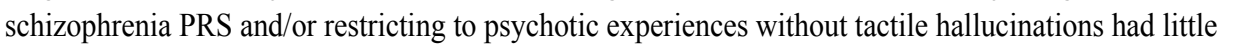

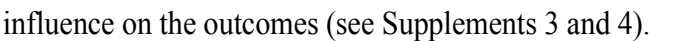

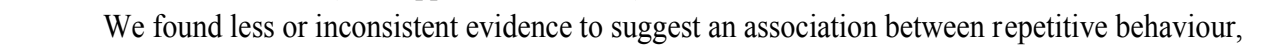

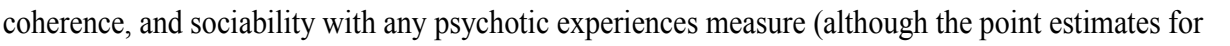

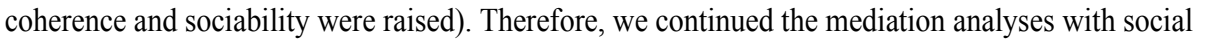

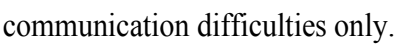



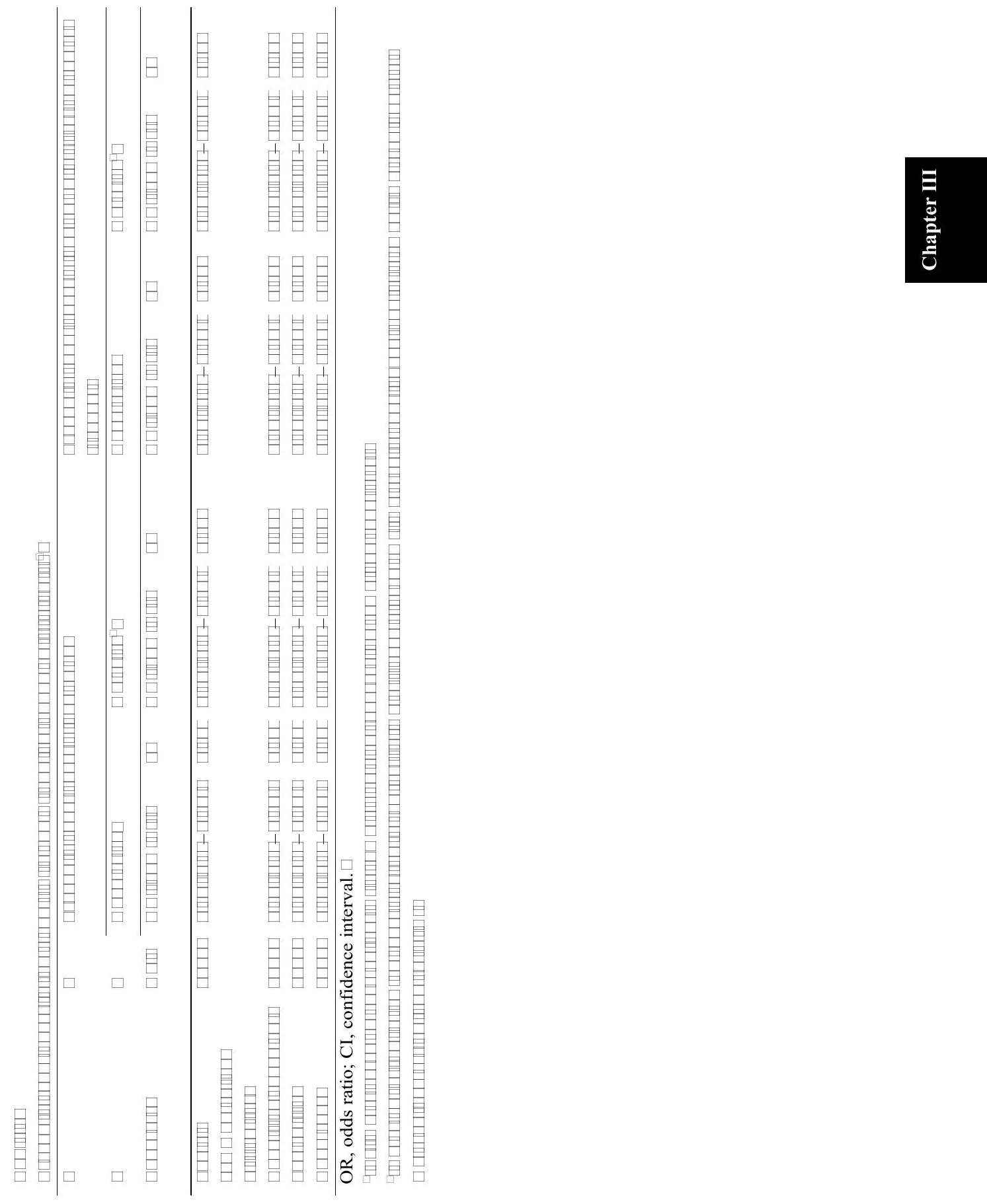


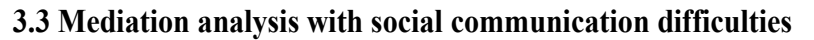

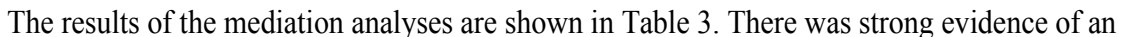

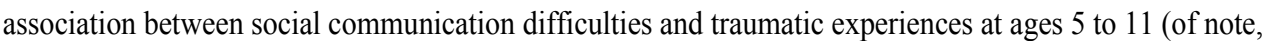

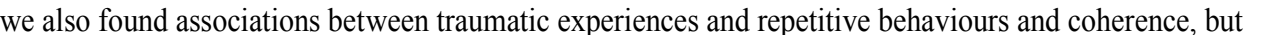
not sociability; see Supplement 5). In the adjusted analysis, we found that $39.2 \%$ of the association

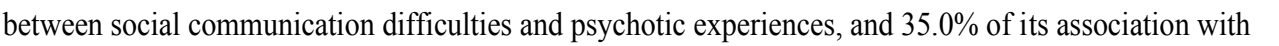
distressing and/or frequent psychotic experiences, was mediated by traumatic experiences. After adjusting

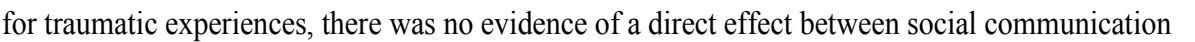

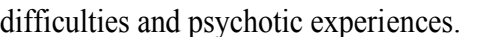

Results of the mediation analyses were comparable when we adjusted for schizophrenia PRS (see Supplement 3) or examined psychotic experiences but excluded tactile hallucinations (see Supplement 4).

$\square$

पाणाणाए

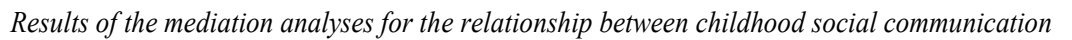

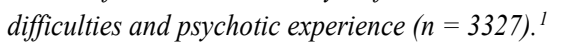

\begin{tabular}{|c|c|c|c|c|}
\hline \multirow{2}{*}{ 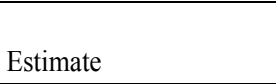 } & \multicolumn{2}{|l|}{ Unadjusted $\square$} & \multicolumn{2}{|l|}{ Adjusted $^{2} \square$} \\
\hline & OR $(95 \% \mathrm{CI}) \square$ & $\square$ & OR $(95 \% \mathrm{CI}) \square$ & $\square$ \\
\hline 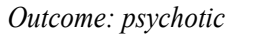 & $\square$ & $\square$ & $\square$ & $\square$ \\
\hline \multicolumn{5}{|c|}{ 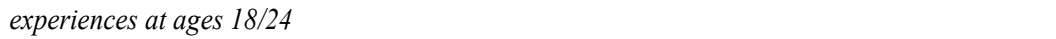 } \\
\hline 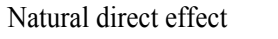 & $1.27(0.89-1.81) \square$ & $0.19 \square$ & $1.22(0.85-1.74) \sqsubset$ & $0.28 \square$ \\
\hline 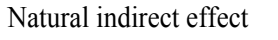 & 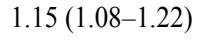 & पणाए। & 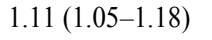 & पणाएण \\
\hline 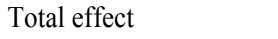 & $1.45(1.02-2.08) \square$ & $0.04 \square$ & $1.36(0.95-1.94) \sqsubset$ & $0.09 \square$ \\
\hline Proportion mediated $\square$ & $41.2 \% \square$ & $\square$ & $39.2 \% \square$ & $\square$ \\
\hline$\square$ & $\square$ & $\square$ & $\square$ & $\square$ \\
\hline 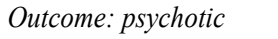 & $\square$ & $\square$ & $\square$ & $\square$ \\
\hline \multicolumn{5}{|c|}{ 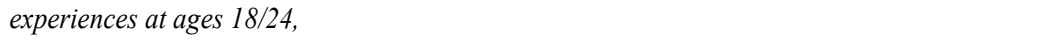 } \\
\hline \multicolumn{5}{|c|}{ 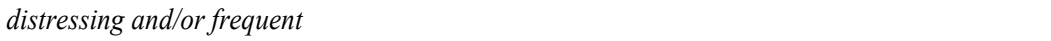 } \\
\hline 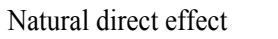 & 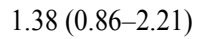 & 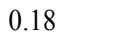 & $1.37(0.85-2.20) \sqsubset$ & $0.19 \square$ \\
\hline 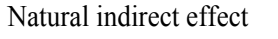 & 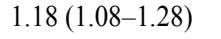 & पणापा & 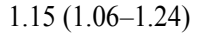 & 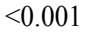 \\
\hline 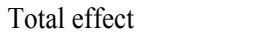 & $1.62(1.01-2.59) \square$ & $0.04 \square$ & $1.57(0.98-2.50) \sqsubset$ & $\square \amalg$ \\
\hline Proportion mediated $\square$ & $39.1 \% \square$ & $\square$ & $35.0 \% \square$ & $\square$ \\
\hline
\end{tabular}

OR, odds ratio; $\mathrm{CI}$, confidence interval. $\square$

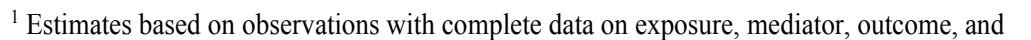

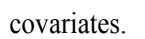

${ }^{2}$ Adjusted for the following covariates: child sex, parity, major financial problems, maternal highest

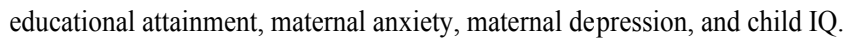




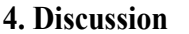

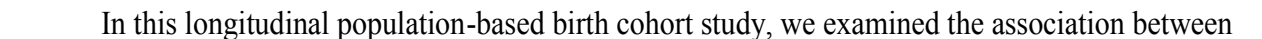

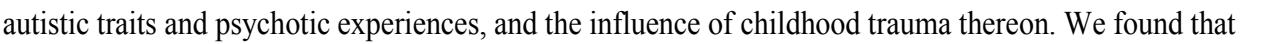

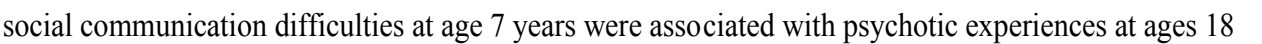

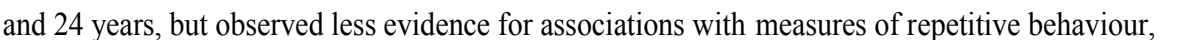

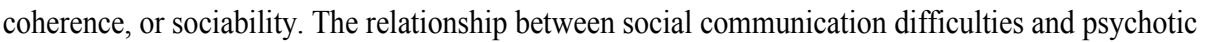

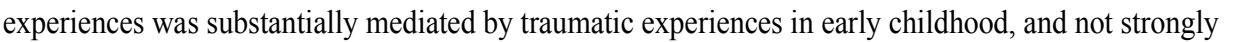

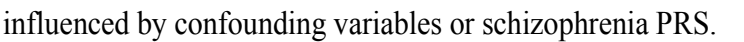

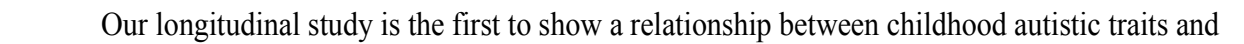

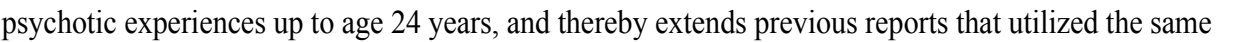

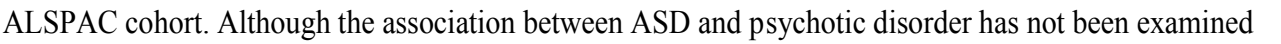

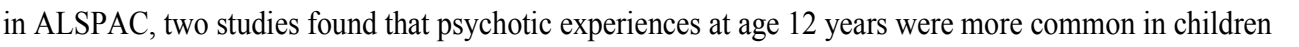

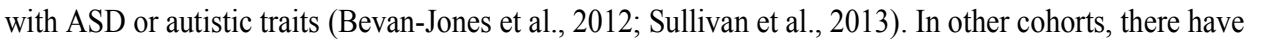

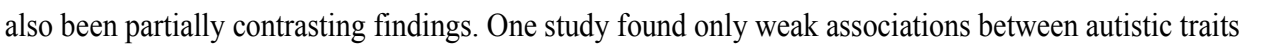

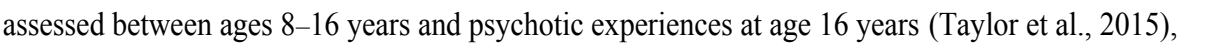

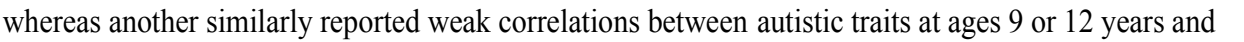

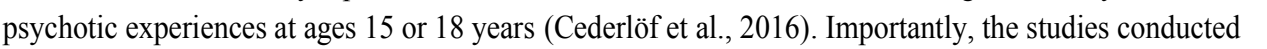

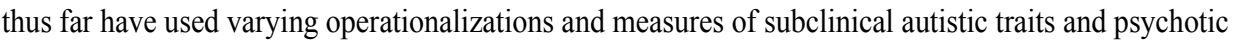

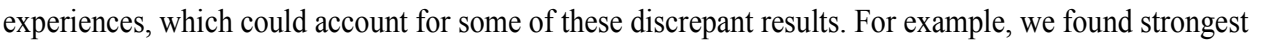

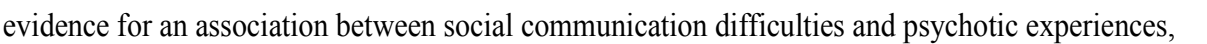

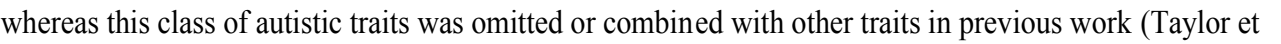
al., 2015) $\square$

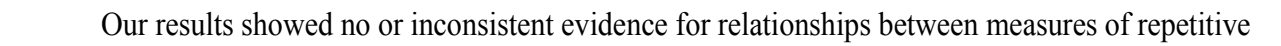

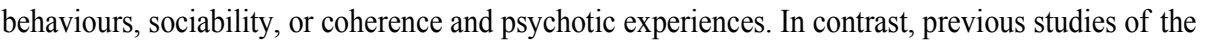

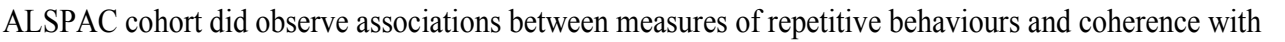

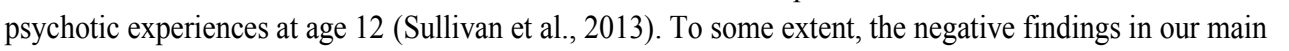

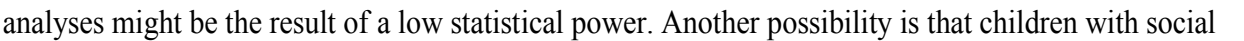

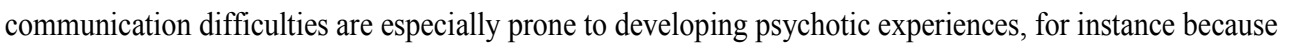

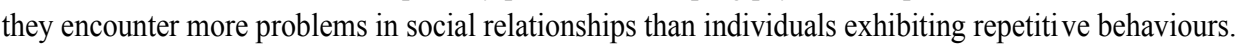

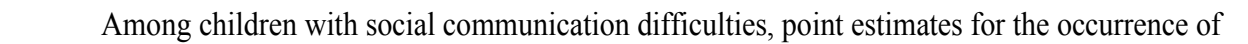

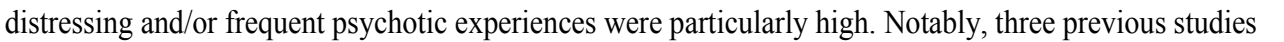

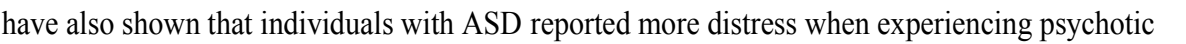

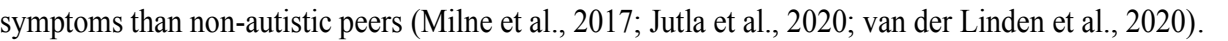

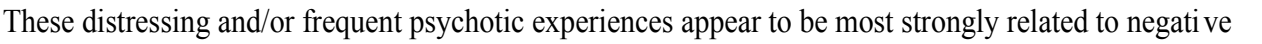

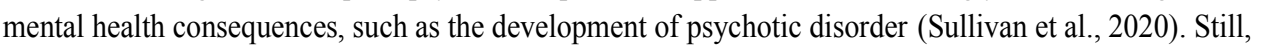
प

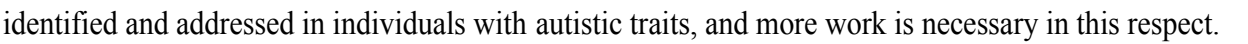

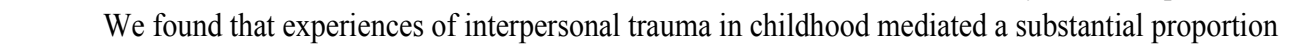

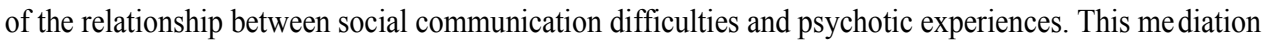

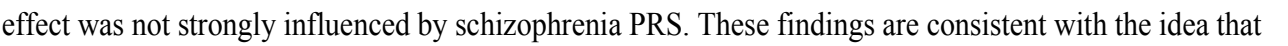

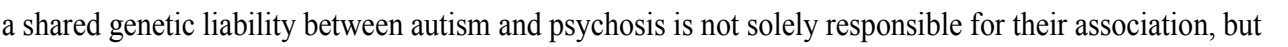

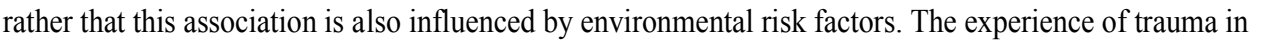

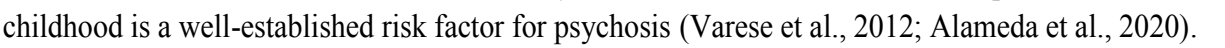

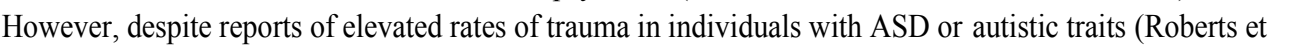


al., 2015; McDonnell et al., 2019), studies of its mental health consequences are lacking (Hoover, 2015) Our findings indicate that trauma may be an important, potentially modifiable pathway between autistic features and later onset of psychotic experiences, and more work is necessary to examine how (the consequences of) trauma can best be prevented, identified, or treated in autistic individuals. Additionally, elucidating the mechanisms through which these traumatic experiences lead to psychosis, building on work in non autistic populations (Selten et al., 2013; Alameda et al., 2020; Bloomfield et al., 2021), can be an important avenue for future research.

Strengths of our study include its longitudinal design and long term follow up in a representative, population based cohort. A limitation of the study is that the measures of autistic traits partially overlapped with the age at exposure to trauma. To some extent, early traumatic experiences might have exacerbated autistic traits such as difficulties in social communication. However, social communication difficulties were associated with an ASD diagnosis and ASD PRS in the ALSPAC cohort (Steer et al., 2010; Rai et al., 2018), indicating that they are unlikely to be the sole result of trauma. A second limitation is that $95 \%$ CIs in some analyses crossed one and that estimates of effects became statistically non significant, in particular if we would have taken into account multiple testing. We expect that this is mainly the result of a lower statistical power, as a relatively small sample had complete data on measures of interest $\square$ Moreover, even if $95 \%$ CIs were wide, point estimates of the effects remained increased, and multiple imputation of missing data resulted in narrower CIs (data not shown).

Nevertheless, replication studies are necessary to confirm our findings.

In conclusion, social communication difficulties in childhood are associated with psychotic experiences until young adulthood. This association is substantially mediated by experiences of childhood trauma, and not the result of an overlap with schizophrenia genetic liability. Childhood trauma constitutes a potentially modifiable environmental risk factor for psychosis in autistic individuals that warrants further attention in research and clinical practice. 


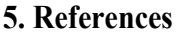

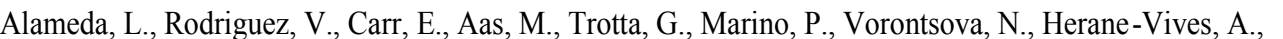

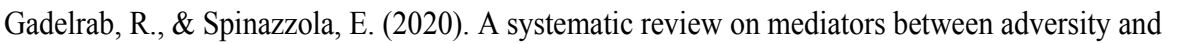

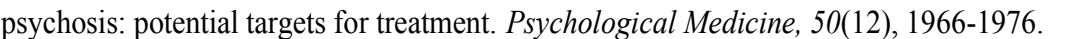

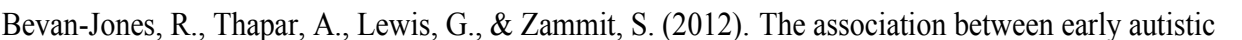

ए

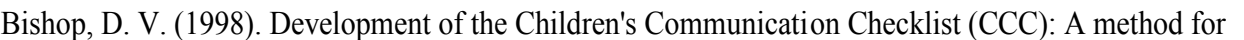

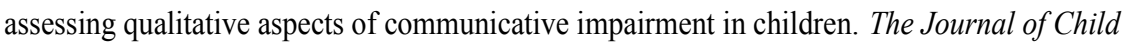

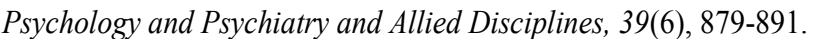

a

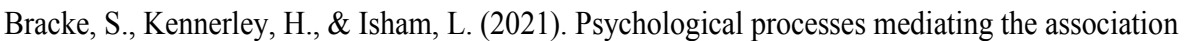

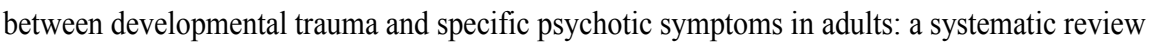

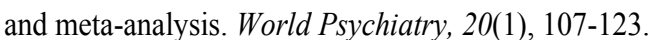

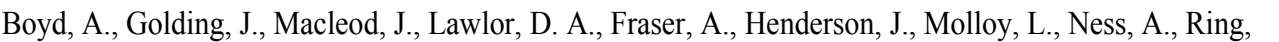

S., \& Davey Smith, G. (2013). Cohort profile: the 'children of the 90s'-

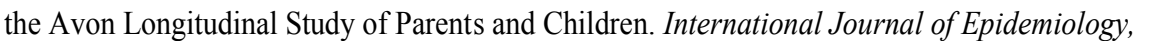

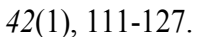

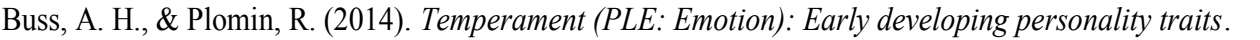

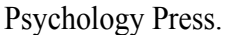

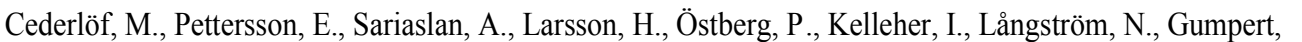

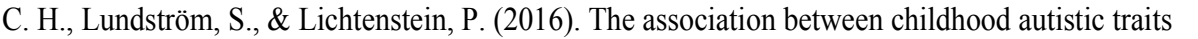

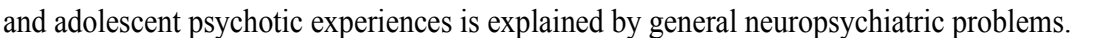

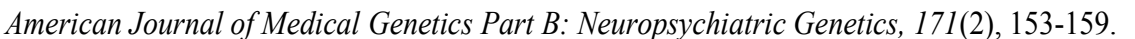

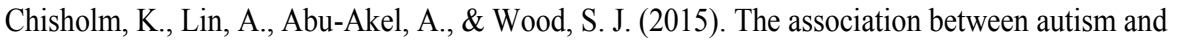

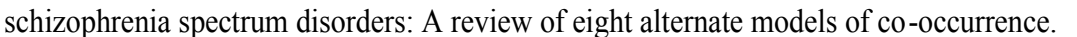

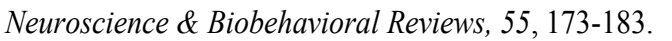

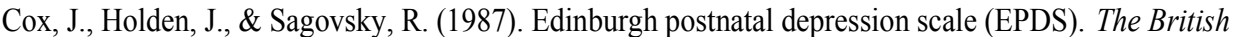

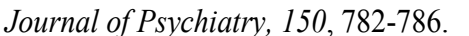

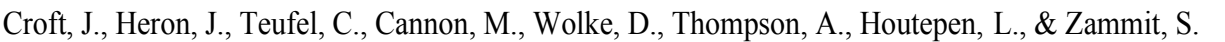

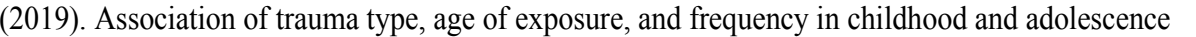

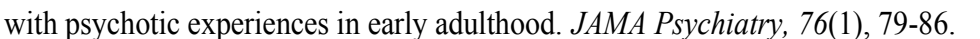

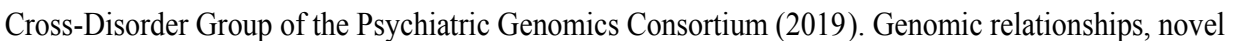
ए ए।

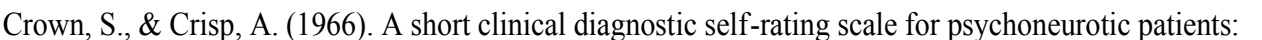

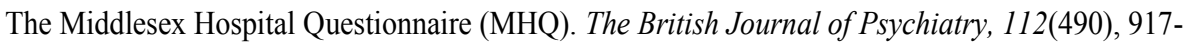
$\square \square \square$

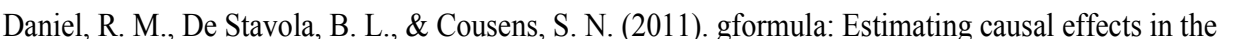

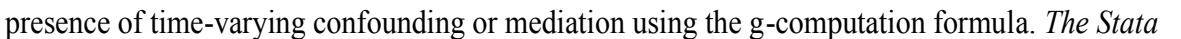

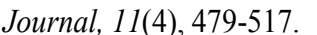

Demirkaya, S. K., Tutkunkardaş, M. D., \& Mukaddes, N. M. (2016). Assessment of suicidality in

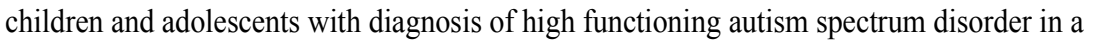

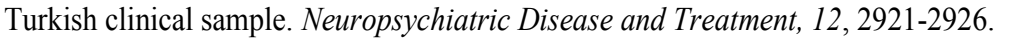

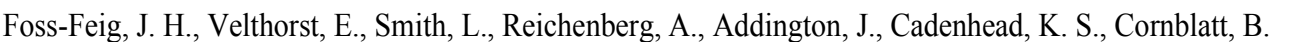

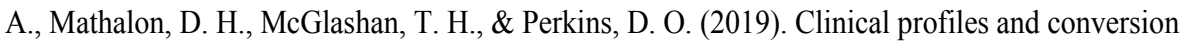




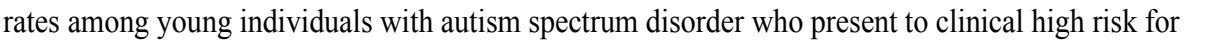

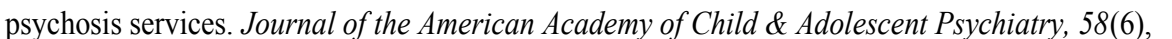
$\square \mid\|1\| \square$

a

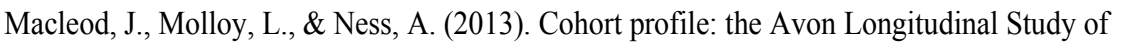

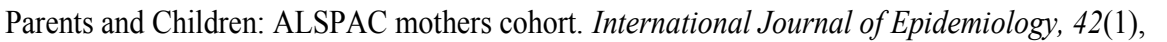

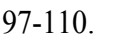

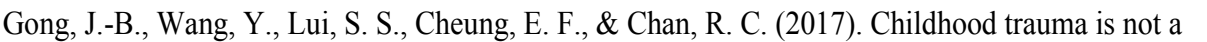

ए

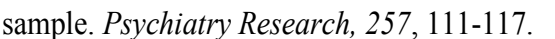

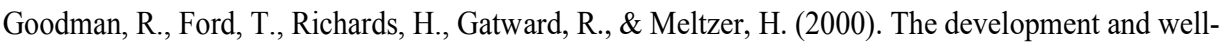

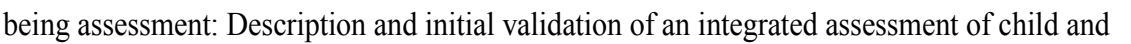

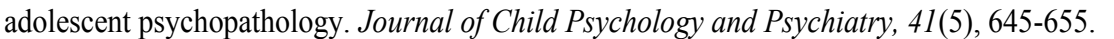

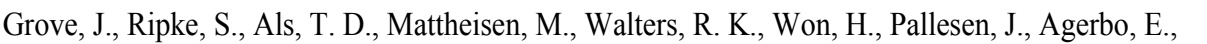

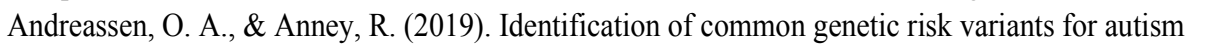

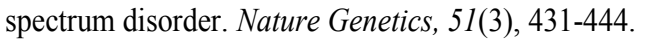

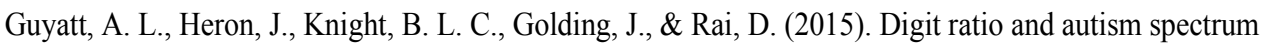

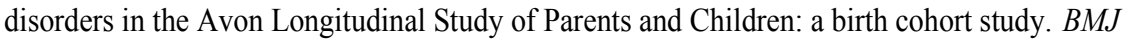

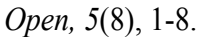

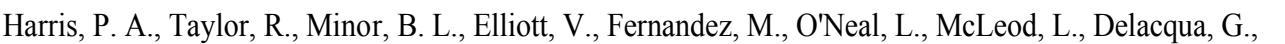

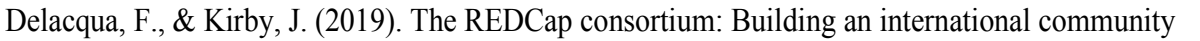

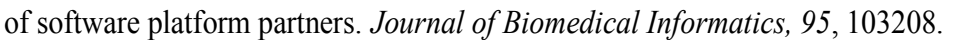

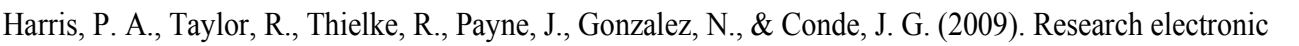

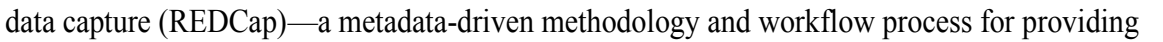

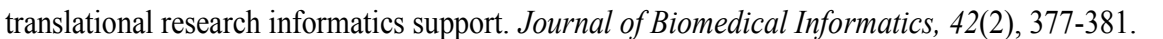

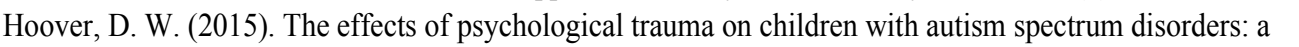

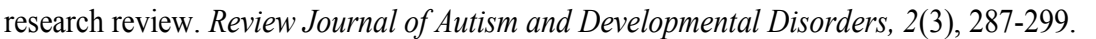

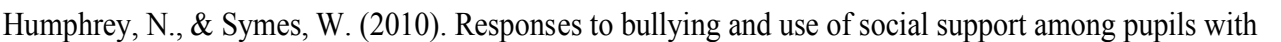

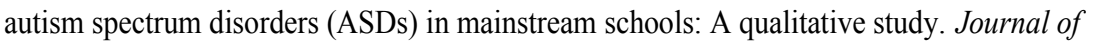

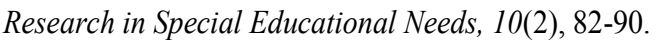

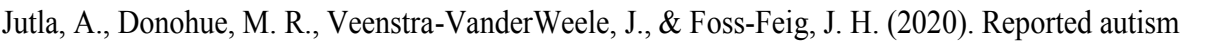

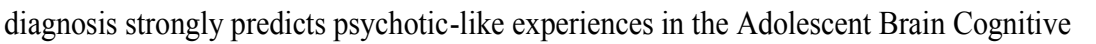

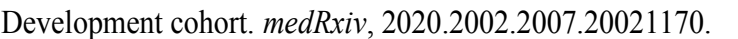

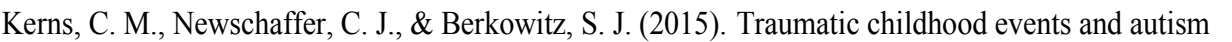

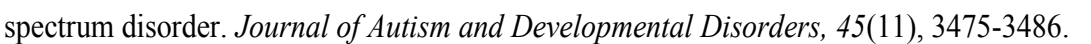

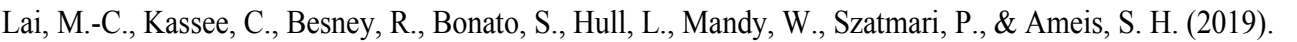

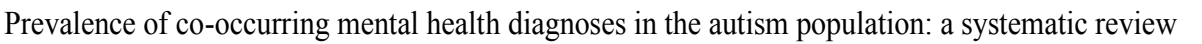

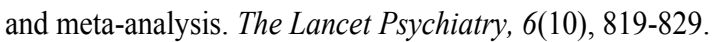

a

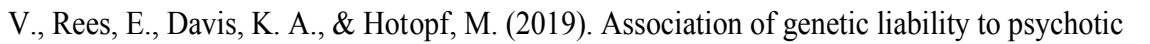

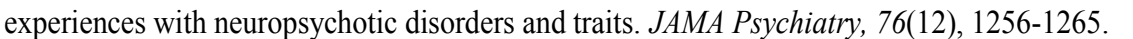

Maclean, M. J., Sims, S., Bower, C., Leonard, H., Stanley, F. J., \& O’Donnell, M. (2017). Maltreatment

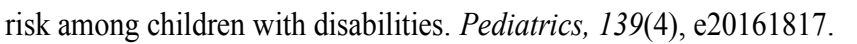




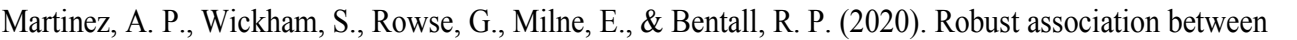

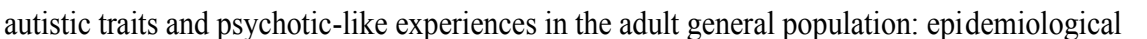

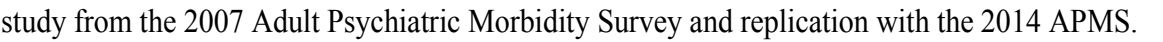

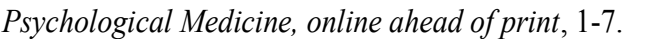

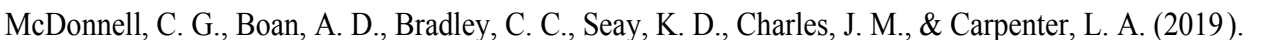

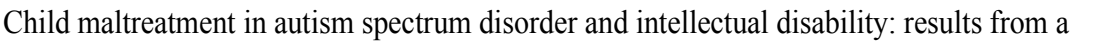

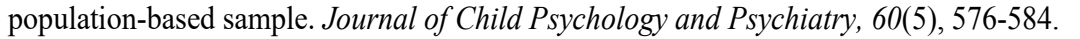

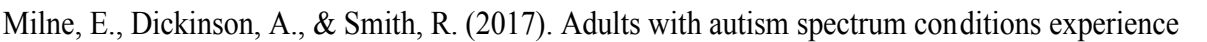

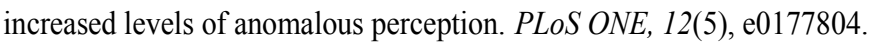

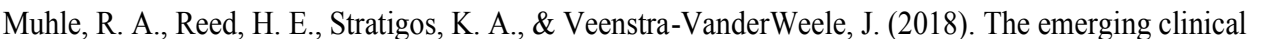

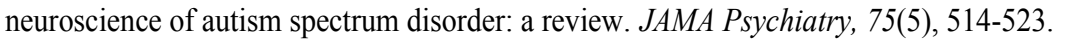

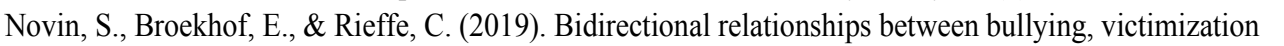

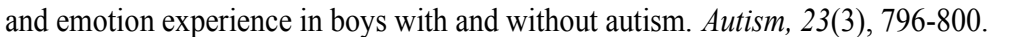

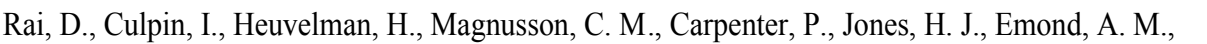

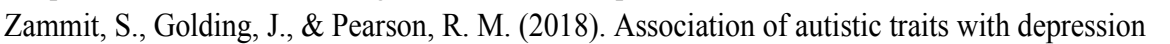

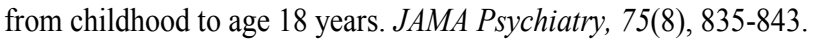

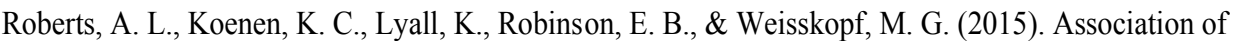

ए ए

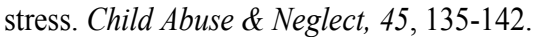

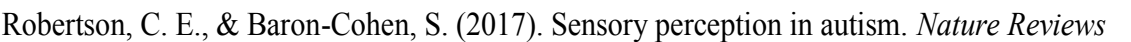

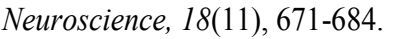

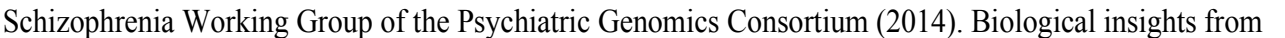

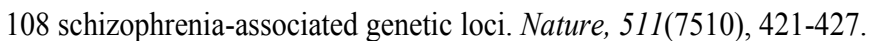

a

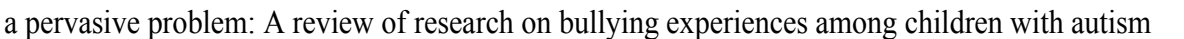

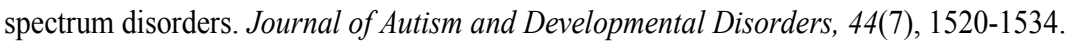

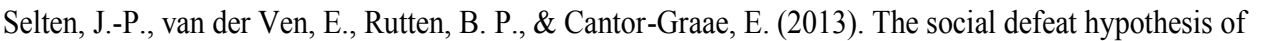

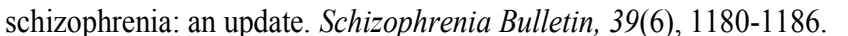

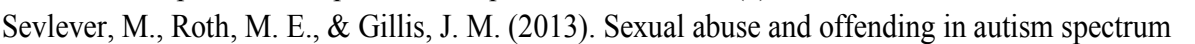

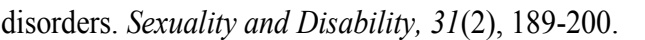

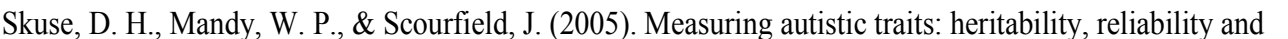

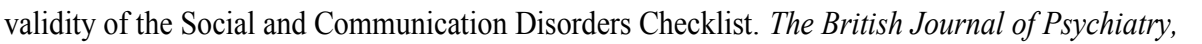

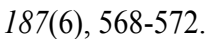

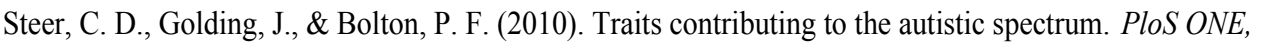

पणाणामाए

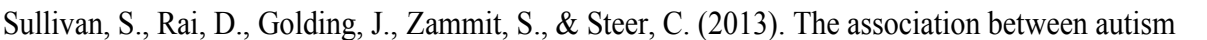

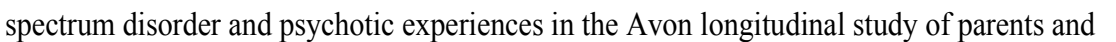

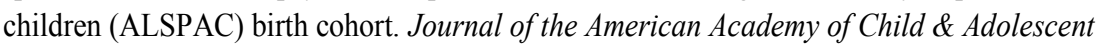

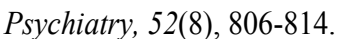

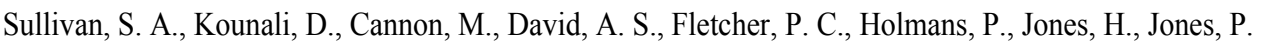

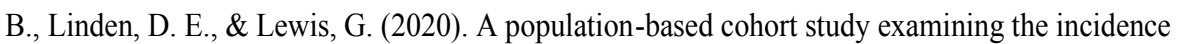

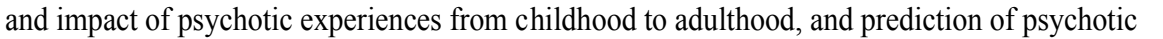

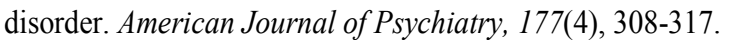




\section{Chapter III}

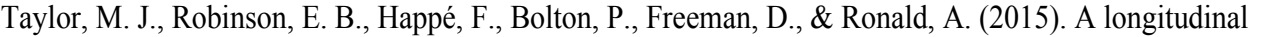

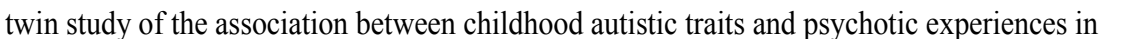

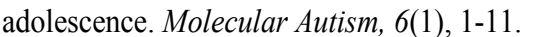

प

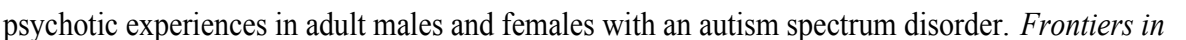

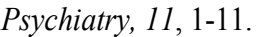

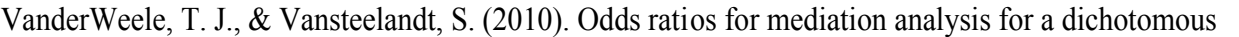

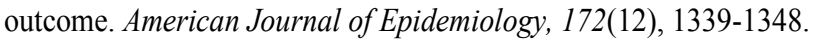

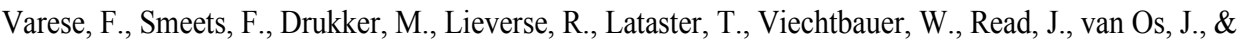

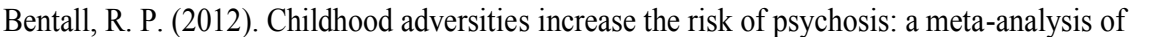

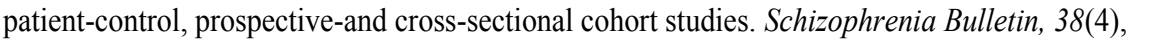
पाणाणा

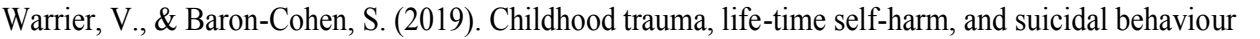

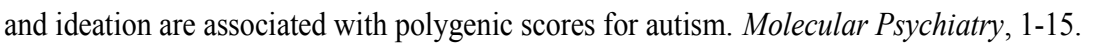

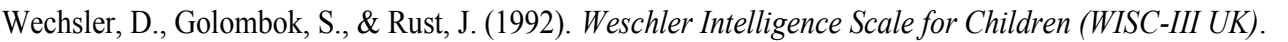

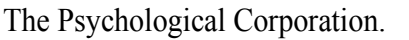

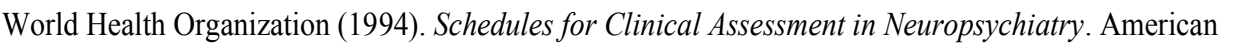

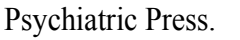

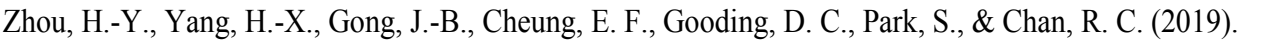

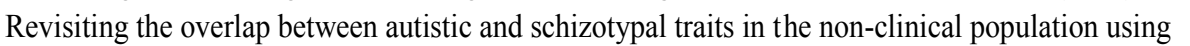

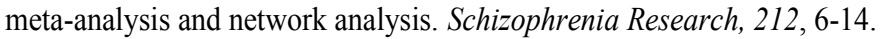


$\square$

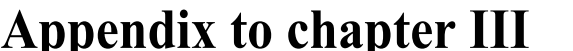

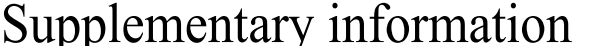

$\square$

$\square$ 


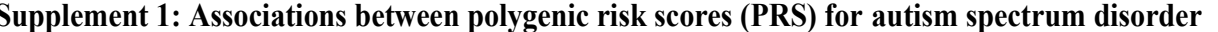

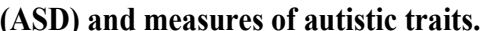

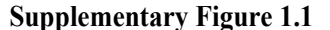

Association between ASD PRS and ASD diagnosis (sample $n=7509 ;$ ASD diagnosis $n=80$ ).

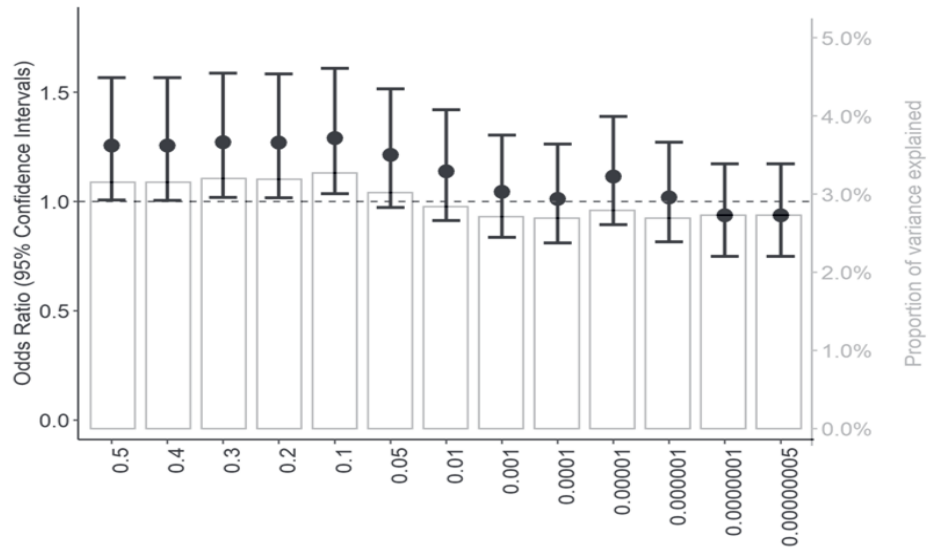

Pvalue Thresholds

\footnotetext{
$\square$
}

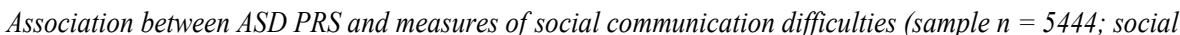
communication difficulties $n=519$ ). $\square$

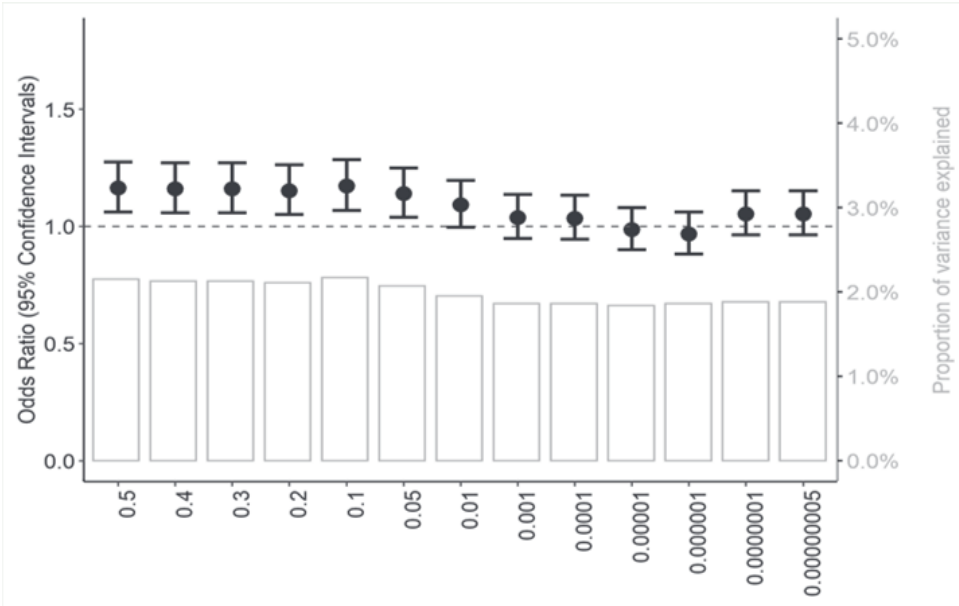

Pvalue Thresholds 


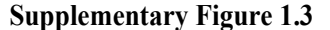

Association between ASD PRS and measures of repetitive behaviour (sample $n=5550$; repetitive behaviours $n=$ प1णाँ

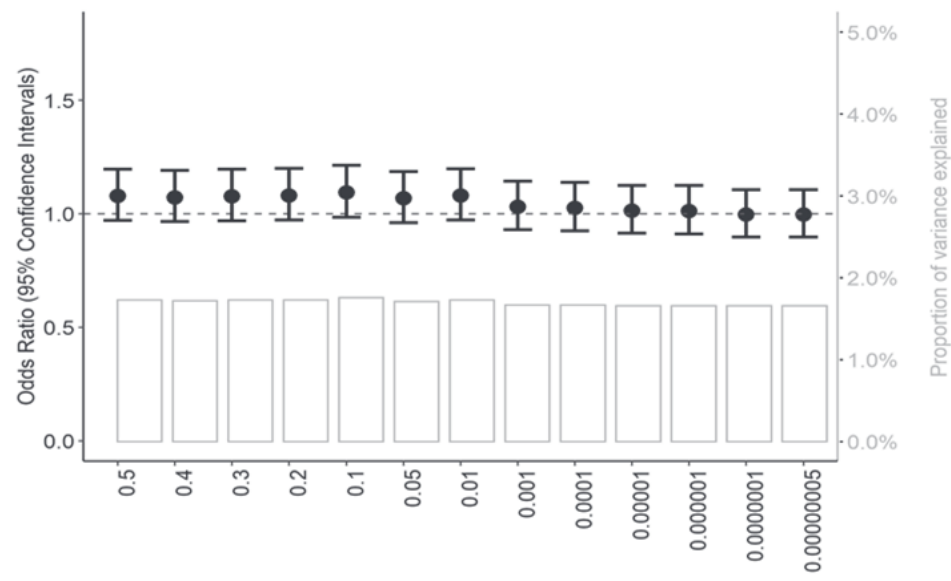

Pvalue Thresholds

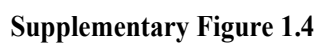

Association between ASD PRS and measures of sociability (sample $n=6170$; sociability $n=714$ ). $\square$

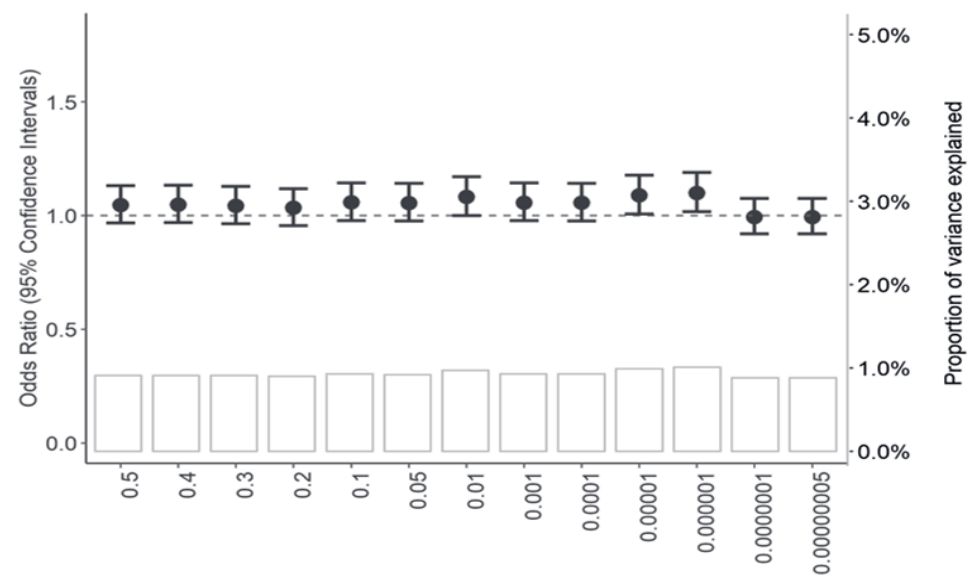

Pvalue Thresholds 


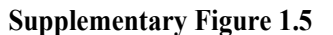

Association between ASD PRS and measures of coherence (sample $n=5563$; coherence $n=551$ ). $\square$

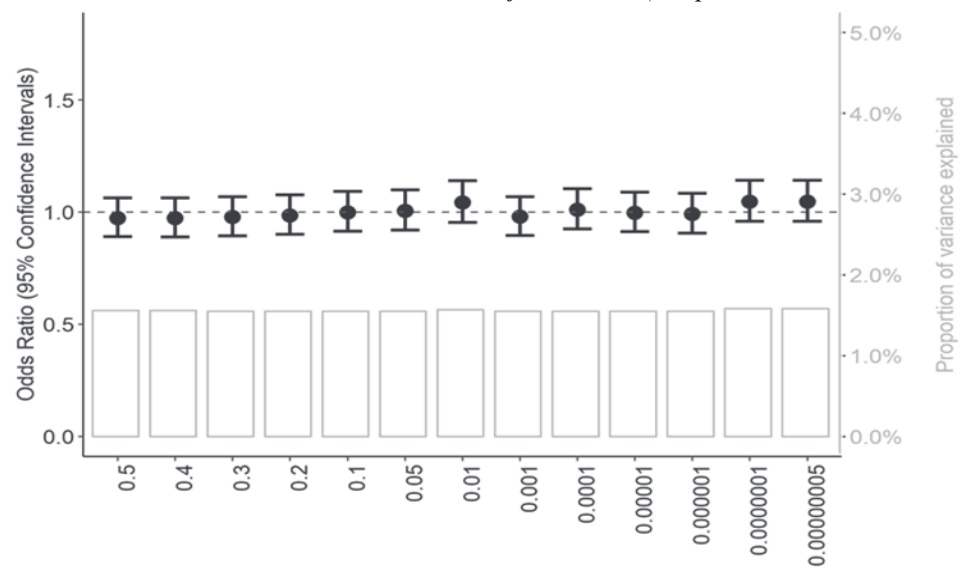

Pvalue Thresholds 


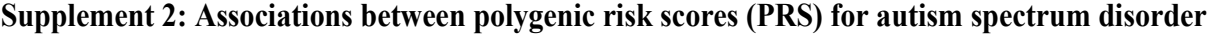

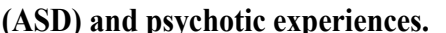

$\square$

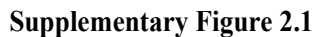

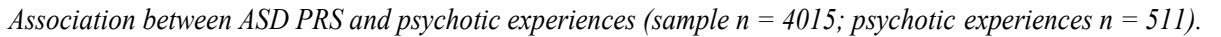

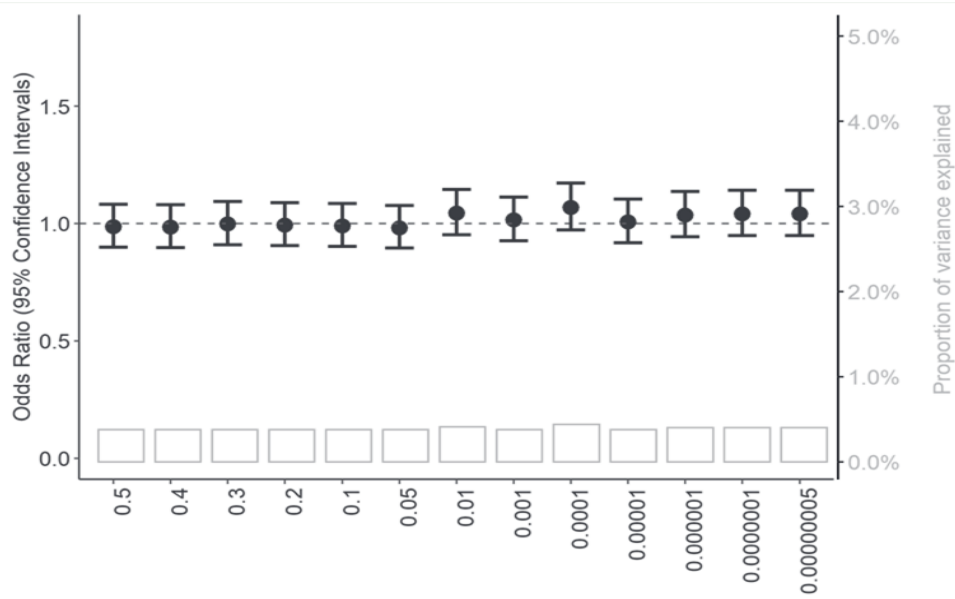

Pvalue Thresholds

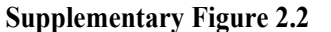

Association between ASD PRS and distressing and/or frequent psychotic experiences (sample $n=4015$;

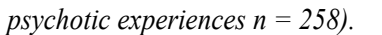

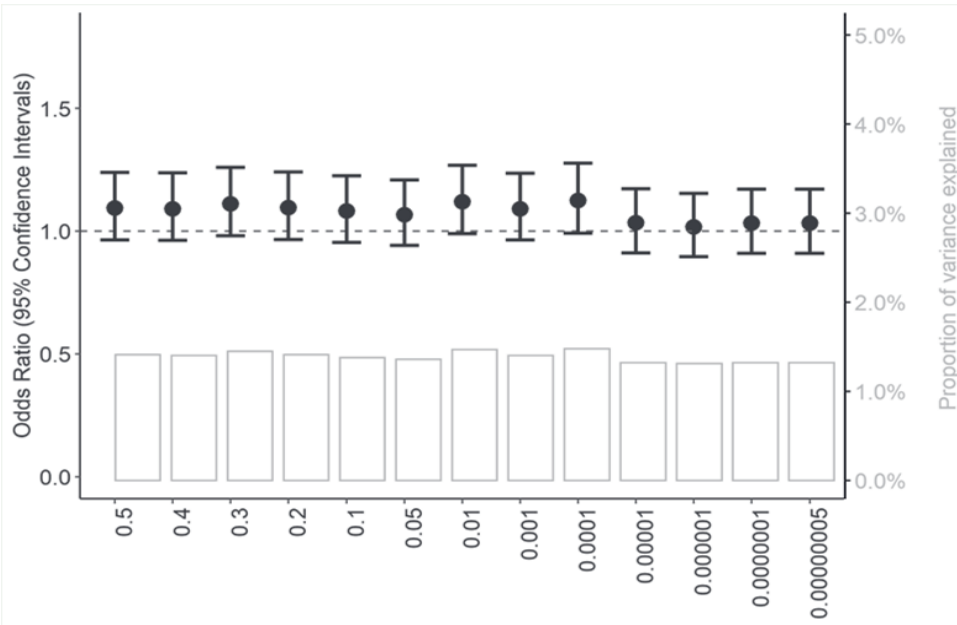

Pvalue Thresholds 


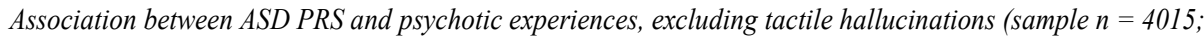

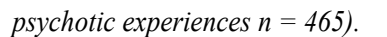

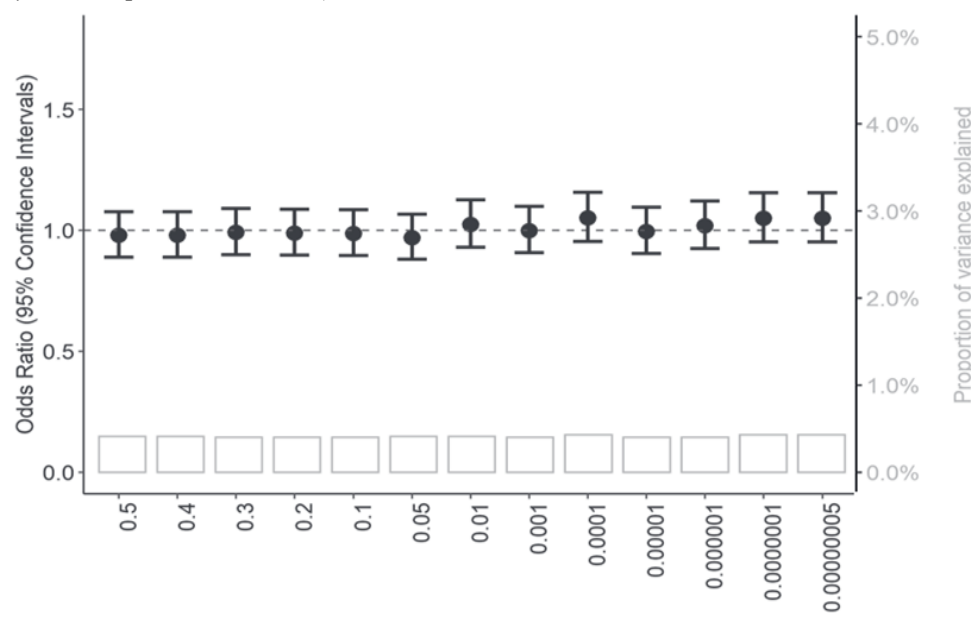

Pvalue Thresholds

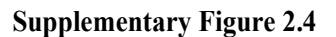

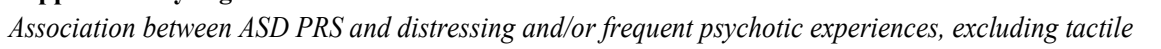

$\square|\Pi| \Pi|\Pi| \square$ ample $n=4015$; psychotic experiences $n=245)$. $\square$

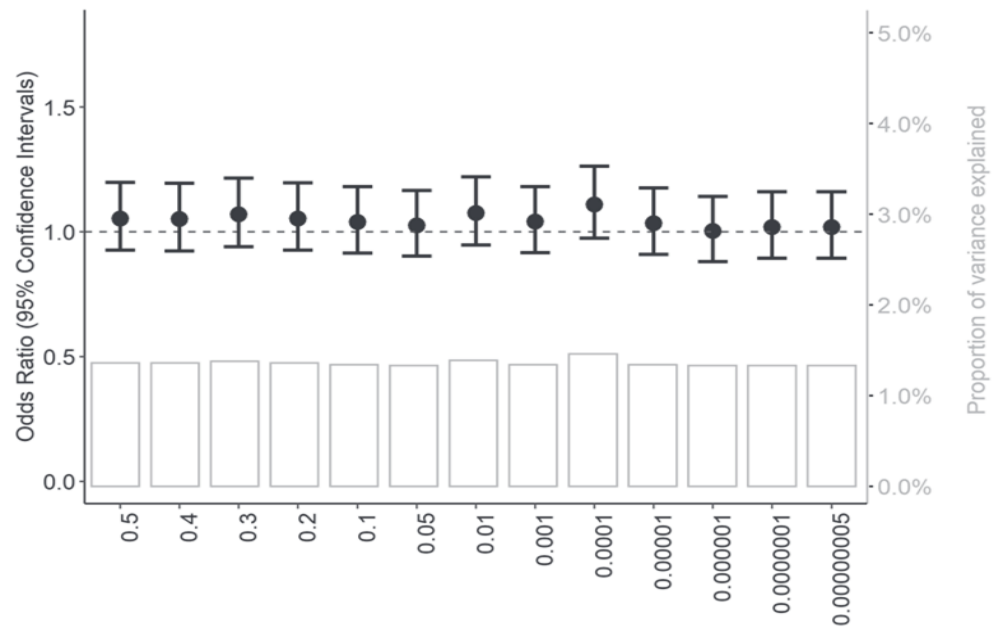

Pvalue Thresholds 

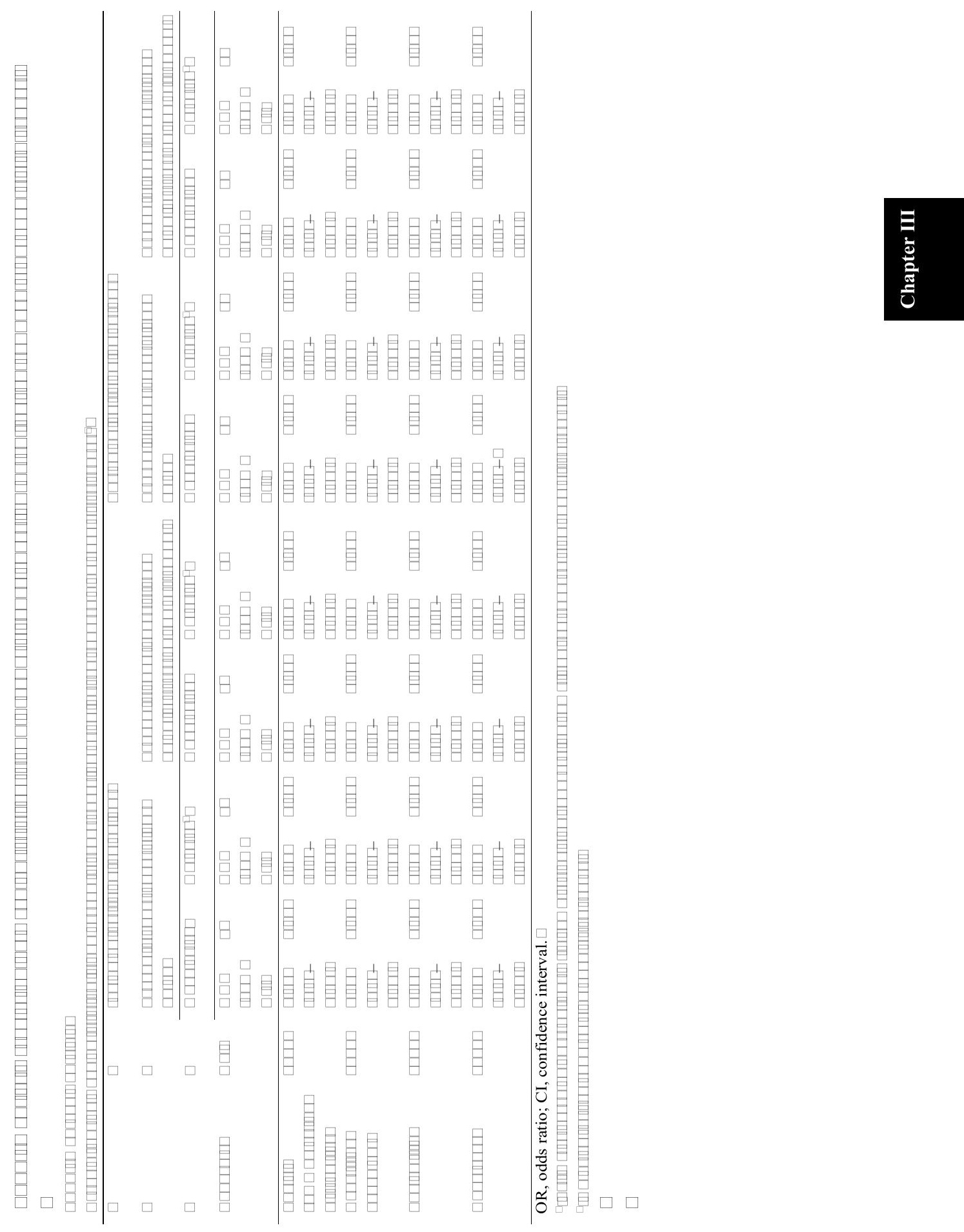


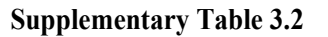

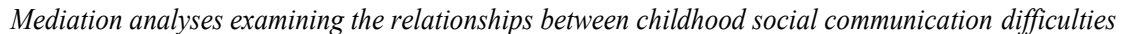

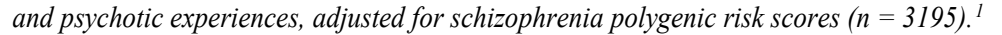

\begin{tabular}{|c|c|c|c|c|}
\hline \multirow{2}{*}{ 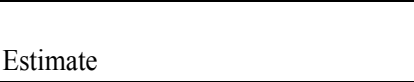 } & \multicolumn{2}{|l|}{ 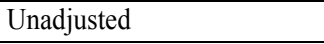 } & \multicolumn{2}{|c|}{ 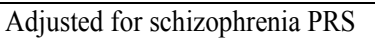 } \\
\hline & 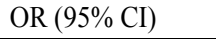 & $\square$ & 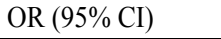 & $\square$ \\
\hline 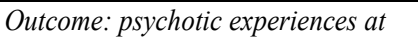 & $\square$ & $\square$ & $\square$ & $\square$ \\
\hline \multicolumn{5}{|l|}{ 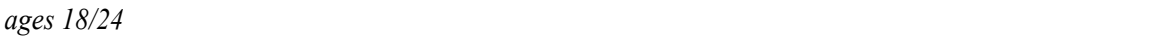 } \\
\hline 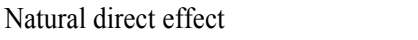 & 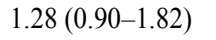 & एण & 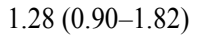 & एण \\
\hline 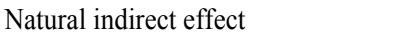 & 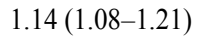 & 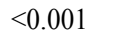 & 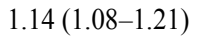 & 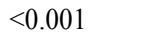 \\
\hline पणपाणाणाप & 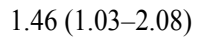 & $\square \square$ & 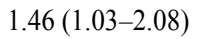 & $\square \square$ \\
\hline 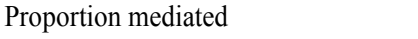 & पाणम & $\square$ & $\square \square \square \square$ & $\square$ \\
\hline$\square$ & $\square$ & $\square$ & $\square$ & $\square$ \\
\hline 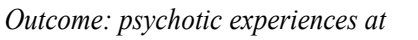 & $\square$ & $\square$ & $\square$ & $\square$ \\
\hline \multicolumn{5}{|l|}{ 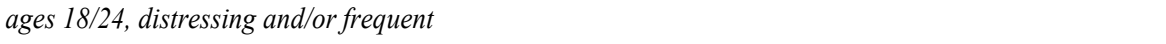 } \\
\hline 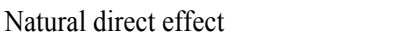 & 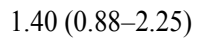 & $\square$ & 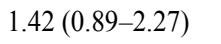 & एणा \\
\hline 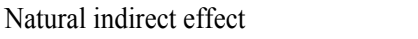 & 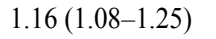 & 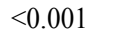 & 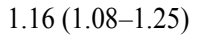 & $\square \square \square \square$ \\
\hline 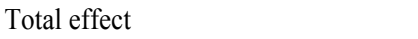 & 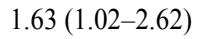 & $\square$ & 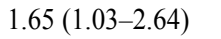 & $\square \square$ \\
\hline 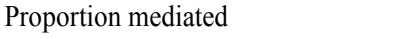 & $\square \mathrm{CI} \square$ & $\square$ & $\square \square \square \square$ & $\square$ \\
\hline$\square$ & $\square$ & $\square$ & $\square$ & $\square$ \\
\hline 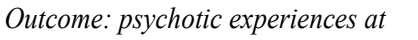 & $\square$ & $\square$ & $\square$ & $\square$ \\
\hline \multicolumn{5}{|l|}{ 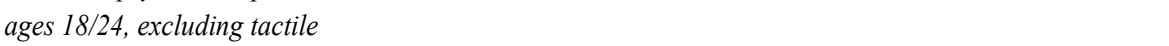 } \\
\hline \multicolumn{5}{|l|}{ पाणाणाणाए } \\
\hline 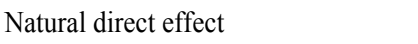 & 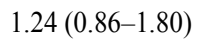 & $\square$ & पणाणाम-पणाए & एणा \\
\hline 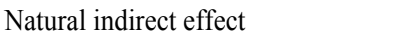 & 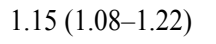 & 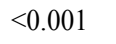 & एणाणाम-एणाण & 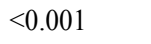 \\
\hline 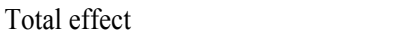 & 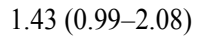 & $\mathrm{\square प \square}$ & 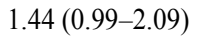 & पण口 \\
\hline 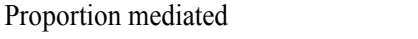 & पाणिए & $\square$ & $\square \square \square \square$ & $\square$ \\
\hline$\square$ & $\square$ & $\square$ & $\square$ & $\square$ \\
\hline 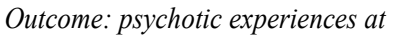 & $\square$ & $\square$ & $\square$ & $\square$ \\
\hline \multicolumn{5}{|l|}{ 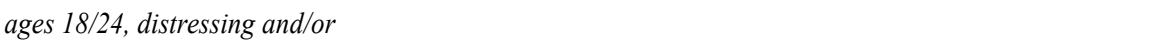 } \\
\hline \multicolumn{5}{|l|}{ 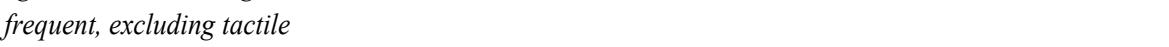 } \\
\hline \multicolumn{5}{|l|}{ पापापापाणाए } \\
\hline 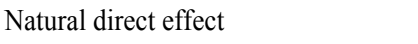 & 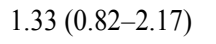 & $\square \square$ & 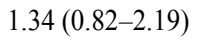 & $\square \square$ \\
\hline 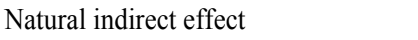 & 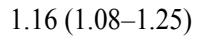 & 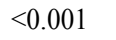 & 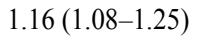 & 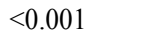 \\
\hline पणताणाणा & 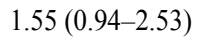 & $\square$ & 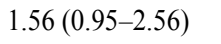 & एणा \\
\hline 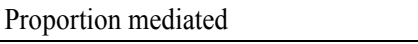 & पाणि & $\square$ & पणा & $\square$ \\
\hline
\end{tabular}

PRS, polygenic risk scores; OR, odds ratio; $\mathrm{CI}$, confidence interval. $\square$

Estimates based on observations with complete data on exposure, mediator, outcome, and

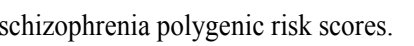

$\square$

$\square$ 

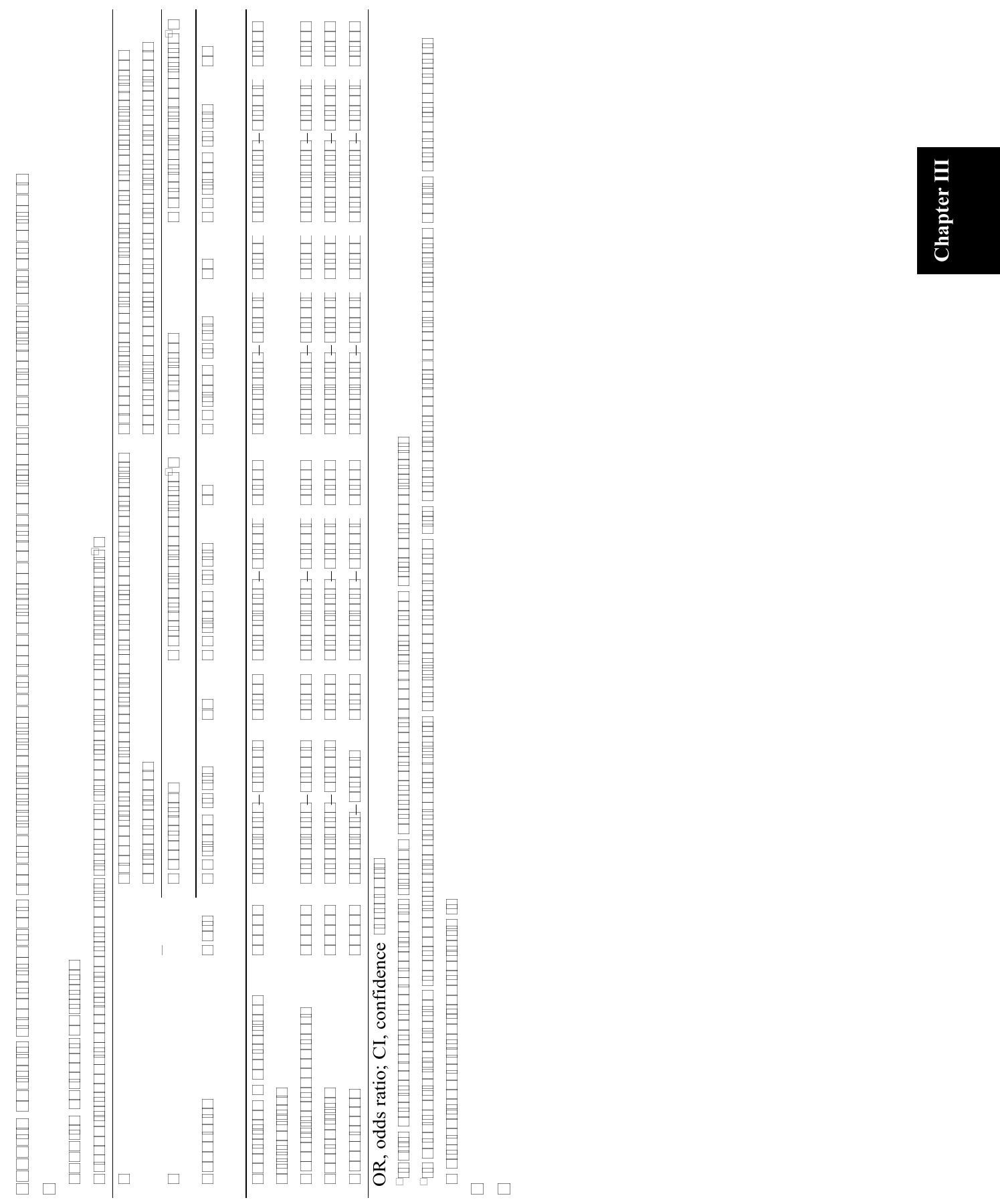
Chapter III

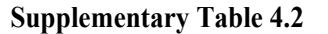

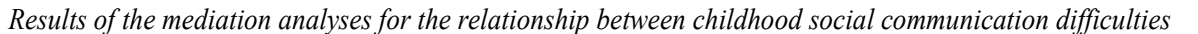

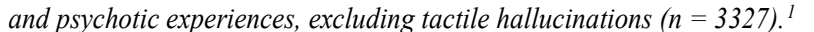

\begin{tabular}{|c|c|c|c|c|}
\hline \multirow{2}{*}{ 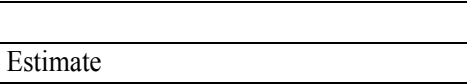 } & \multicolumn{2}{|l|}{ 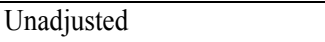 } & \multicolumn{2}{|c|}{ 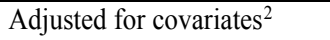 } \\
\hline & 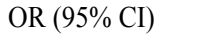 & $\square$ & 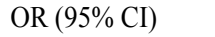 & $\square$ \\
\hline 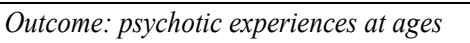 & $\square$ & $\square$ & $\square$ & $\square$ \\
\hline \multicolumn{5}{|l|}{ 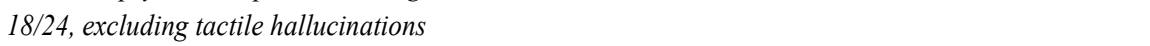 } \\
\hline 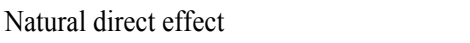 & 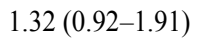 & एणा & 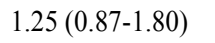 & $\mathrm{\square ाए}$ \\
\hline 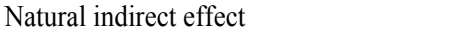 & 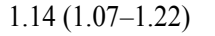 & $\square \square \square$ & 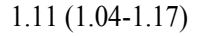 & घणाए \\
\hline 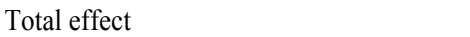 & 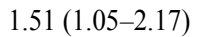 & पणा & 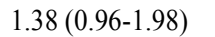 & पणा \\
\hline 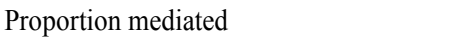 & पाणिए & $\square$ & एणी & $\square$ \\
\hline$\square$ & $\square$ & $\square$ & $\square$ & $\square$ \\
\hline 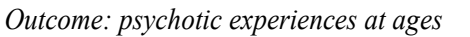 & $\square$ & $\square$ & $\square$ & $\square$ \\
\hline \multicolumn{5}{|l|}{ 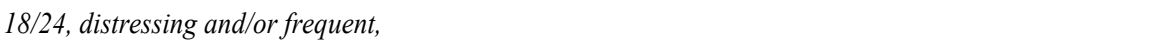 } \\
\hline \multicolumn{5}{|l|}{ 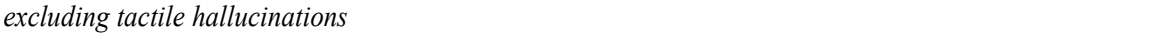 } \\
\hline 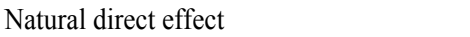 & 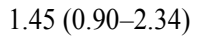 & एणा & 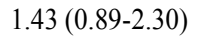 & एण \\
\hline 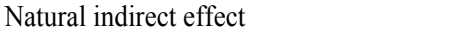 & 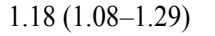 & पाणाप & 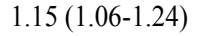 & पणएण \\
\hline 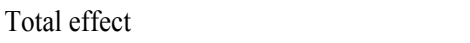 & 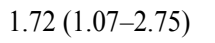 & पणा & 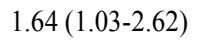 & $\square \square$ \\
\hline 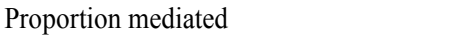 & 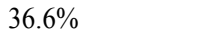 & $\square$ & एणा म & $\square$ \\
\hline
\end{tabular}

OR, odds ratio; CI, confidence interval. $\square$

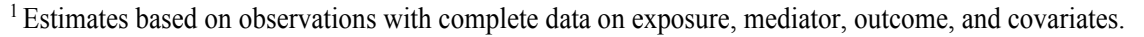

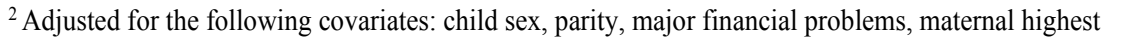

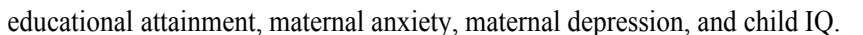

$\square$ 


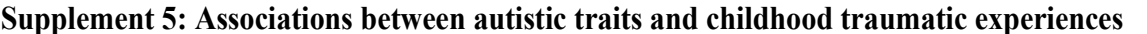

$\square$

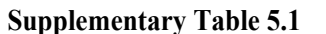

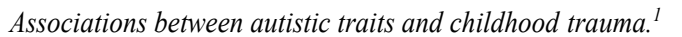

\begin{tabular}{|c|c|c|c|c|c|}
\hline \multirow{3}{*}{$\begin{array}{l}\square \\
\square \\
\square \square|||\||\|| \square \\
\end{array}$} & \multicolumn{5}{|c|}{ 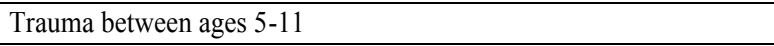 } \\
\hline & \multicolumn{3}{|c|}{ 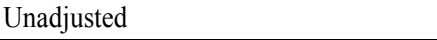 } & \multicolumn{2}{|c|}{ 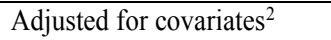 } \\
\hline & पाII & 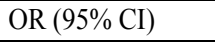 & $\square$ & 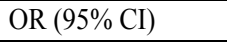 & $\square$ \\
\hline 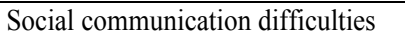 & 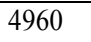 & 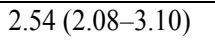 & 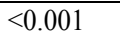 & 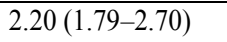 & 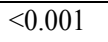 \\
\hline 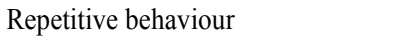 & $\square \square$ & 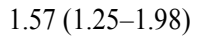 & पाणाए & 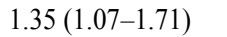 & एणा \\
\hline 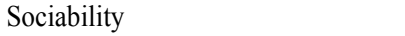 & $\square \square$ & 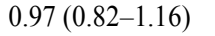 & एण & 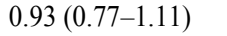 & पणा \\
\hline पणाणाए & $\square 10$ & 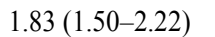 & पाणाए & 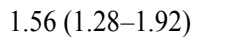 & पाणाए \\
\hline
\end{tabular}

OR, odds ratio; CI, confidence interval.

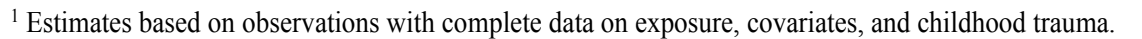

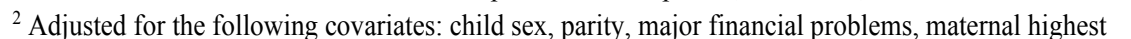

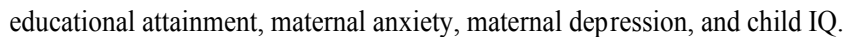

$\square$

$\square$

$\square$

$\square$

$\square$ 


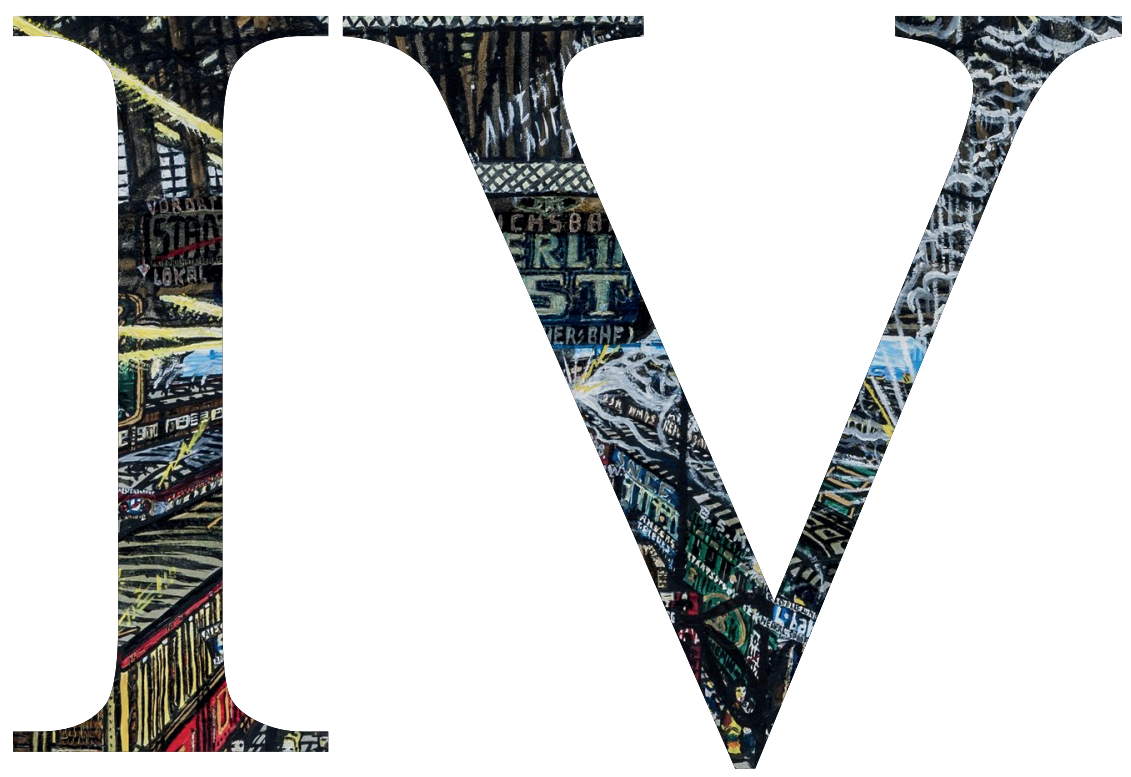




\section{Chapter IV}

\section{Striatal dopamine synthesis capacity in autism spectrum disorder and its relation with social defeat: an $\left[{ }^{18}\right.$ F $]$-FDOPA PET/CT study}

Schalbroeck, R., van Velden, F. H. P., de Geus-Oei, L. F., Yaqub, M., van Amelsvoort, T., Booij, J., \& Selten, J. P.

Translational Psychiatry (2021), 11(1), 1-10. 


\section{Chapter IV}

प्णाणाण

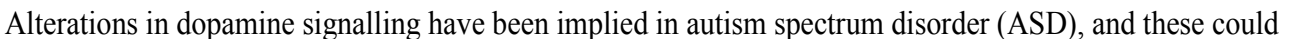

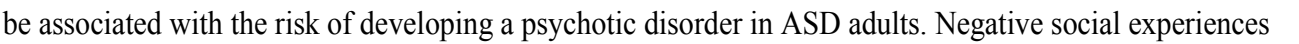

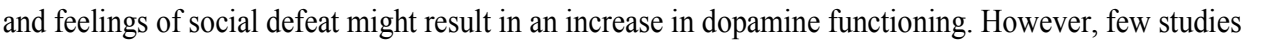

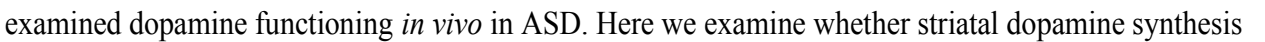

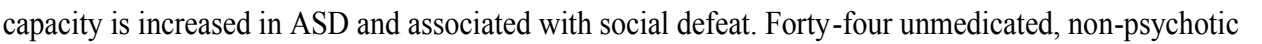

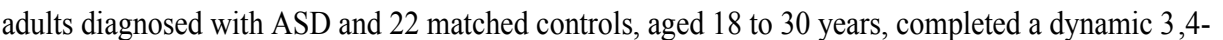

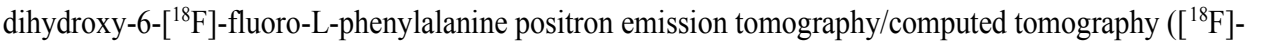

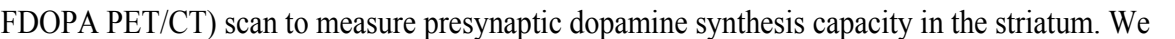

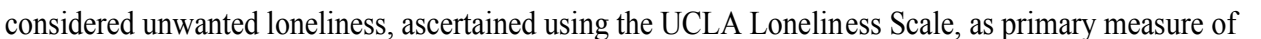

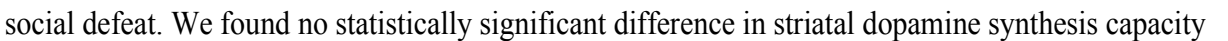

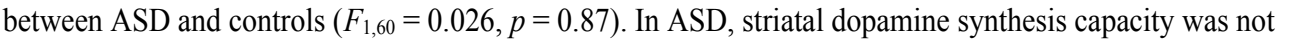

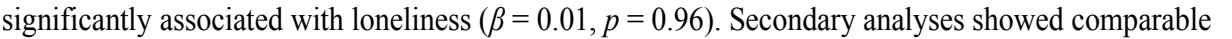

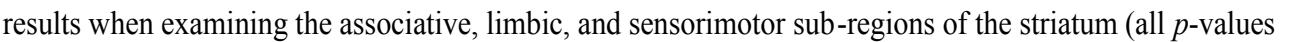

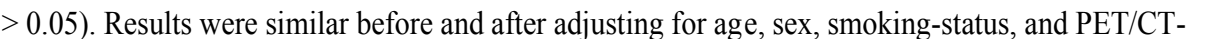

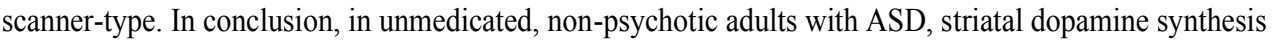

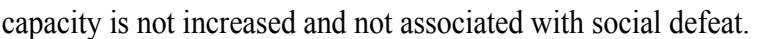




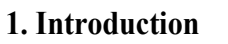

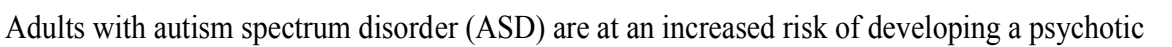

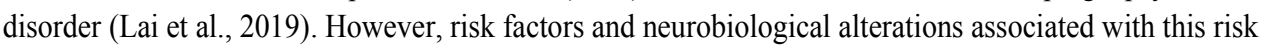

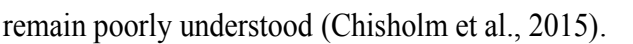

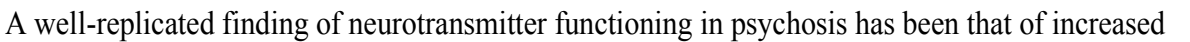

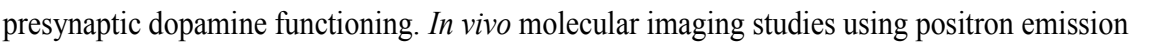

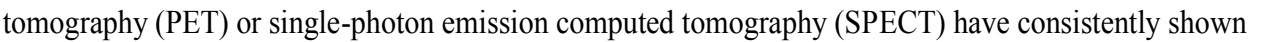

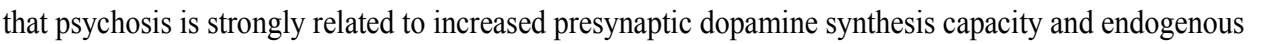

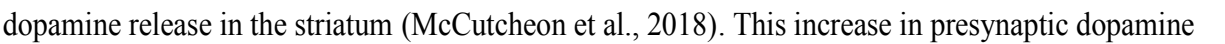

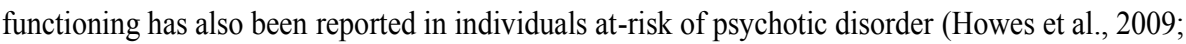

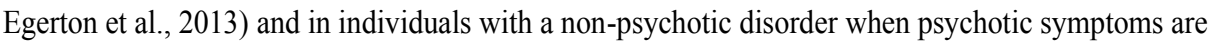

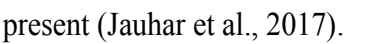

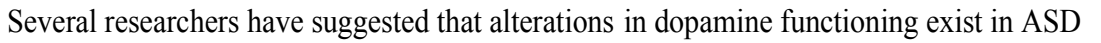

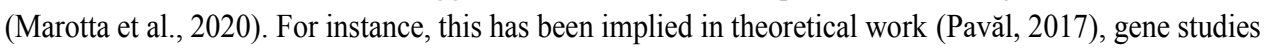

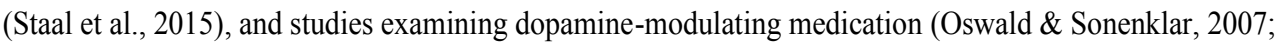

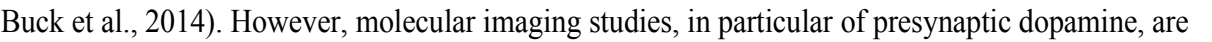

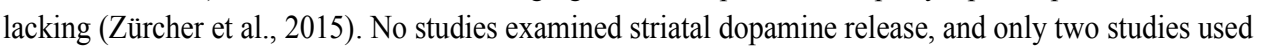

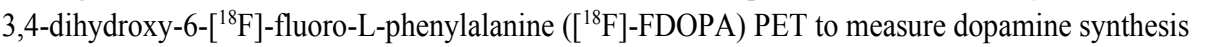

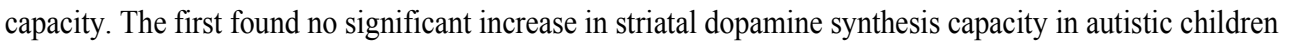

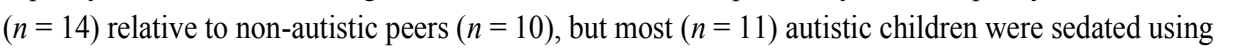

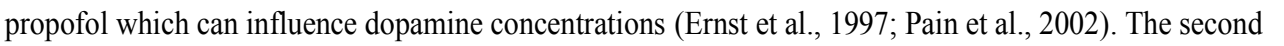

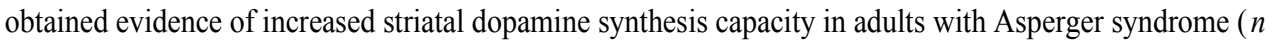

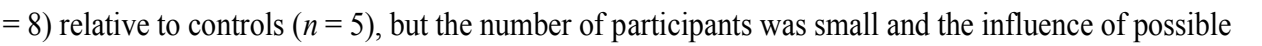

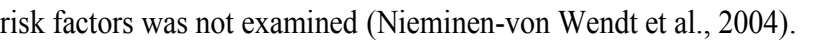

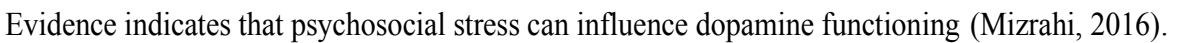

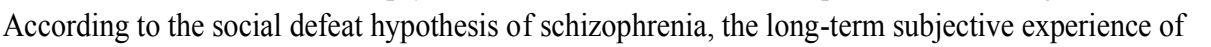

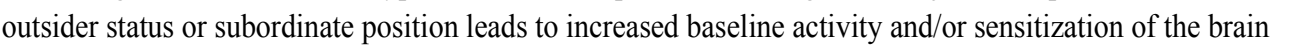

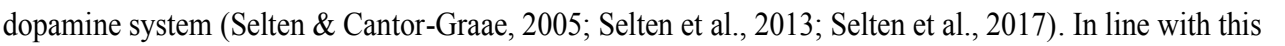

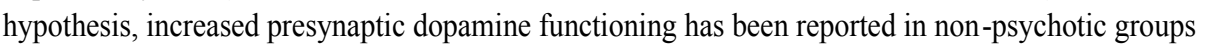

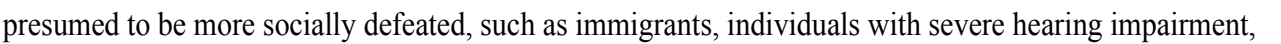

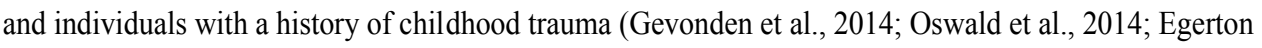
et al., 2016; Egerton et al., 2017)

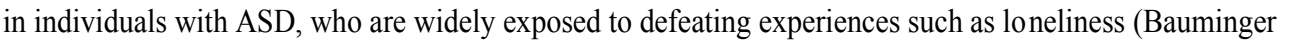

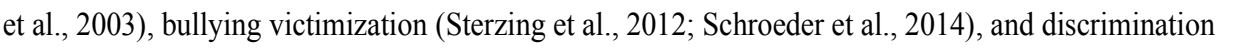

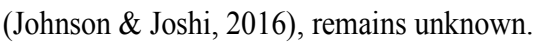

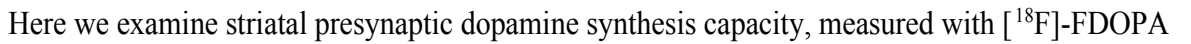

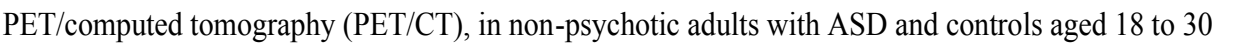

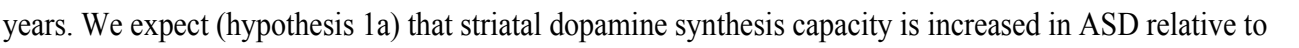

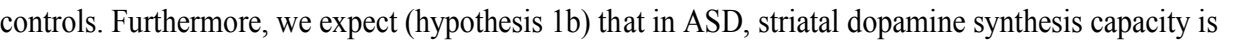

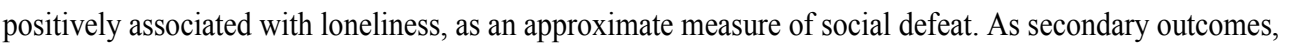

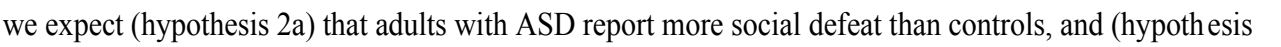

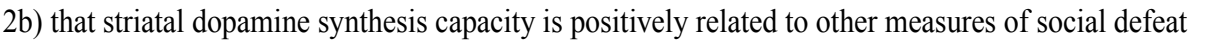

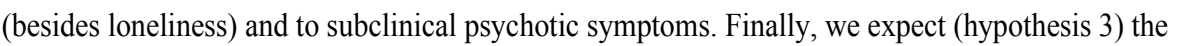
एव 


\section{Chapter IV}

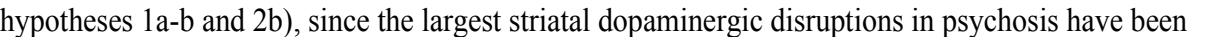

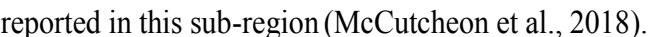




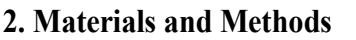

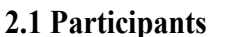

\begin{tabular}{l}
\hline \\
\hline
\end{tabular}

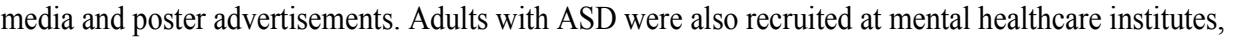

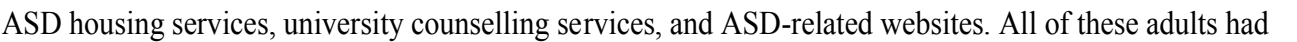

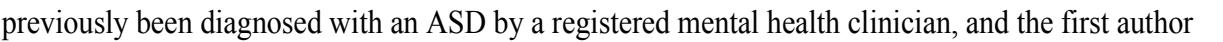

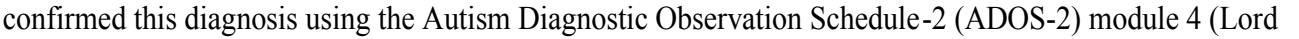

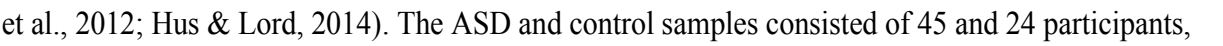

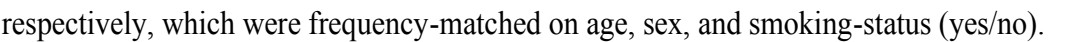

\begin{aligned} \hline \\ \hline\end{aligned}

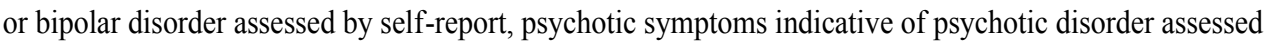

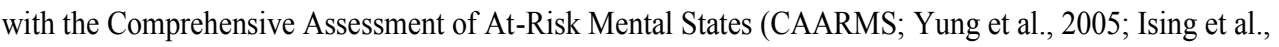
$\square 11$, IQ lower tha $\square\|\|\|\|$ or drug abuse or dependence assessed with the Composite International Diagnostic Interview

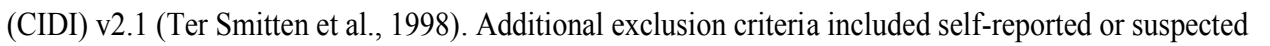

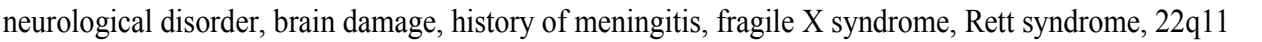

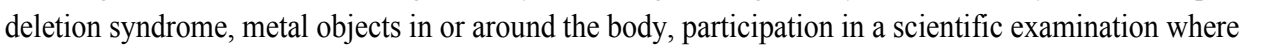

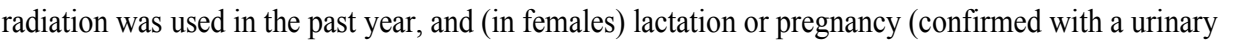

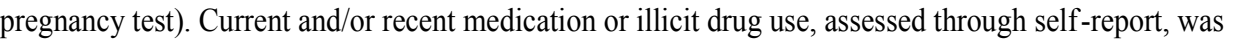

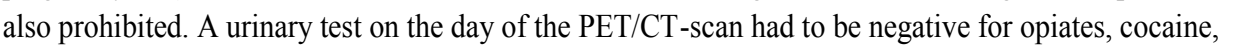

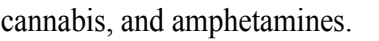

$\square$

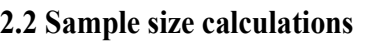

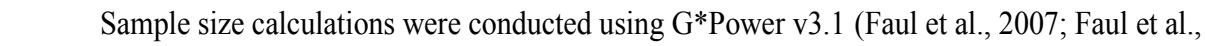

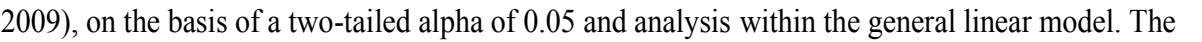

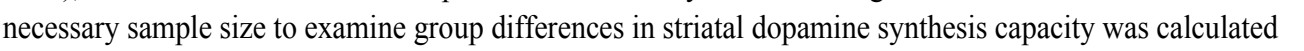

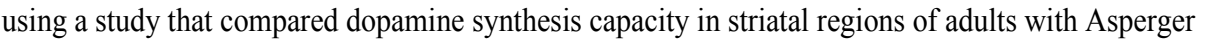

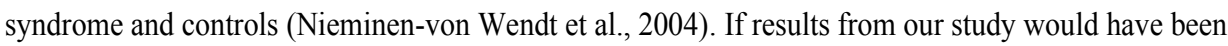

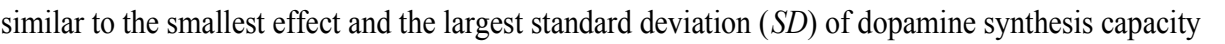

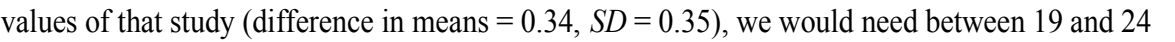

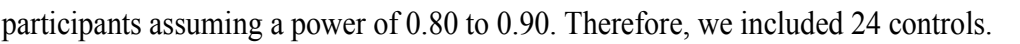

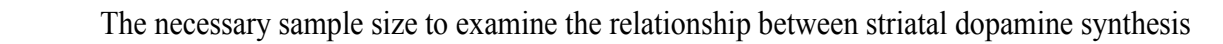

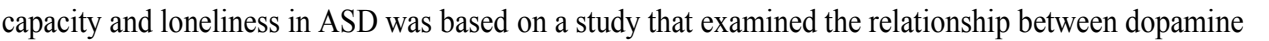

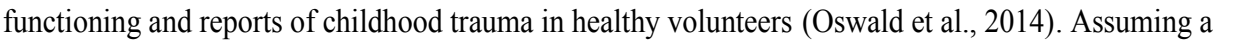

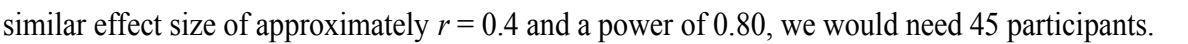

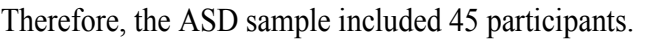

$\square$

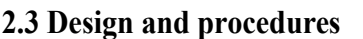

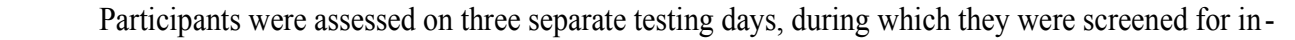

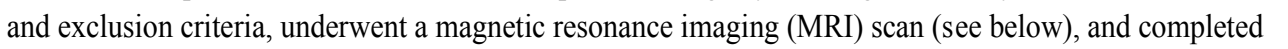

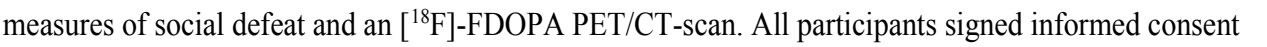

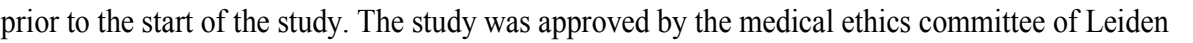

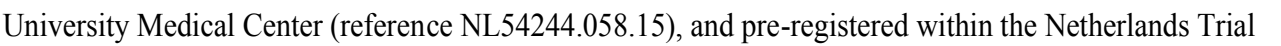

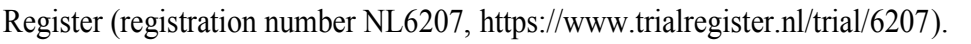




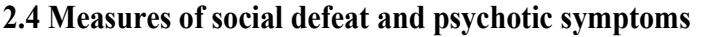

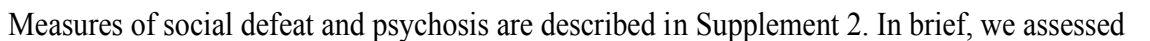

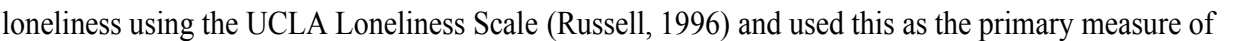

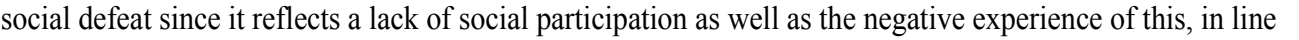

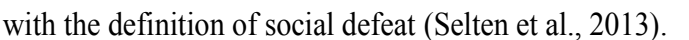

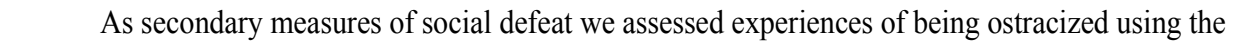

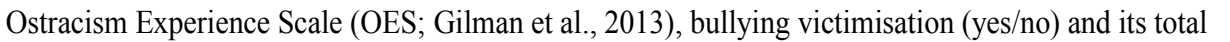

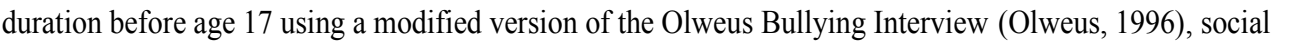

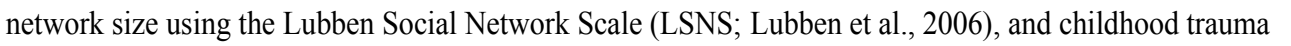

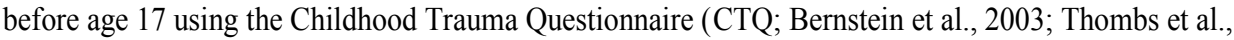

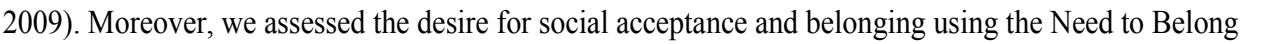

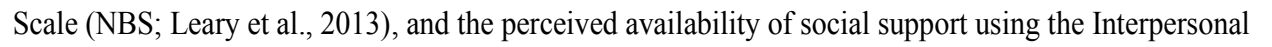

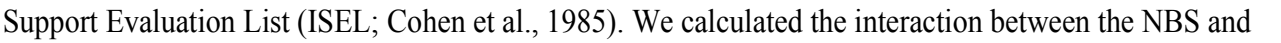

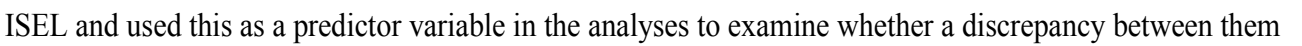

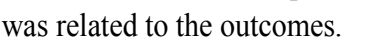

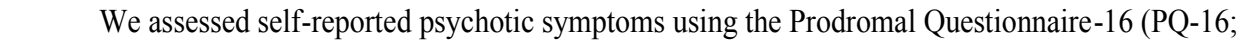

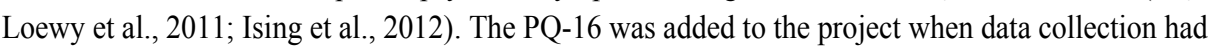

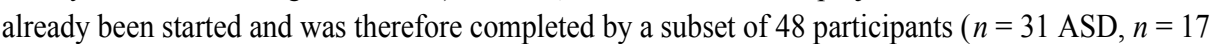
controls). Furthermore, we assessed depressed mood and anxiety using the Beck's Depression Inventory $\square$

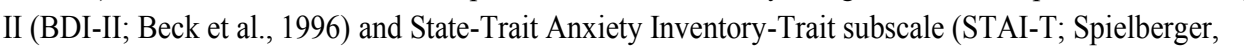

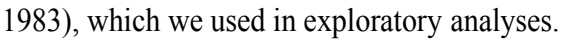
$\square$

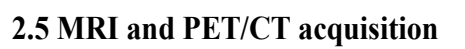

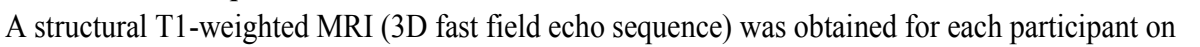

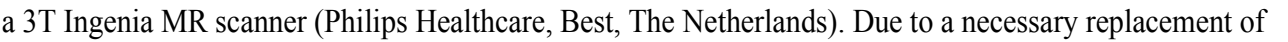

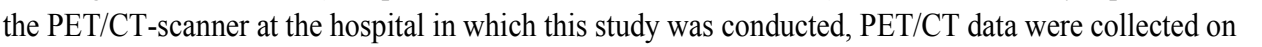

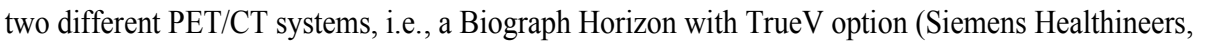

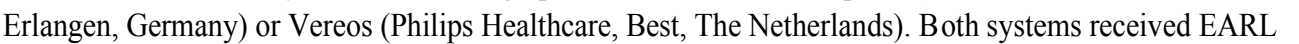

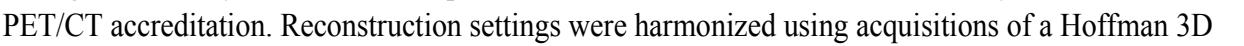

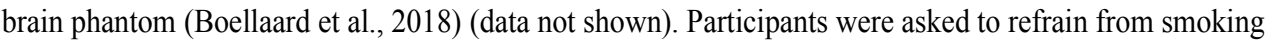

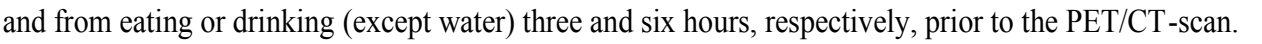

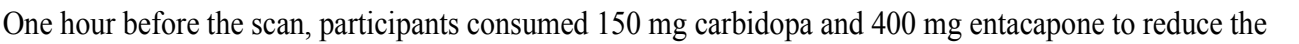

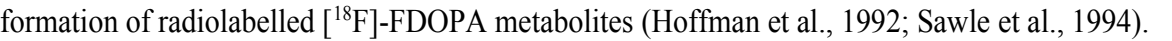

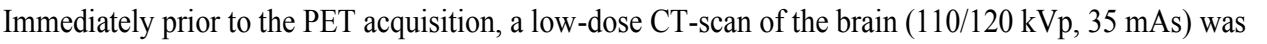

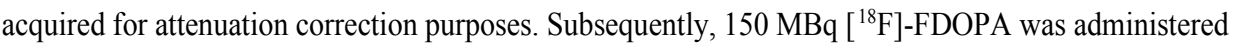
प

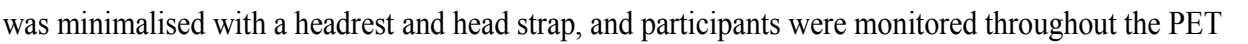

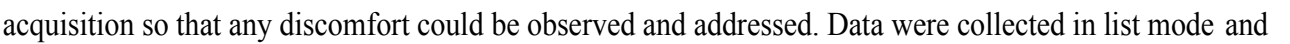

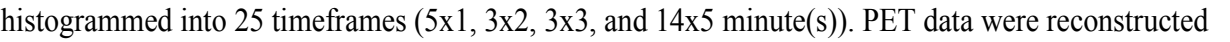
प

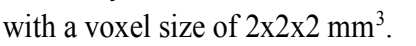

$\square$

$\square$

$\square$ 


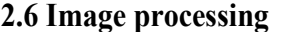

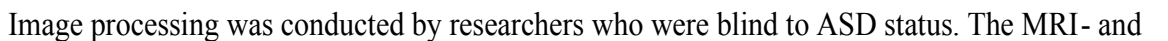

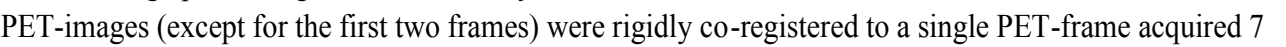

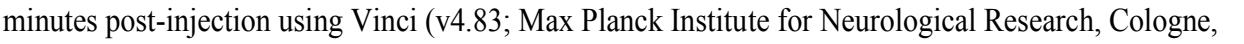

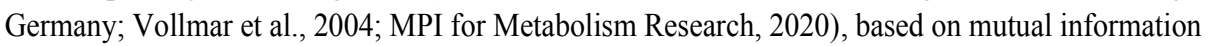

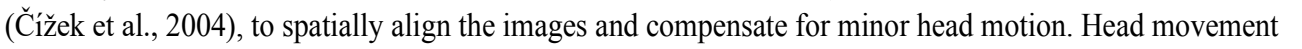

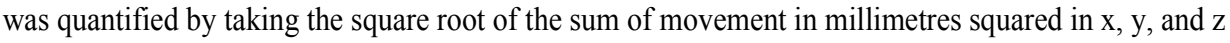
directions from the last PET frame relative to the reference frame. Prior to pharmacokinetic analysis,

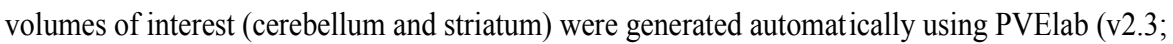

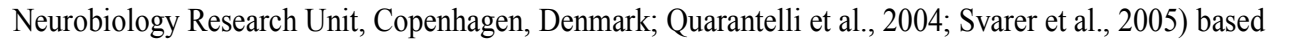

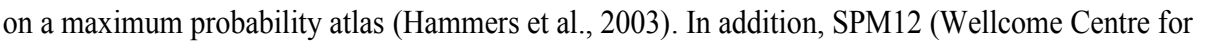

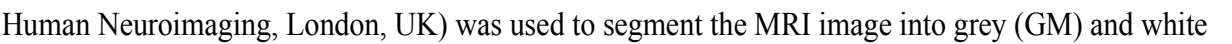

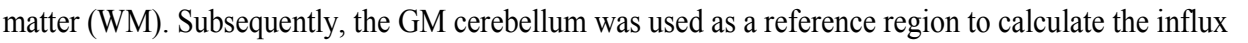

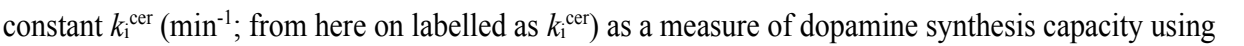

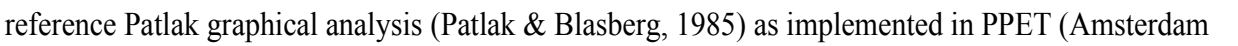
UMC, Amsterdam, The Netherlands; Boellaard et al., 2006) and 90 were used for linear fit, resulting in a whole

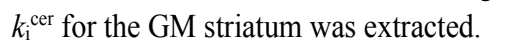

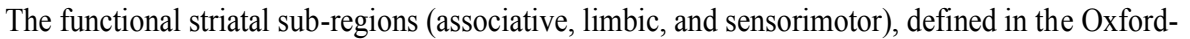

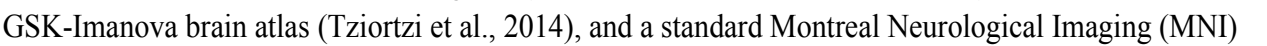
brain template were extracted from FSLeyes v0.3 in FSL (v6.0; Analysis Group, Oxford, United Kingdom; Jenkinson et al., 2012; McCarthy, 2020)

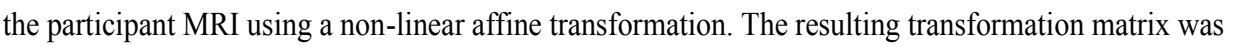

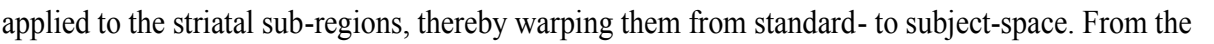

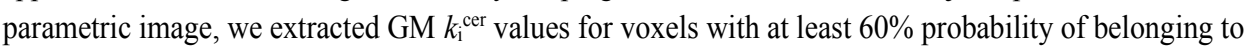

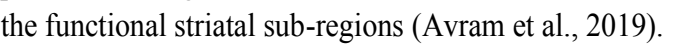

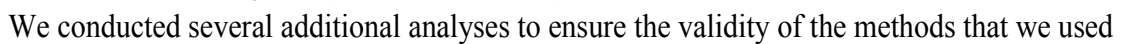

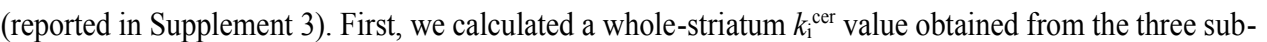

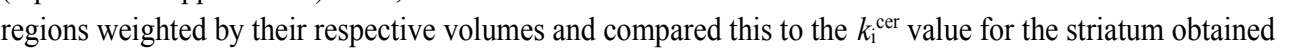

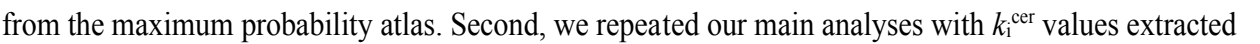

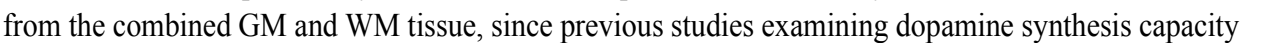

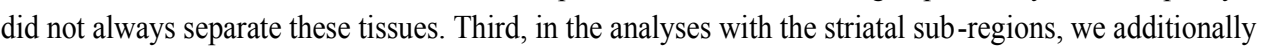
investigated a stricter threshold of at least $90 \%$ probability. Fourth, we compared the mean standardized uptake values (SUV) in GM cerebellum in ASD and controls, to examine whether non specific uptake of

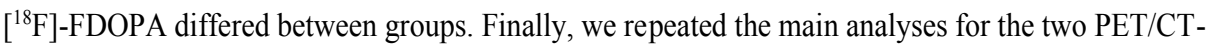

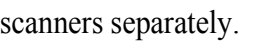

$\square$

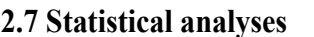

Statistical analyses were conducted using SPSS v26. A two tailed alpha of $\alpha=0.05$ was used to

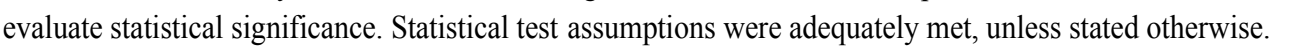
We had few missing data on the measures of social defeat (less than $0.25 \%$ of total responses on any

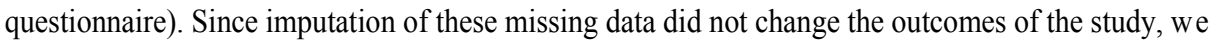

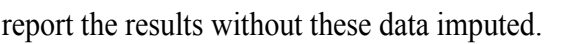




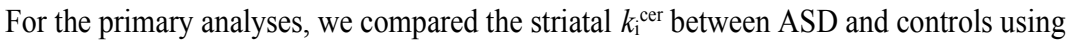

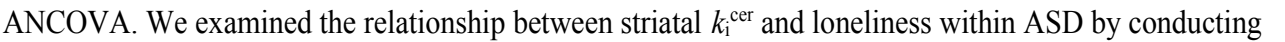

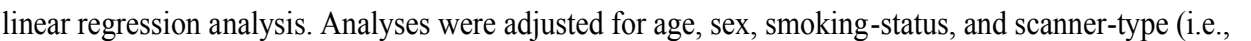

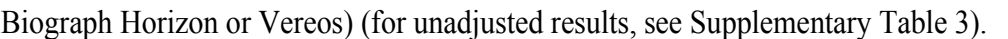

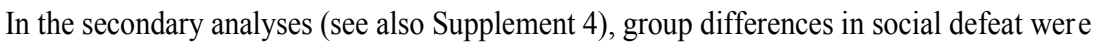

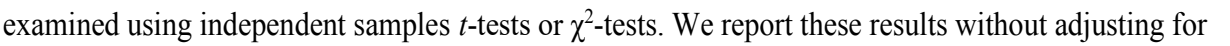

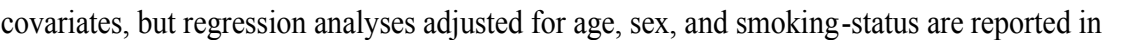

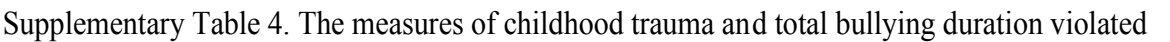

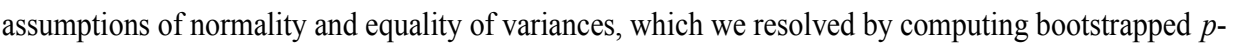
पाय(Rietveld \& van Hout, 2015; Dwivedi et al., 2017)

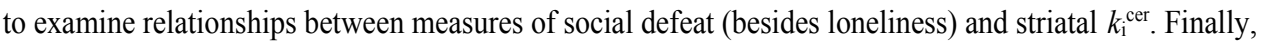

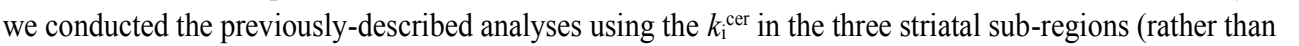

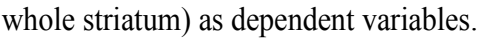

$\square$ 


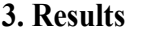

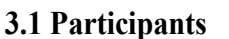

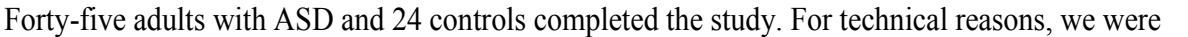
प

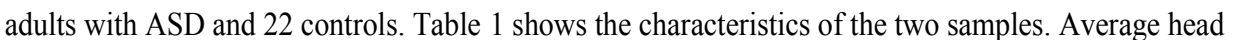

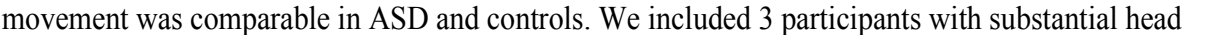
movement (> $5 \mathrm{~mm} ; 1$ control and 2 ASD participants), as we excluded deviating frames during

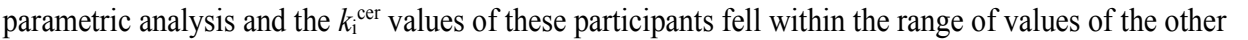
participants. Moreover, excluding them did not alter the results.

प्रापालाप

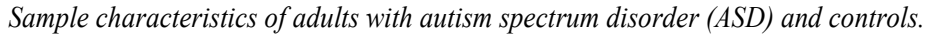

\begin{tabular}{|c|c|c|}
\hline 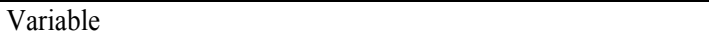 & 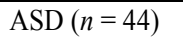 & 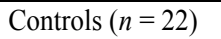 \\
\hline 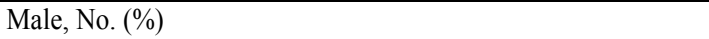 & 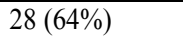 & 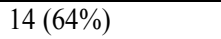 \\
\hline 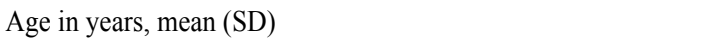 & 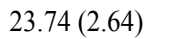 & पणापाणाण \\
\hline 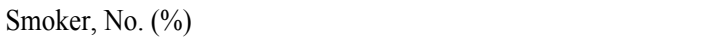 & पा山ा & प⿴囗十丁 \\
\hline 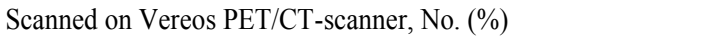 & एण口冋 & एण口冋 \\
\hline 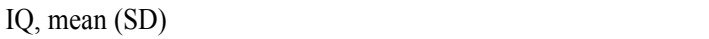 & 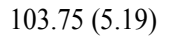 & 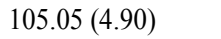 \\
\hline 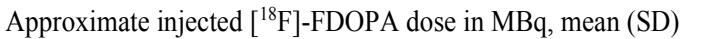 & 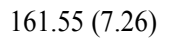 & 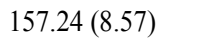 \\
\hline 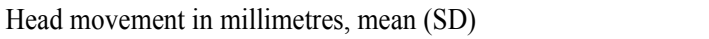 & 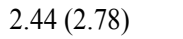 & 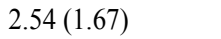 \\
\hline
\end{tabular}

SD, standard deviation; IQ, intelligence quotient; MBq, megabecquerel. $\square$

$\square$

$\square$

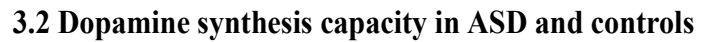

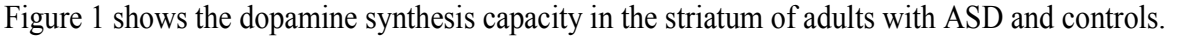
प

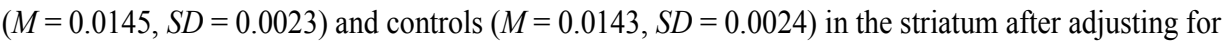

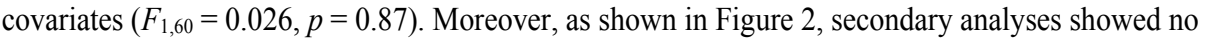

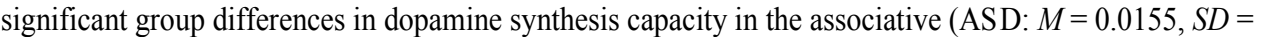

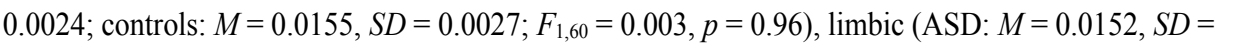

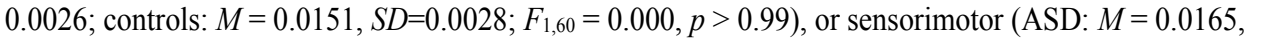

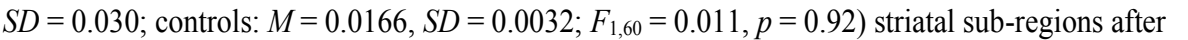
adjusting for covariates. $\square$ 


\section{Chapter IV}

पाणाणाए

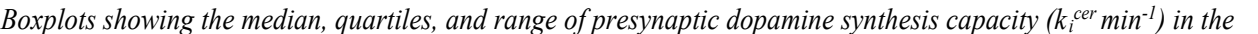

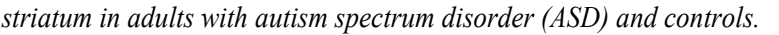

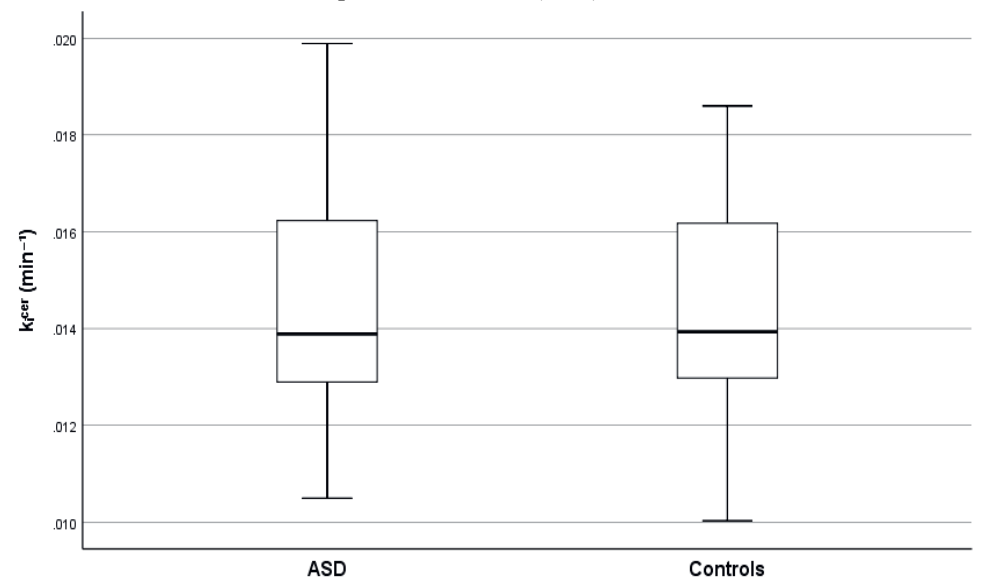

$\square$

$\square$

पापणाणा

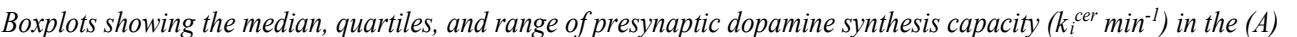

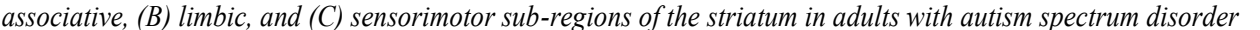

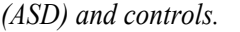
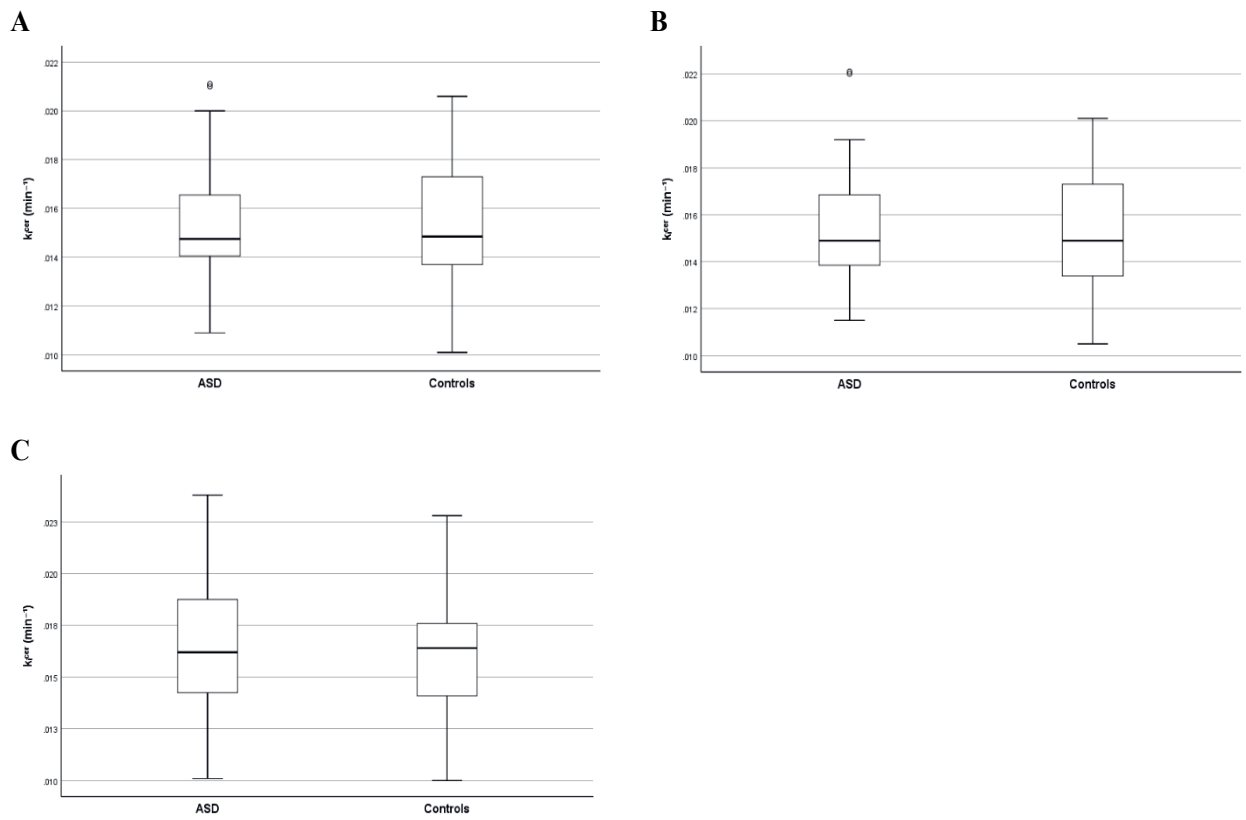

$\square$ 


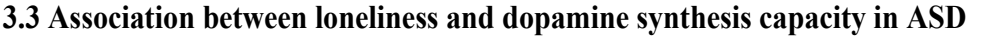

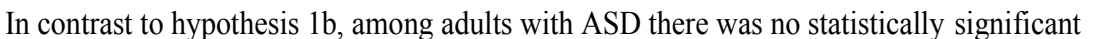

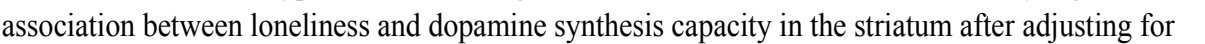

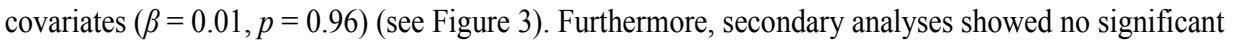

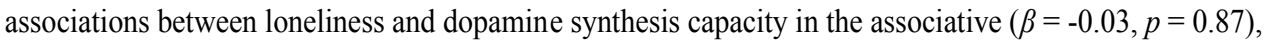

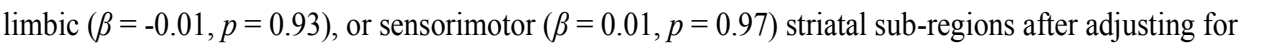

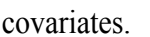

पाणाणा

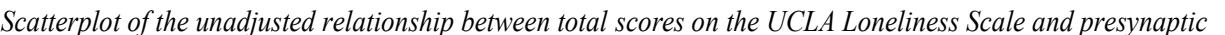

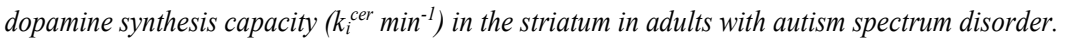

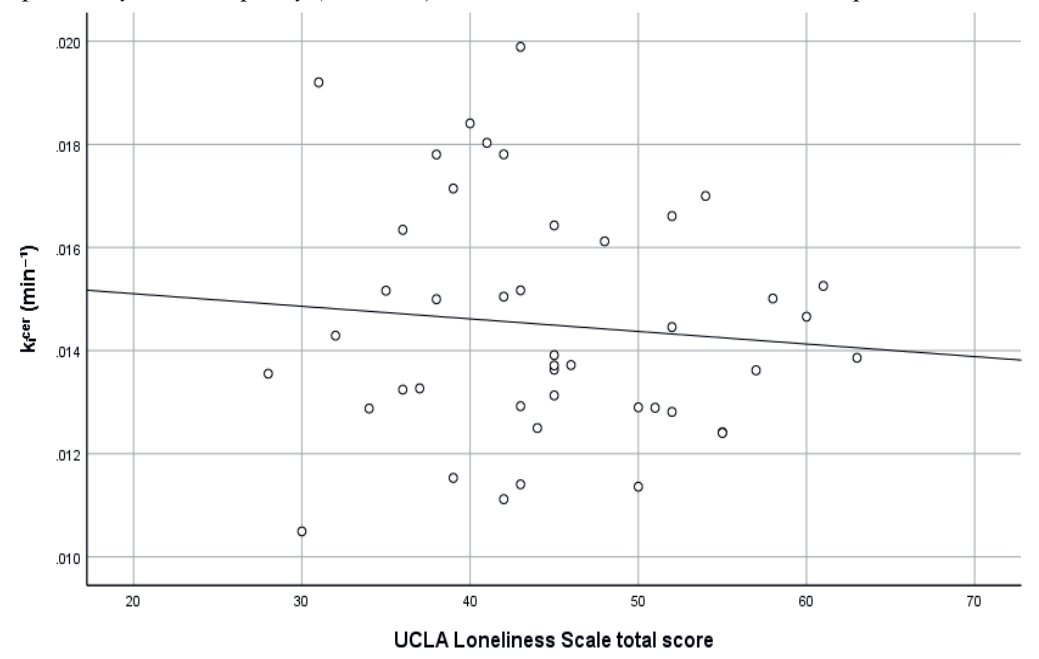

$\square$

$\square$

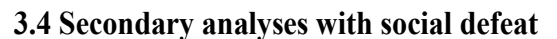

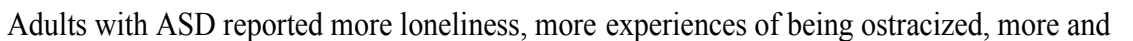

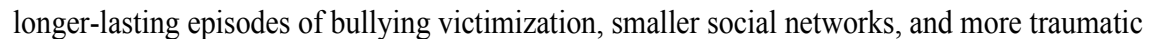

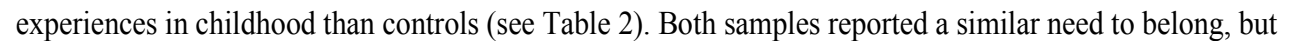

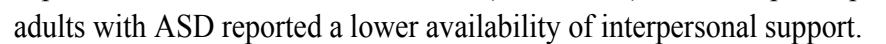

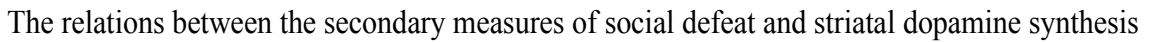

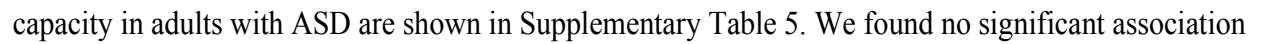

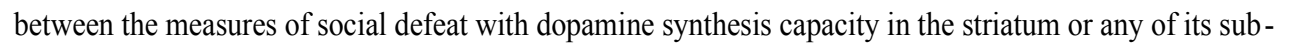

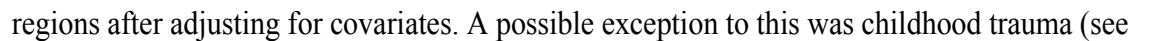

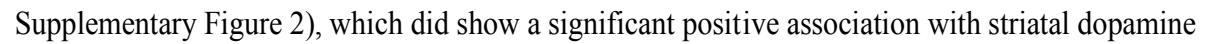

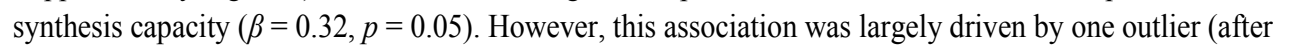

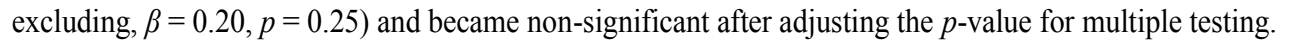

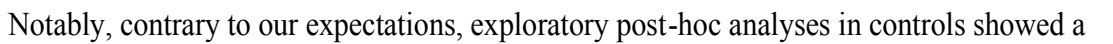

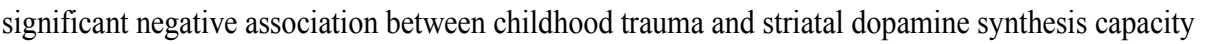

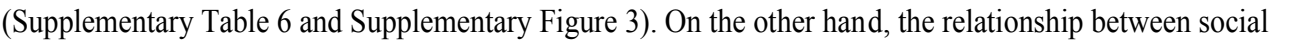




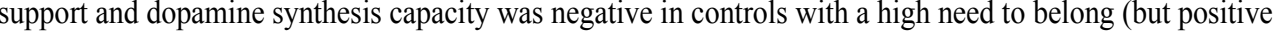
in those with a low need to belong; Supplementary Figure 4).

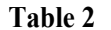

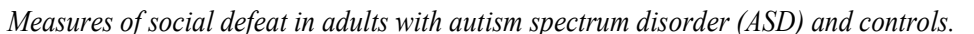

\begin{tabular}{|c|c|c|c|}
\hline 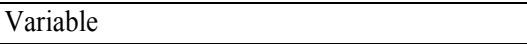 & $\operatorname{ASD}(\square=44) \square$ & $\square \square \mid \mathrm{m}\|\mathrm{m}\|=22) \square$ & 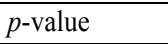 \\
\hline UCLA Loneliness Scale, mean (SD) $\square$ & $44.66(8.65) \square$ & $32.14(5.77) \square$ & $\square<0.001^{1} \square$ \\
\hline OES, mean (SD) $\square$ & $29.73(5.76) \square$ & $21.86(4.35) \square$ & $\mathrm{p}<0.001^{1} \square$ \\
\hline Bullied (yes/no), No. (\%) $\square$ & $36(82 \%) \square$ & $11(50 \%) \square$ & $\square=0.01 \square$ \\
\hline Bullying total duration in months, mean (SD) $\square$ & $48.57(40.57) \square$ & $11.32(18.63) \square$ & $\square<0.001^{1,3,4} \square$ \\
\hline LSNS, mean (SD) $\square$ & $15.89(5.34) \square$ & $21.36(3.13) \square$ & $\square<0.001^{1, \square} \square$ \\
\hline CTQ, mean (SD) $\square$ & $38.70(12.29) \square$ & $30.32(4.65) \square$ & $\square<0.001^{1,3,4} \square$ \\
\hline NBS, mean (SD) $\square$ & $31.36(6.43) \square$ & $31.45(4.62) \square$ & $\square=0.95^{1, \square} \square$ \\
\hline ISEL, mean (SD) $\square$ & $119.25(16.13) \square$ & $137.45(7.79) \square$ & $\square<0.001^{1, \square} \square$ \\
\hline
\end{tabular}

SD, standard deviation; OES, Ostracism Experience Scale; LSNS, Lubben Social Network Scale; CTQ,

Childhood Trauma questionnaire; NBS, Need to Belong Scale; ISEL, Interpersonal Support Evaluation List.

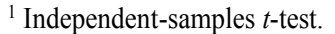

$\chi$ test.

Equal variances not assumed.

${ }^{4}$ Estimated with 10000 bootstrapping samples.

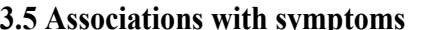

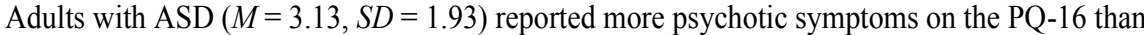

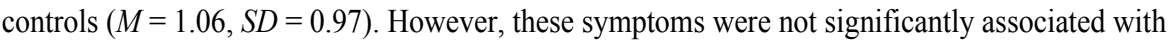
dopamine synthesis capacity in the striatum in $\operatorname{ASD}(\beta \square \square .05$, $\square=0.81)$ or in controls $(\beta \square \square 0.26$,

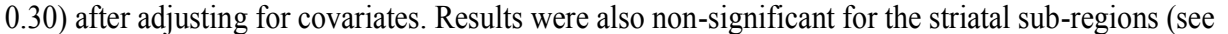
Supplementary Table 7).

Exploratory analyses showed no statistically significant associations between dopamine synthesis capacity and depressed mood or anxiety (see Supplementary Table 8).

As shown in Supplement 3,

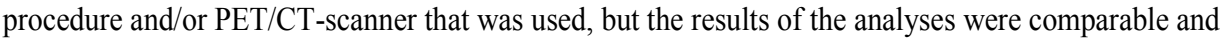

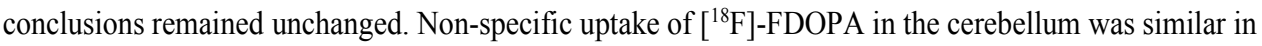
ASD and controls. 


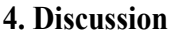

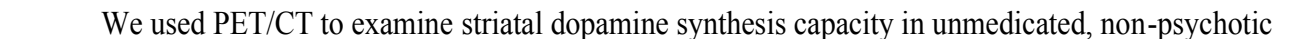

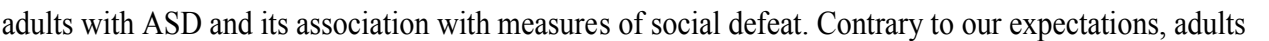

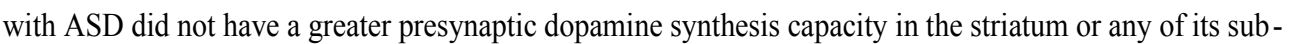

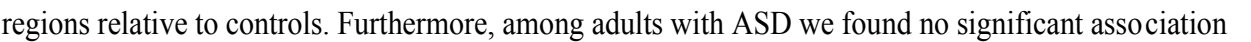

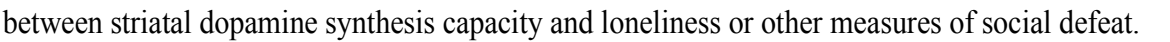

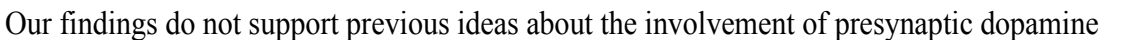

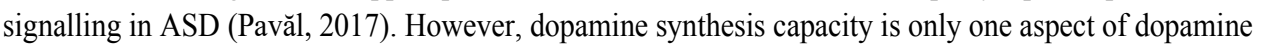

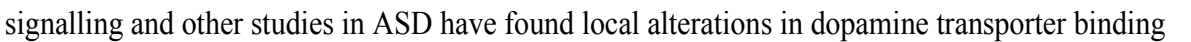

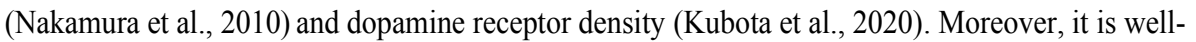

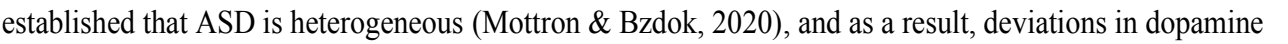

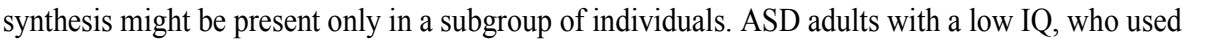

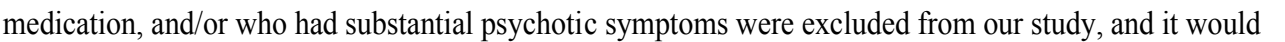

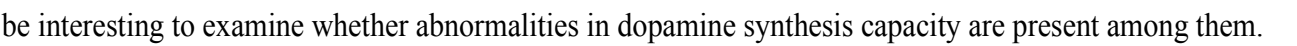

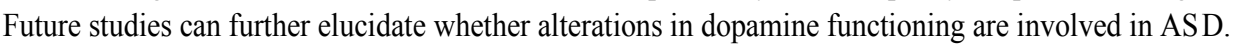

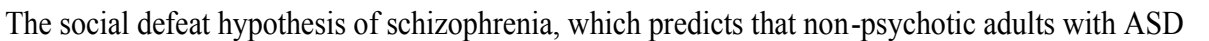

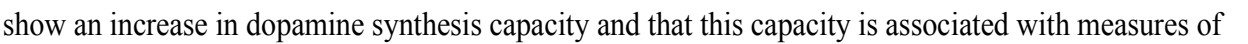

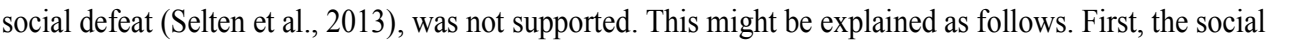

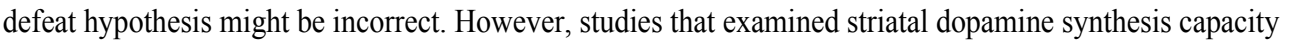

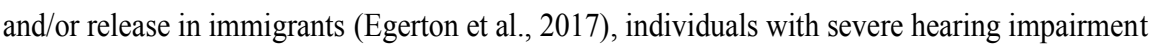

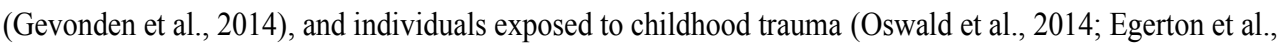

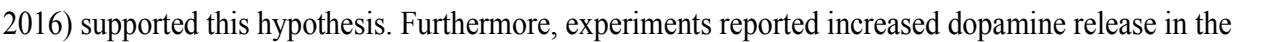

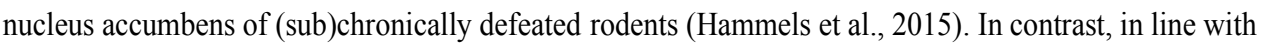

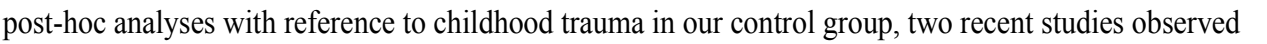

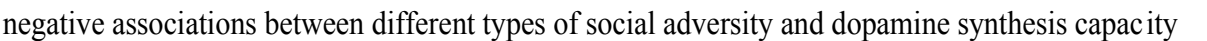

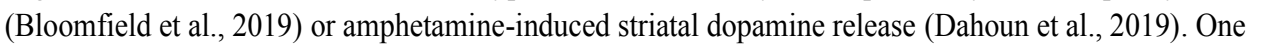

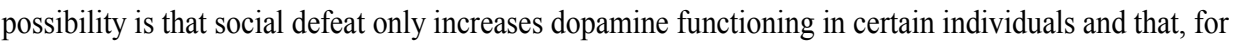

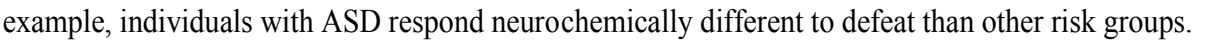

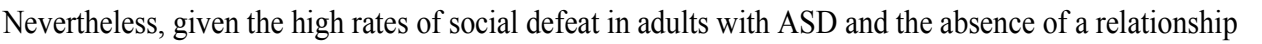

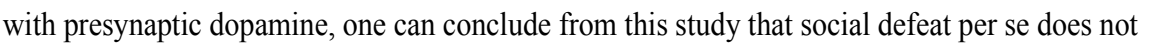

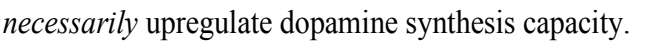

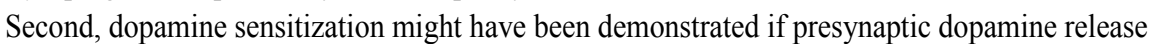

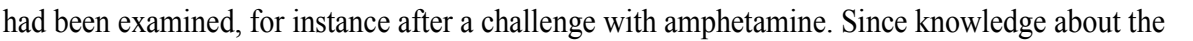

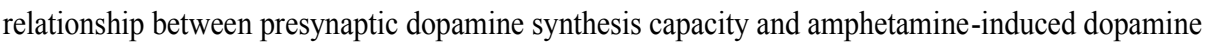

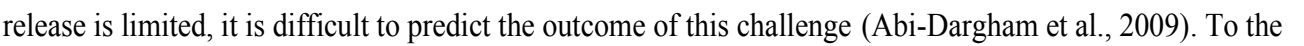

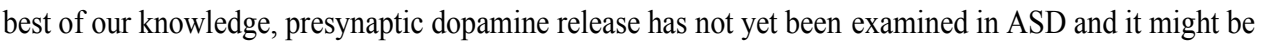

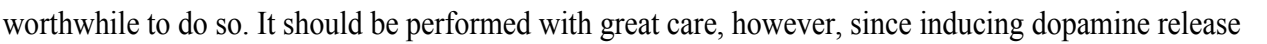

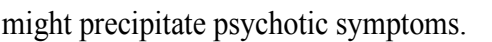

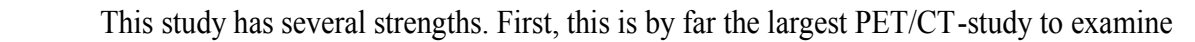

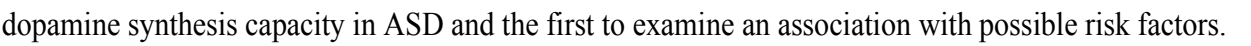

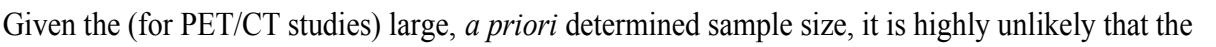

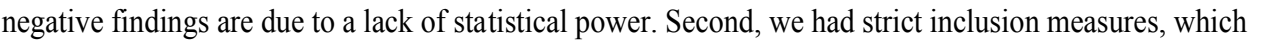

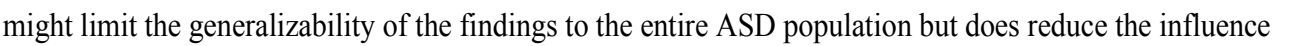

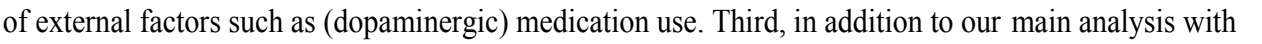




\section{Chapter IV}

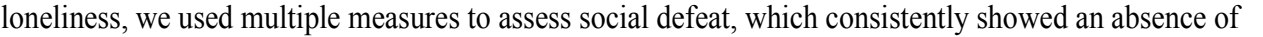

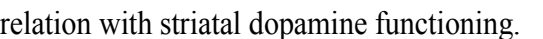

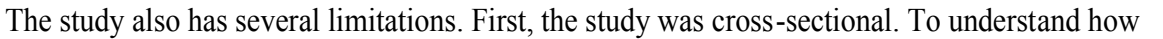

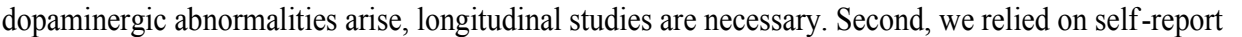

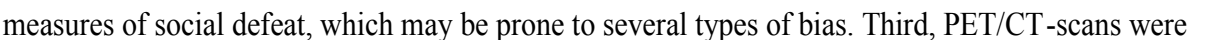

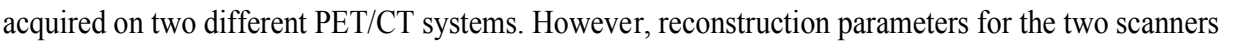

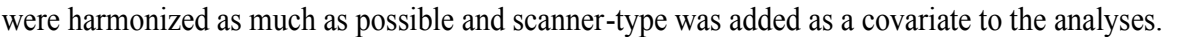

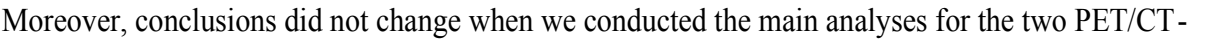

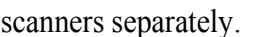

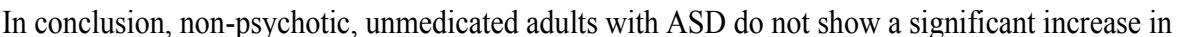

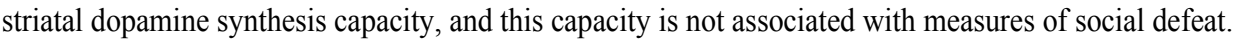




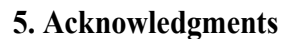

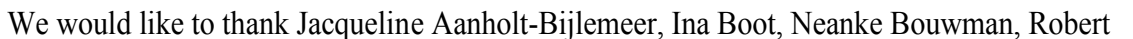

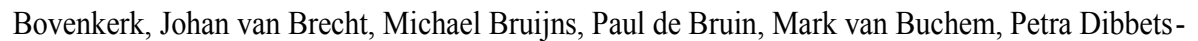

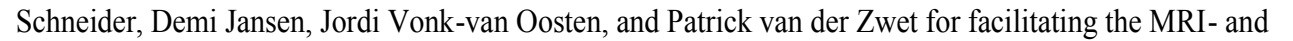

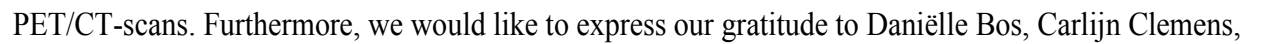

Truda Driesen, Deborah Op ‘t Eijnde, Erik Giltay, Jori Henke, and Jessie Kosterman for their assistance

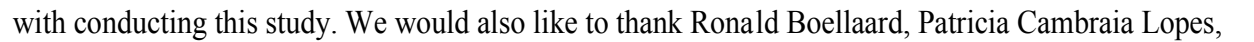

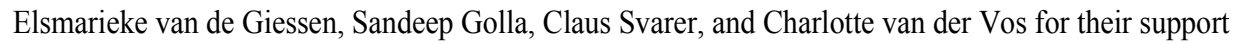

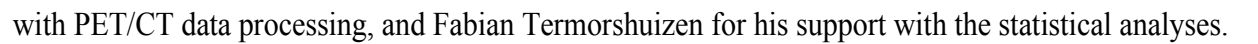

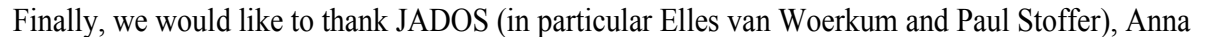

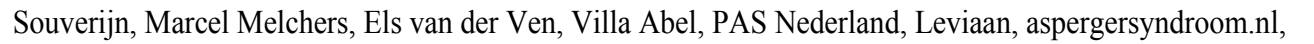

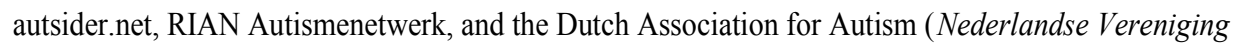

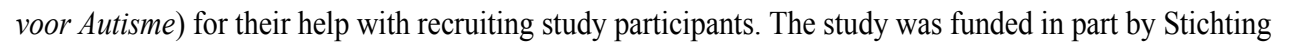

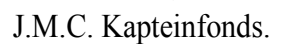




\section{Chapter IV}

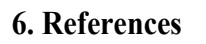

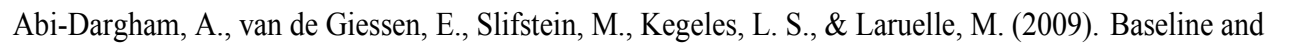

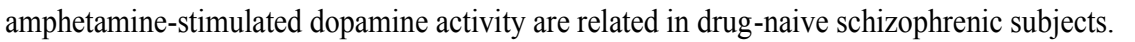

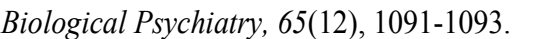

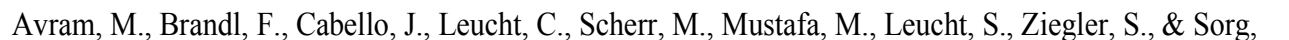

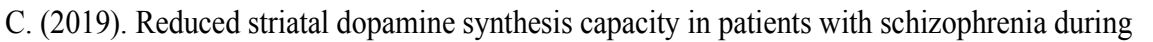

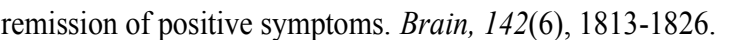

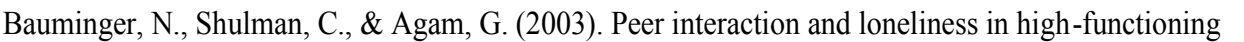

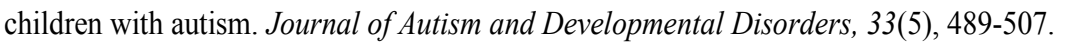

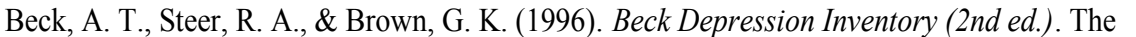

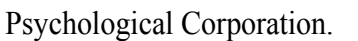

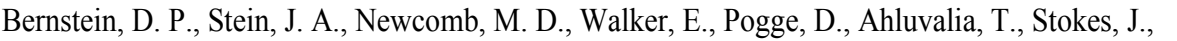

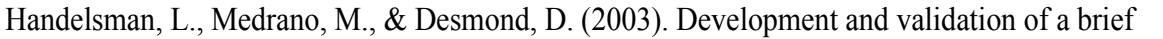

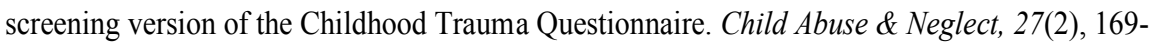

$\square 10$

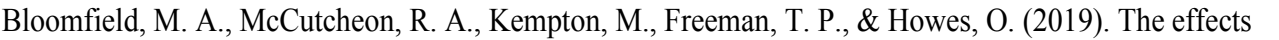

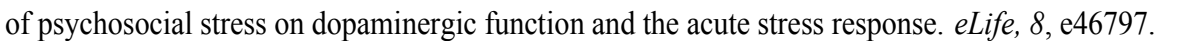

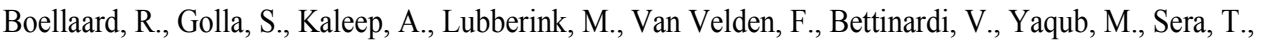

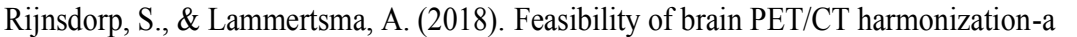

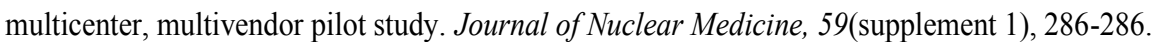

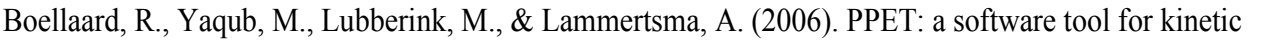

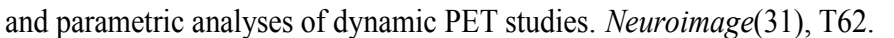

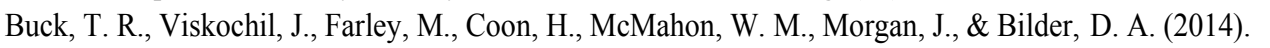

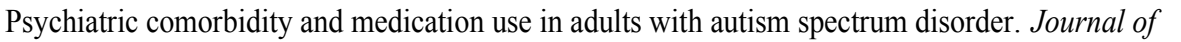

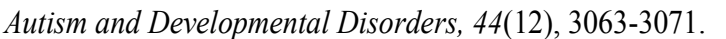

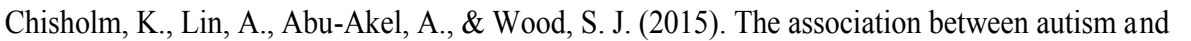

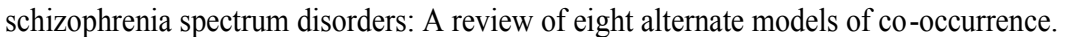

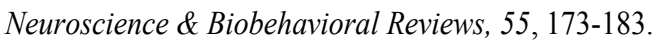

Č́żžek, J., Herholz, K., Vollmar, S., Schrader, R., Klein, J., \& Heiss, W.

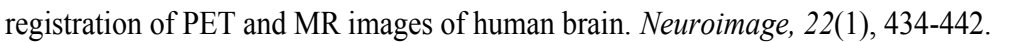

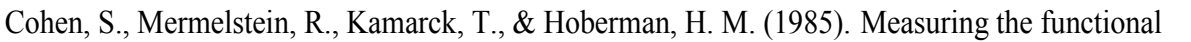

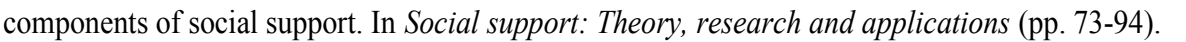

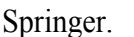

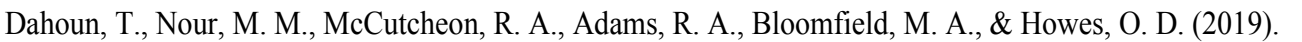

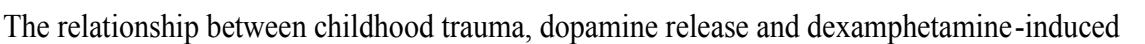

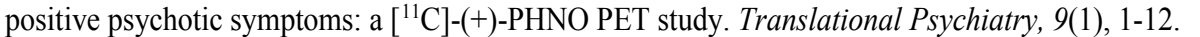

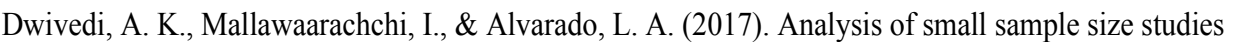

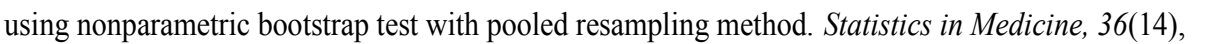

पामाणाप

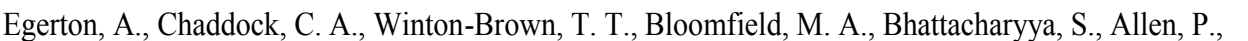

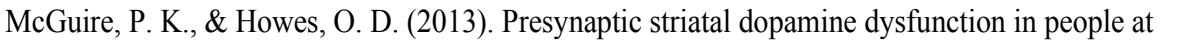

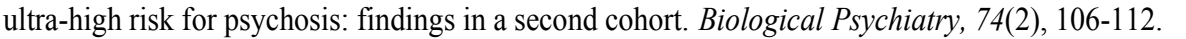

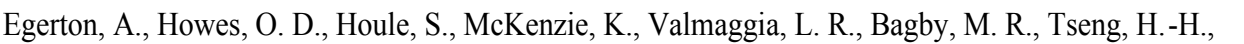

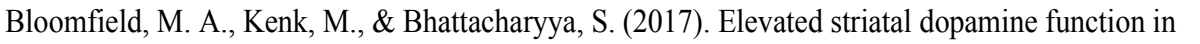




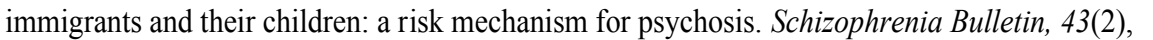
पाणाणा

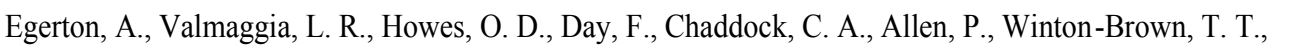

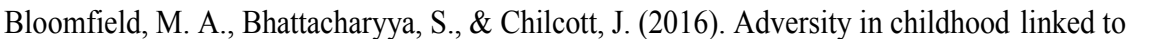

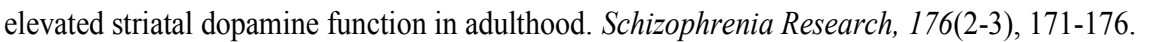

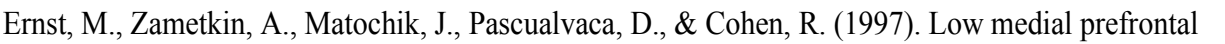

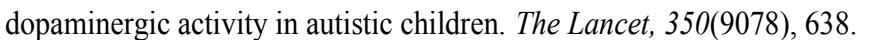

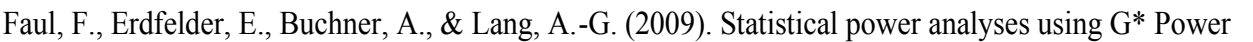

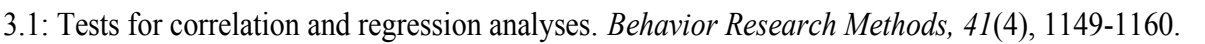

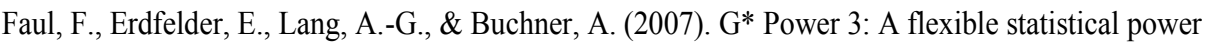

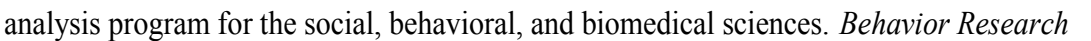

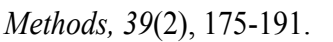

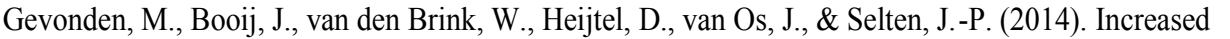

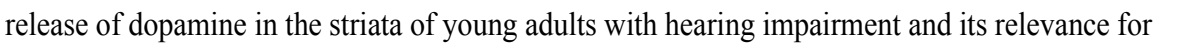

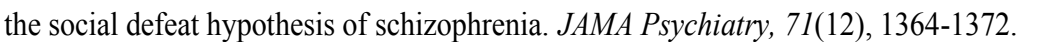

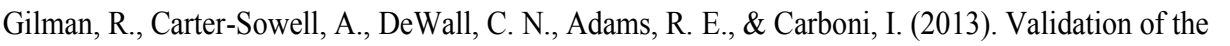

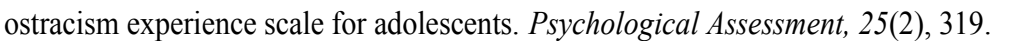

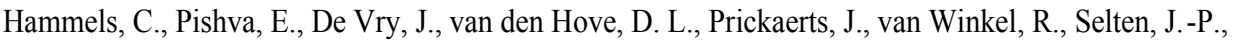

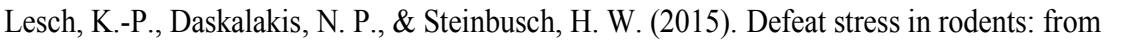

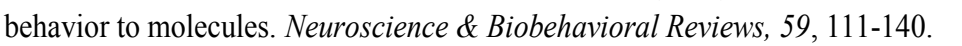

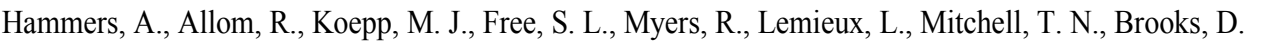

$\square \amalg \square \square$ n, J. S. (2003). Three-dimensional maximum probability atlas of the human brain,

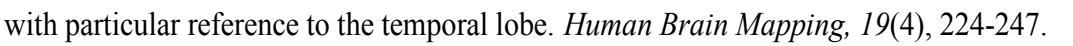

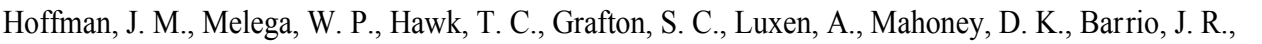

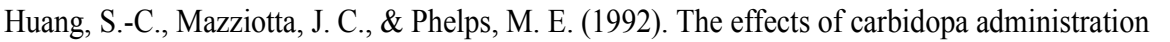

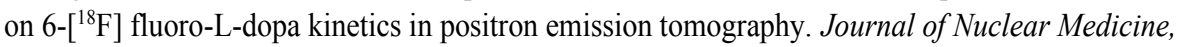
पा山ा山ामणमाण

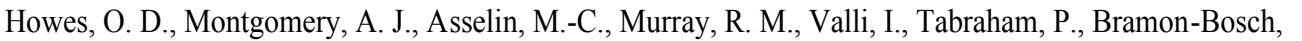

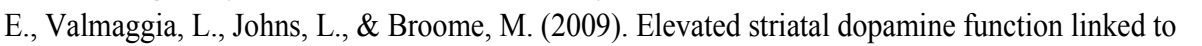

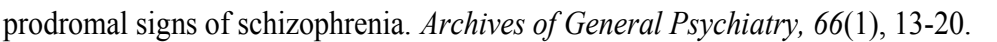

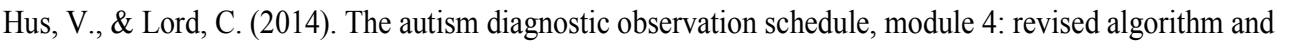

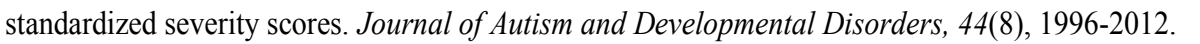

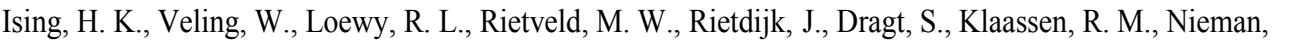

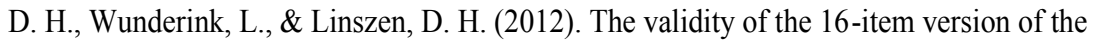

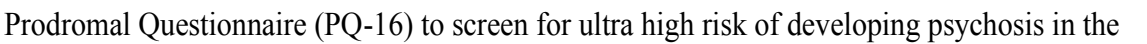

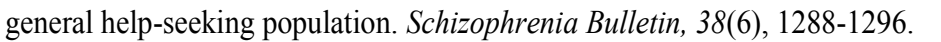

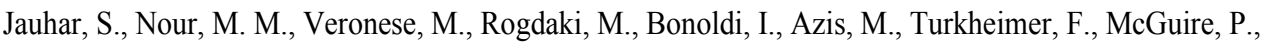

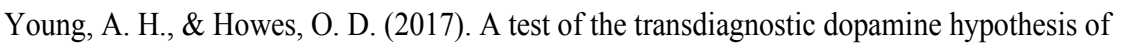

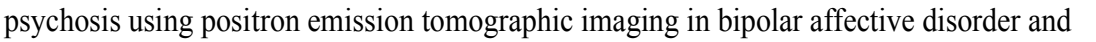

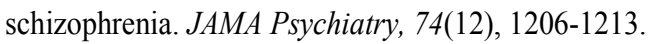

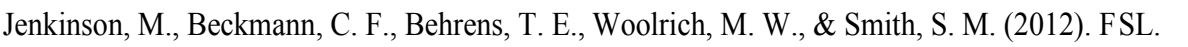

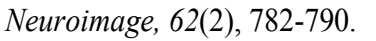




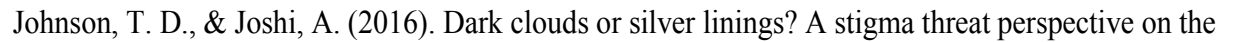

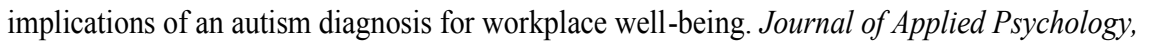

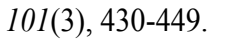

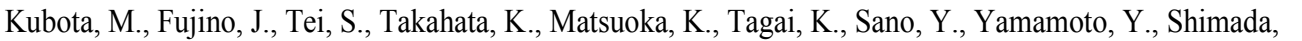

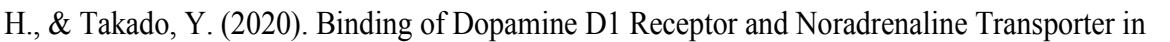

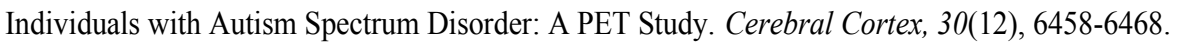

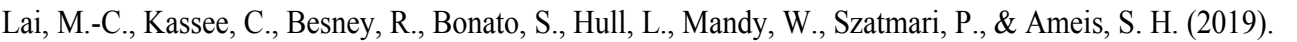

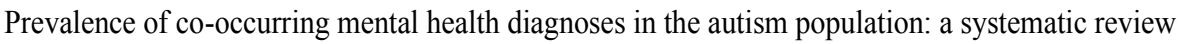

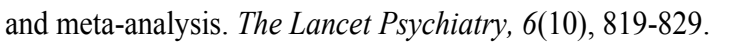

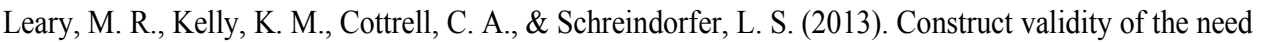

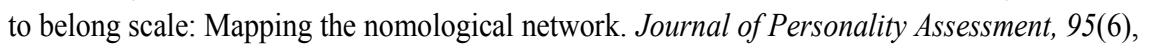
पाणाएा

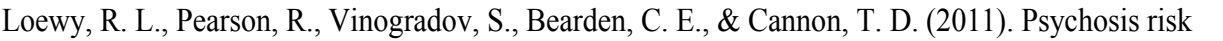

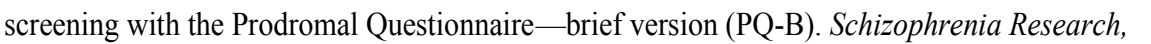
पामाणाणाm

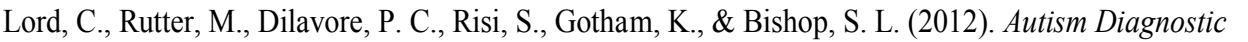

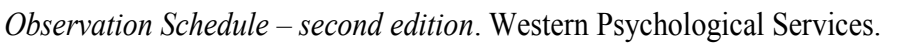

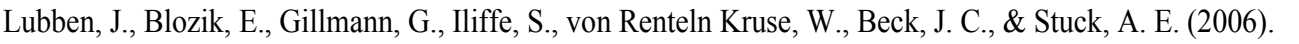

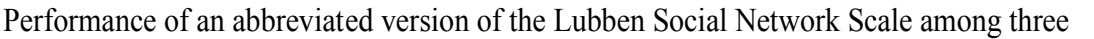

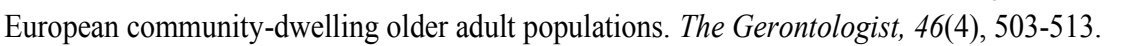

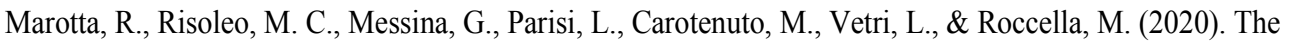

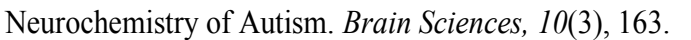

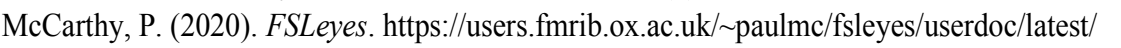

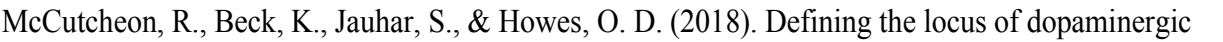

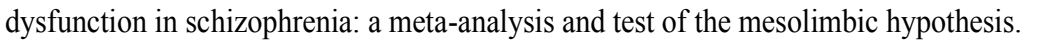

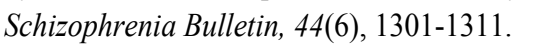

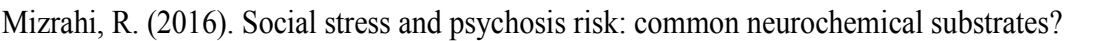

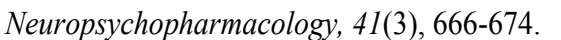

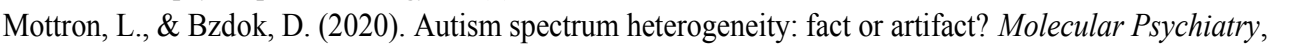
एणाए

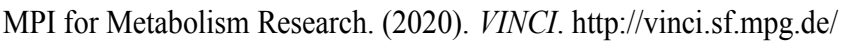

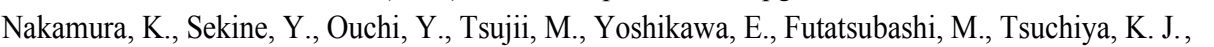

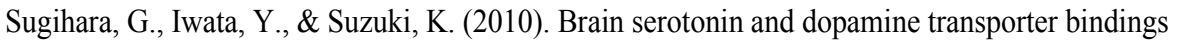

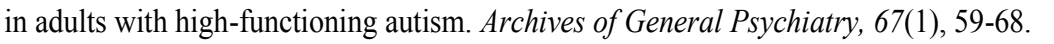

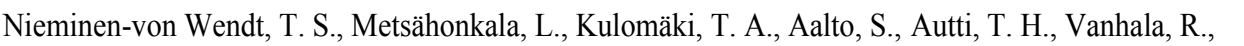

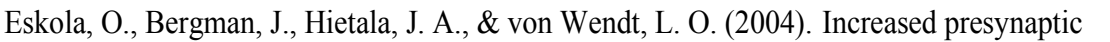

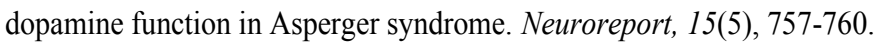

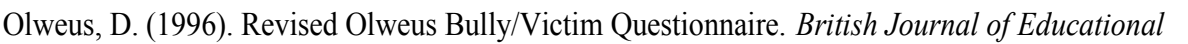

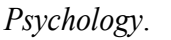

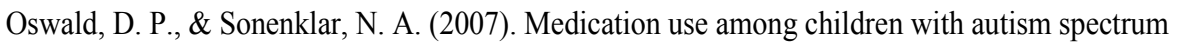

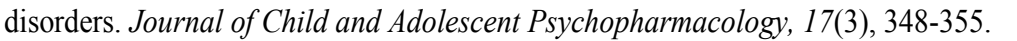

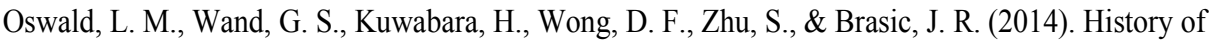

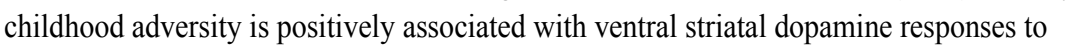

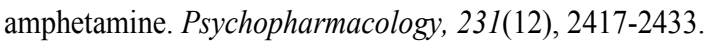




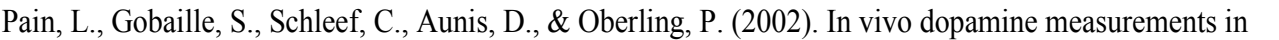

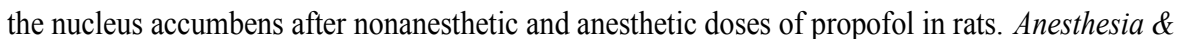

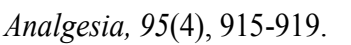

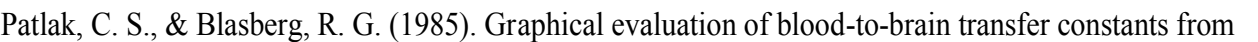

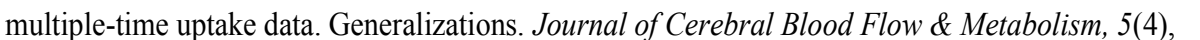

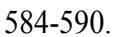

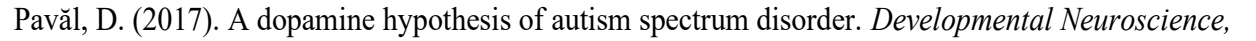
पाणाणमणाण

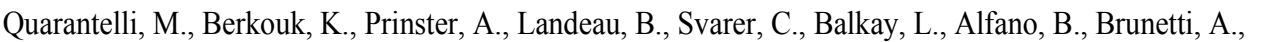

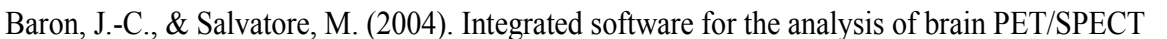

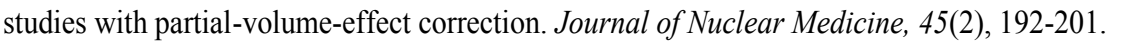

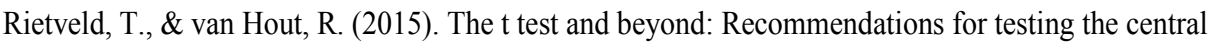

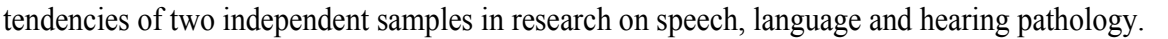

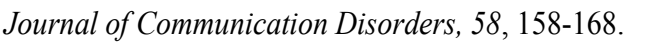

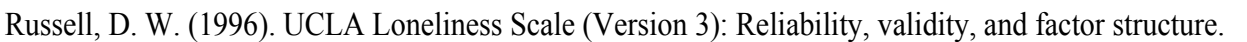

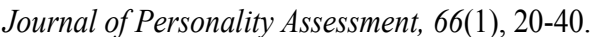

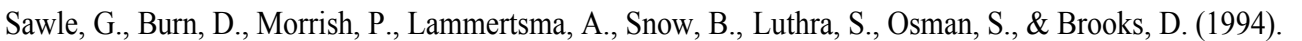
The effect of entacapone (OR-611) on brain [ ${ }^{\square}$ F]-6-L-fluorodopa metabolism: Implications for

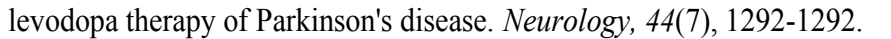

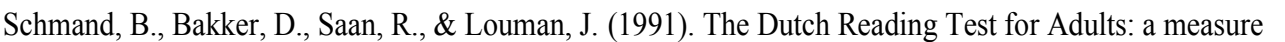

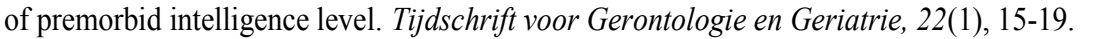
a

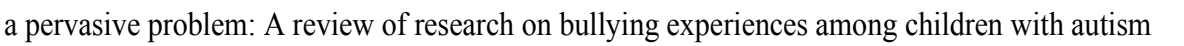

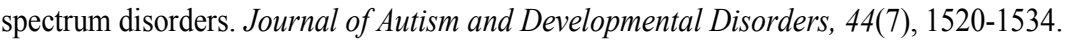

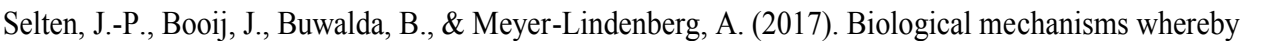

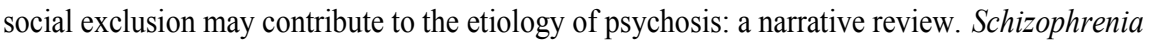

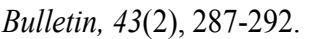

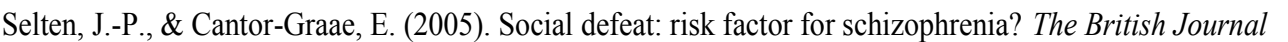

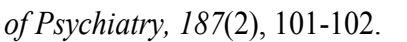

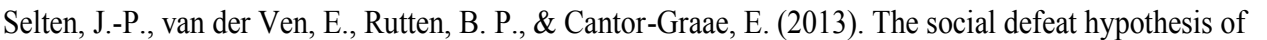

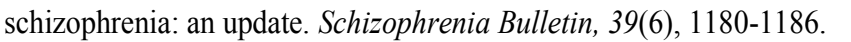

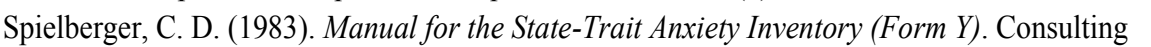

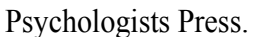

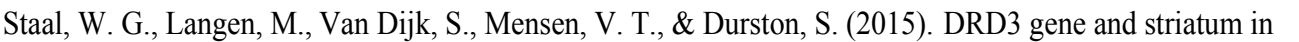

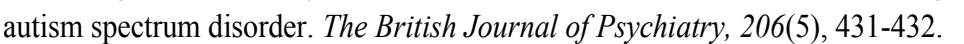

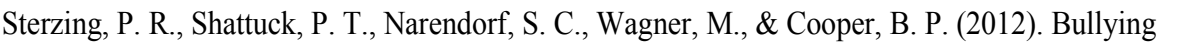

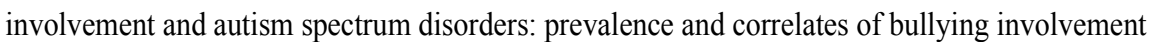

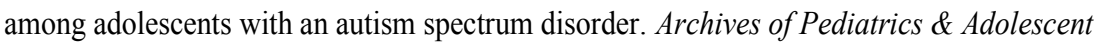

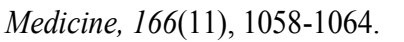

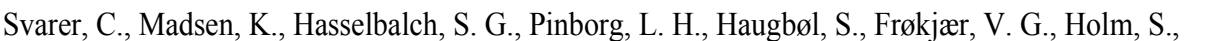

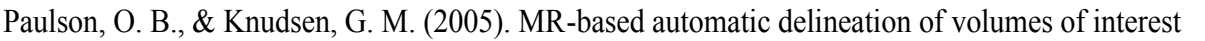

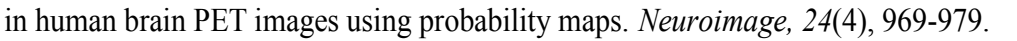




\section{Chapter IV}

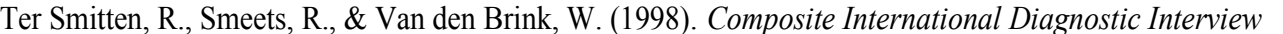

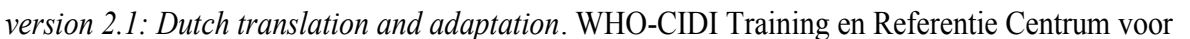

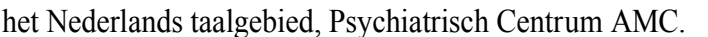

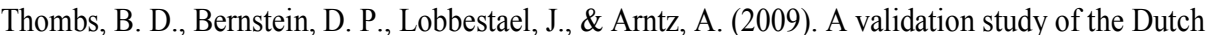

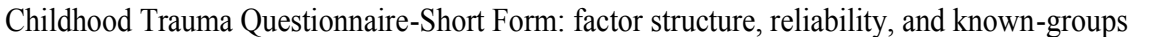

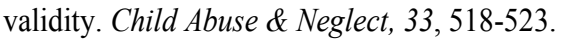

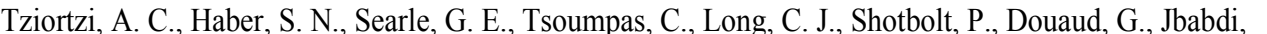

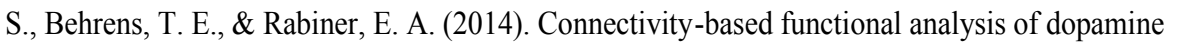

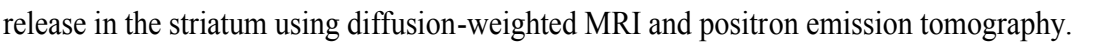

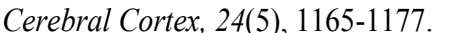

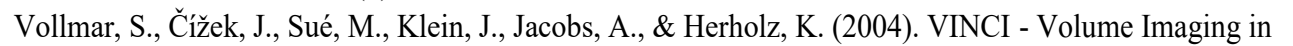

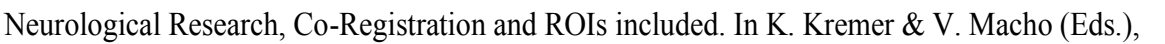

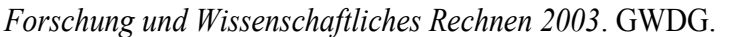

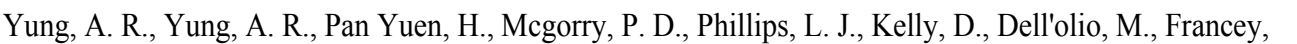

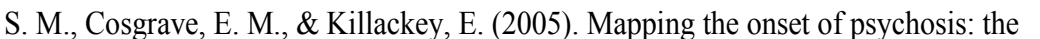

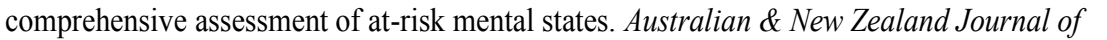

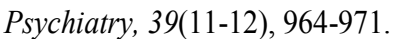

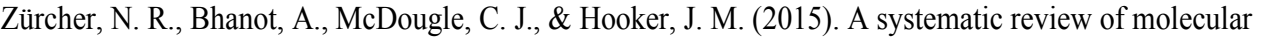

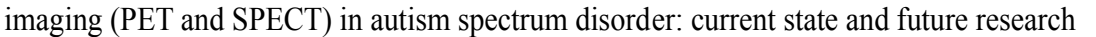

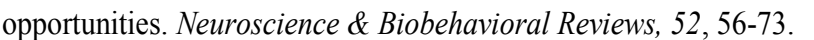

$\square$ 
$\square$

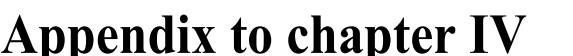

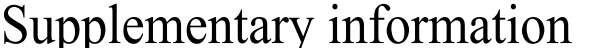

$\square$

$\square$

$\square$ 


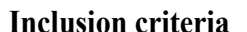

$\square \square \square \square 5$ diagnosis of autism spectrum disorder (ASD; only for the ASD sample). $\square$

$\square \square \square \square \square-30$ years. $\square$

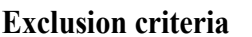

$\square \square \square \square 5$ diagnosis of ASD (controls only). $\square$

$\square$ Autism spectrum disorder due to a known organic disorder ("Syndromal ASD", e.g., due to Fragile X syndrome, Klinefelter syndrome, 22q11 deletion syndrome). $\square$

Neurological disorder (e.g., epilepsy) or evidence of brain damage. $\square$

History of meningitis.

पापाणाण

$\square \square$ affective psychotic disorder or bipolar disorder (DSM

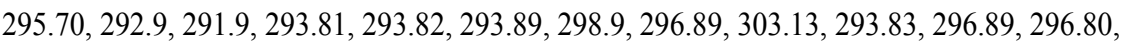
296.4x, 296.5x, 296.7).

$\square$ Social exclusion due to other causes than ASD, such as visible ethnic minority status, serious physical disability, serious visual or hearing impairment, at discretion of the researcher.

$\square$ Current use of drugs (XTC, cocaine, etc.). Use of cannabis was allowed, but should have been stopped at least one month before the study. Cannabis abuse earlier in life was not allowed. Alcohol $\square$ or drug abuse or dependence (DSM 5).

$\square$ Use of an antipsychotic (ever) if prescribed for a psychotic disorder, as a former psychotic disorder is an exclusion criterion. Occasionally, antipsychotics are prescribed against e.g. anxiety or aggression. In these cases: $\square$

$\square$ Incidental former use of antipsychotic was allowed, if the last use had been more than a year ago. $\square$

b. Regular former use of antipsychotic was allowed, if the last use had been more than tw years ago. $\square$

$\square$ Antipsychotic formerly administered as depot medication was allowed, if the last injection had been more than two years ago. $\square$

Use of the antipsychotic quetiapine (ever), if prescribed in relation to a psychotic disorder. However, quetiapine is often prescribed against sleep difficulties and has a low affinity to

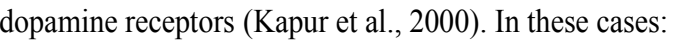

$\square$ Consumption was allowed if previously consumed in a low dose ( $\leq 50 \mathrm{mg})$, but last use had been more than 3 months ago.

b. Consumption was allowed if previously consumed in a high dose ( $>50 \mathrm{mg})$, but last use had been more than 6 months ago. $\square$

Use of medication usually prescribed for attention deficit/hyperactivity disorder (ADHD) (e.g., methylphenidate). Individuals who had stopped using these drugs for at least one year could participate in the study. $\square$

Use of benzodiazepine or promethazine, unless last use had been more than 1 month ago.

$\square$ Use of other psychotropic drugs. Individuals who had stopped using the drugs for at least 3 months could participate in the study. 


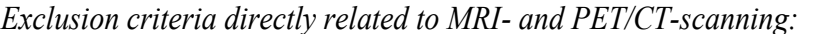

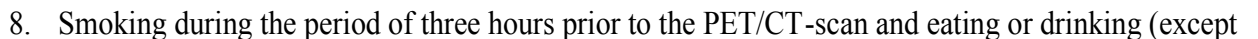

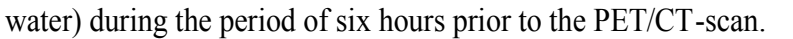

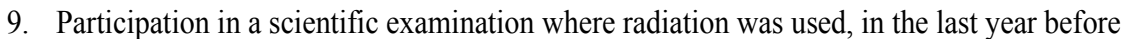

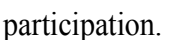

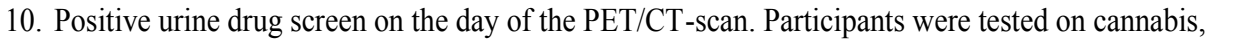

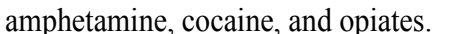

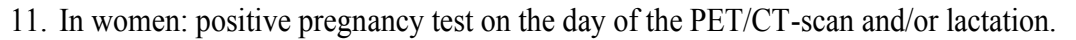

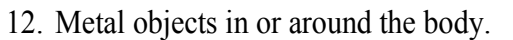

$\square$

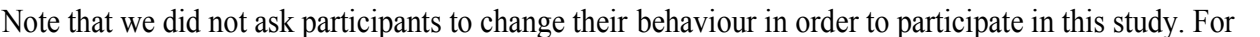

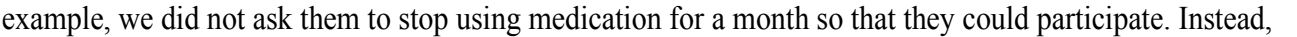

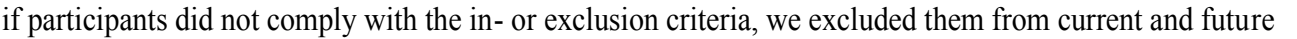

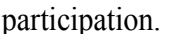

\section{$\square$}




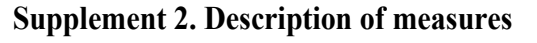

पमापाणाणम

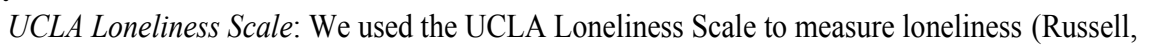

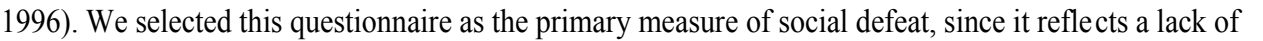

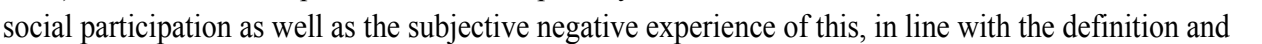

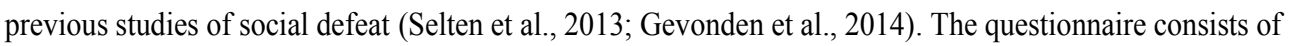
20 items (e.g., "How often do you feel that you lack companionship?"), which are scored between 1 (Never) and 4 (Always). After reverse

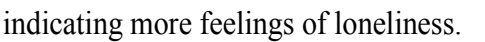

$\square$

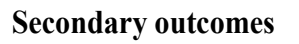

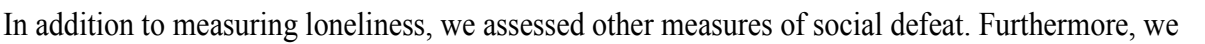

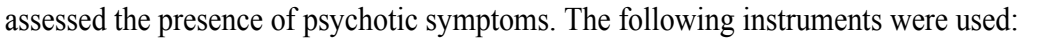

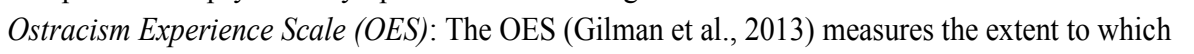
participants feel excluded or ignored (i.e., ostracized). The questionnaire consists of 11 items (e.g., "In general, others ignore me during conversation"), which are scored between 1 (Never) and 5 (Always).

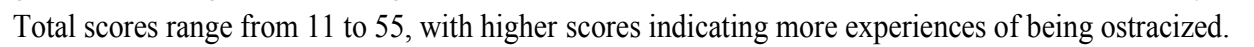

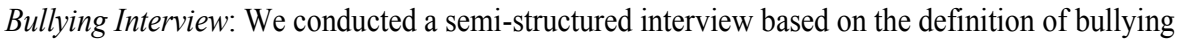

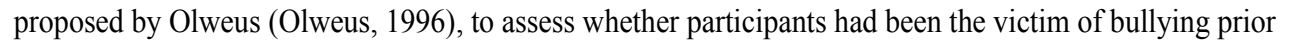
to age 17. This definition was given as follows: "We say a child is being bullied when another child, or

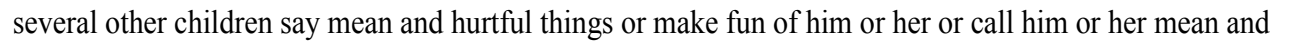

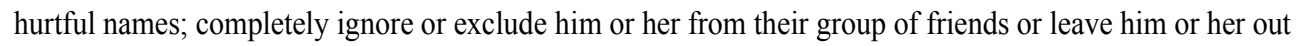
of things on purpose; hit, kick, push, shove around, or lock him or her inside a room; tell lies or spread

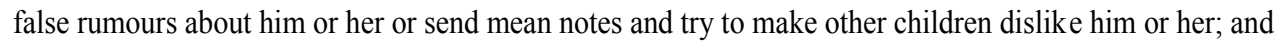

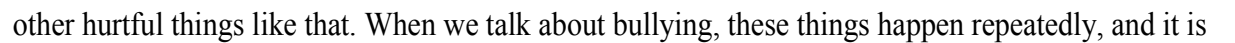

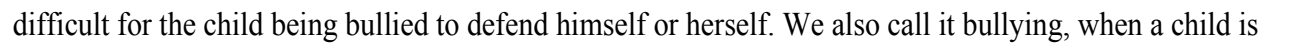
पाता

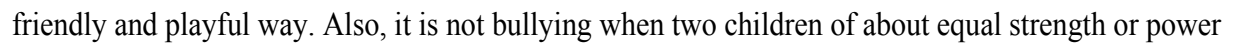

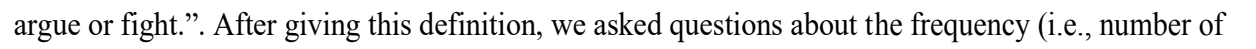

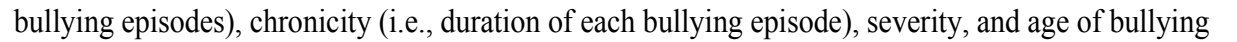

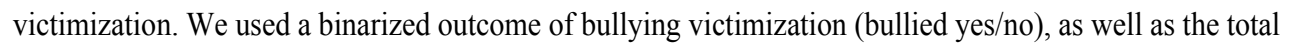

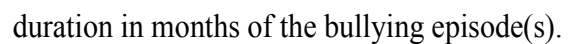

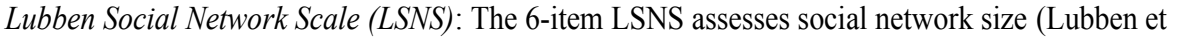

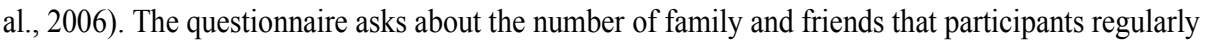

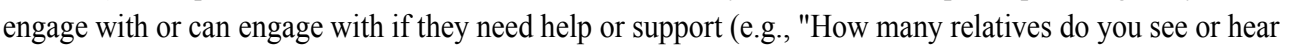
ए

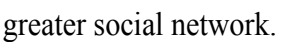

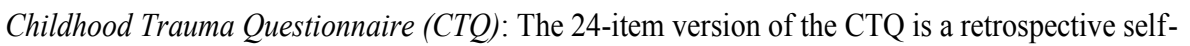

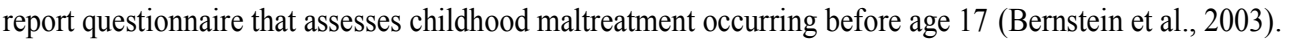

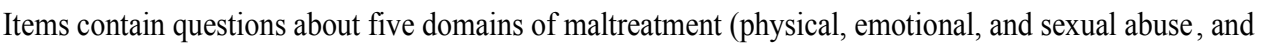
physical and emotional neglect; e.g., "When I was growing up, I thought that my parents wished I had never been born."), which are scored between 1 (Never true) and 5 (Very often true). All subscales consist

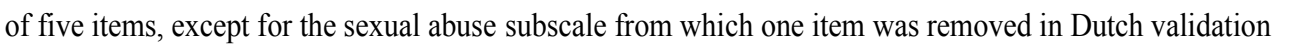


口प⿴囗十 (Thombs et al., 2009; Spinhoven et al., 2014). In this study total scores (between 24 and 120) were used, with greater scores indicating more experiences of childhood trauma.

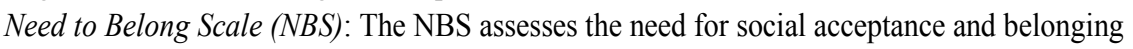
(Leary et al., 2013). The questionnaire consists of 10 items (e.g., "I want other people to accept me.”), which are scored between 1 (Not at all) and 5 (Extremely). After revers $\square$ coding, total scores range from 10 to 50 , with higher scores indicating a greater need to belong. $\square$

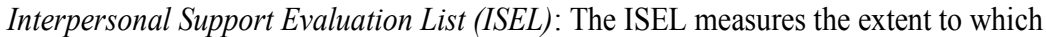
participants perceive that social support is available (Cohen et al., 1985). The questionnaire consists of 40 items (e.g., "If I decide one afternoon that I would like to go to a movie that evening, I could easily find someone to go with me."), which are scored between 1 and 4 . Total scores range from 40 to 160. Higher scores indicate a greater availability of social support.

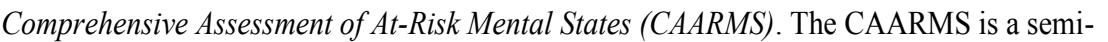
structured interview, which assesses the presence of positive psychotic symptoms (Yung et al., 2005; Ising et al., 2012) risk of developing a psychotic disorder. This classification is made in case of past year reduced social functioning, combined with the presence of attenuated psychotic symptoms or the presence of a psychotic disorder in first degree relatives.

16 was used to assess self reported psychotic symptoms (Loewy et al., 2011; Ising et al., 2012). The questionnaire consists of 16 items (e.g., "I have heard things other people can't hear like voices of people whispering or talking"), which are dichotomously scored (False $=0$ or True $=1$ ). Total scores range from 0 to 16 . 


\section{Chapter IV}

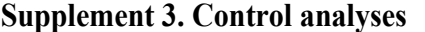

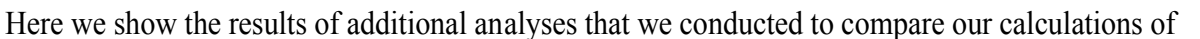

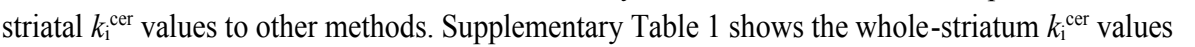

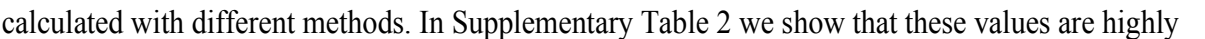

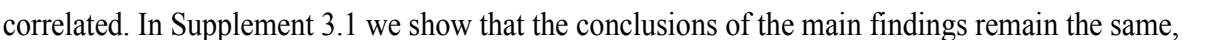

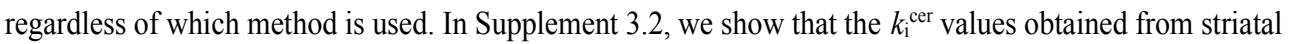

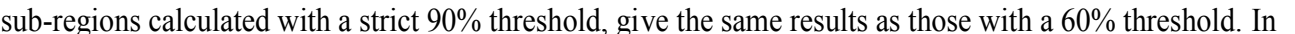

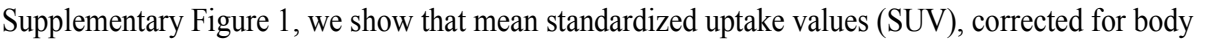

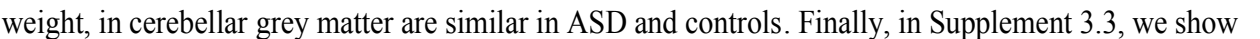

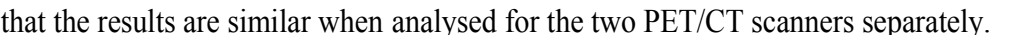
$\square$ 


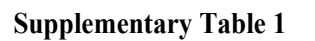

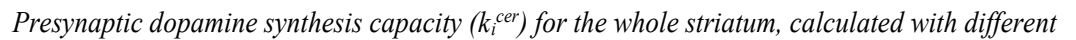
$\square \square\|\|\|\|$

\begin{tabular}{|c|c|c|c|}
\hline 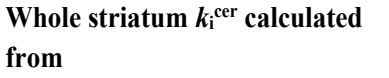 & $\square \square \square \square$ & 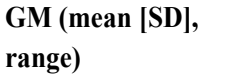 & 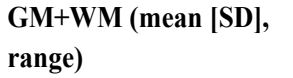 \\
\hline \multirow[t]{2}{*}{ 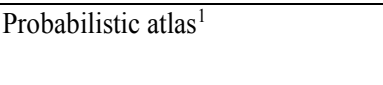 } & $\begin{array}{c}\square \square \square \\
\square \square\end{array}$ & 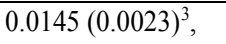 & 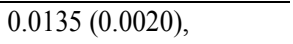 \\
\hline & & 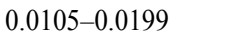 & $\square \square \|-\square \square \square \square$ \\
\hline \multirow[t]{2}{*}{$\square$} & 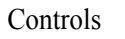 & 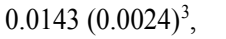 & 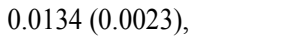 \\
\hline & & $\square \| \square-\square \square \square \square$ & $\square\|\square-\square\| \square$ \\
\hline 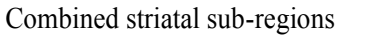 & प्णि & 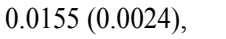 & 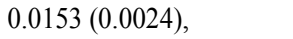 \\
\hline एயम & & $\square \square \square-\square \square \square \square$ & $\square \square \square-\square \square \square \square$ \\
\hline \multirow[t]{2}{*}{$\square$} & 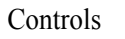 & 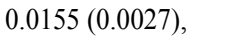 & 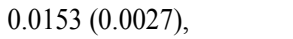 \\
\hline & & 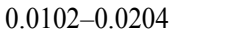 & $\square[11-\square \square \square \square$ \\
\hline 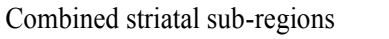 & प्णि & 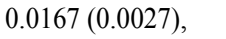 & 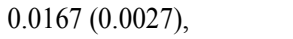 \\
\hline 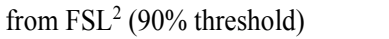 & & $\square \square \square-\square \square \square \square$ & $\square \square \square-\square \square \square \square$ \\
\hline \multirow[t]{2}{*}{$\square$} & 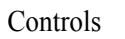 & 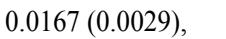 & 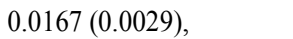 \\
\hline & & 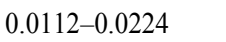 & $\square\|\|-\square\|\| \square$ \\
\hline
\end{tabular}

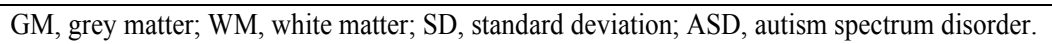

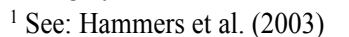

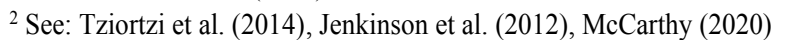

As reported in the main article. $\square$

$\square$

$\square$

$\square$ 


\section{Chapter IV}

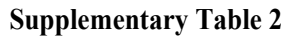

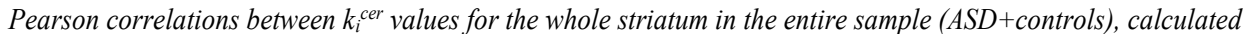

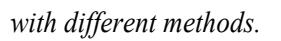

\begin{tabular}{|c|c|c|c|c|c|c|}
\hline 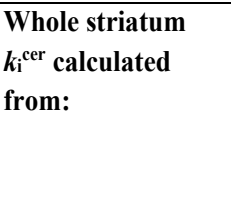 & 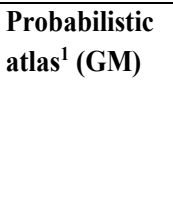 & 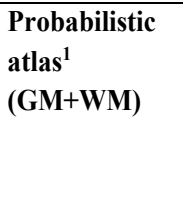 & 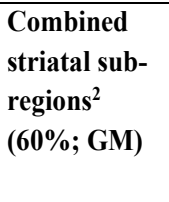 & 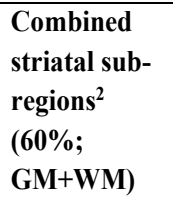 & 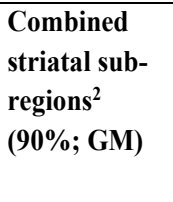 & 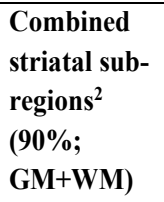 \\
\hline 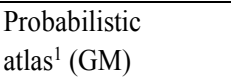 & $\square$ & $\square$ & $\square$ & $\square$ & $\square$ & $\square$ \\
\hline 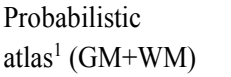 & 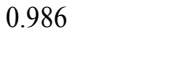 & $\square$ & $\square$ & $\square$ & $\square$ & $\square$ \\
\hline 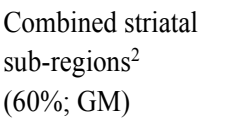 & पणा & पण口प & $\square$ & $\square$ & $\square$ & $\square$ \\
\hline 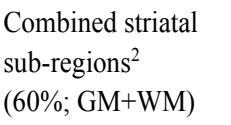 & पामा & 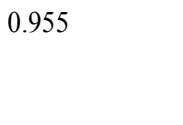 & पणाए & $\square$ & $\square$ & $\square$ \\
\hline 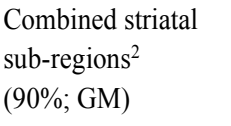 & 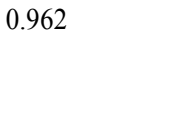 & पण口प & 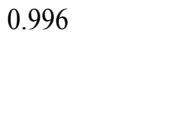 & $\square \square \square \square$ & $\square$ & $\square$ \\
\hline 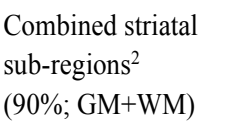 & पण口 & पण口 & पाणए & पणाए & पाएण & $\square$ \\
\hline
\end{tabular}

ASD, autism spectrum disorder; $\square \square \square(\mathrm{m} \| \mathrm{y}$ matter; WM, white matter. $\square$

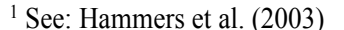

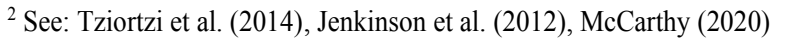

$\square$

$\square$

$\square$ 


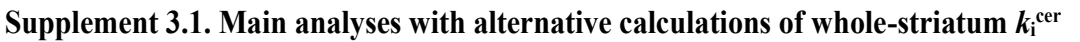

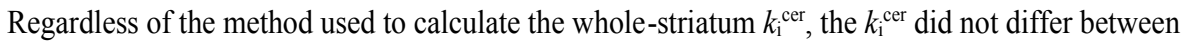

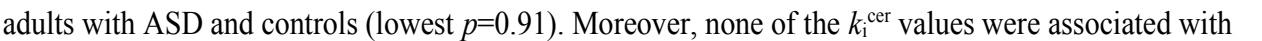

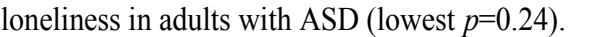
$\square$

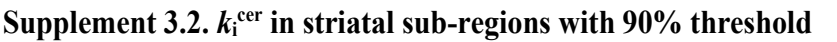

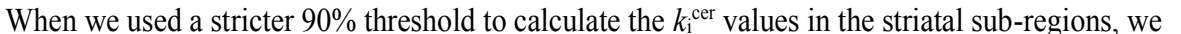

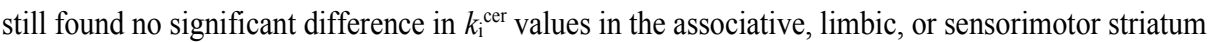

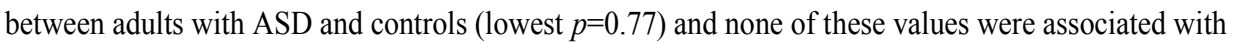

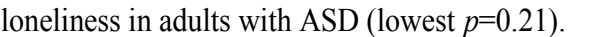
$\square$ 


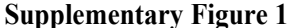

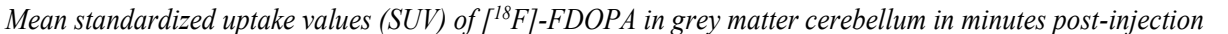

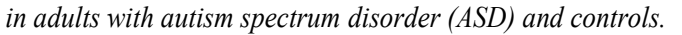

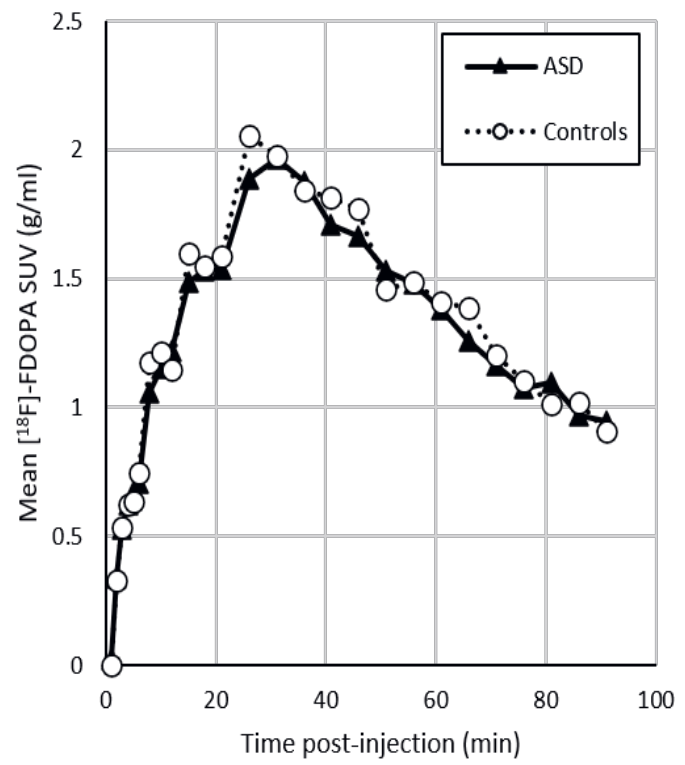




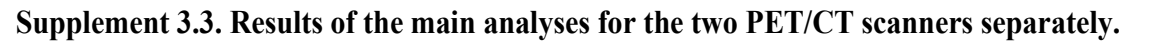

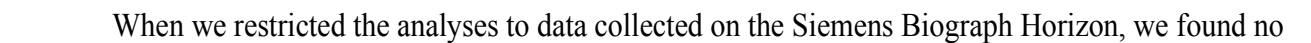

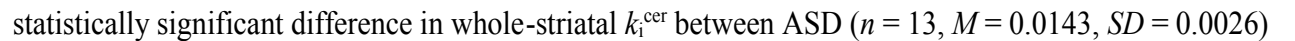

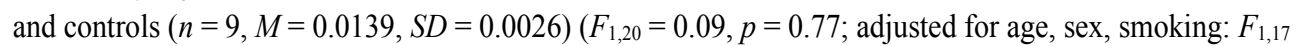

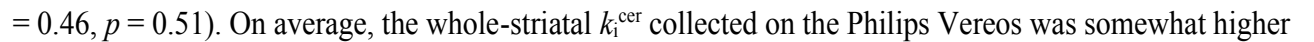

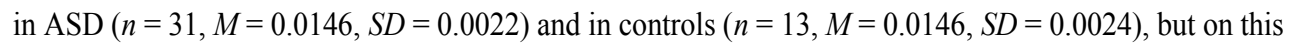

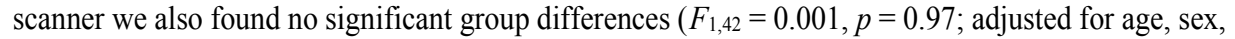

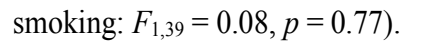

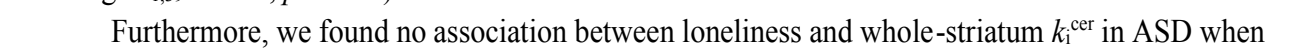

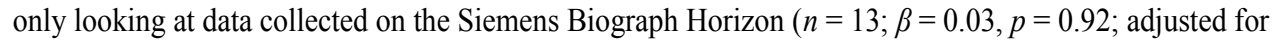

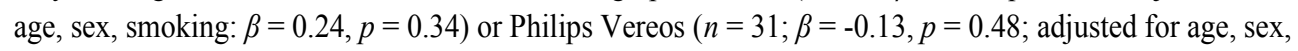

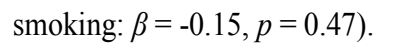




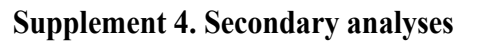

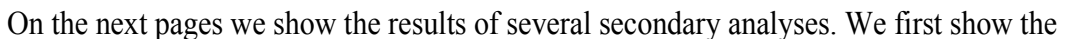

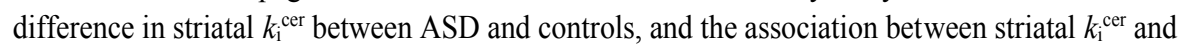
ए

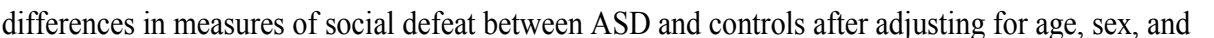

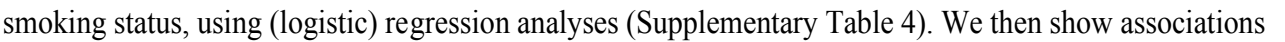
पाther measures of social defeat in ASD (Supplementary Table 5; Supplementary Figure 2) and controls (Supplementary Table 6; Supplementary Figures 3 and 4). We t $\square \square \square \square \square$

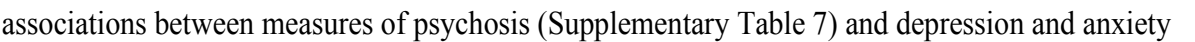

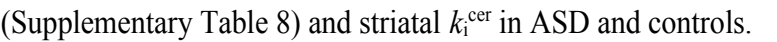




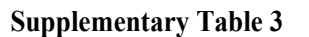

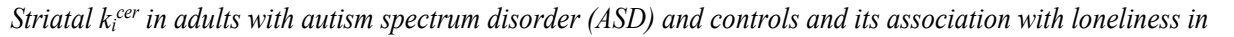

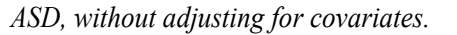

\begin{tabular}{|c|c|}
\hline पणापापाण & 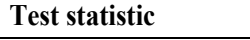 \\
\hline 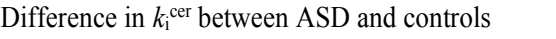 & $\square$ \\
\hline 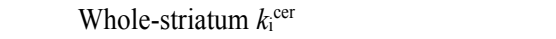 & 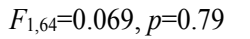 \\
\hline 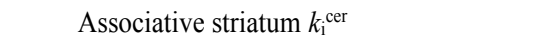 & 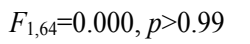 \\
\hline 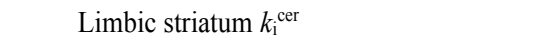 & 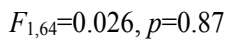 \\
\hline 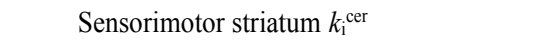 & 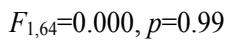 \\
\hline 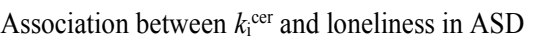 & $\square$ \\
\hline 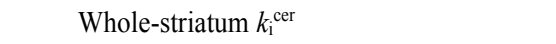 & 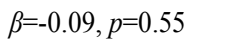 \\
\hline 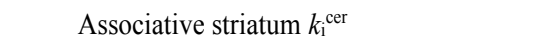 & 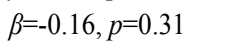 \\
\hline 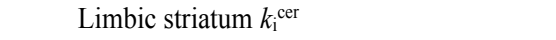 & 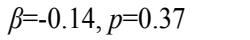 \\
\hline 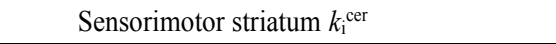 & 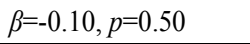 \\
\hline
\end{tabular}

$\square$

$\square$ 


\section{Chapter IV}

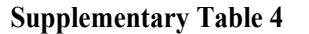

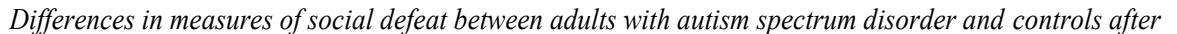

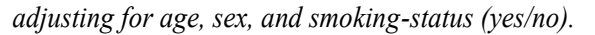

\begin{tabular}{|c|c|}
\hline पपाणापाण & 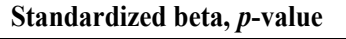 \\
\hline 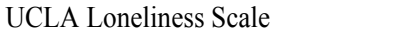 & 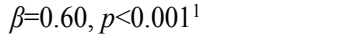 \\
\hline प००० & 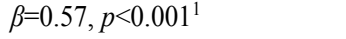 \\
\hline 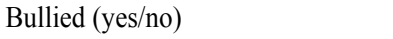 & 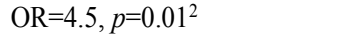 \\
\hline 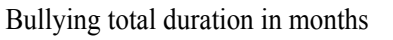 & 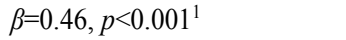 \\
\hline $\begin{array}{ll}\square \square \square \\
\end{array}$ & 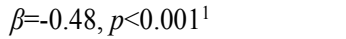 \\
\hline प्म०० & 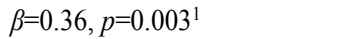 \\
\hline$\square \square \square \square$ & 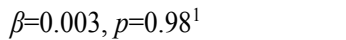 \\
\hline पाप्रा & 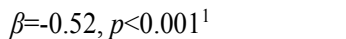 \\
\hline
\end{tabular}

OES, Ostracism Experience Scale; LSNS, Lubben Social Network Scale; CTQ, Childhood Trauma

Questionnaire; NBS, Need to Belong Scale; ISEL, Interpersonal Support Evaluation List; OR, odds ratio. $\square$

Multivariable linear regression analysis.

Multivariable logistic regression analysis. $\square$

미 


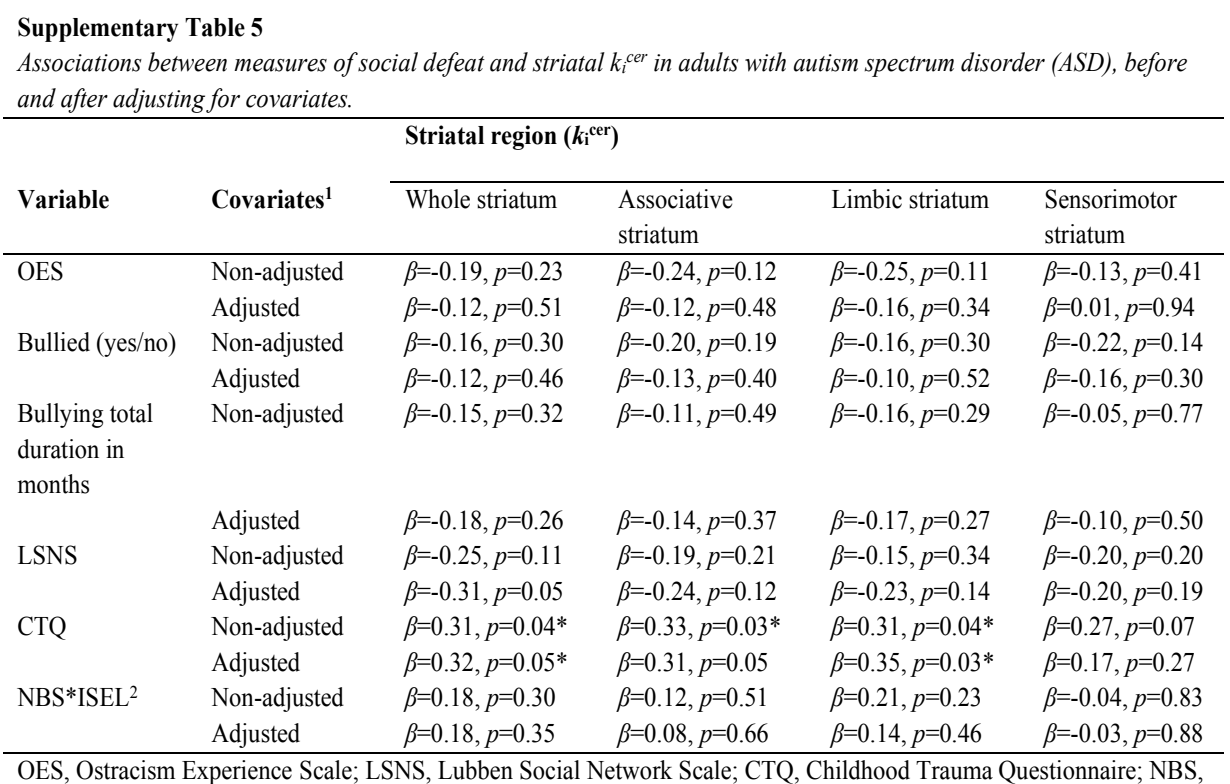

Need to Belong Scale; ISEL, Interpersonal Support Evaluation List; NBS*ISEL, interaction between the two variables. $\square$

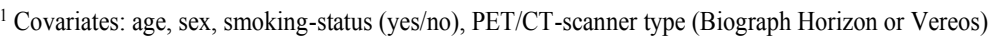

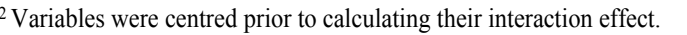

पाणाणाणा 


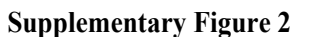

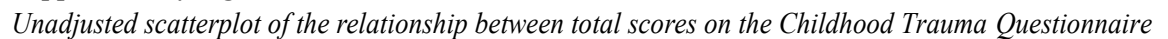

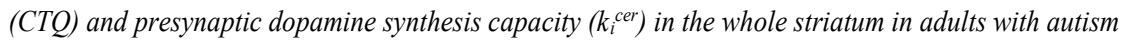

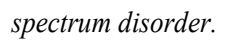

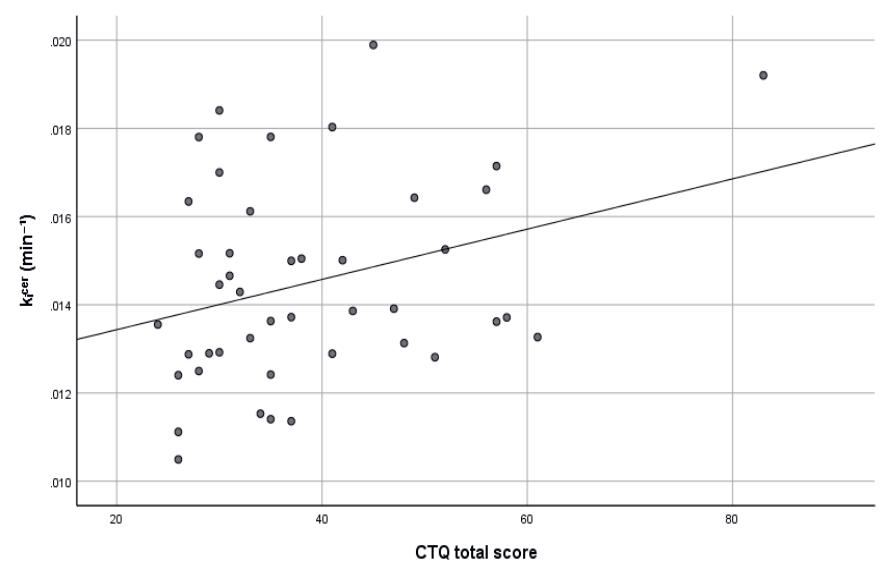

$\square$ 


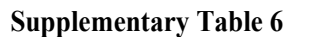

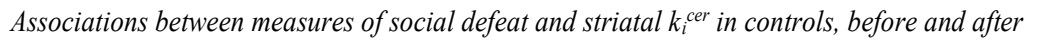

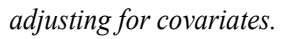

\begin{tabular}{|c|c|c|c|c|c|}
\hline \multirow{2}{*}{ 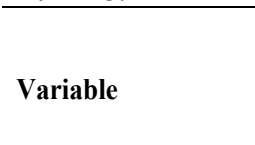 } & \multirow{2}{*}{$\begin{array}{l}\square \\
\square \square ण\|ण\|^{\square}\end{array}$} & \multicolumn{4}{|c|}{ 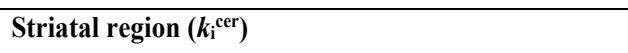 } \\
\hline & & 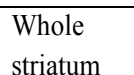 & 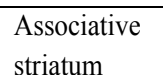 & 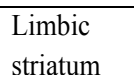 & 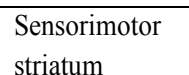 \\
\hline 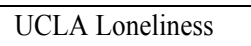 & 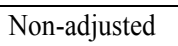 & 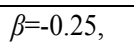 & 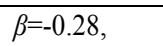 & 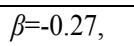 & 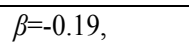 \\
\hline पाणा & & एणाए & एवाण & पणणए & पणाए \\
\hline \multirow[t]{2}{*}{$\square$} & 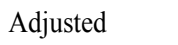 & $\beta \square \square \| ा \square \square$ & 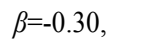 & $\beta \square \square\|ा\| \square$ & 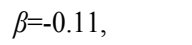 \\
\hline & & एपाए & पाणा & एपाए & पाणा \\
\hline प्सा & 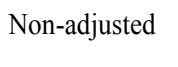 & 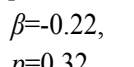 & 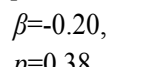 & 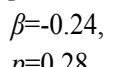 & 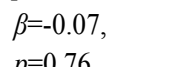 \\
\hline \multirow[t]{2}{*}{$\square$} & 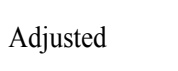 & $\beta \square \square$ पाणाणा & $\beta \square$ एवाणाए & 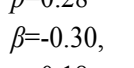 & 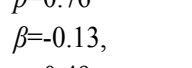 \\
\hline & & एपाए & एप⿴囗十 & एणाए & एपणा \\
\hline 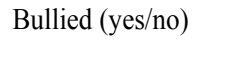 & 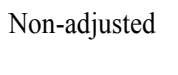 & 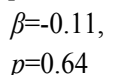 & 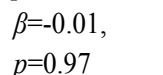 & 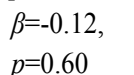 & 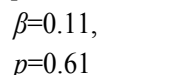 \\
\hline$\square$ & 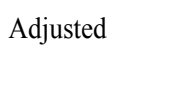 & 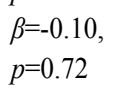 & 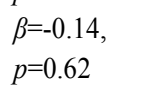 & 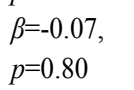 & 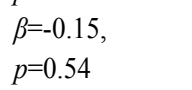 \\
\hline 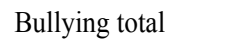 & பாயாயण & 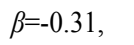 & 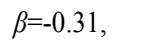 & 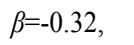 & 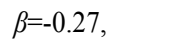 \\
\hline एणாயாயாயण & & एणाए & एणाए & एवाण & पाणाए \\
\hline$\square$ & 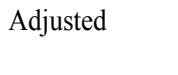 & $\begin{array}{l}\beta \square\|\| \| \square \square \\
\square \square \| \square \square\end{array}$ & 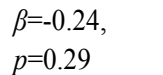 & 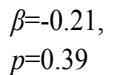 & 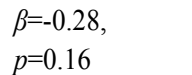 \\
\hline \multirow[t]{2}{*}{ 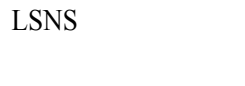 } & 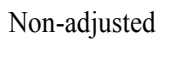 & $\beta \square \square \square \square \square$ & $\beta \square \square \| ा \square$ & $\beta \square \square \square \square \square$ & $\beta \square \square \square \square$ \\
\hline & & $\square \square \square$ & $\square \square \square$ & $\square \square \square$ & $\square \square \square$ \\
\hline$\square$ & 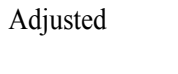 & $\begin{array}{l}\beta \square \square \square \square \square \\
\square \square \square \square \square\end{array}$ & 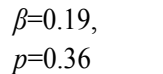 & 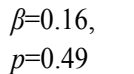 & 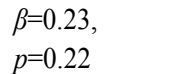 \\
\hline प्य० & 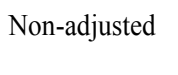 & 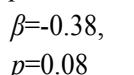 & 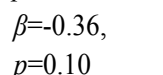 & 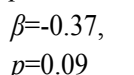 & $\beta$ \\
\hline \multirow[t]{2}{*}{$\square$} & 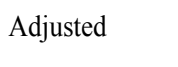 & $\beta \square \square$ वाणाण & 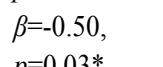 & 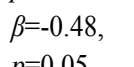 & 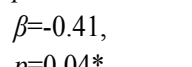 \\
\hline & & घणाए & एवाण & एणाए & एवण \\
\hline 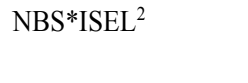 & 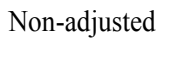 & 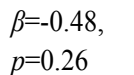 & 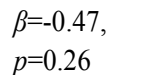 & 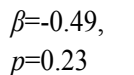 & 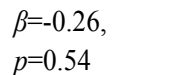 \\
\hline$\square$ & 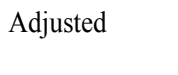 & 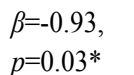 & 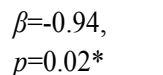 & 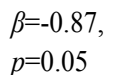 & 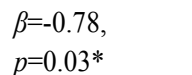 \\
\hline
\end{tabular}

OES, Ostracism Experience Scale; LSNS, Lubben Social Network Scale; CTQ, Childhood

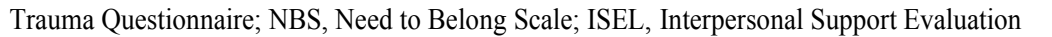
पाताII)

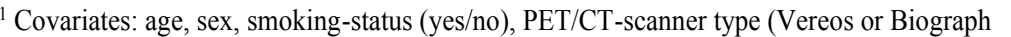

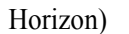

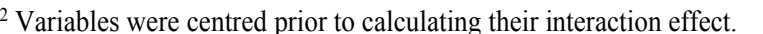
पाणाणाणा

$\square$ 


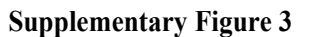

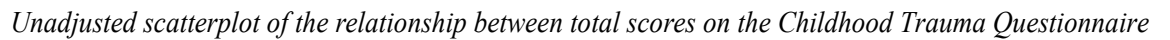

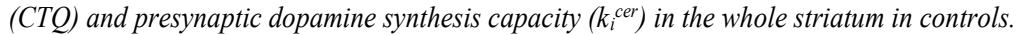

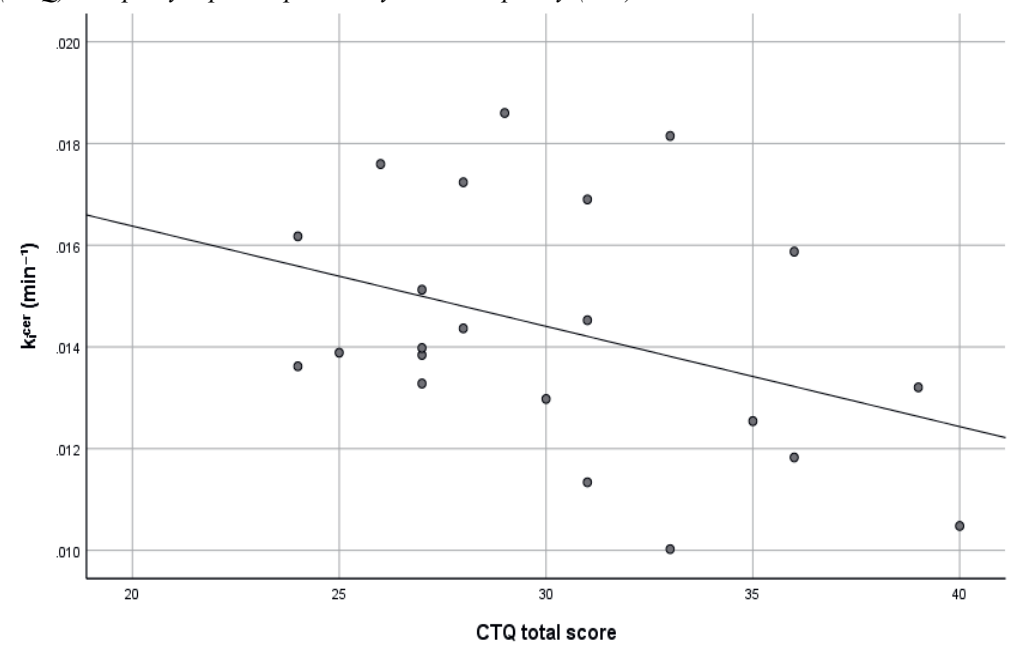

$\square$

$\square$ 


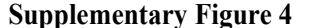

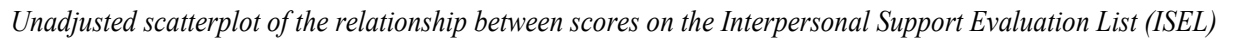

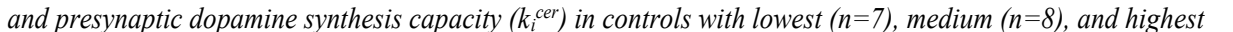

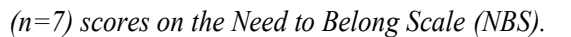

$\square$

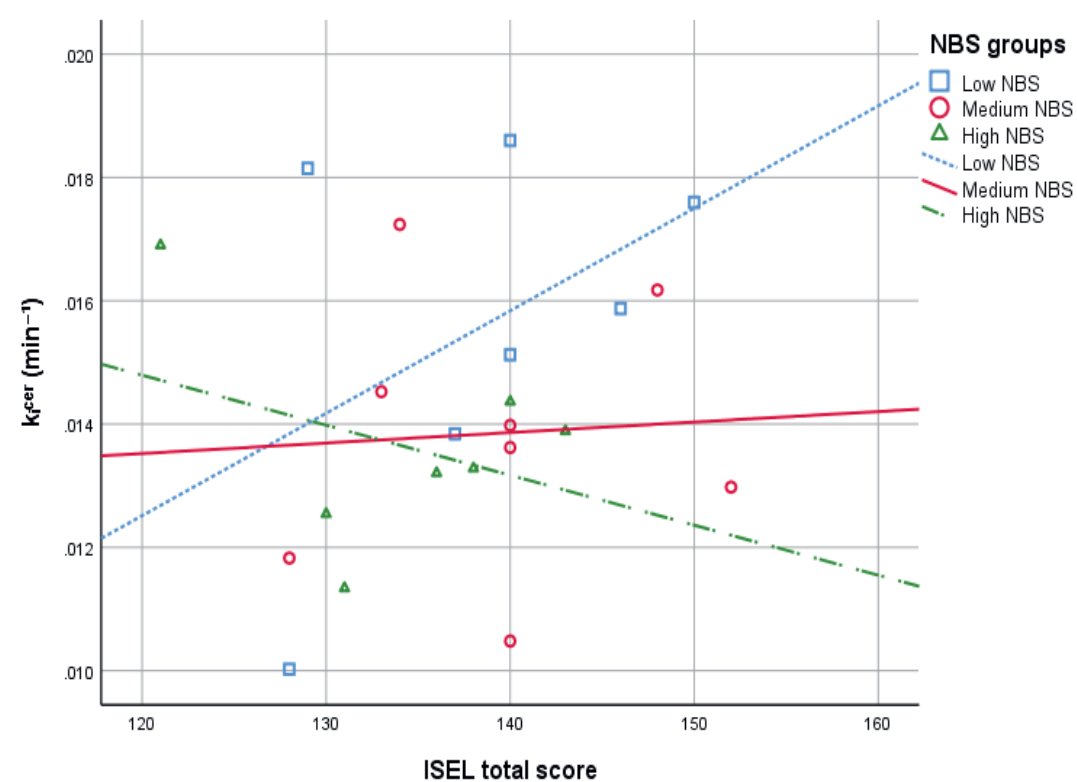




\section{Chapter IV}

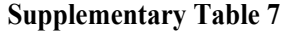

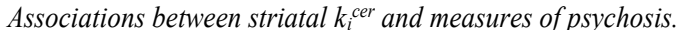

\begin{tabular}{|c|c|c|c|c|c|}
\hline \multirow{2}{*}{ 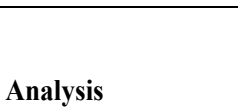 } & \multirow{2}{*}{ 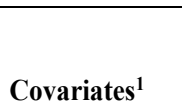 } & \multicolumn{4}{|c|}{ 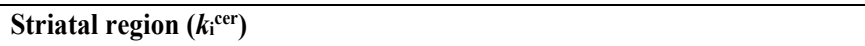 } \\
\hline & & 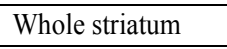 & 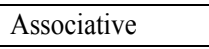 & 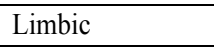 & 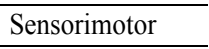 \\
\hline 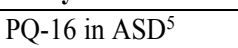 & 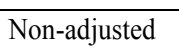 & 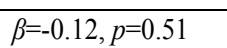 & 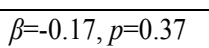 & 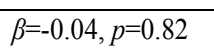 & 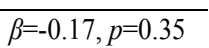 \\
\hline$\square$ & पणमणण & 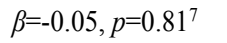 & 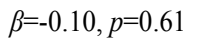 & 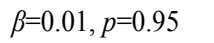 & 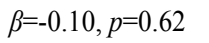 \\
\hline 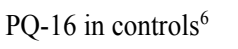 & पमाणाणाए & 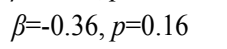 & 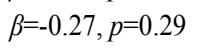 & 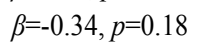 & 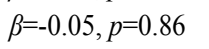 \\
\hline$\square$ & पणमणणा & 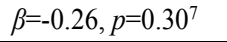 & 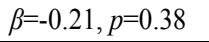 & 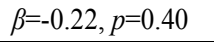 & 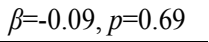 \\
\hline
\end{tabular}

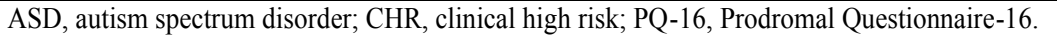

Covariates: age, sex, smoking status (yes/no), PET/CT scanner type (Vereos or Biograph Horizon)

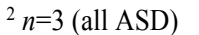

पापएए

पाणए।

पापएए

पाणए।

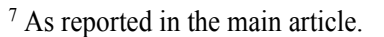
$\square$

$\square$ 


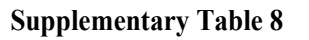

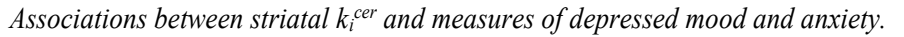

\begin{tabular}{|c|c|c|c|c|}
\hline \multirow{2}{*}{$\begin{array}{l}\square \\
\square \square \square|m| \square \square\end{array}$} & \multirow{2}{*}{$\begin{array}{l}\square \\
\square \square\|\|\|\| \|^{\square}\end{array}$} & \multicolumn{3}{|l|}{ 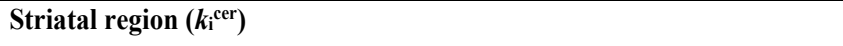 } \\
\hline & & 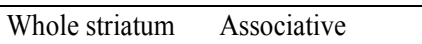 & पापाण & 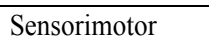 \\
\hline 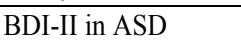 & 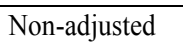 & 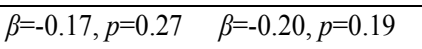 & 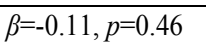 & 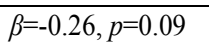 \\
\hline$\square$ & पणाणाए & 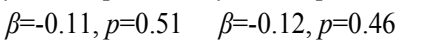 & 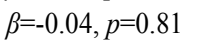 & 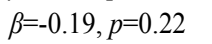 \\
\hline 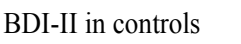 & 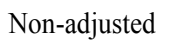 & 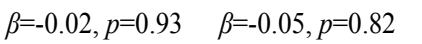 & 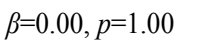 & 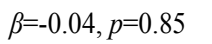 \\
\hline$\square$ & पणाणाण & 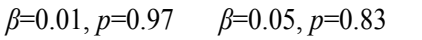 & 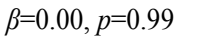 & 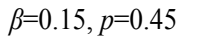 \\
\hline 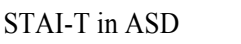 & 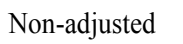 & 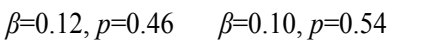 & 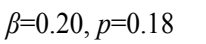 & 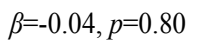 \\
\hline$\square$ & पणाणाए & 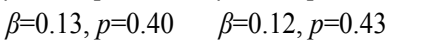 & 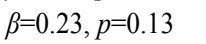 & 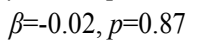 \\
\hline 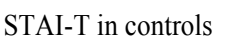 & 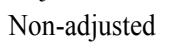 & 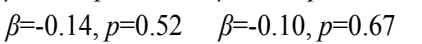 & 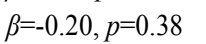 & 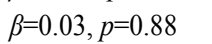 \\
\hline$\square$ & 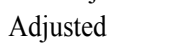 & 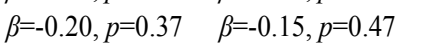 & 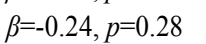 & 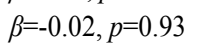 \\
\hline
\end{tabular}

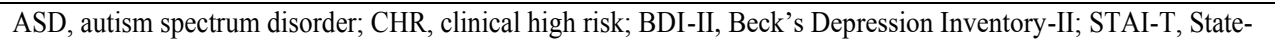

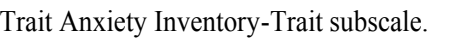

Covariates: age, sex, smoking status (yes/no), PET/CT scanner type (Vereos or Biograph Horizon) $\square$ 


\section{Chapter IV}

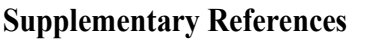

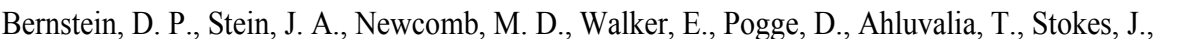

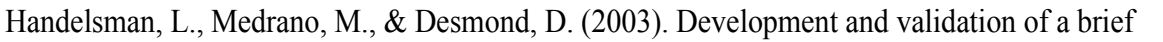

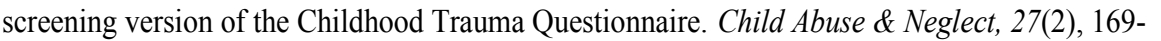
$\square 1 \mathrm{ll}$

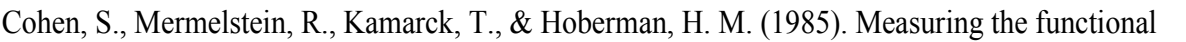

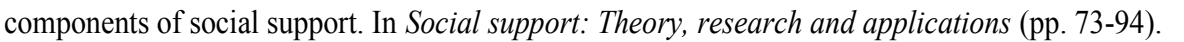

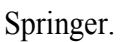

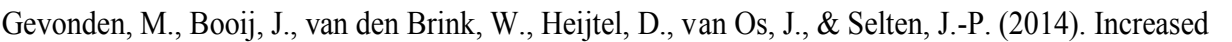

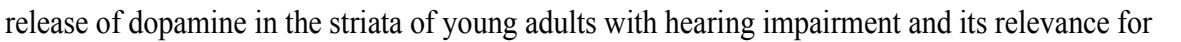
एण

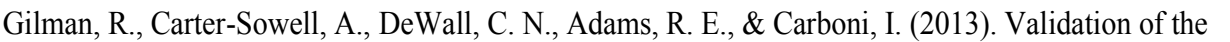

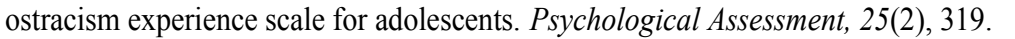

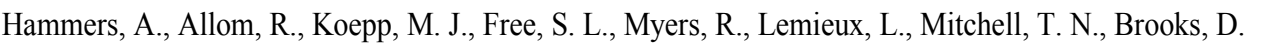

\section{$\square, \&$ Duncan, J. S. (2003). Three-dimensional maximum probability atlas of the human brain,}

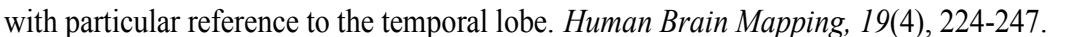

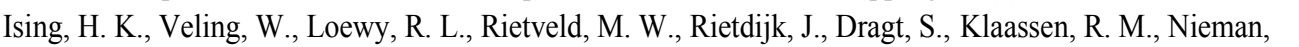

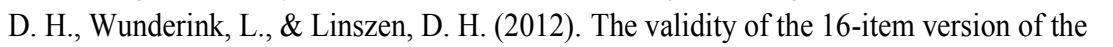

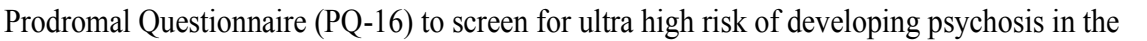

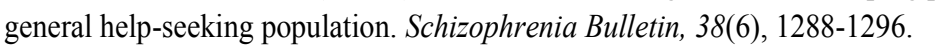

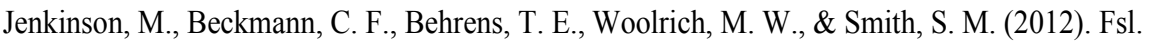

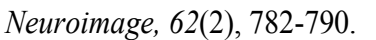

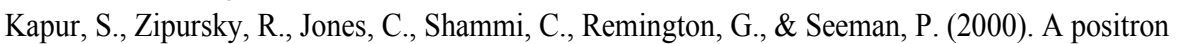

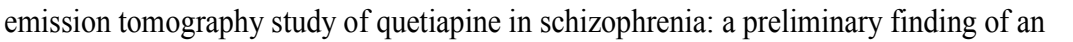

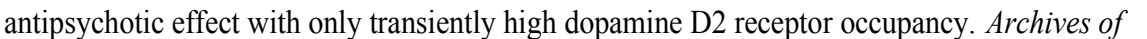

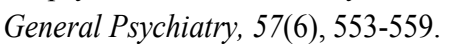

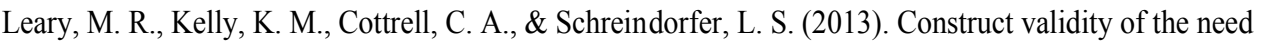

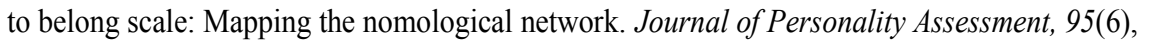

$\square 1 \| 1 \mathrm{~W}$

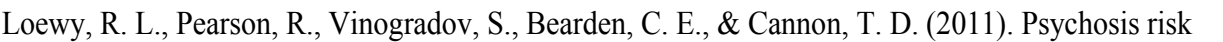

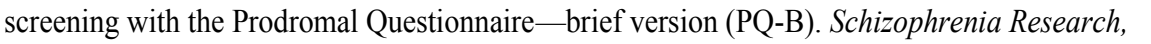

पाणाणाणाप

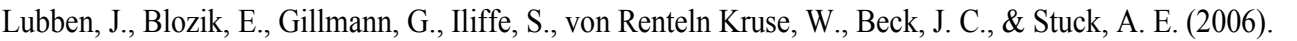

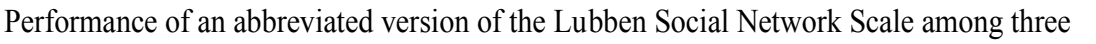

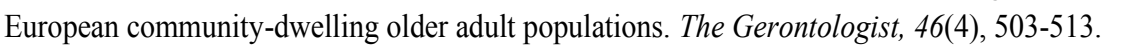

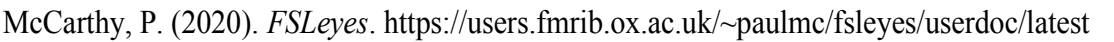

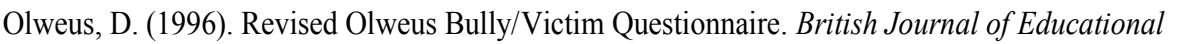

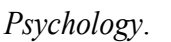

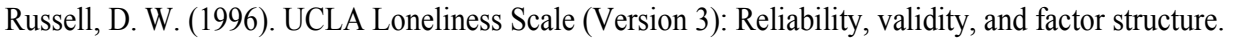

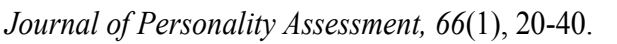

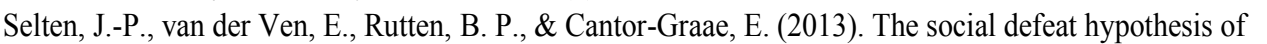

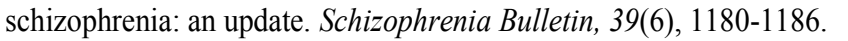




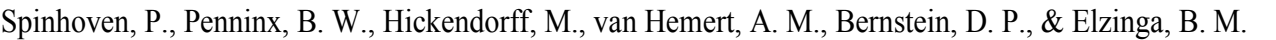

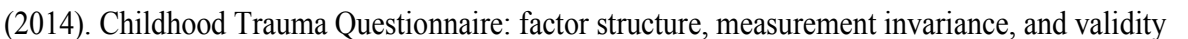

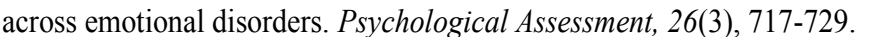

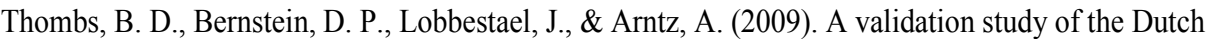

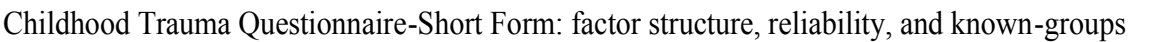

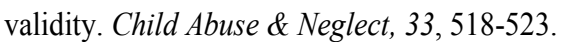

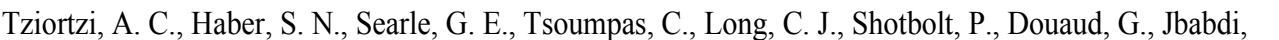

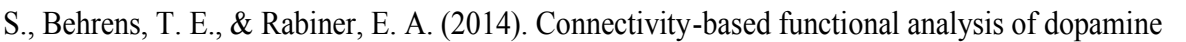

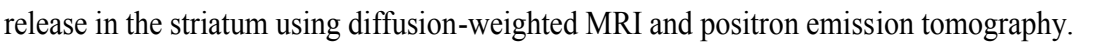

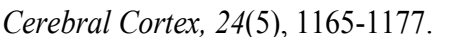

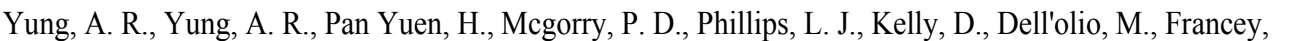

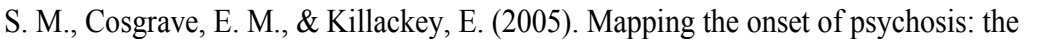

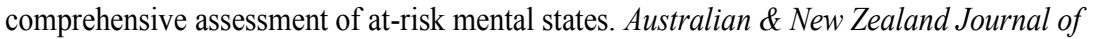

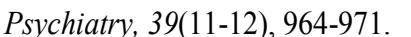




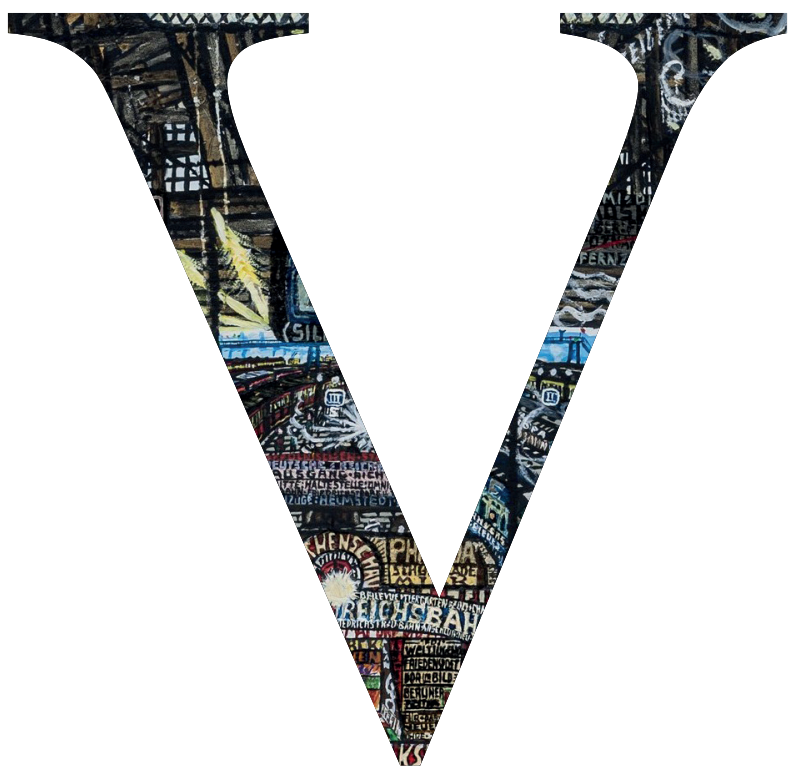




\section{Chapter V}

\section{Cerebral $\left[{ }^{18}\right.$ F]-FDOPA uptake in autism spectrum disorder and its association with autistic traits}

Schalbroeck, R., de Geus-Oei, L. F., Selten, J. P., Yaqub, M., Schrantee, A., van Amelsvoort, T., Booij, J., \& van Velden, F. H. P.

Manuscript submitted 


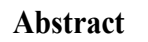

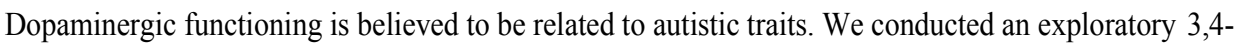

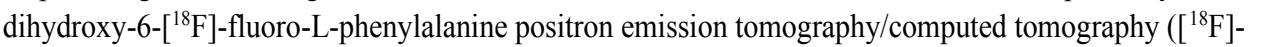

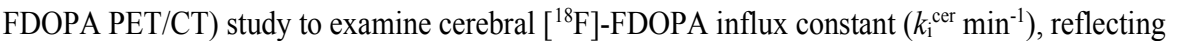

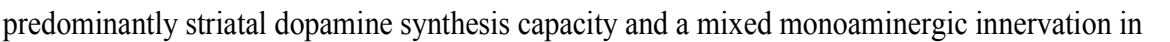

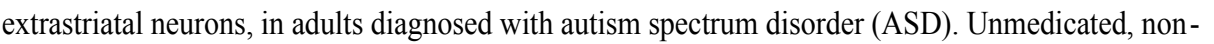

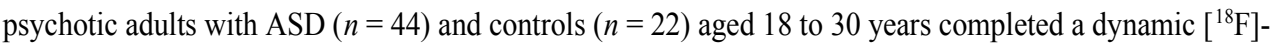

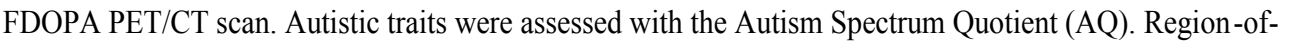

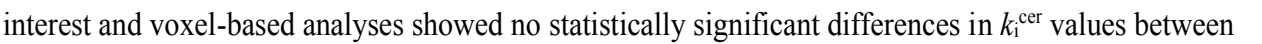

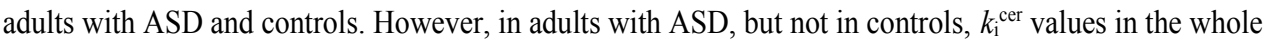

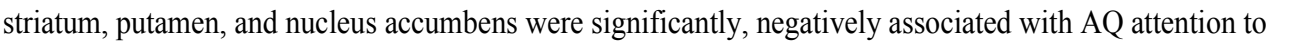

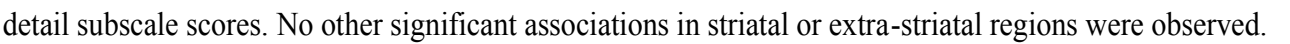
ए

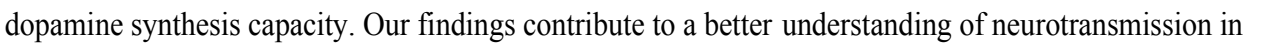

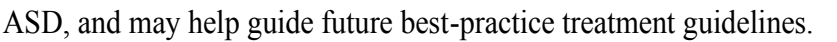

$\square$ 


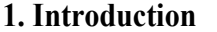

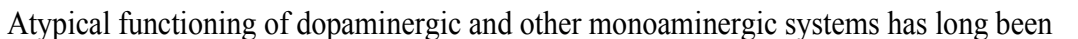

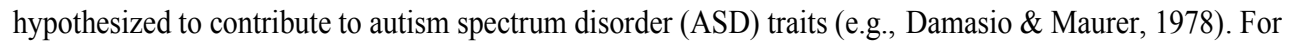

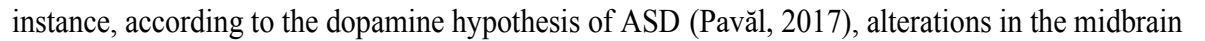

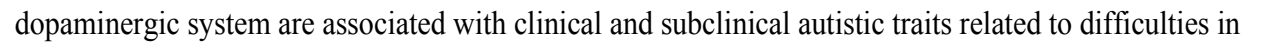

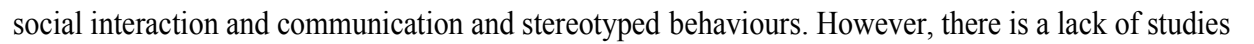

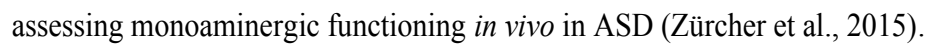

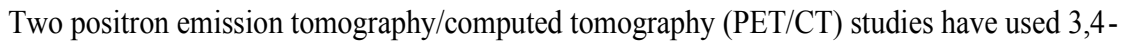

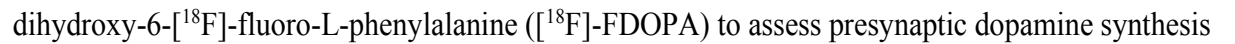

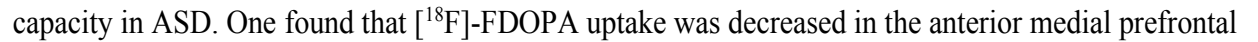

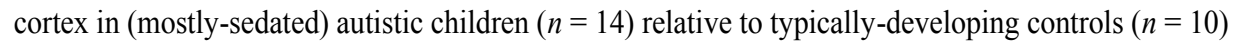

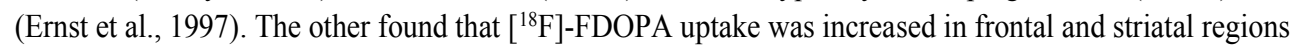
प

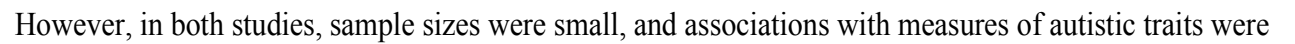

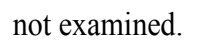

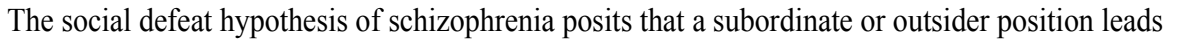

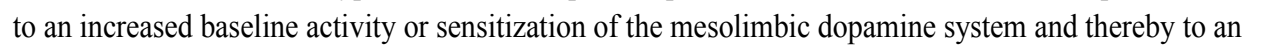

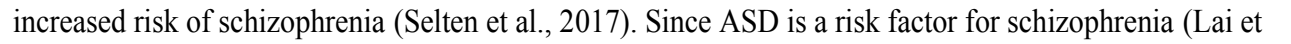

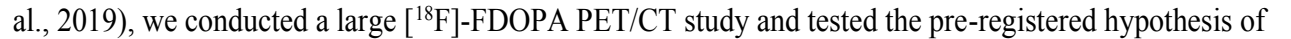

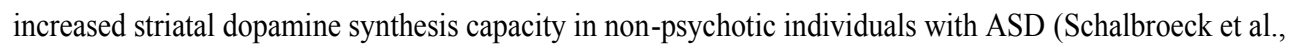

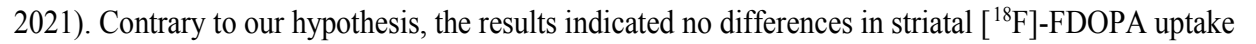

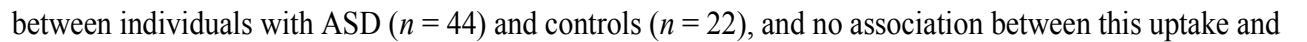

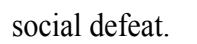

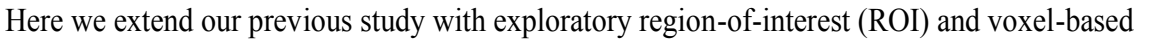

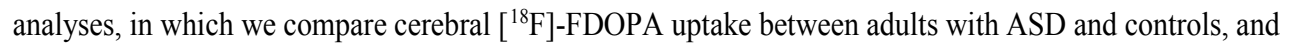

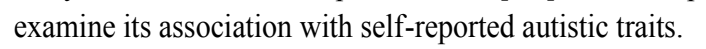
$\square$ 


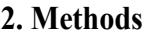

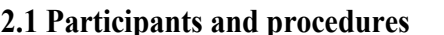

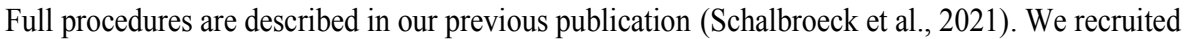

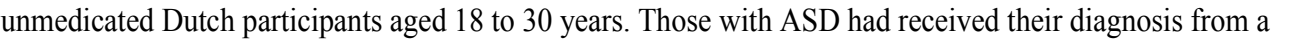

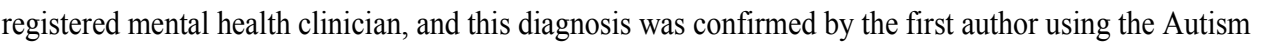

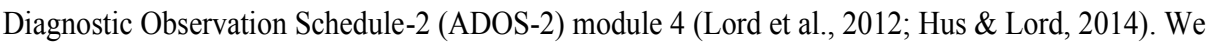
प्रा

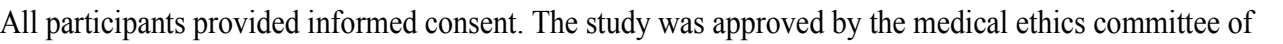

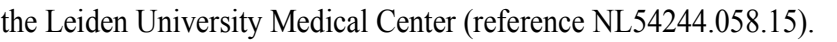

$\square$

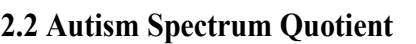

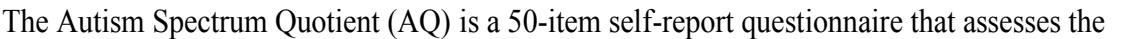

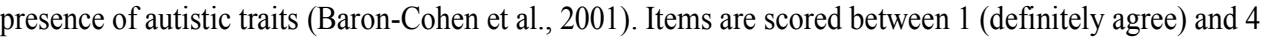

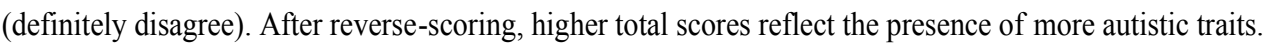

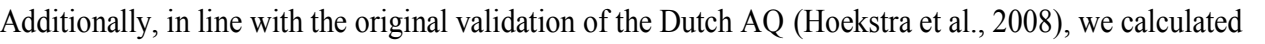
scores on the "social interaction" and "attention to detail" subscales. Higher scores on these subscales

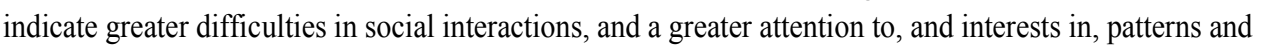

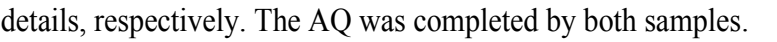
$\square$

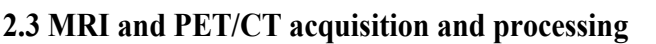

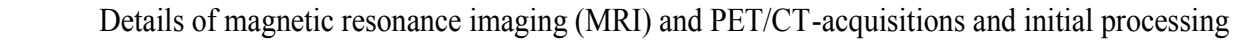

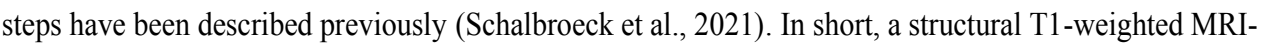

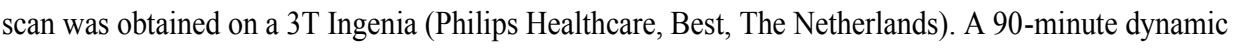

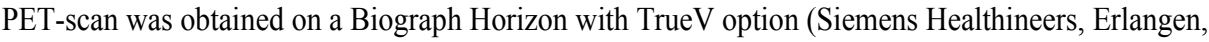
Germany) or Vereos (Philips Healthcare, Best, The Netherlands) directly after the administration of

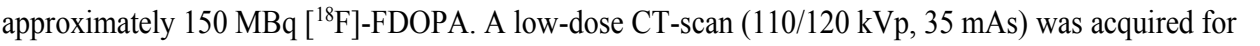

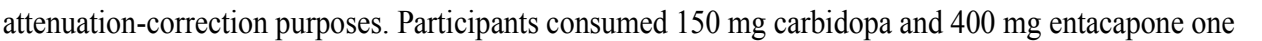

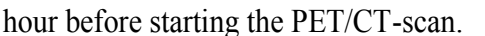

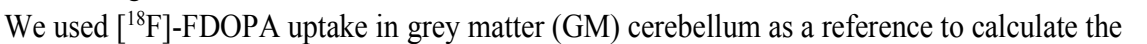

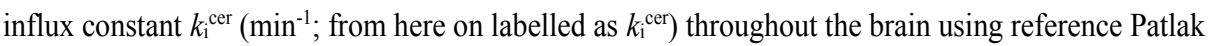

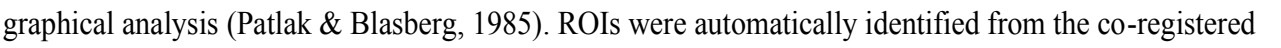

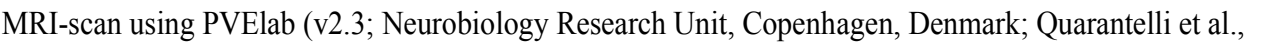

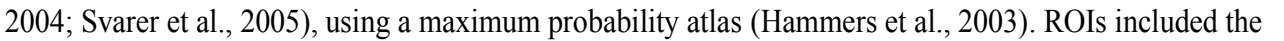

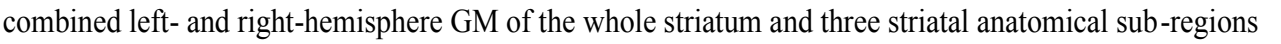

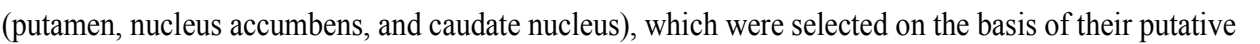

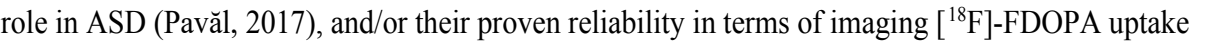

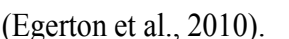

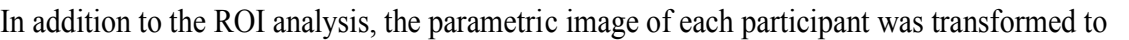

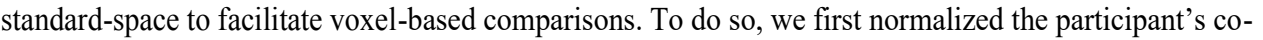

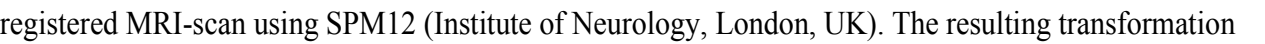

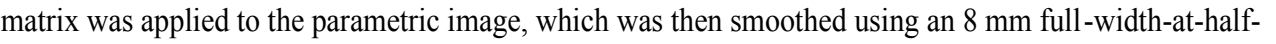

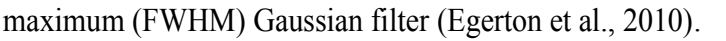




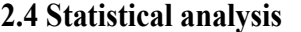

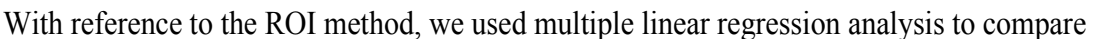

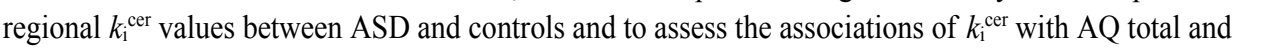

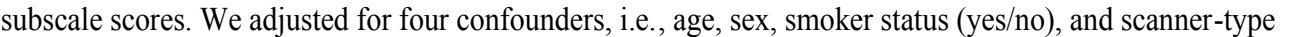

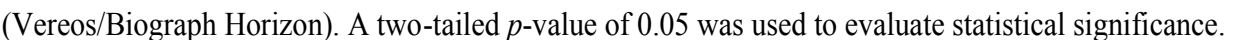

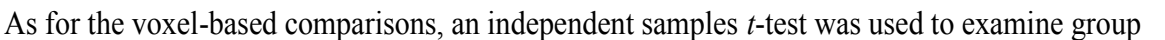

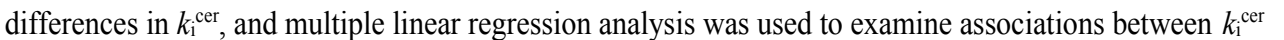

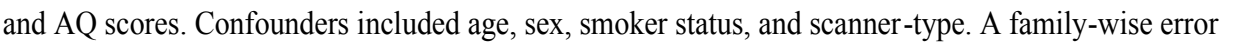
(FWE) rate of $\mathrm{a}=0.05$ was used to evaluate statistical s $\mathrm{m}$ प

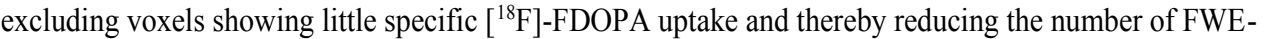

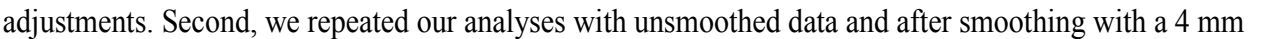

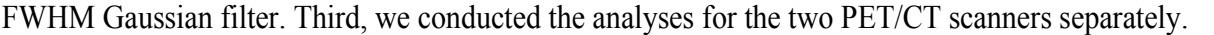




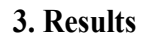

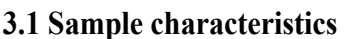

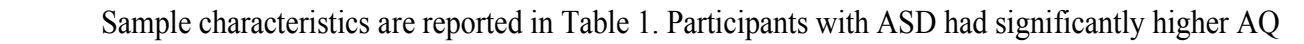

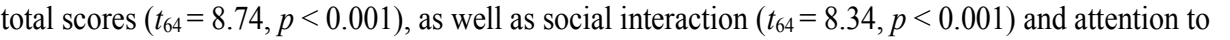

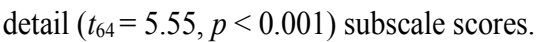

$\square$

$\square$

पापाणाए

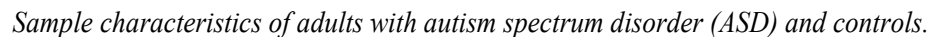

\begin{tabular}{|c|c|c|}
\hline 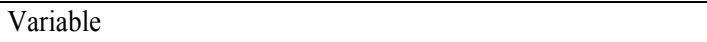 & 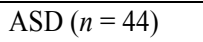 & 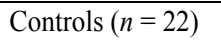 \\
\hline 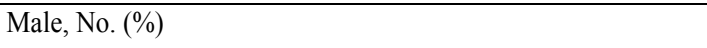 & $\square \square \square \square$ & $\square \square \square \square$ \\
\hline 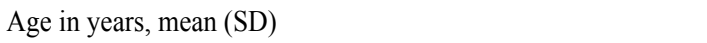 & पाणाणाणा & पाणाणाणा \\
\hline 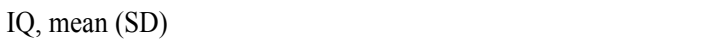 & 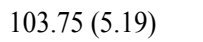 & पापा山ाणा \\
\hline 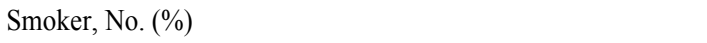 & 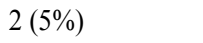 & $\square \square \square \square$ \\
\hline 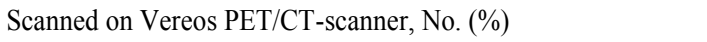 & $\square \square \square \square$ & 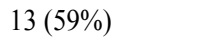 \\
\hline 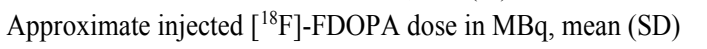 & 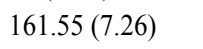 & पालापाणा \\
\hline 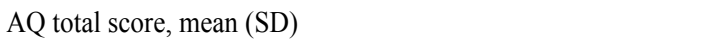 & पाणाणाणा & 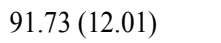 \\
\hline 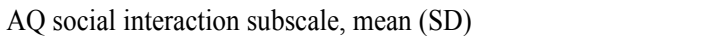 & एवाणाणाणा & 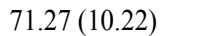 \\
\hline 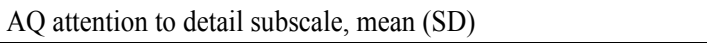 & पाणाणाणाण & पाणाणाणाण \\
\hline
\end{tabular}

SD, standard deviation; IQ, intelligence quotient; MBq, megabecquerel; AQ, Autism Spectrum Quotient. $\square$

$\square$

$\square$

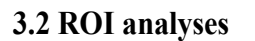

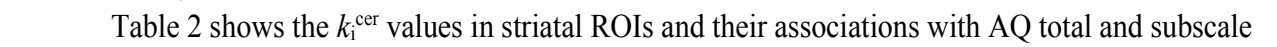

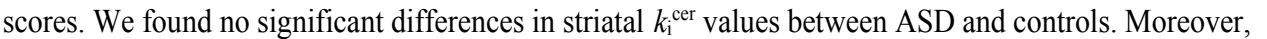

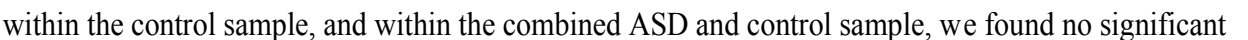

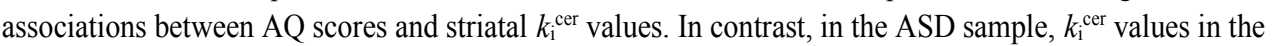

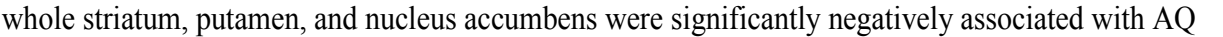

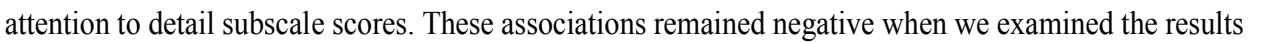

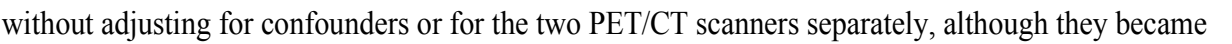

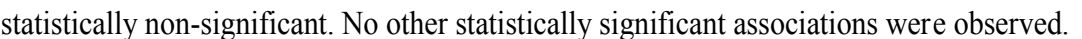




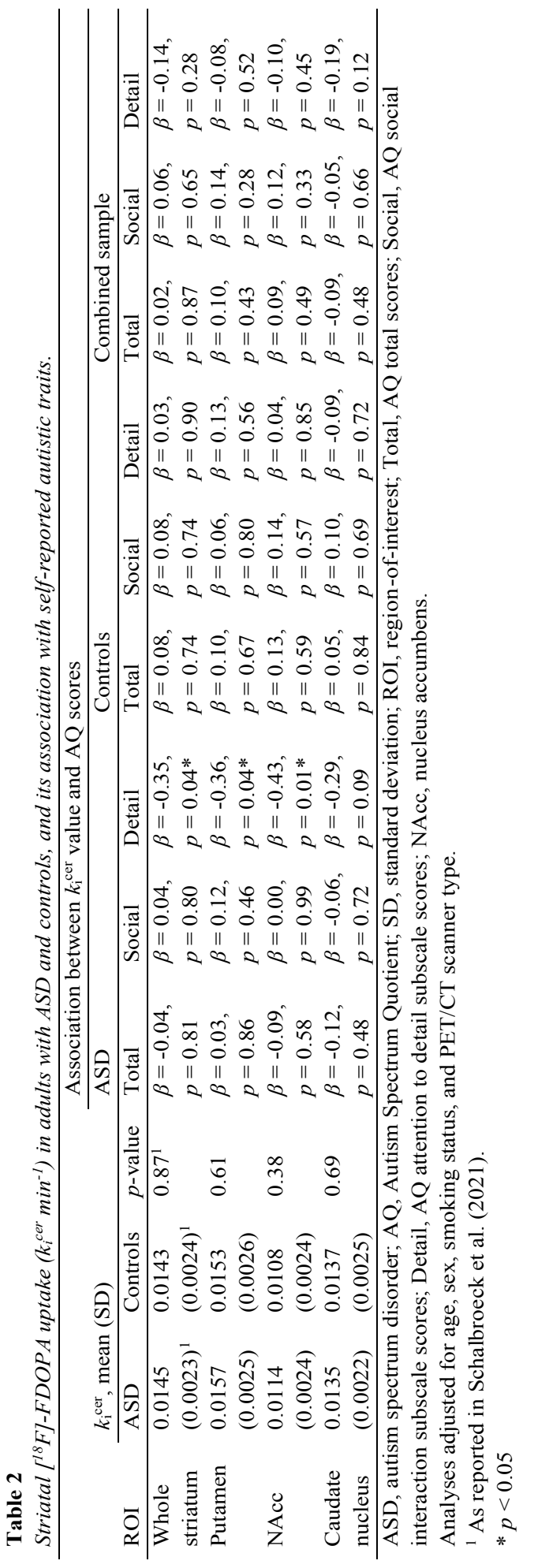




\section{Chapter V}

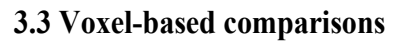

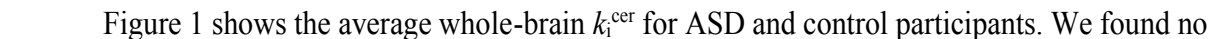

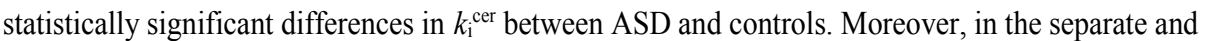

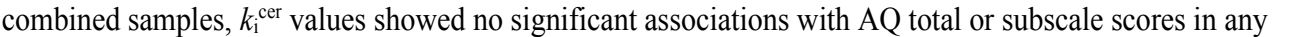

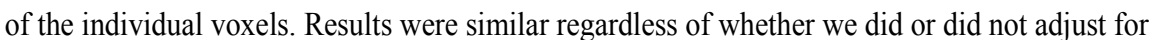

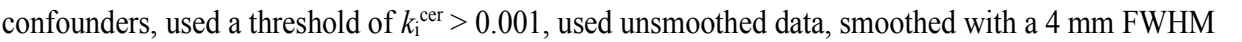

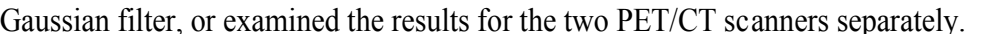

$\square$

पापणाण

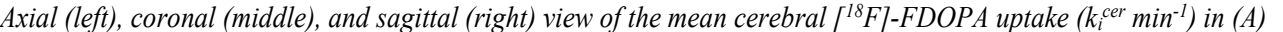
ए

$\square \square$

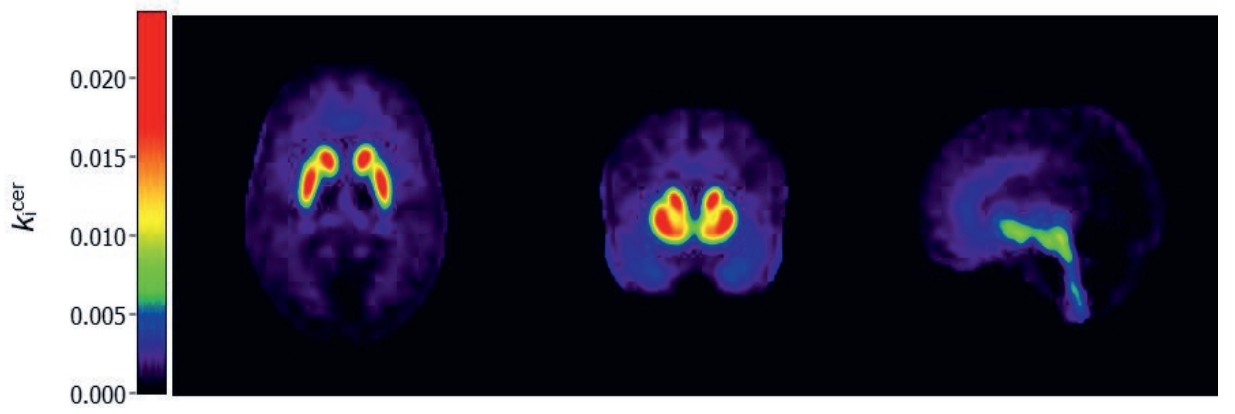

$\square$

$\square \square$

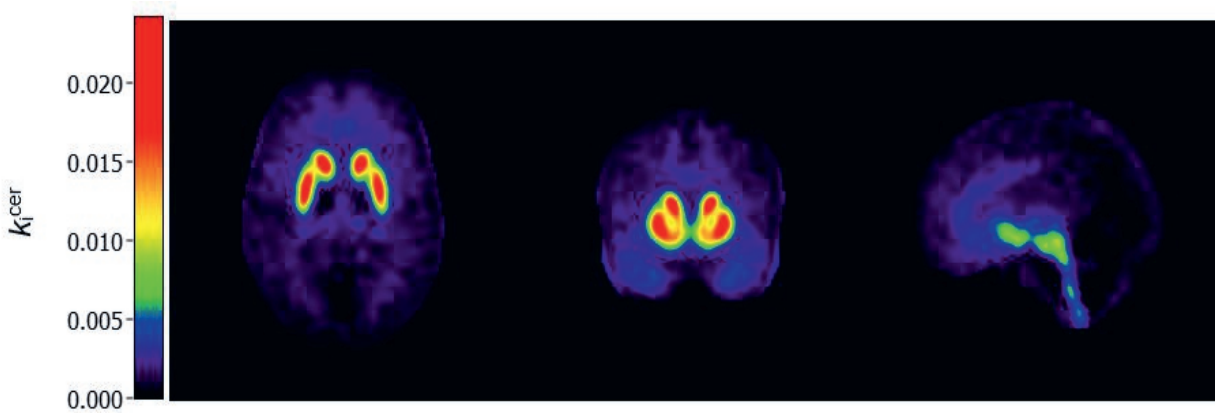

$\square$

$\square$

$\square$ 


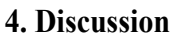

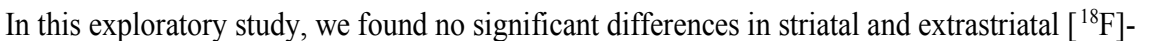

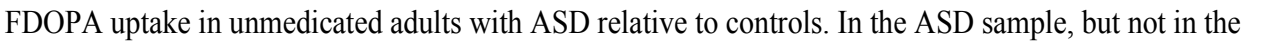

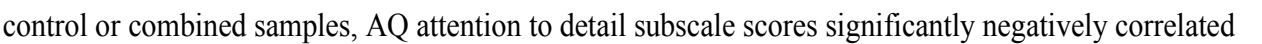

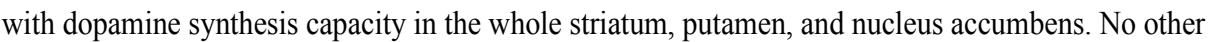

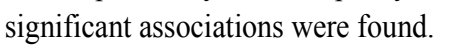

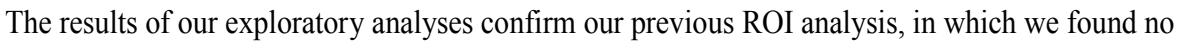

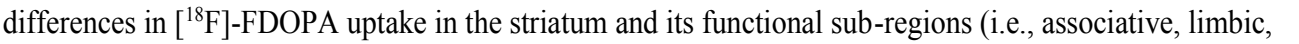

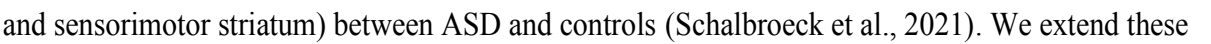

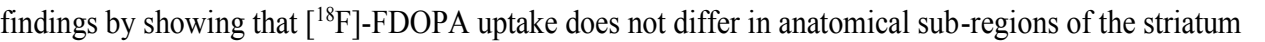

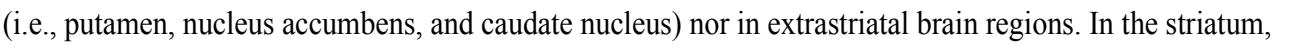

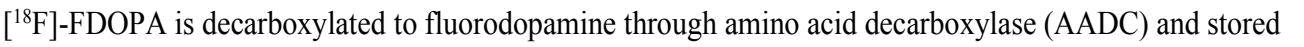
प

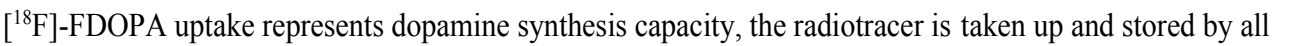

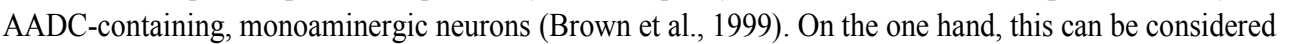

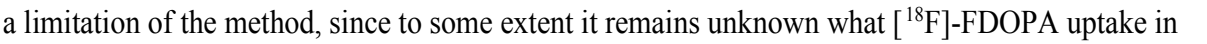

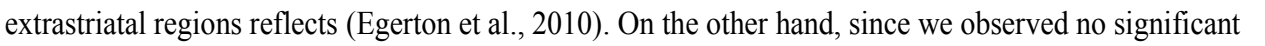

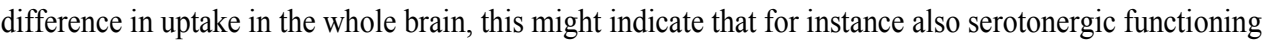

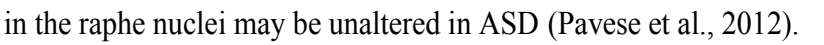

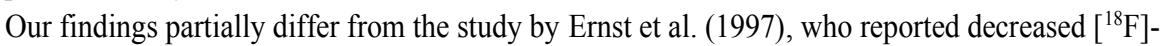

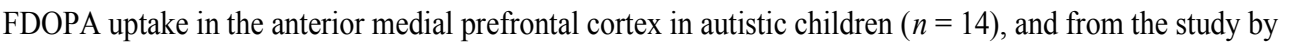

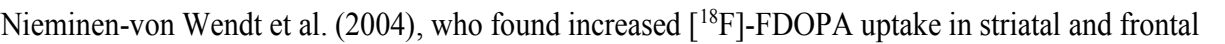

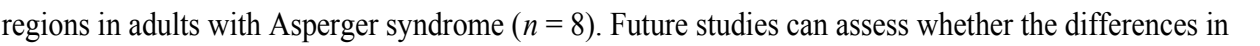

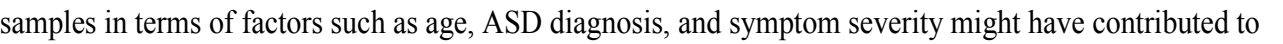

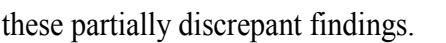

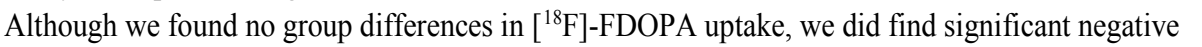

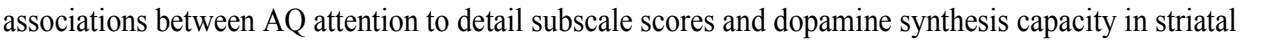

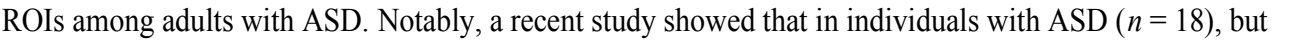
प

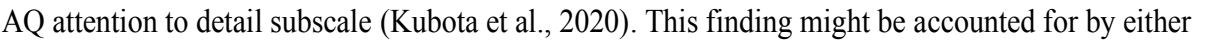

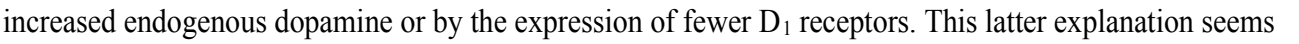

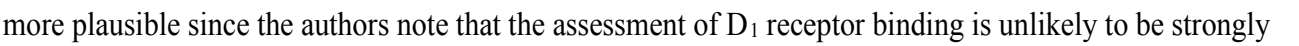

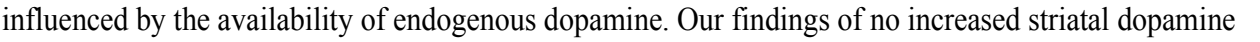

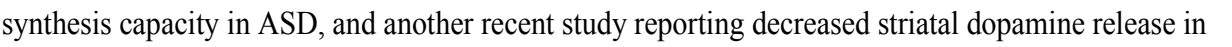

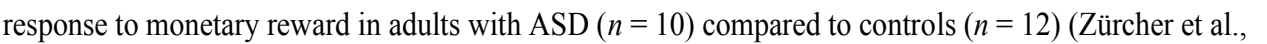

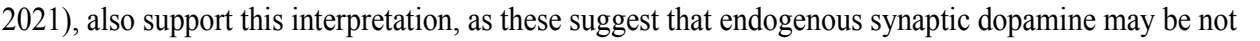

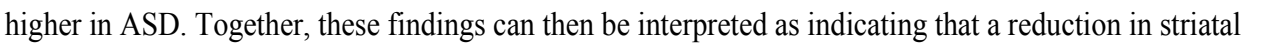

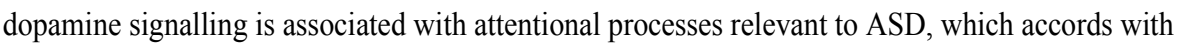

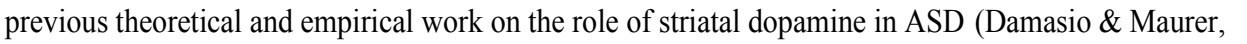
1978; Fuccillo, 2016; Pavăl, 2017) $\square$

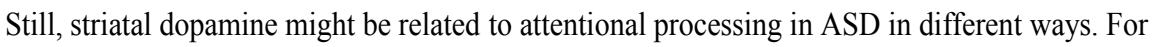

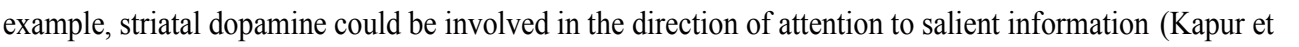

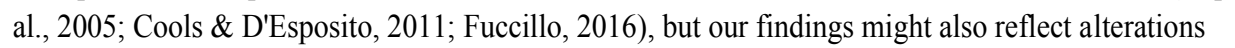

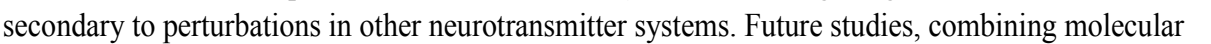




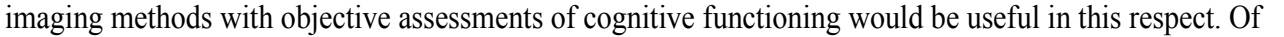

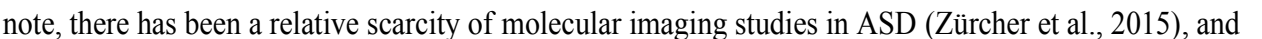

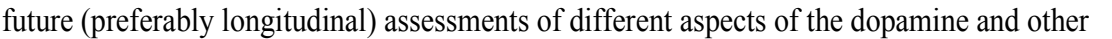

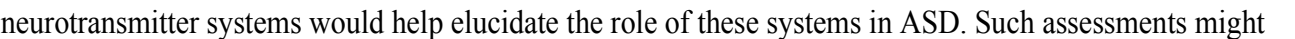

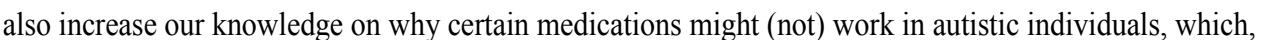

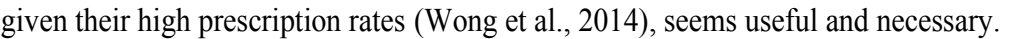

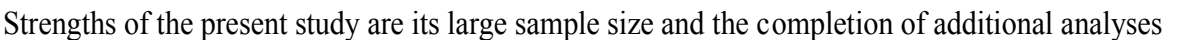
ए

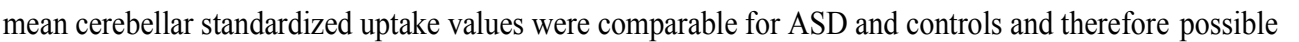

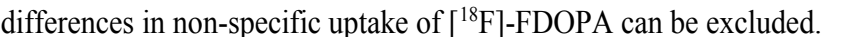

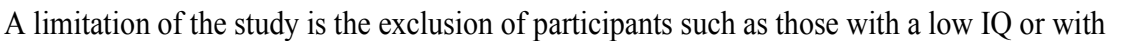

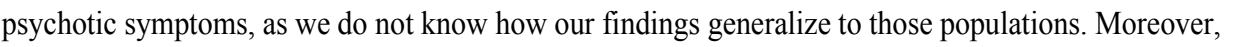

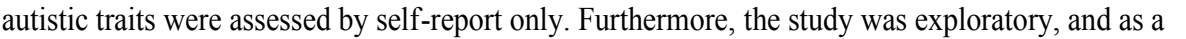

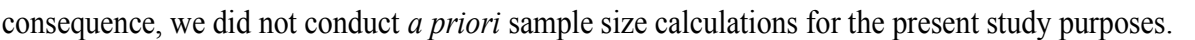

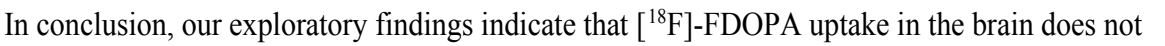

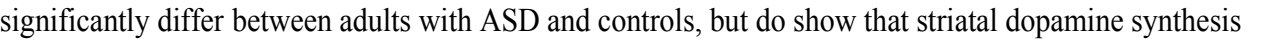

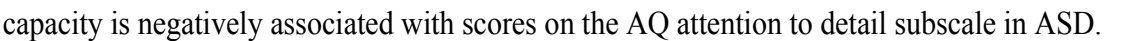




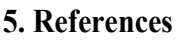

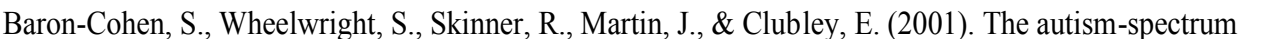

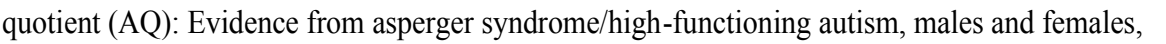

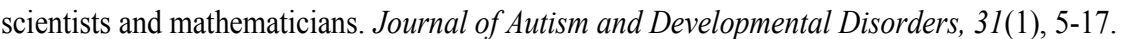
a

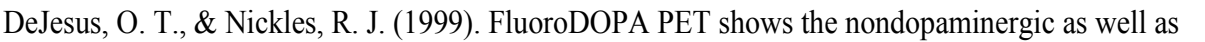

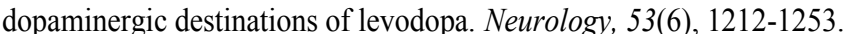

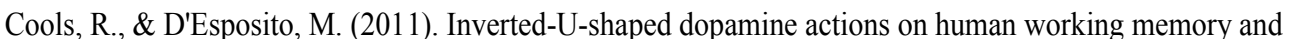

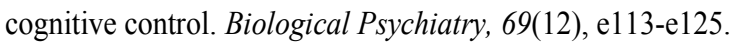

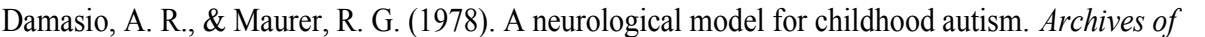

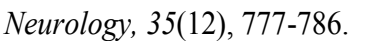

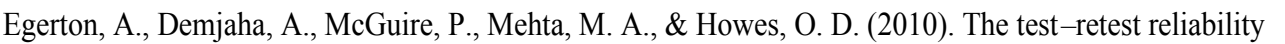

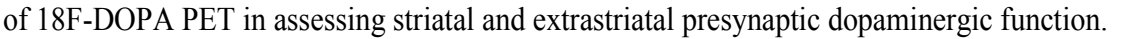

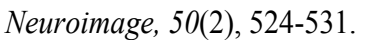

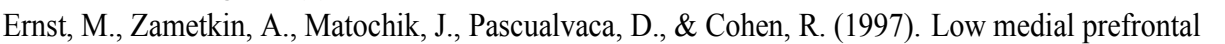

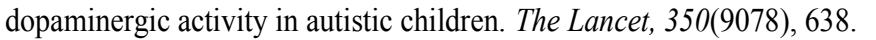

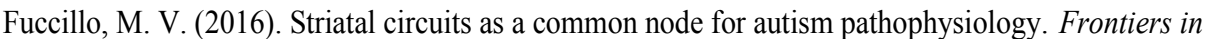

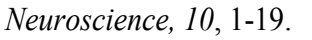

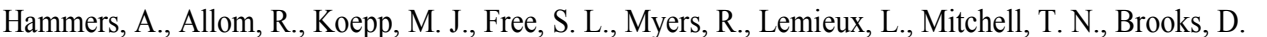

J., \& Duncan, J. S. (2003). Three-dimensional maximum probability atlas of the human brain,

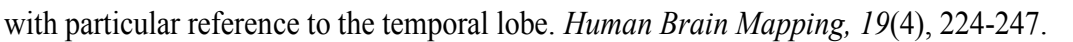

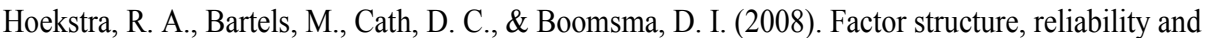

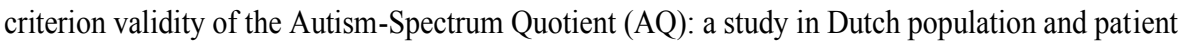

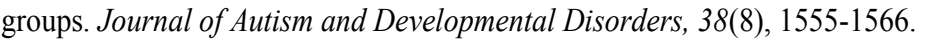

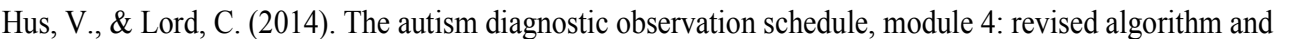

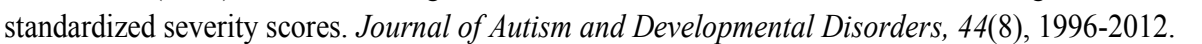

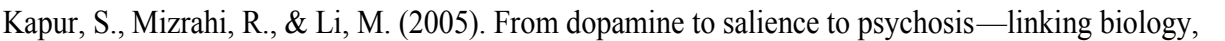

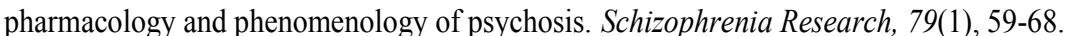

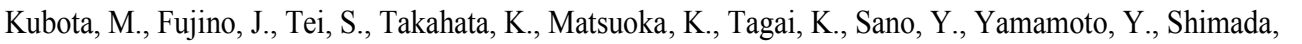

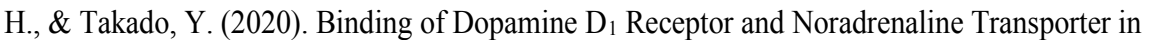

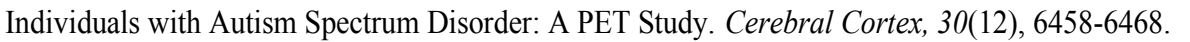

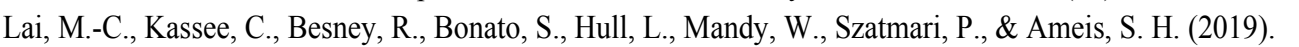

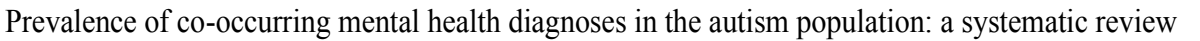

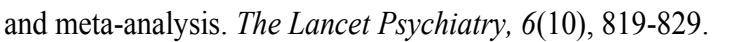

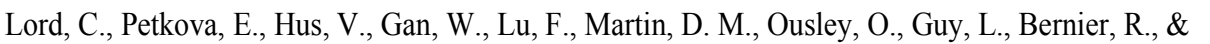

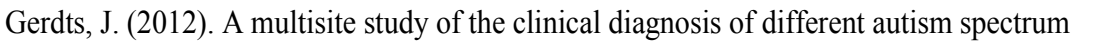

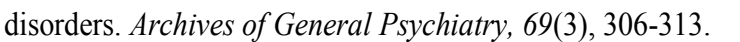

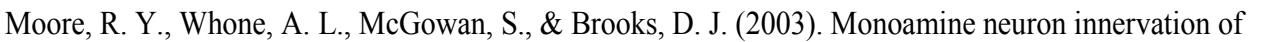

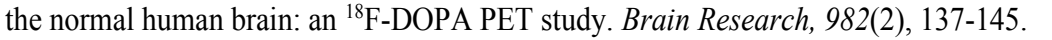

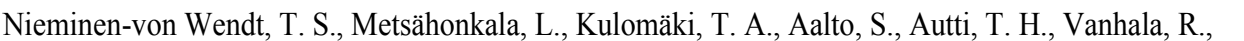

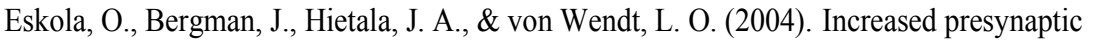

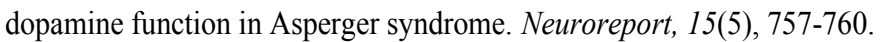




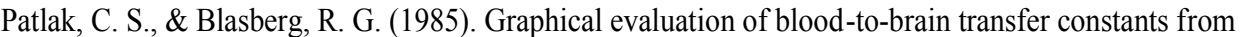

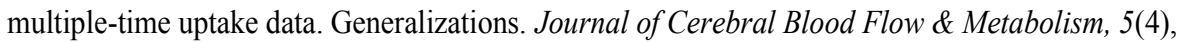
$\square|| 1 \mid 110$

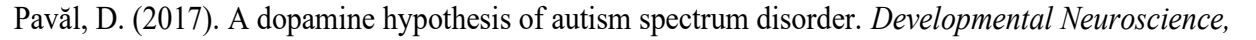

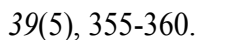

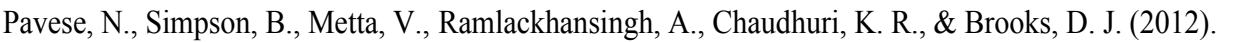

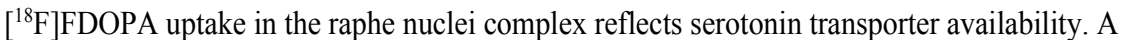

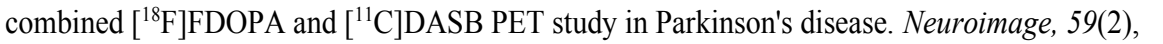

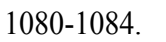

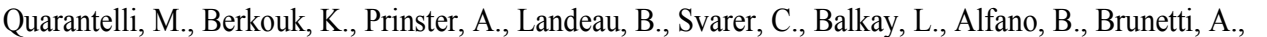

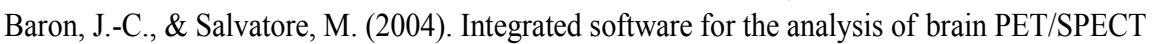

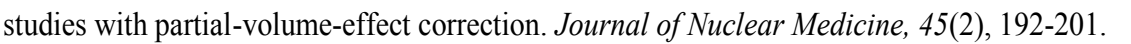

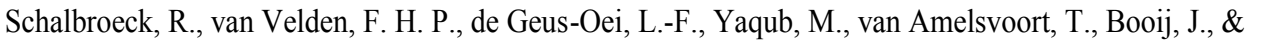

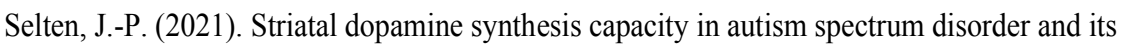

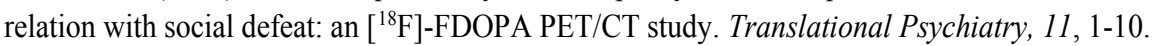

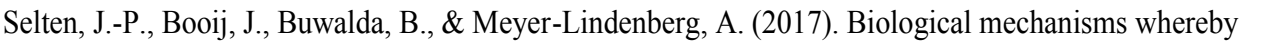

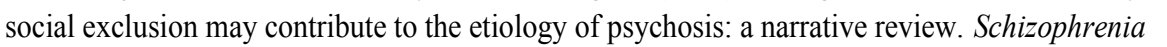

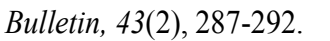

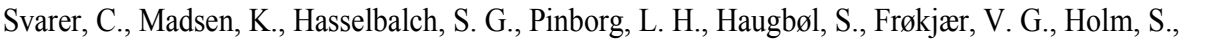

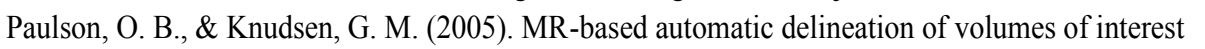

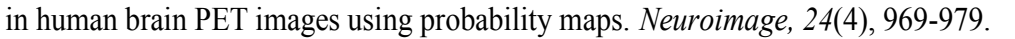

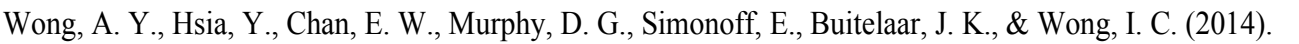

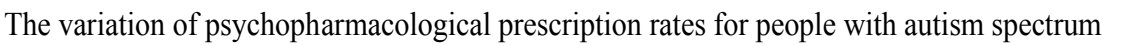

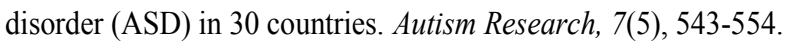

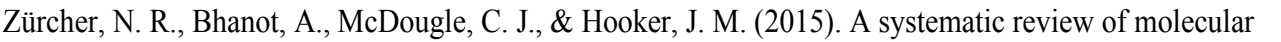

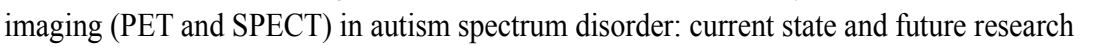

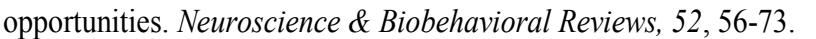

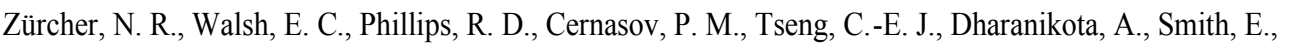

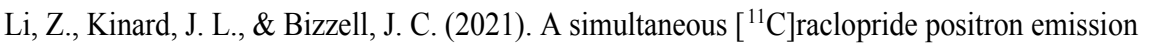

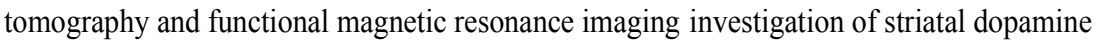

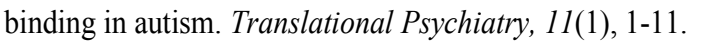

$\square$

$\square$ 


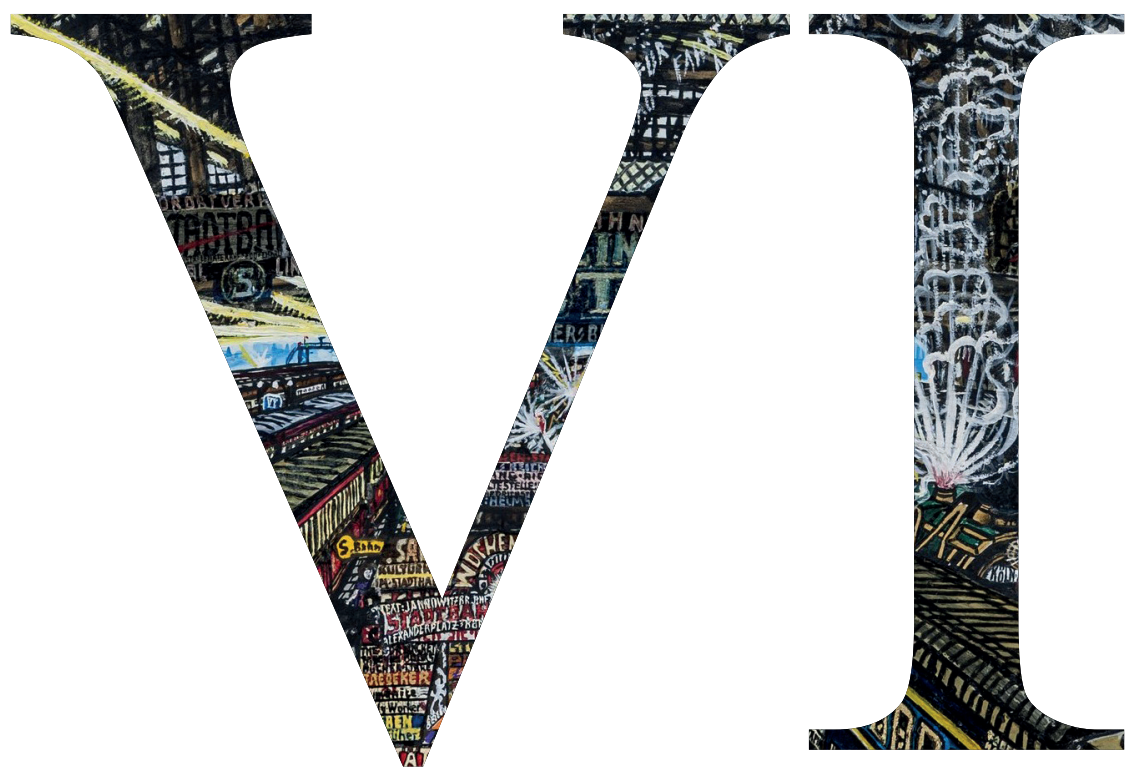




\section{Chapter VI}

\section{The social defeat hypothesis of schizophrenia: a parsimonious explanation for multiple psychosis risk factors?}

Schalbroeck, R.

Psychological Medicine (2020), online ahead of print, 1-2. 
Chapter VI

$\square$

$\square$ 


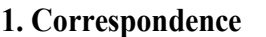

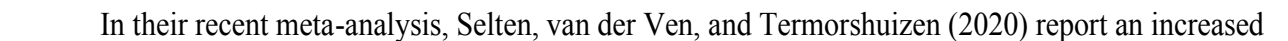
ए

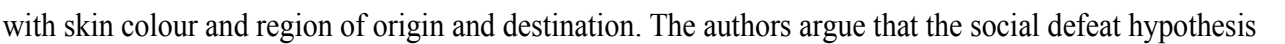

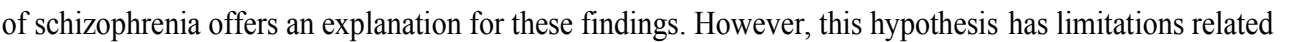

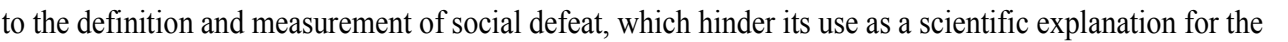

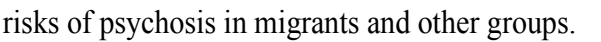

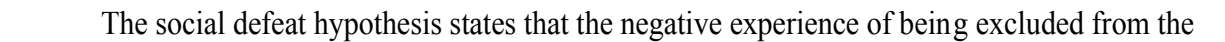

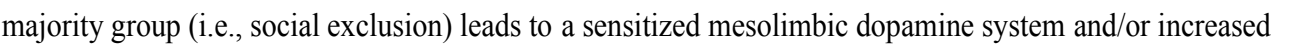
प I

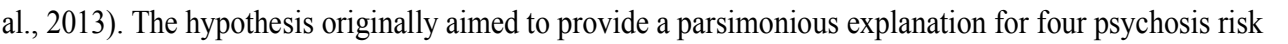

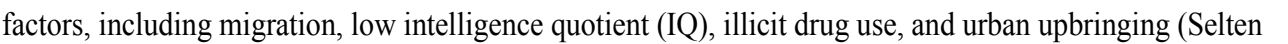

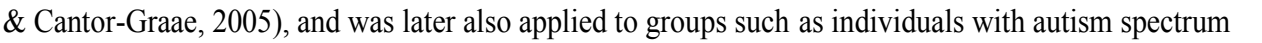

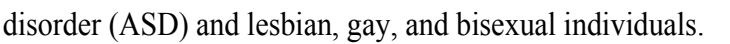

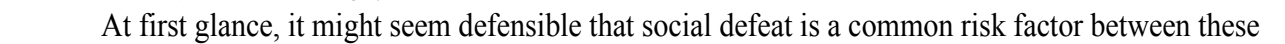

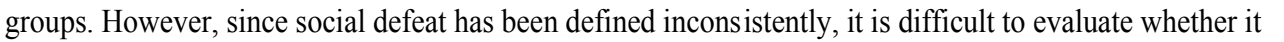

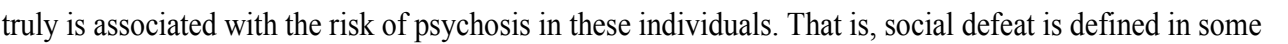

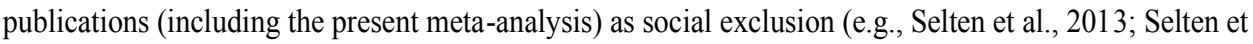

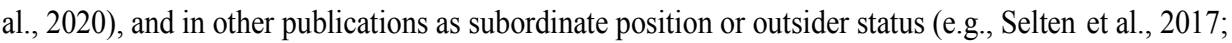

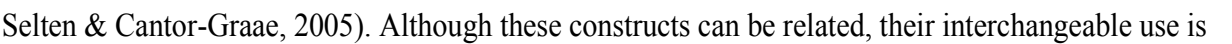

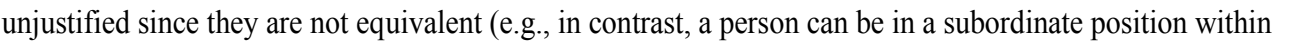

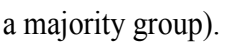

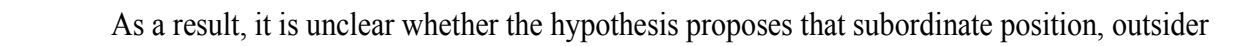

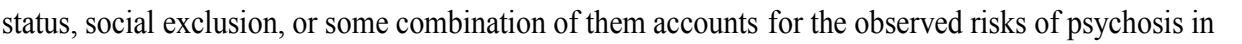

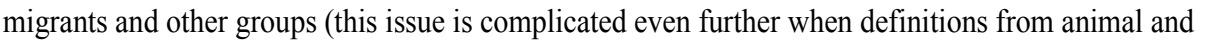

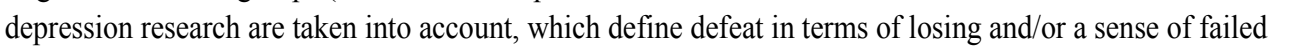

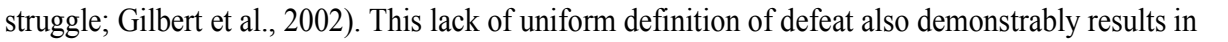

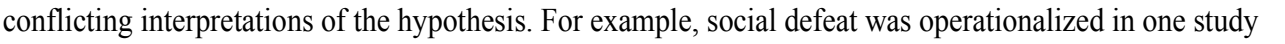

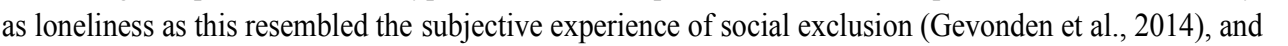

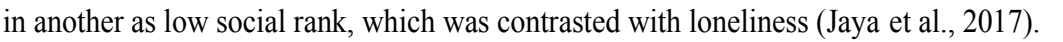

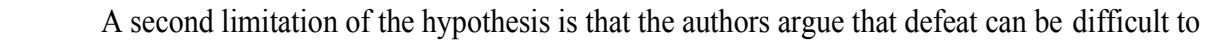

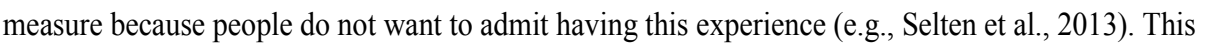

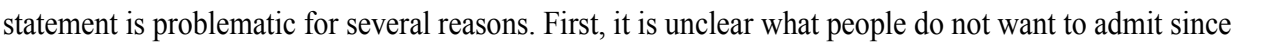

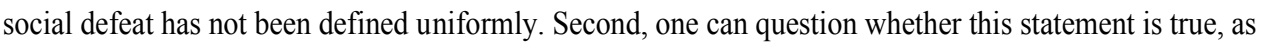

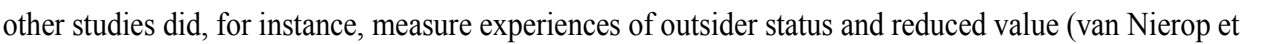

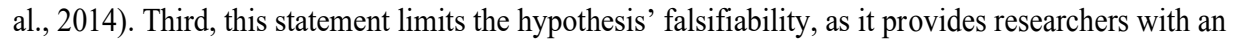

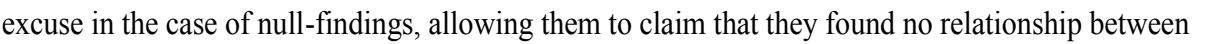

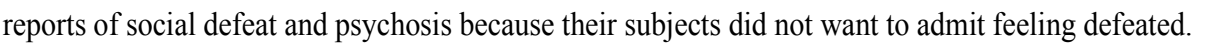

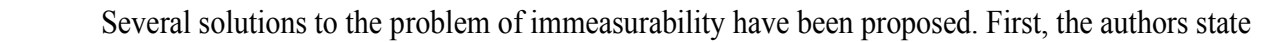
प

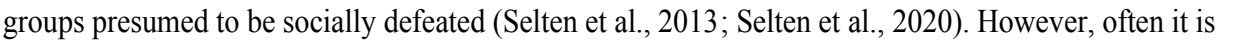

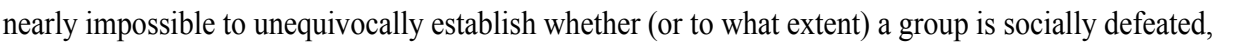

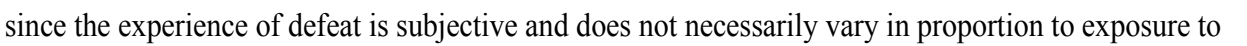
ए ए 


\section{Chapter VI}

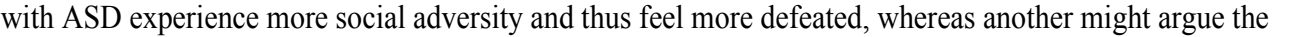

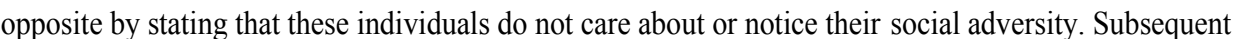

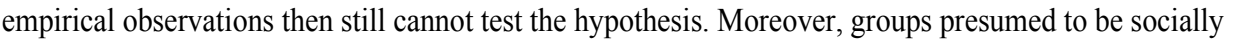

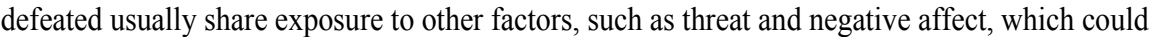

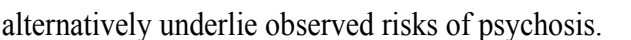

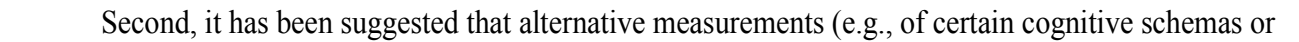

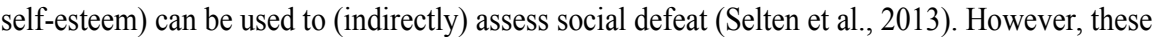

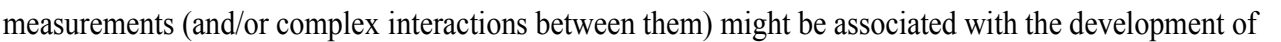

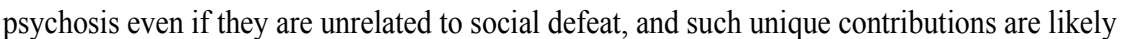

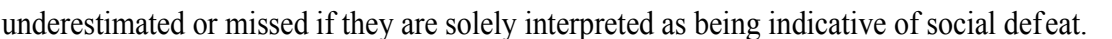

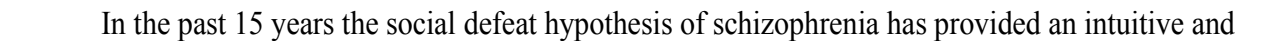

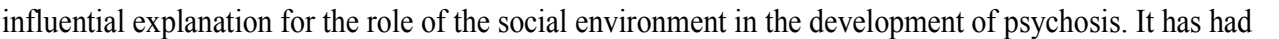

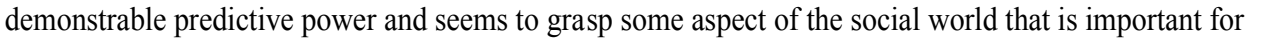

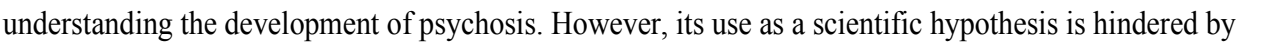

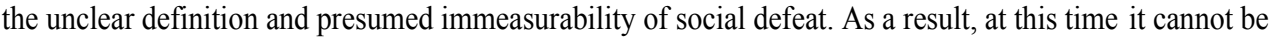
प

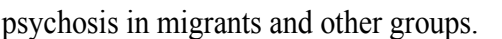
$\square$ 


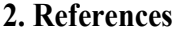

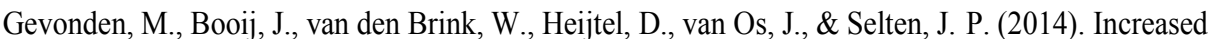

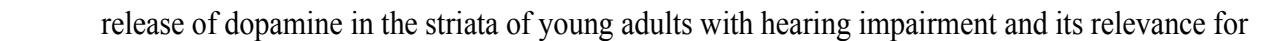

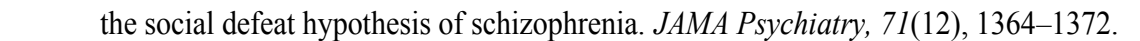

a

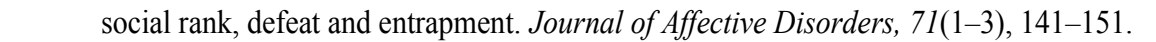

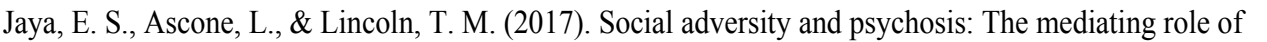

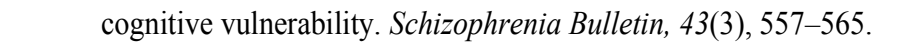

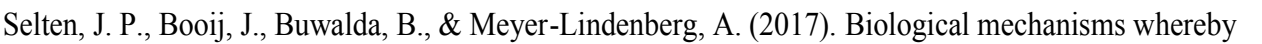

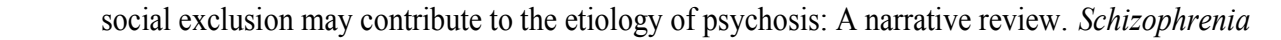

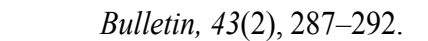

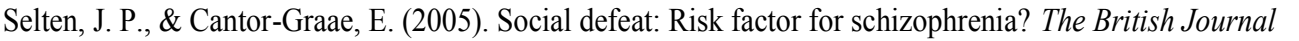

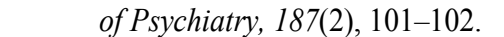

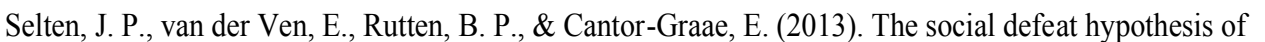

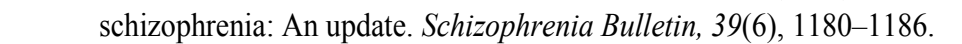

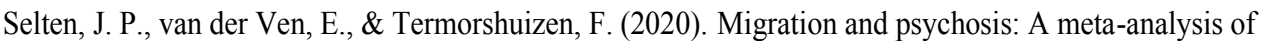

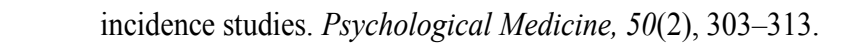

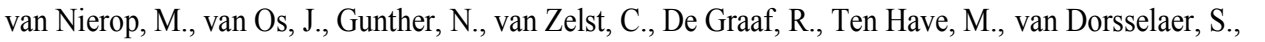

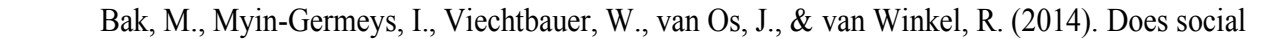

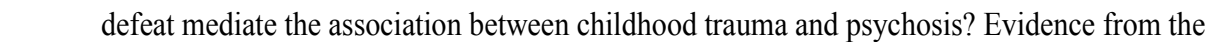

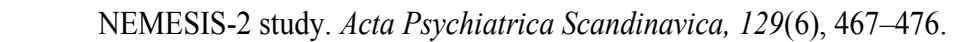

$\square$

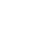


$\square$

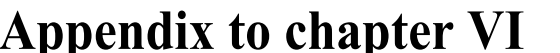

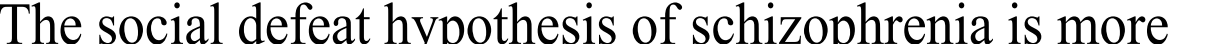

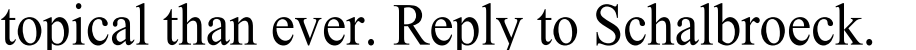

$\square$

$\square$

$\square$

$\square$

$\square$

$\square$

$\square$

$\square$

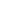

$\square$

$\square$

$\square$

$\square$

$\square$

$\square$

$\square$

$\square$

$\square$

$\square$

$\square$

$\square$

$\square$

$\square$

$\sqcap$

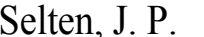

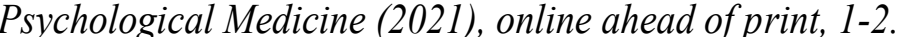




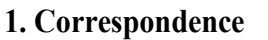

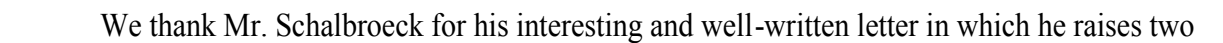

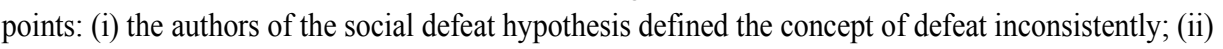

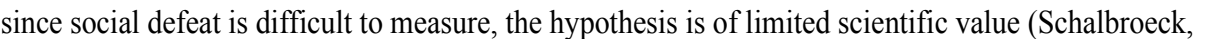
$\square 11 \mathrm{Wl}$

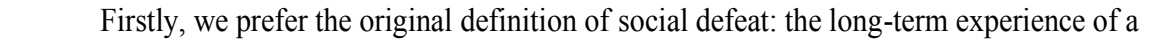

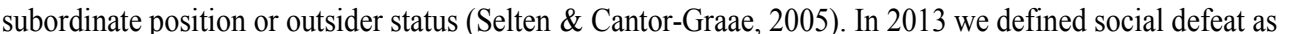

"the negative experience of being excluded from the majority group" to make clear that we refer to an

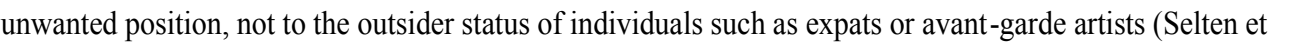

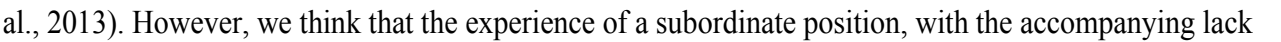

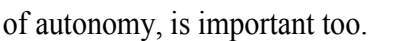

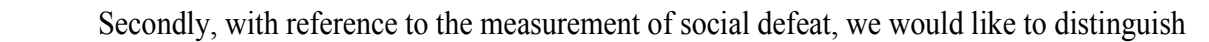

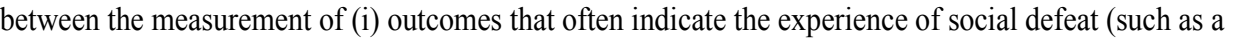

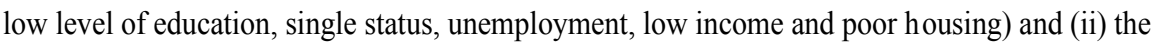

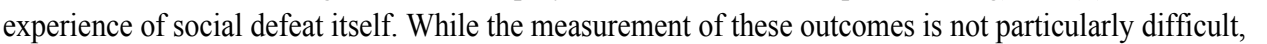
ए

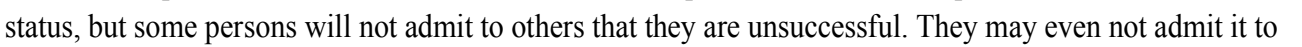

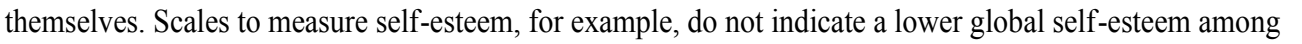

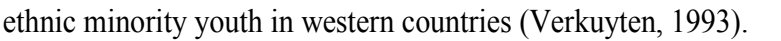

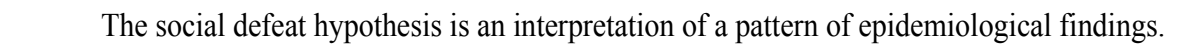

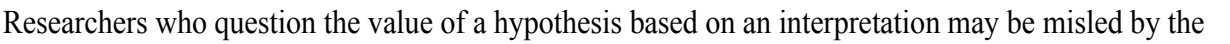

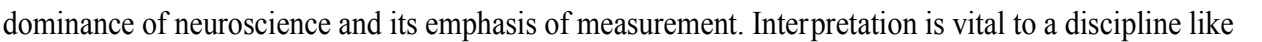

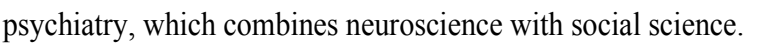

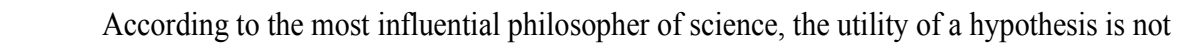

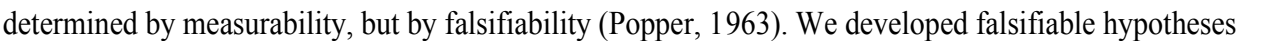

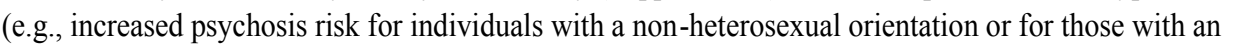
autism spectrum disorder; increased amphetamine

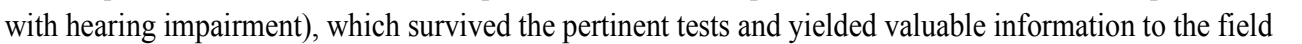
(e.g., Gevonden et al., 2014a; $\square \square\|\|\|\| \| m 2014$ b; Selten et al., 2015). On the basis of our theory one

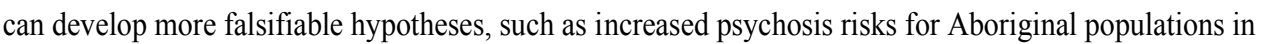

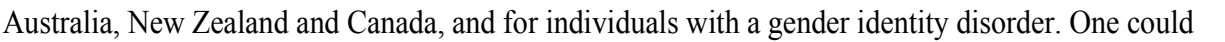

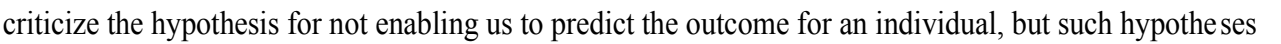

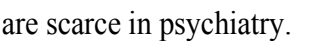

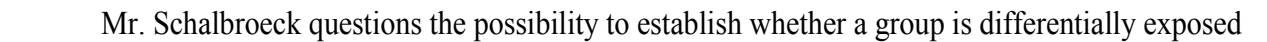

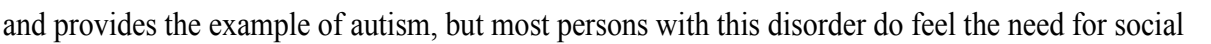

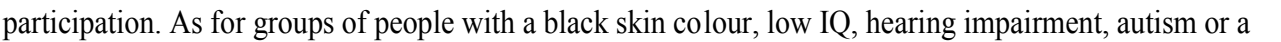

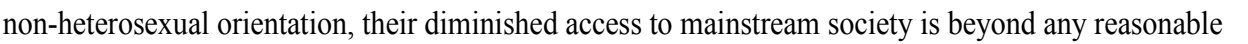

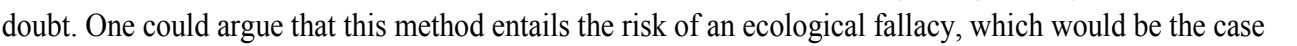
ए

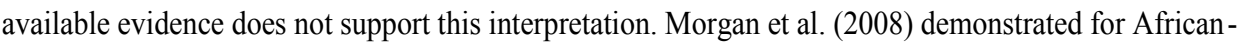

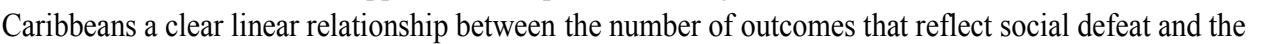

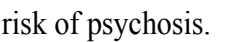

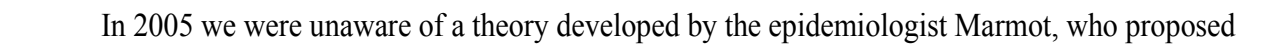

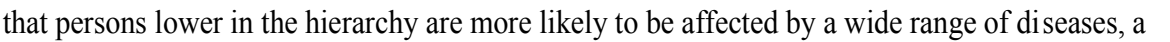


phenomenon he coined status syndrome (Marmot, 2005). He argued that key factors related to a person's position in the hierarchy include a subjective sense of control over one's life (autonomy) and the

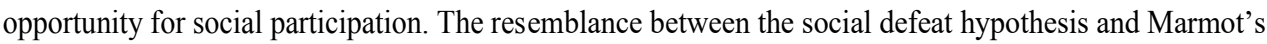

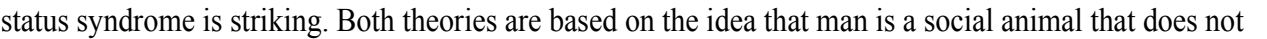

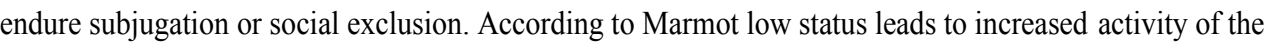
ए

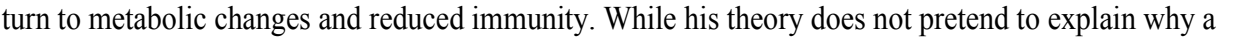

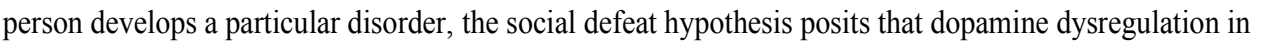

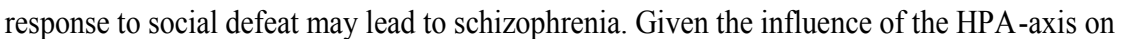

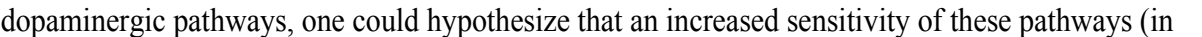

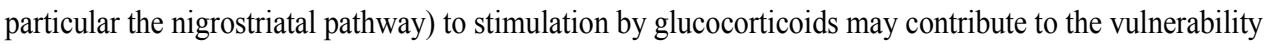

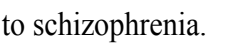

$\square \quad$ In order to avoid any misunderstanding we would like to point out that a "parsimonious

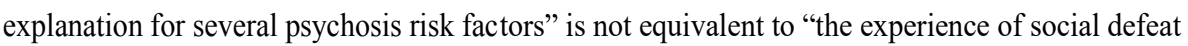
explains everything". As we already observed in 2005 , social defeat is not always followed by the

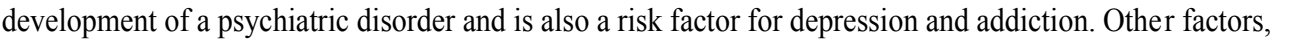

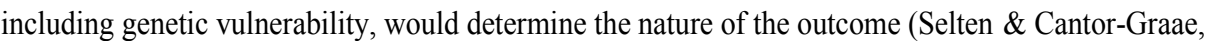
एाएवाण

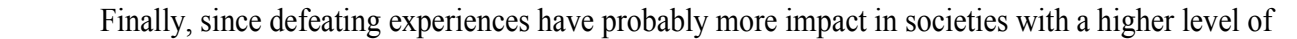

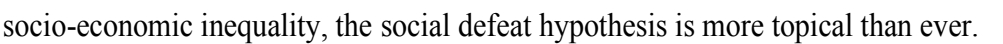




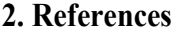

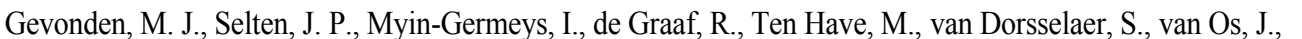

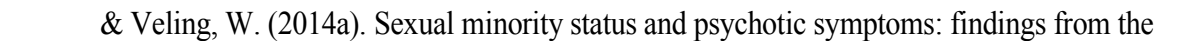

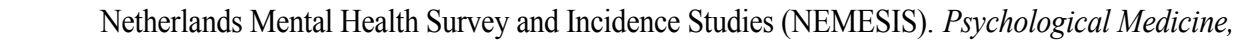

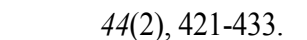

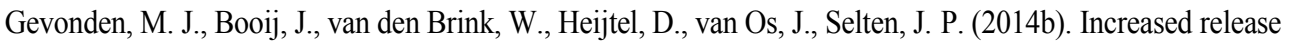

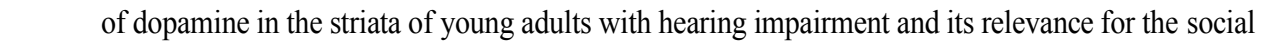

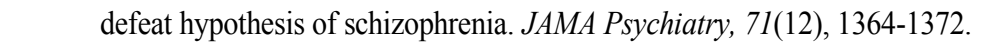

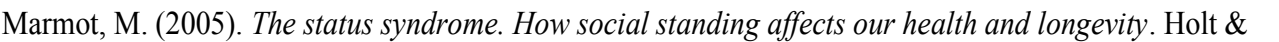

$\square \quad \square \square \square$

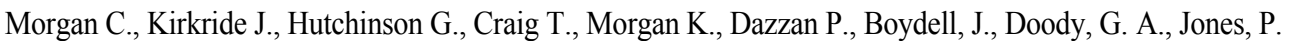

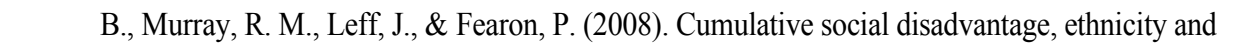

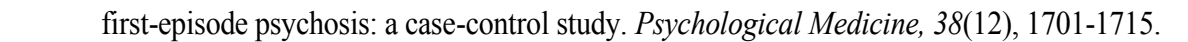

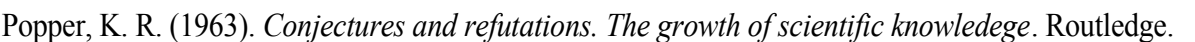

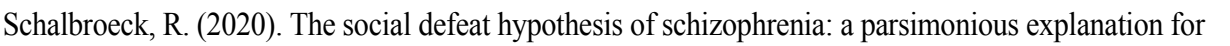

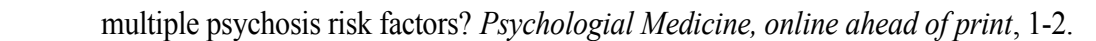

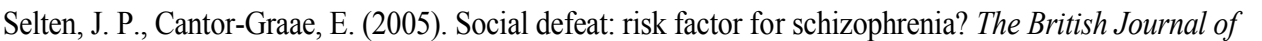

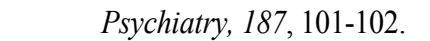

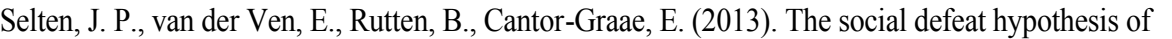

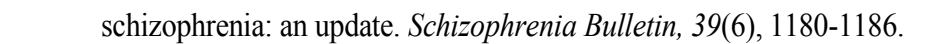

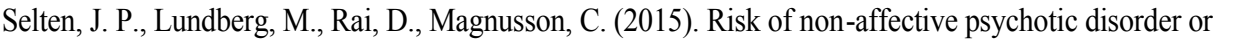

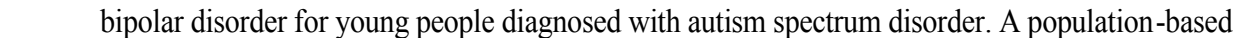

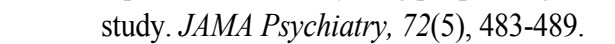

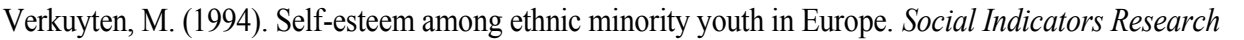

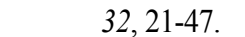

$\square$

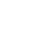



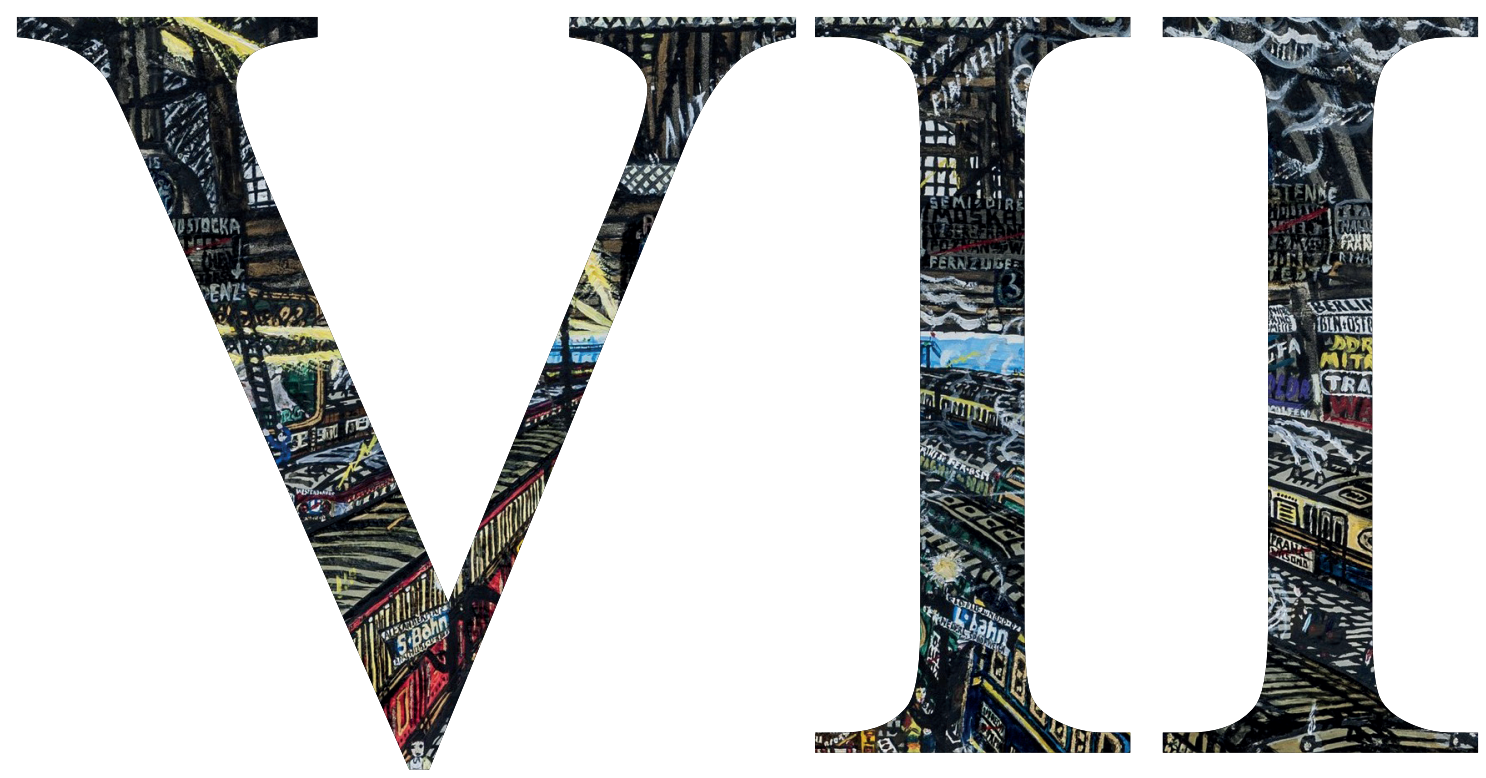


\section{Chapter VII}

\section{General discussion}


Chapter VII

$\square$

$\square$ 


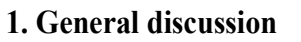

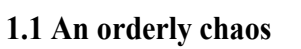

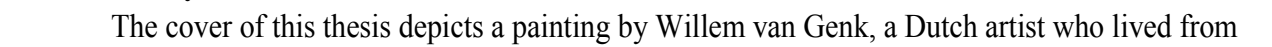

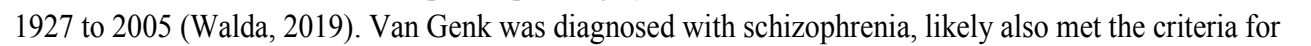

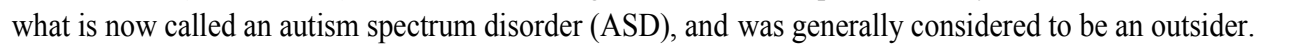

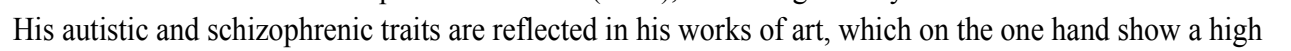

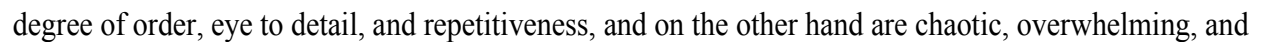

filled with delusional messages. However, Van Genk's autistic and schizophrenic traits were not only a

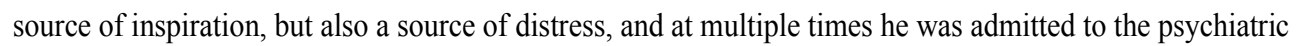

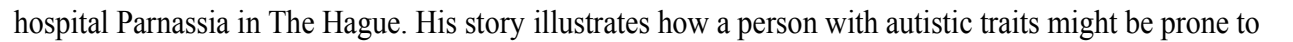

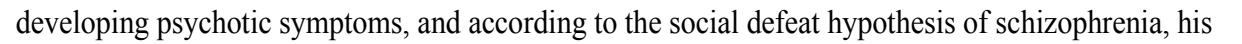

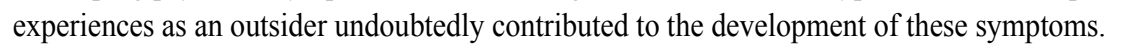

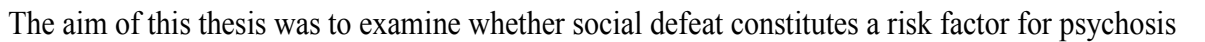
प

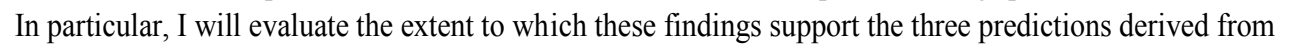

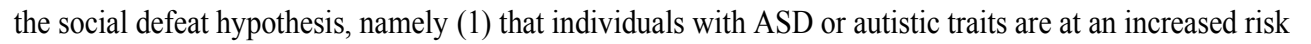

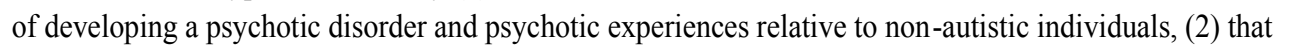

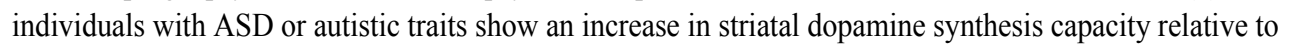

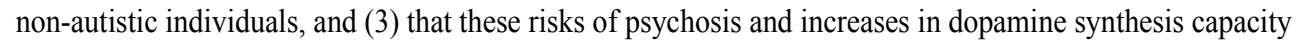

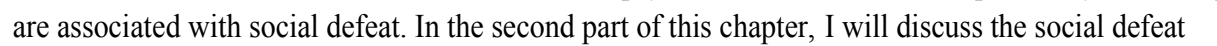

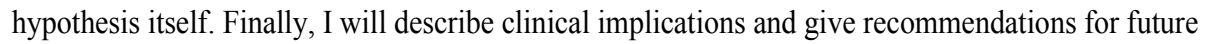
एाणाणा

\section{$\square$}

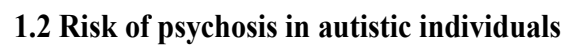

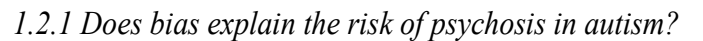

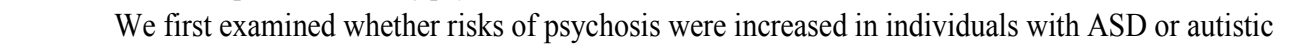

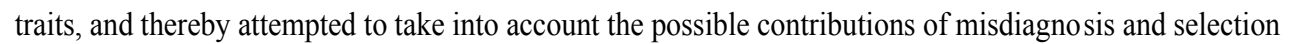

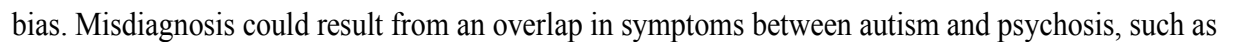

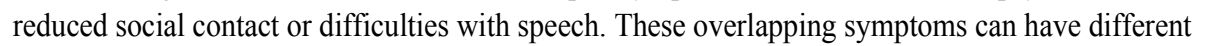

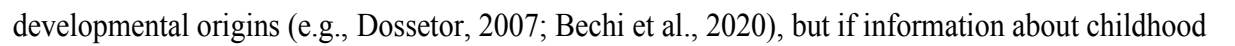

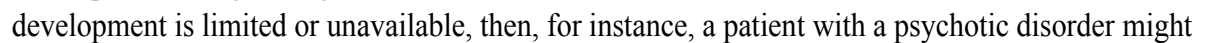

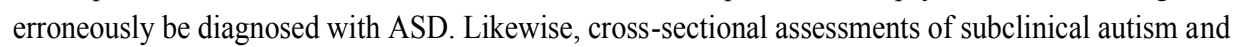

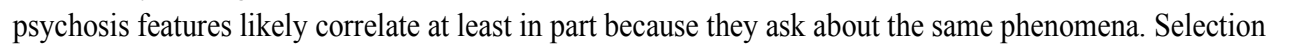

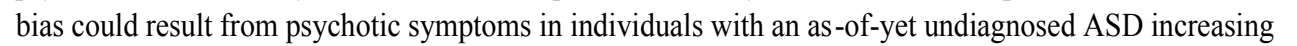

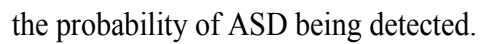

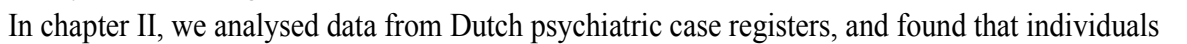

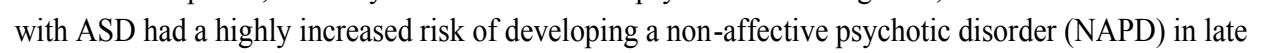

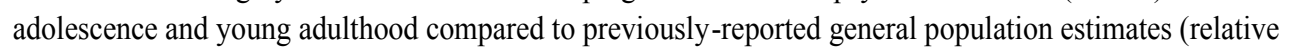

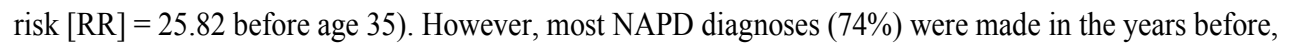

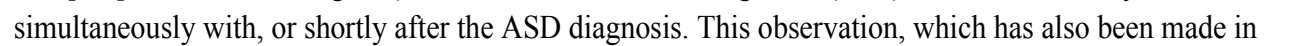

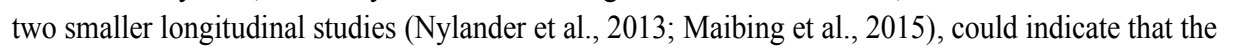

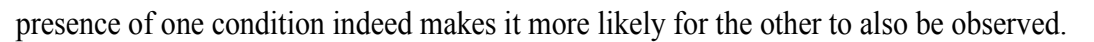

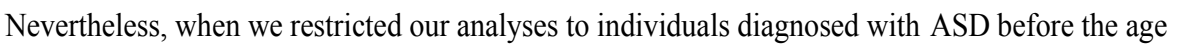

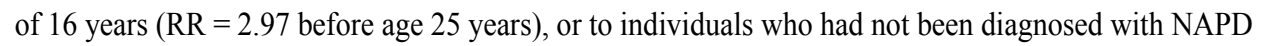




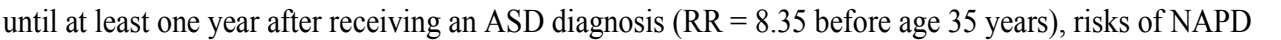

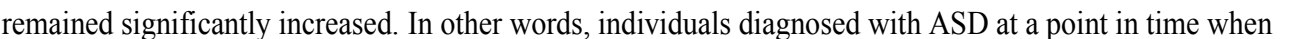

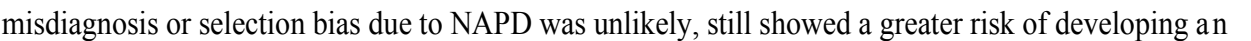

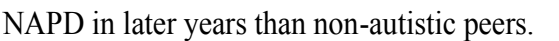

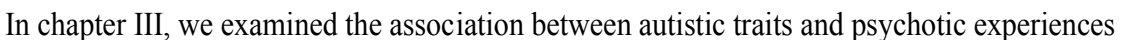

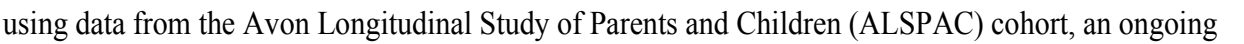

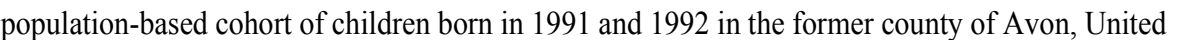

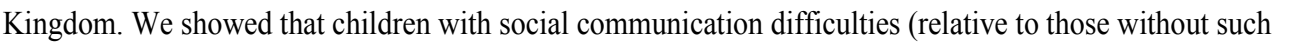

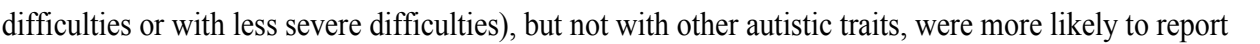

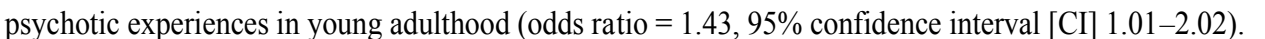

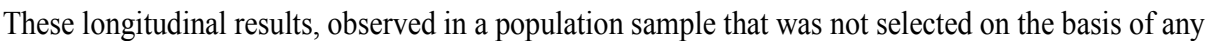

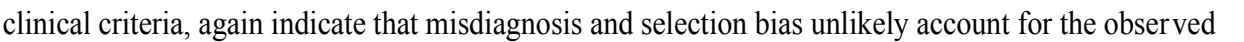

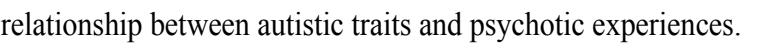

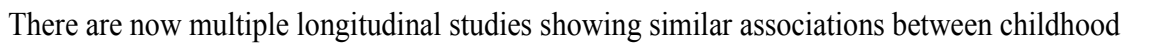

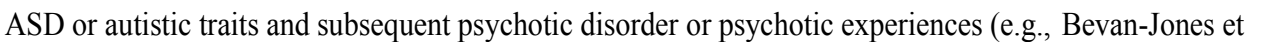

al., 2012; Sullivan et al., 2013; Maibing et al., 2015; Selten et al., 2015)

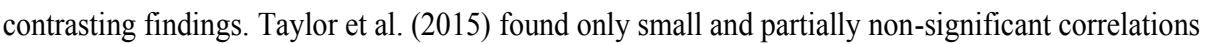

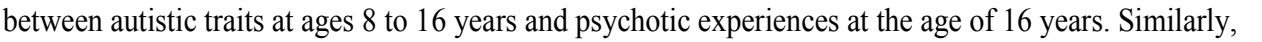

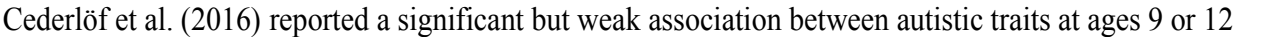

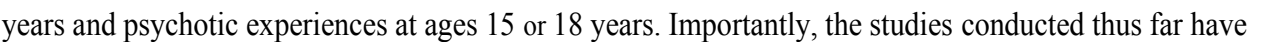

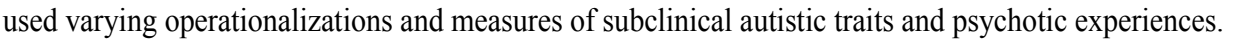

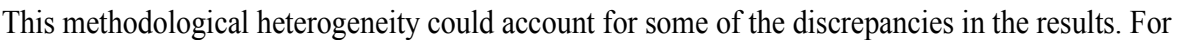

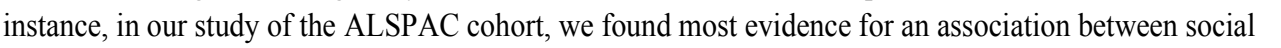

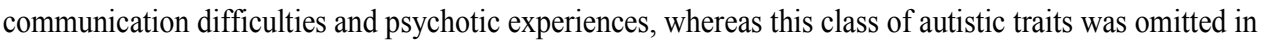

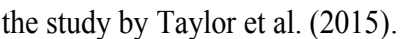

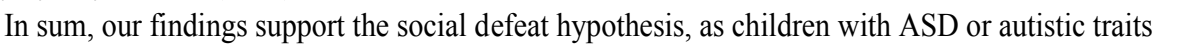

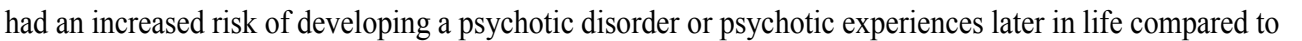

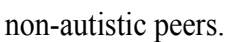

$\square$

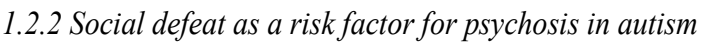

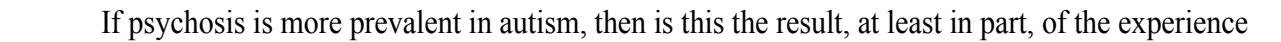

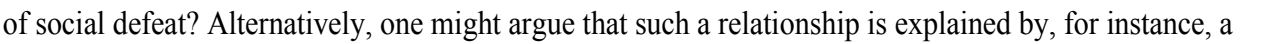

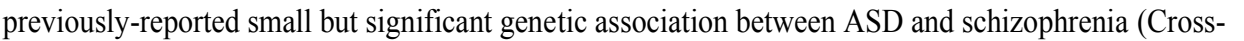

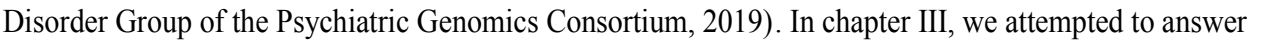

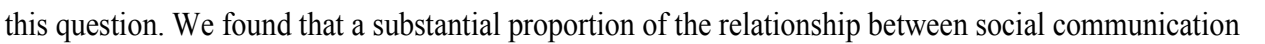

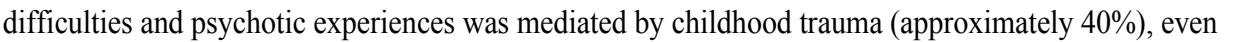

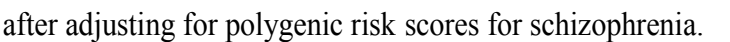

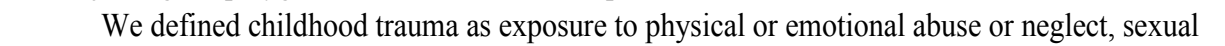

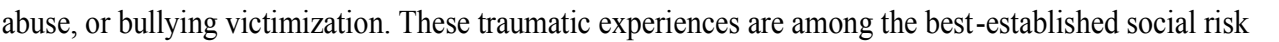

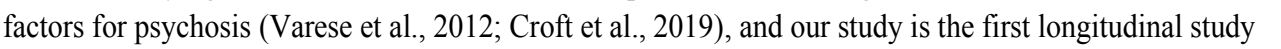

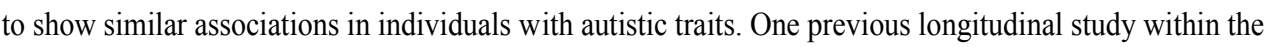

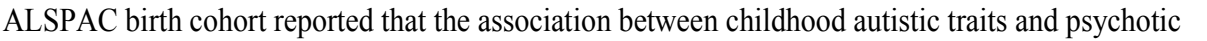

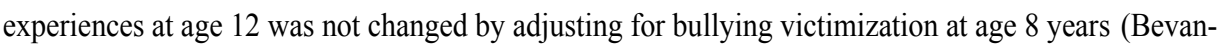

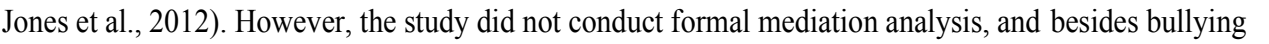




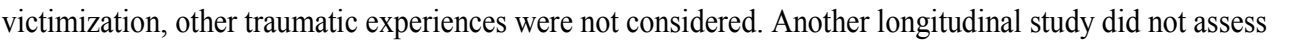

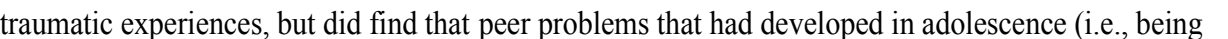

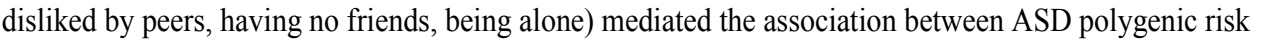

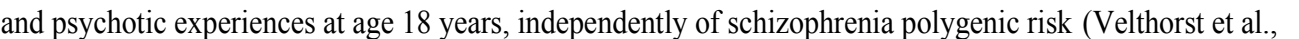
$\square 11 \mathrm{Wl}$

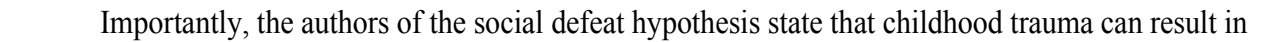

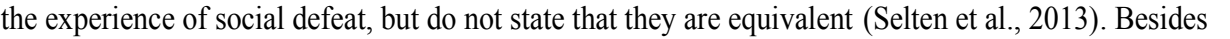

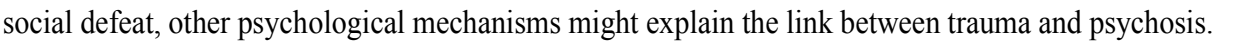

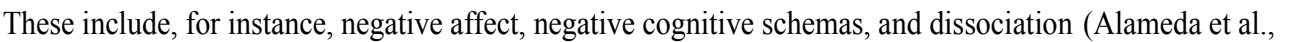

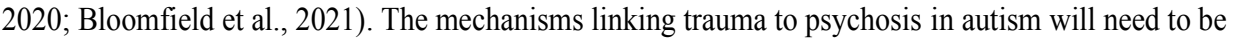

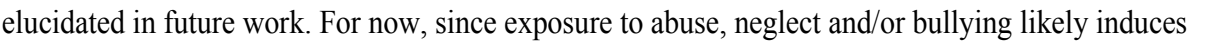

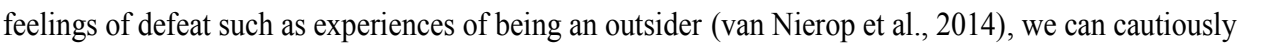

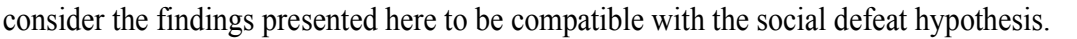
$\square$

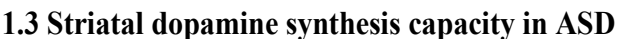

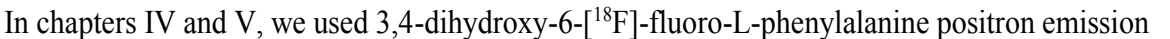

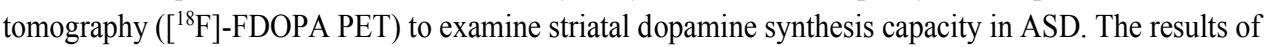
प

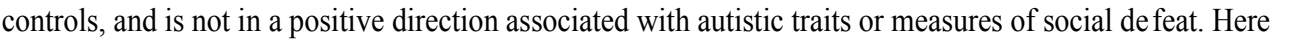

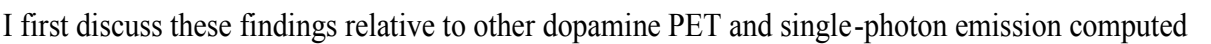
प

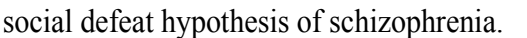

$\square$

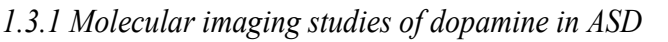

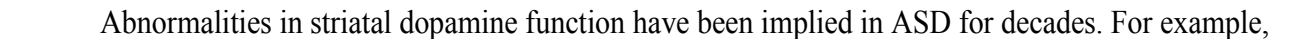

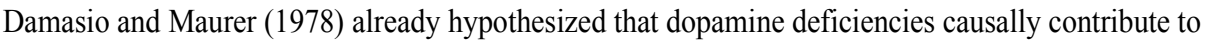

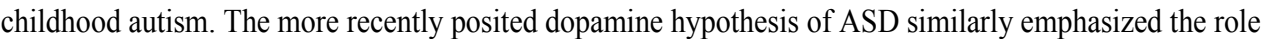

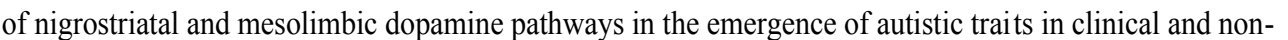

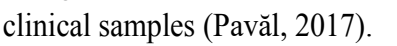

\begin{aligned} \hline \\ \hline\end{aligned}

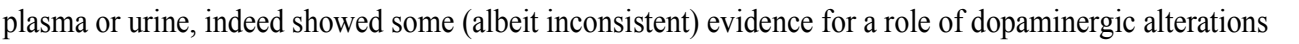
ए

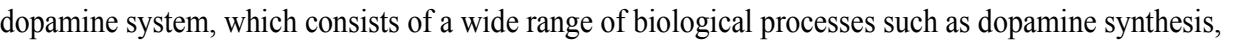

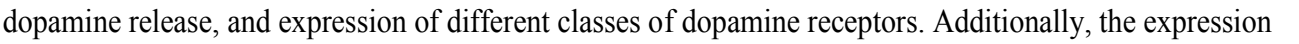

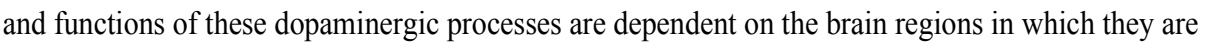

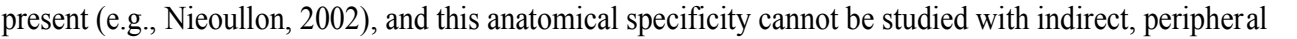

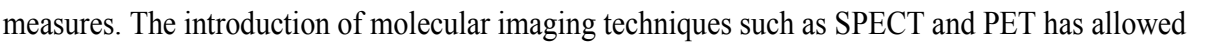

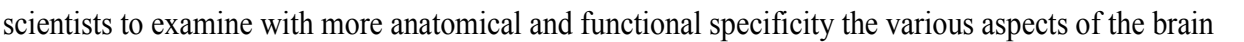

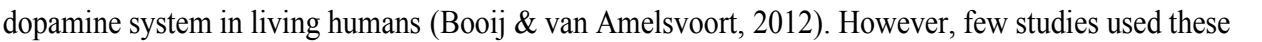
ए

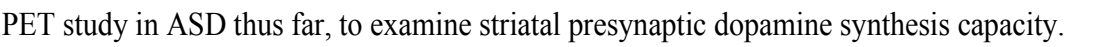

\begin{aligned} \hline \\ \hline\end{aligned}

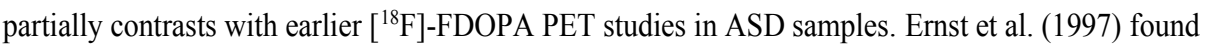

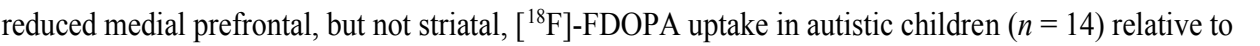




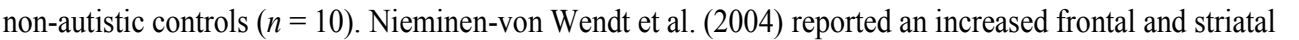

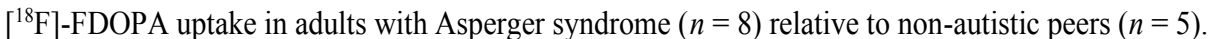

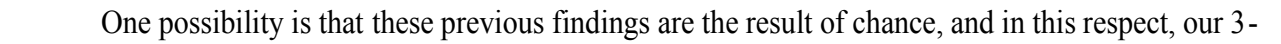

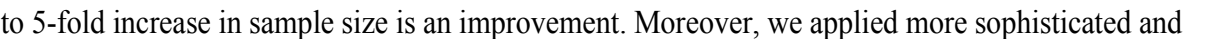

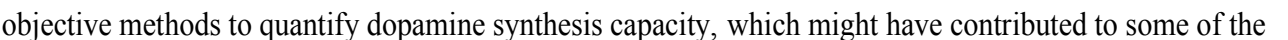

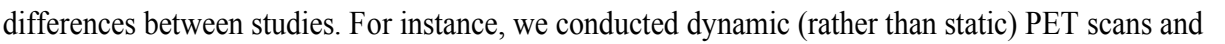

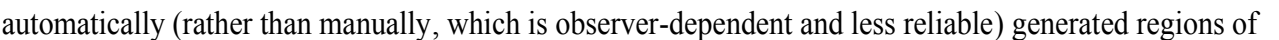

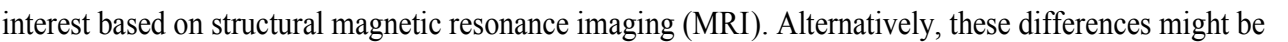

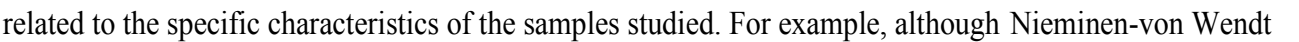

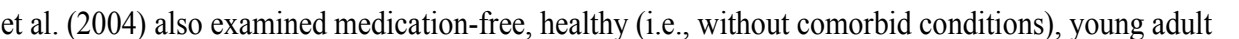

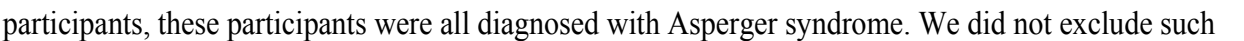
ए

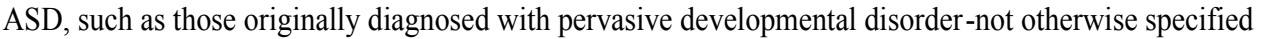

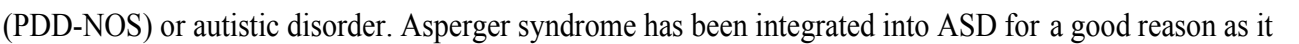

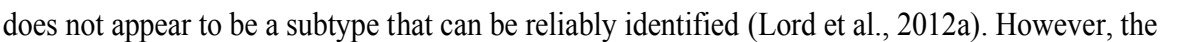

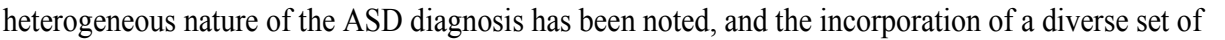

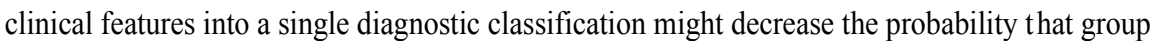

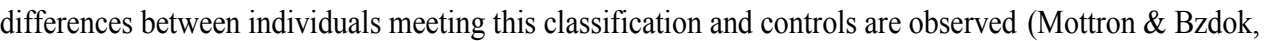

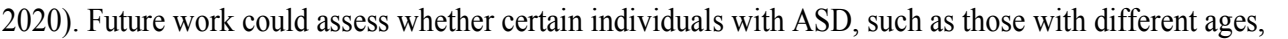

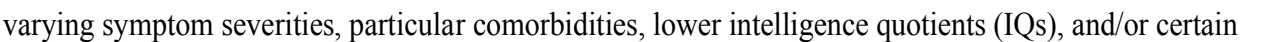

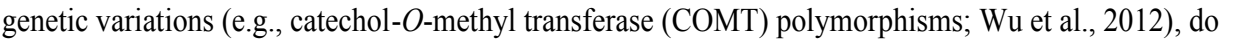

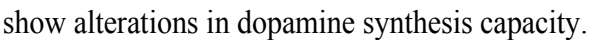

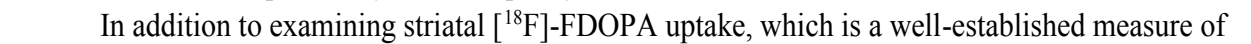

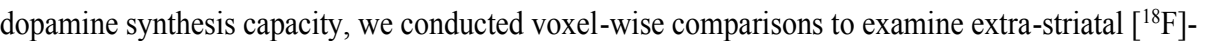

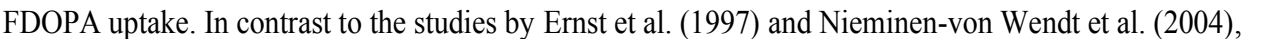

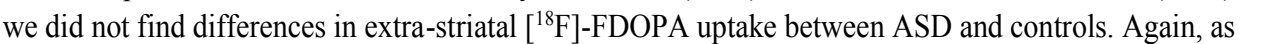

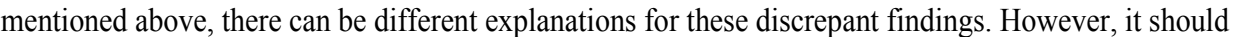

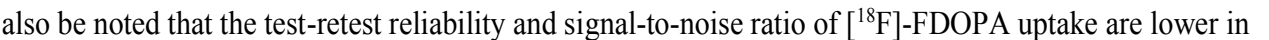

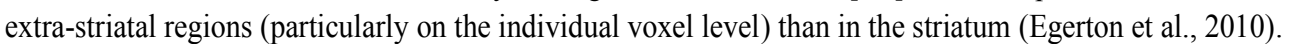

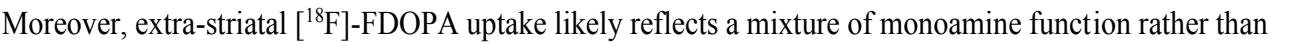

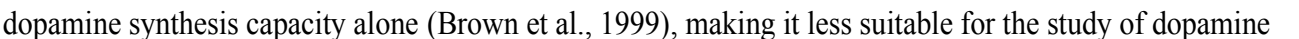
एणाणाणा

\begin{aligned} \hline \\ \hline\end{aligned}

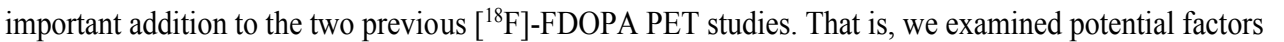

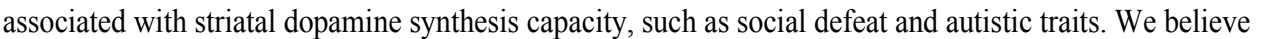

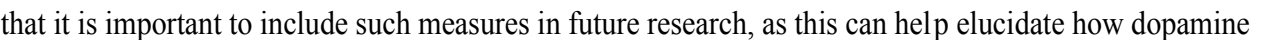

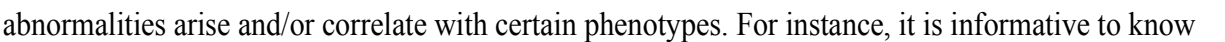

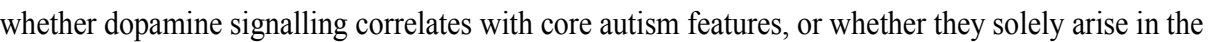

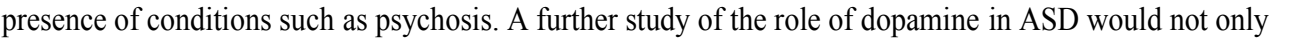

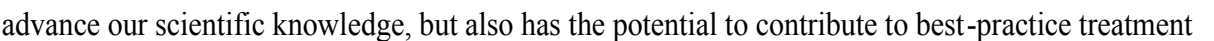

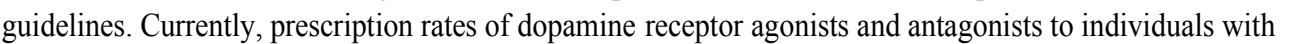

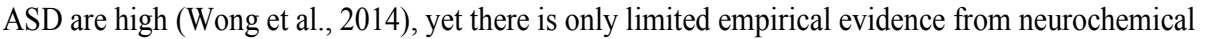

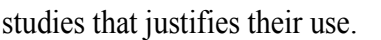




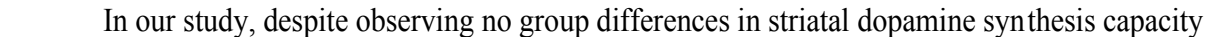

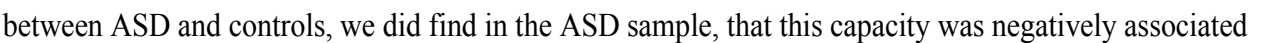

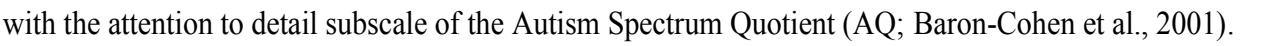

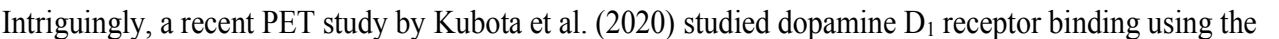

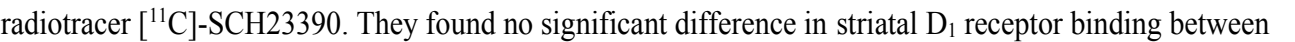

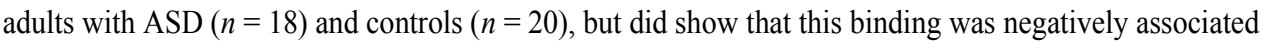

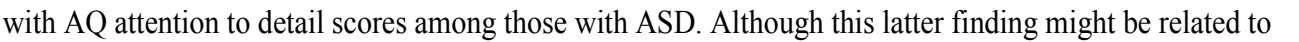

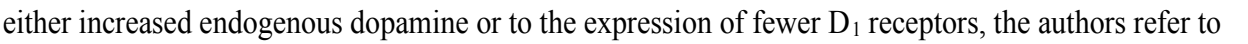

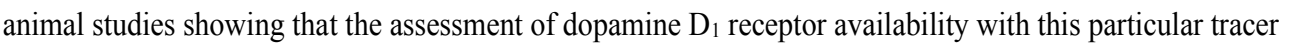

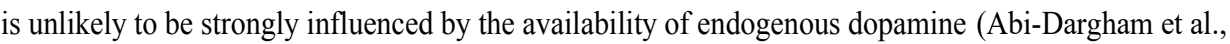

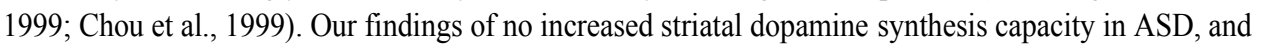

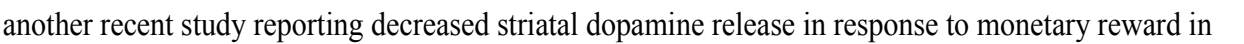

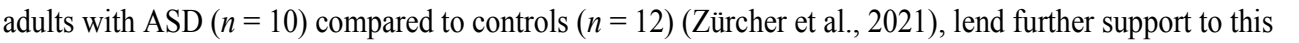

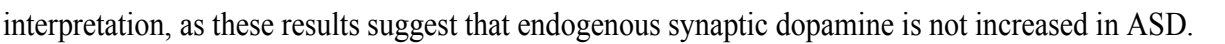

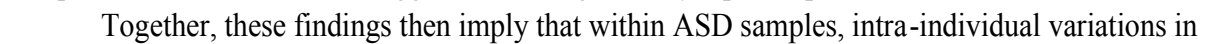

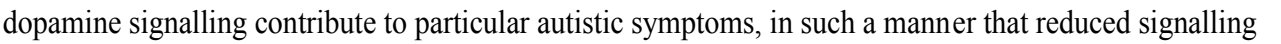

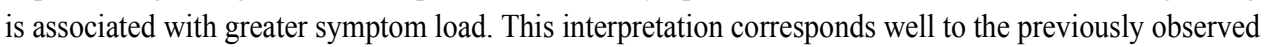

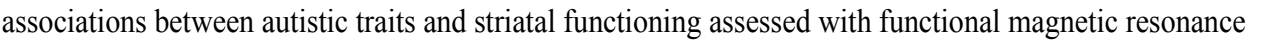

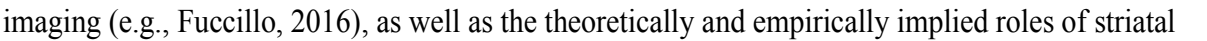

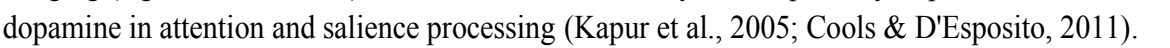

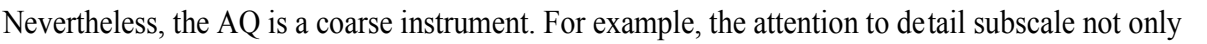

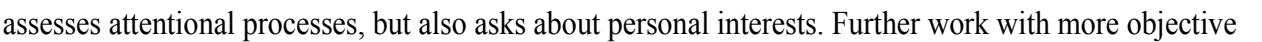

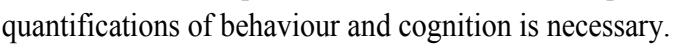

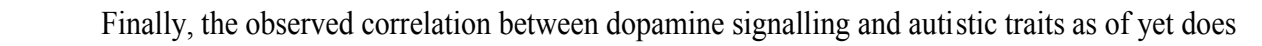

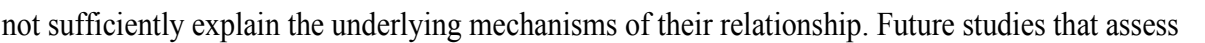

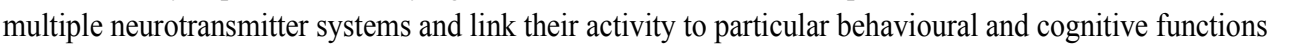

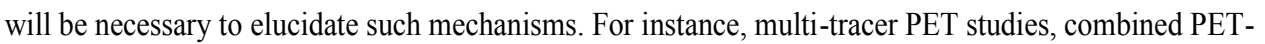

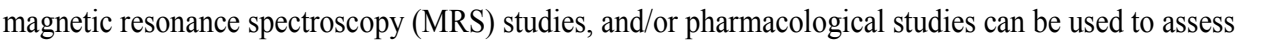

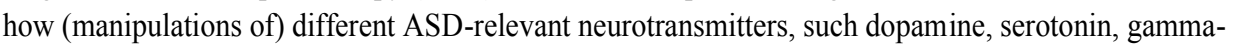

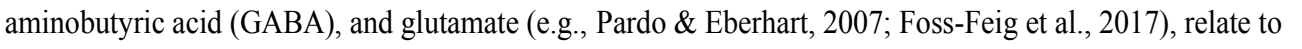

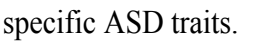

$\square$

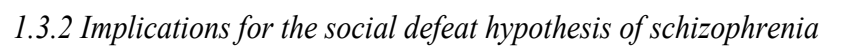

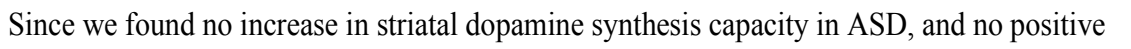

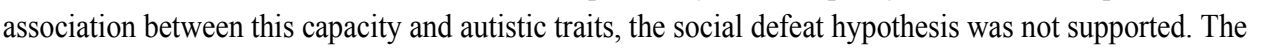

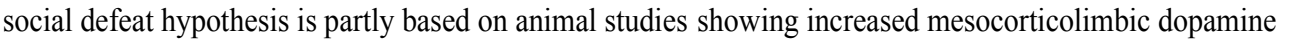

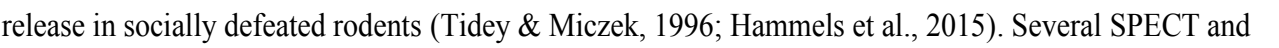

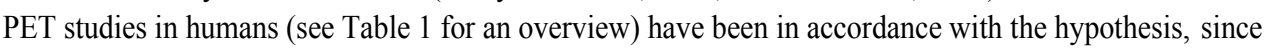

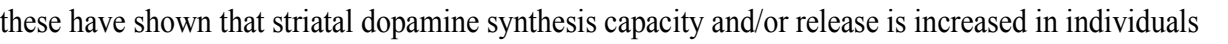

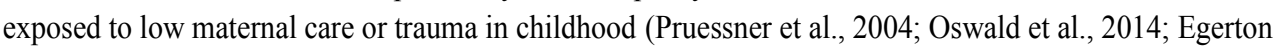

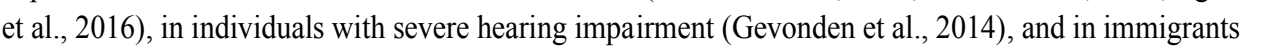

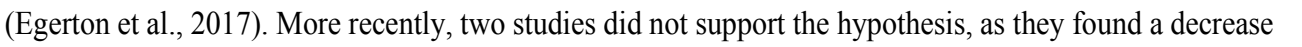

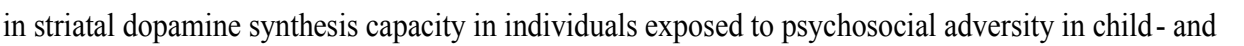

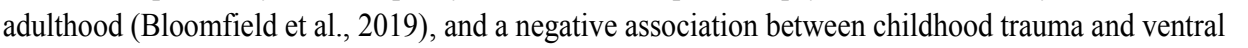




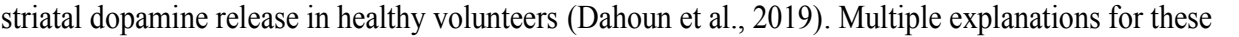

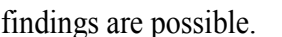

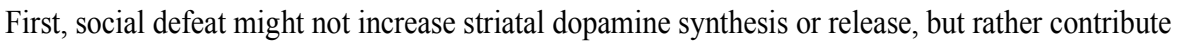
प

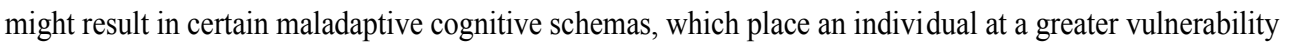

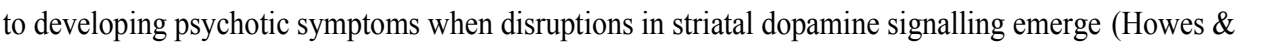

Murray, 2014; Howes \& Nour, 2016)

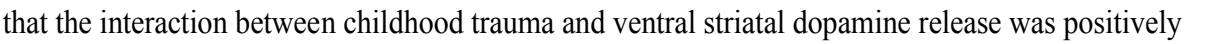

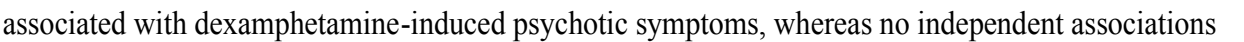

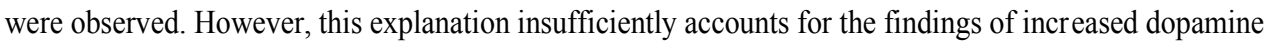

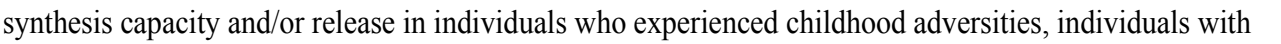

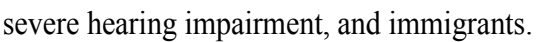

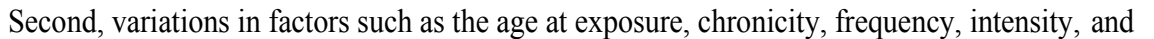

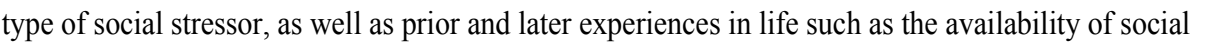

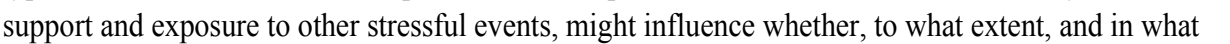

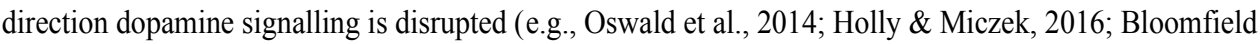

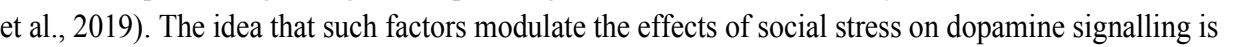

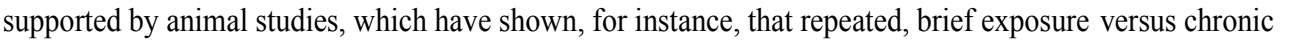

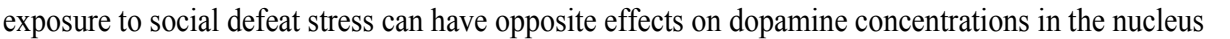

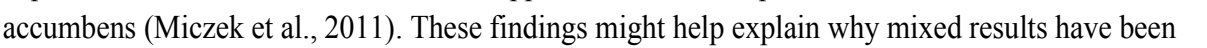

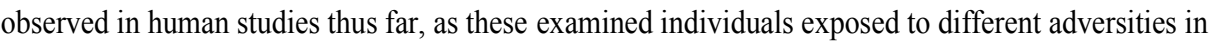

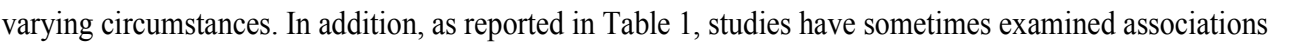

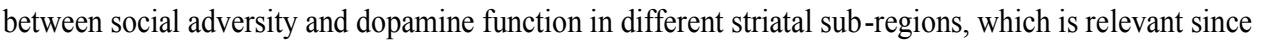
prior work has shown divergent associations of dopamine functioning in anatomical and functional

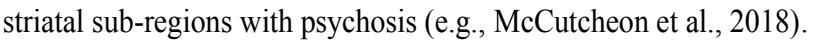

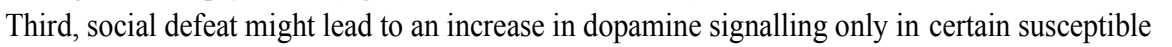

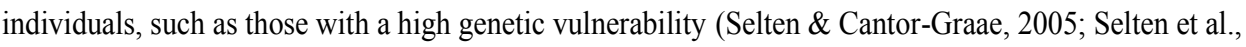

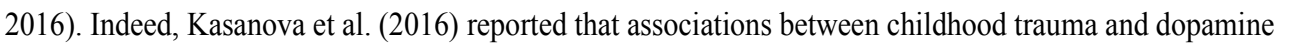

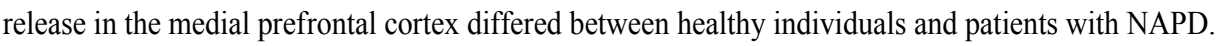

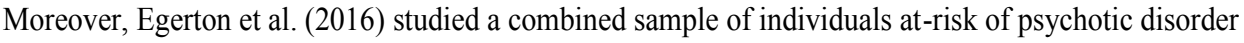

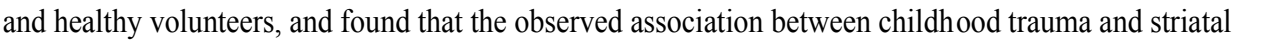

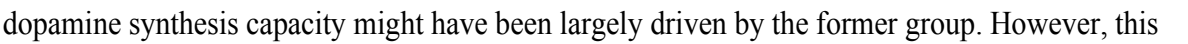

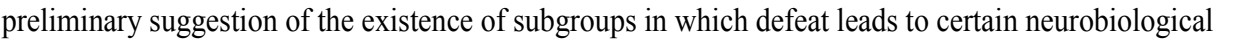

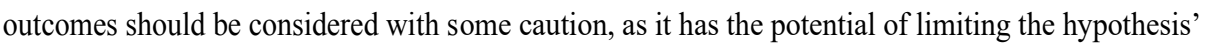

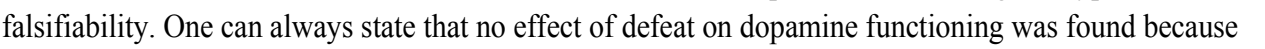

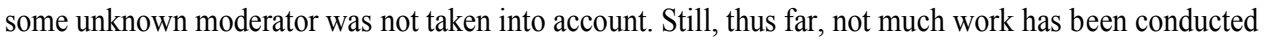

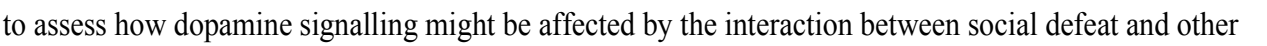
risk factors, and there are several obvious candidate moderators (e.g., polygenic risk for schizophrenia)

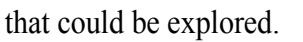

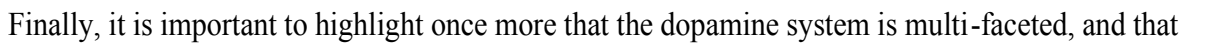

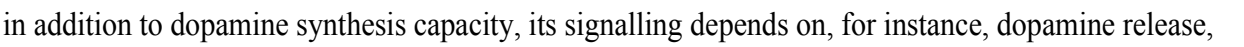

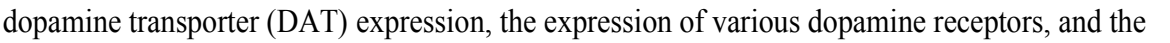

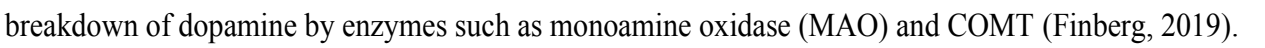

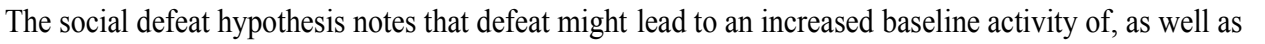


General discussion

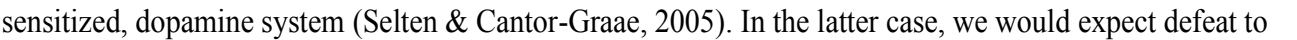

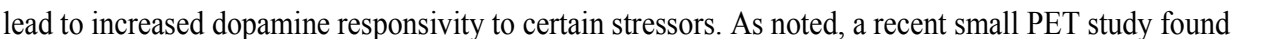

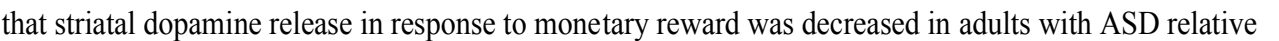

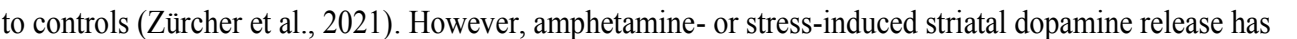

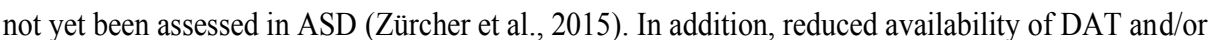

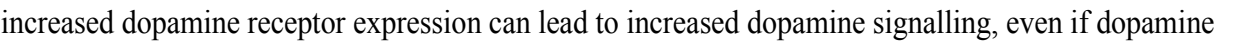

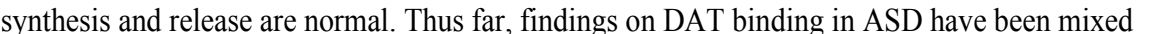

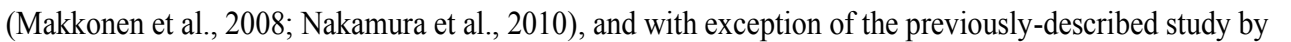

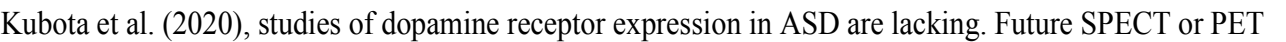

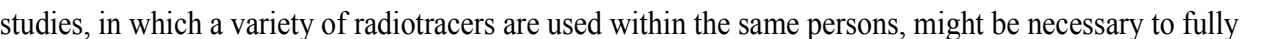

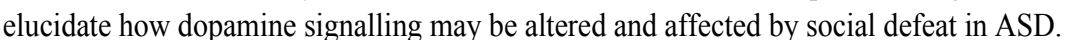

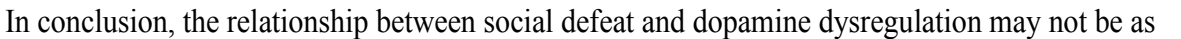

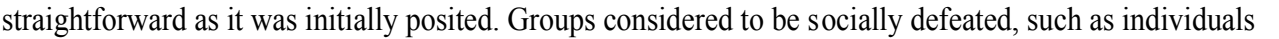
प

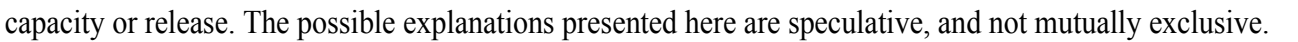

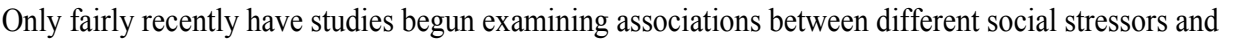

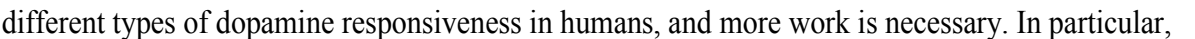

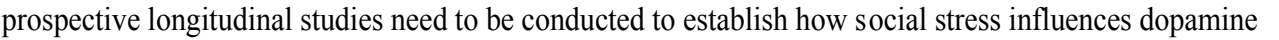

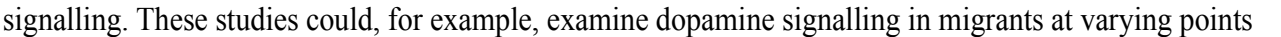

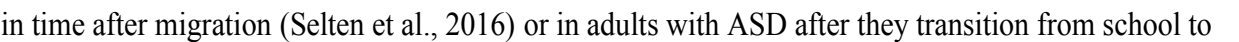
प

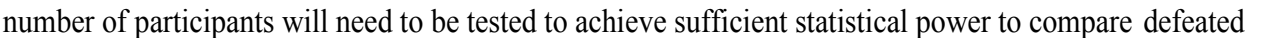

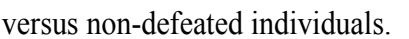




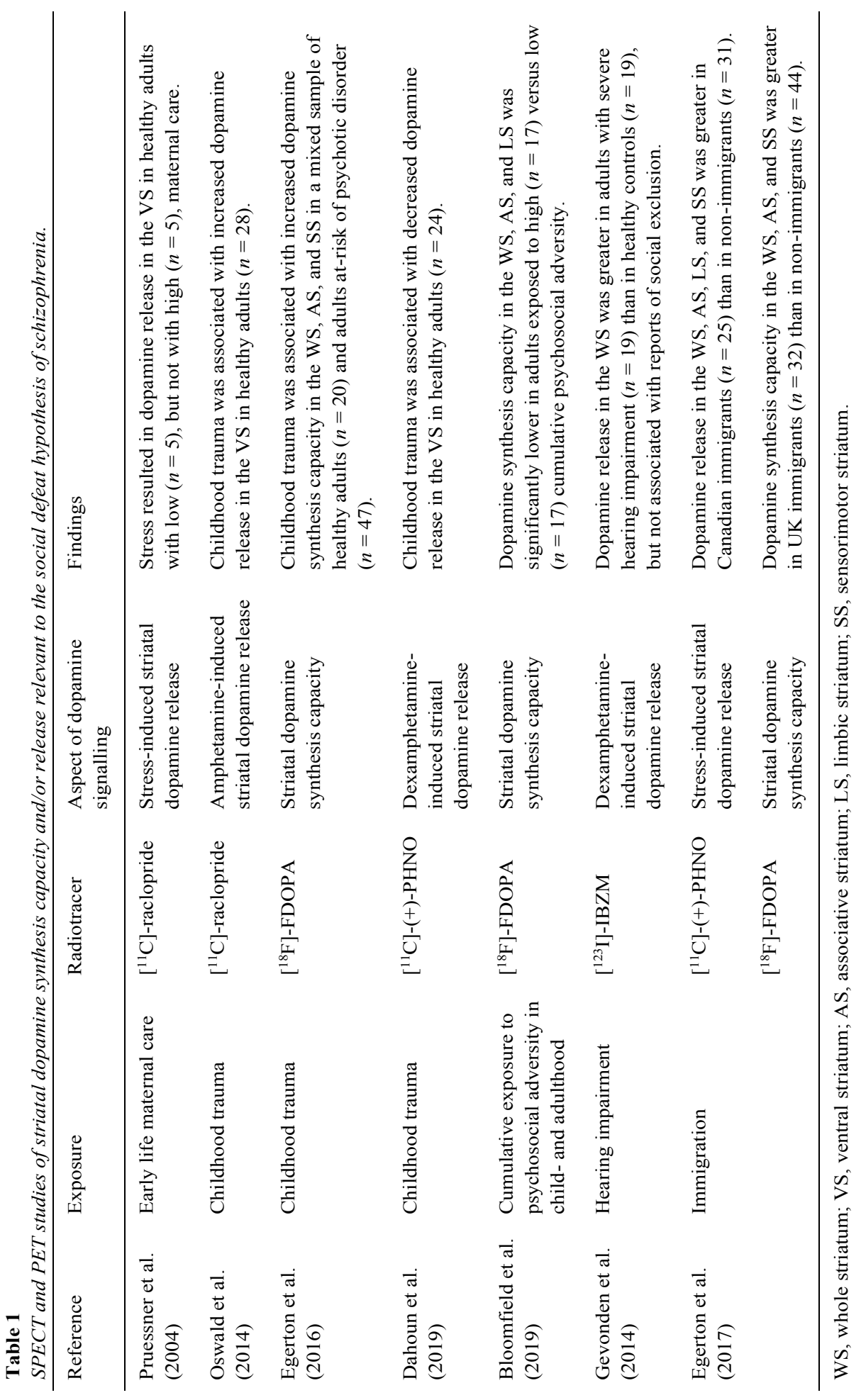




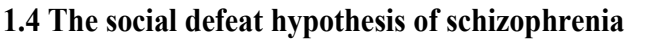

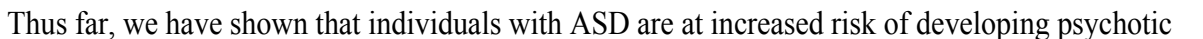

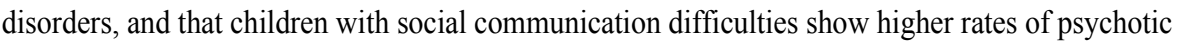

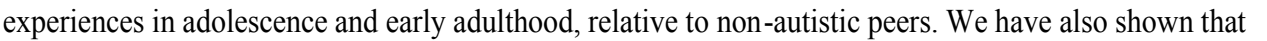

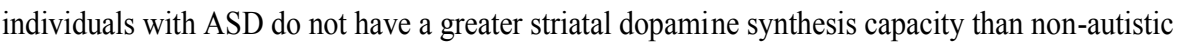

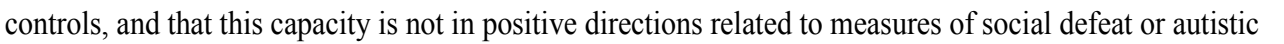
:

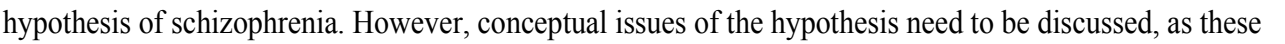

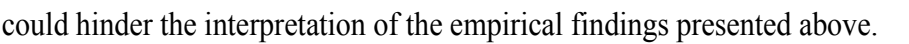

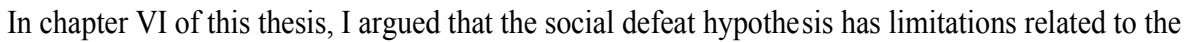

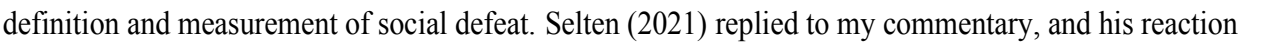
has been included as an appendix to the chapter. Below I further discuss my commentary and Selten's पाणाणा

$\square$

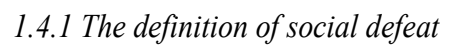

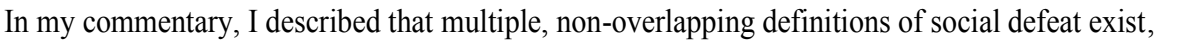

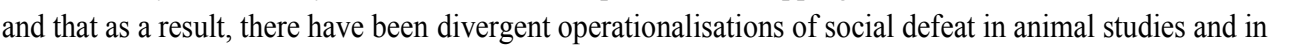

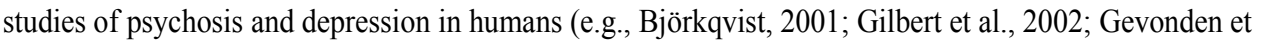
al., 2014; Jaya et al., 2017;

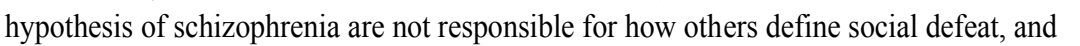

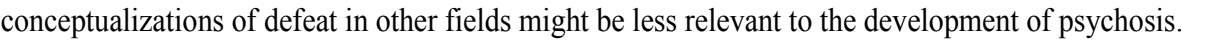

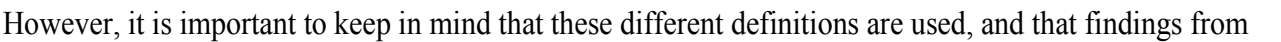

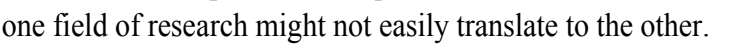

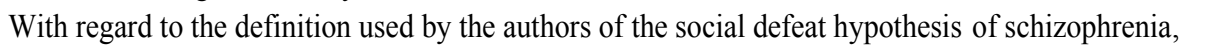

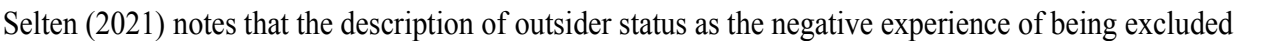

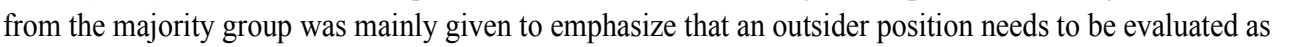

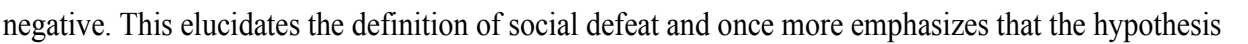

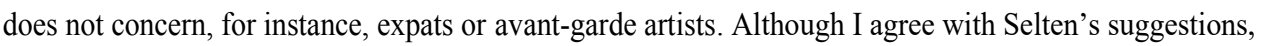

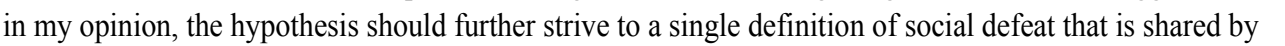

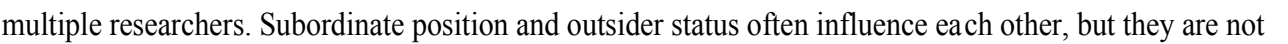

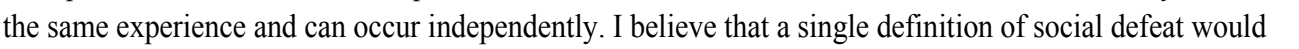

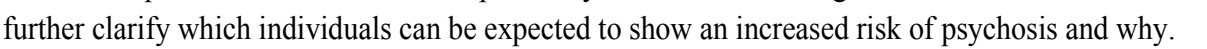
$\square$

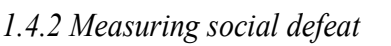

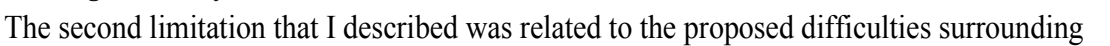

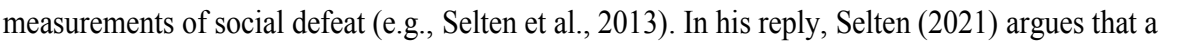

hypothesis' utility is determined by its falsifiability

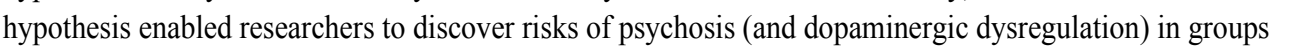

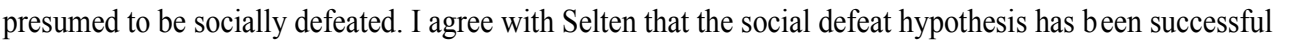

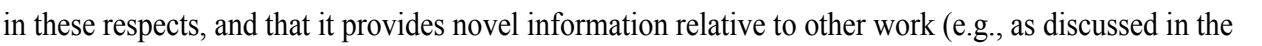

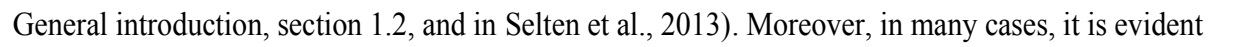

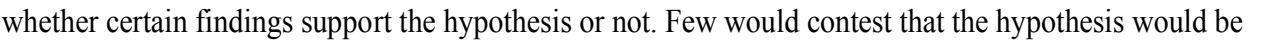

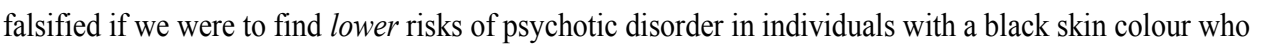

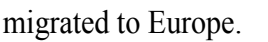




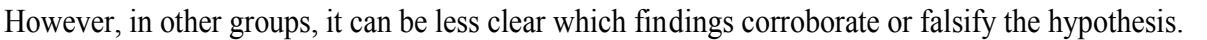

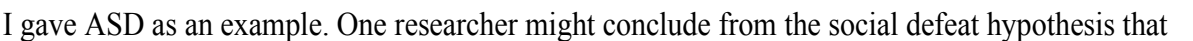
ए

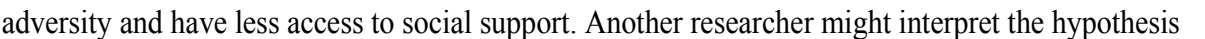

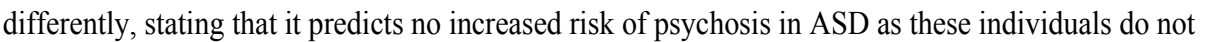

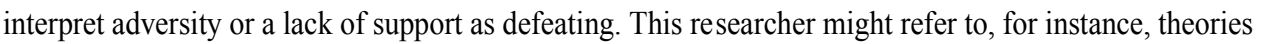
प

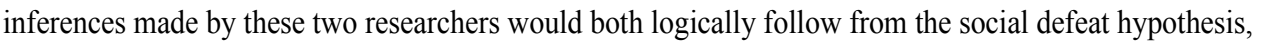

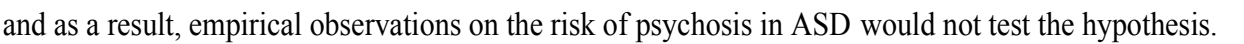

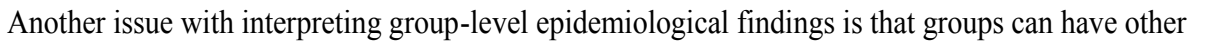

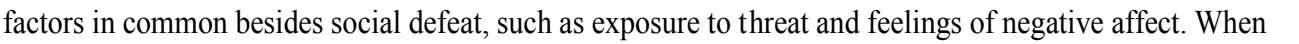

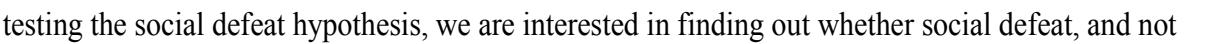

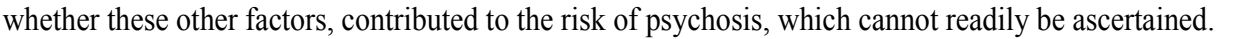

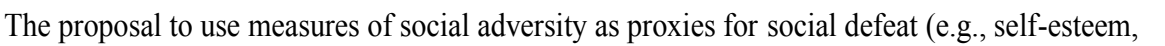

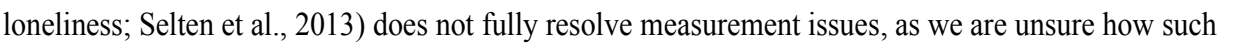

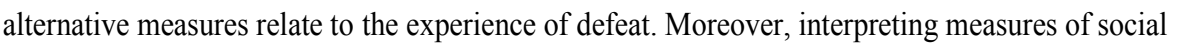

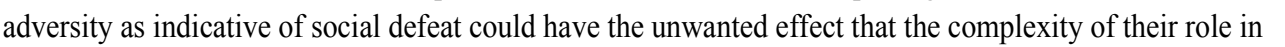

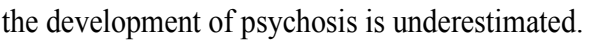

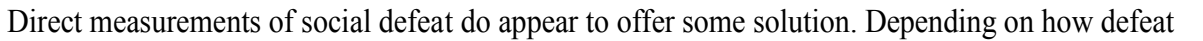

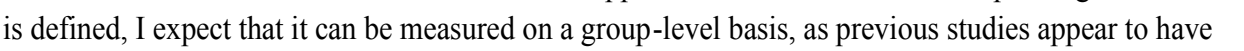

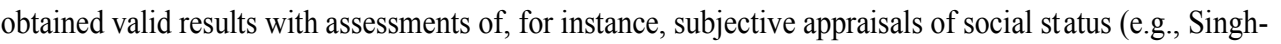
Manoux et al., 2003; Jaya et al., 2017)

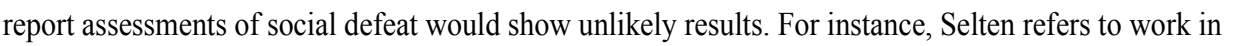

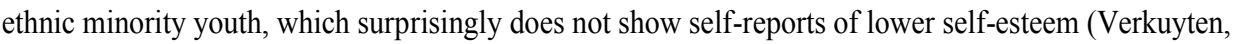

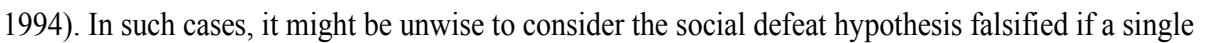

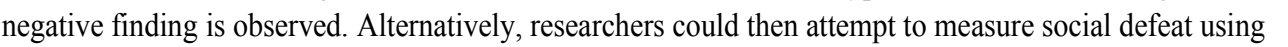

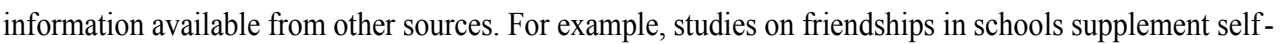

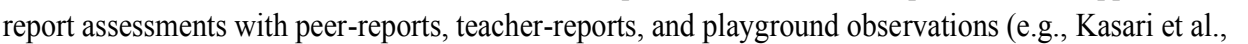

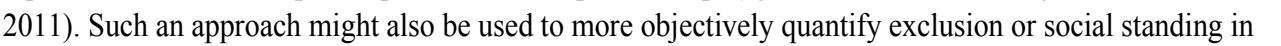

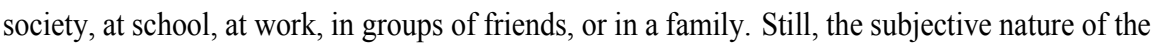

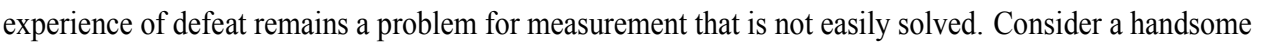
man, 30 years old, with an average level of education, who works as a sports instructor. If he has a 口

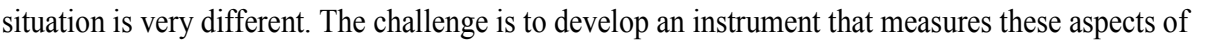

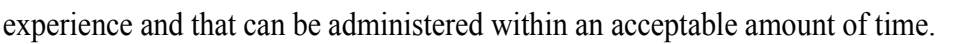

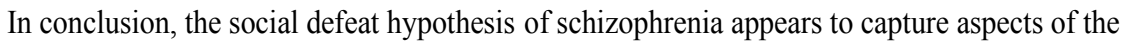

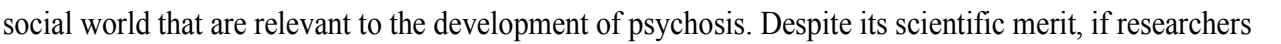

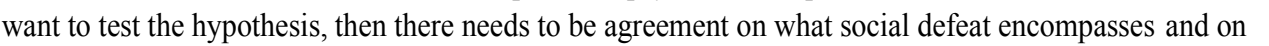

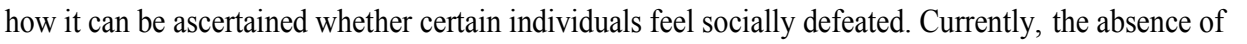

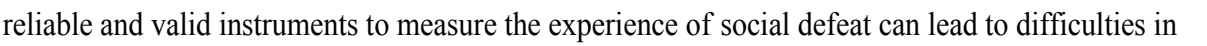

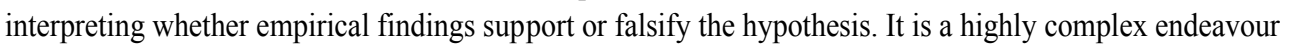
to tackle these issues, but one that might eventually lead to a further improvement of the hypothesis'

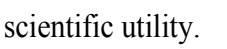
$\square$ 


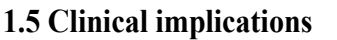

\begin{aligned} \hline \\ \hline\end{aligned}

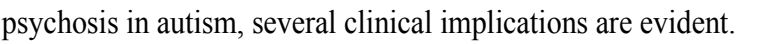

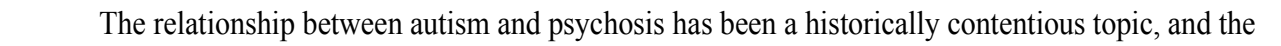

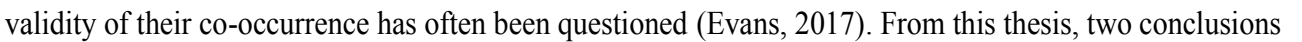

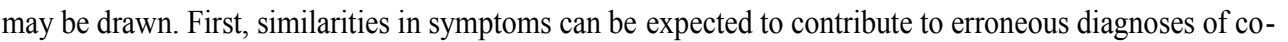

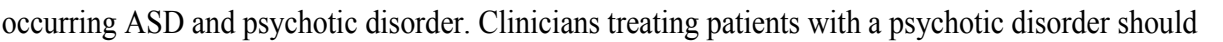

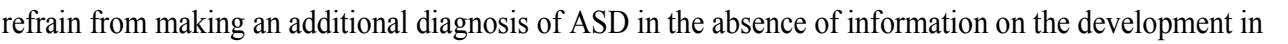

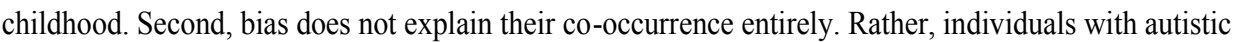

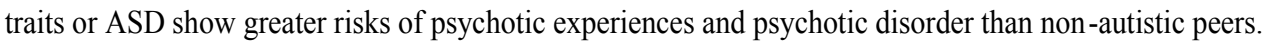

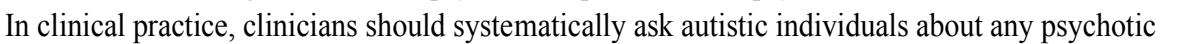

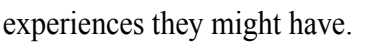

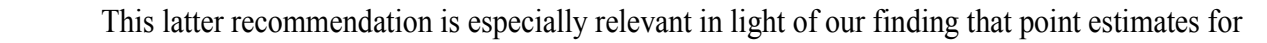

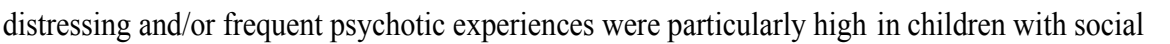

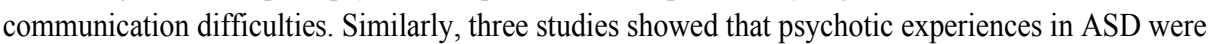

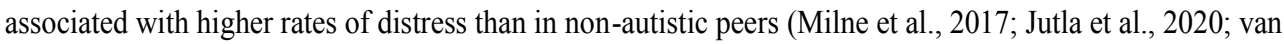

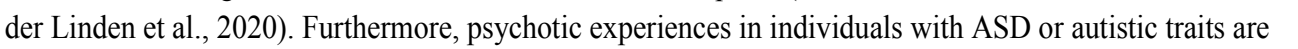

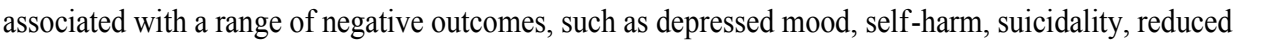

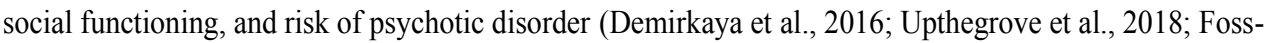

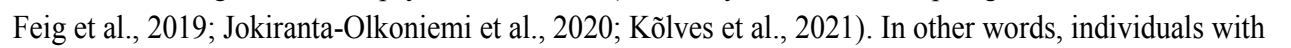

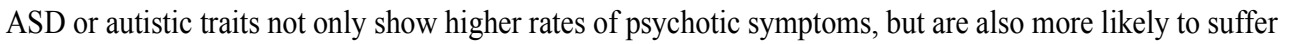

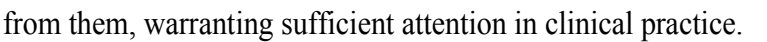

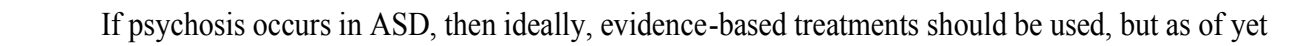

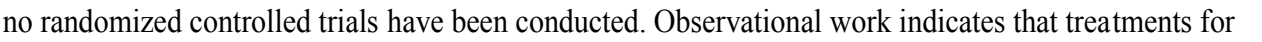

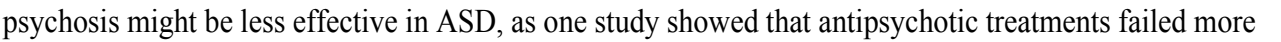

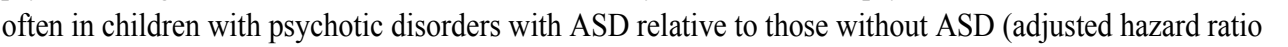

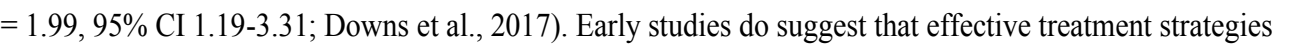

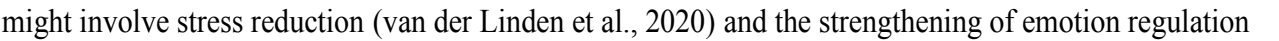

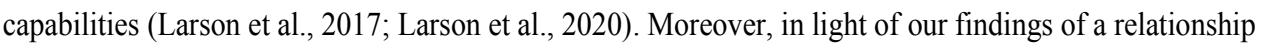

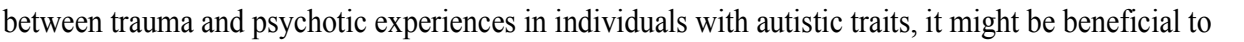

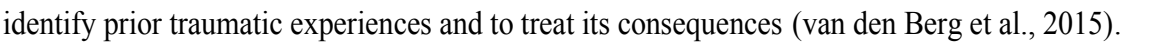

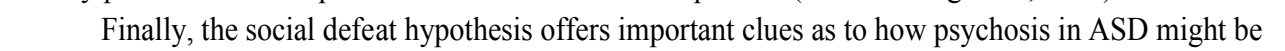

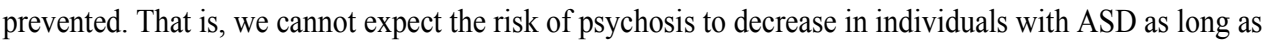

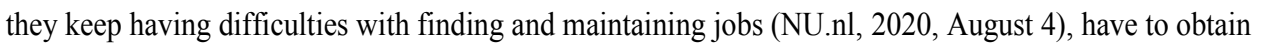

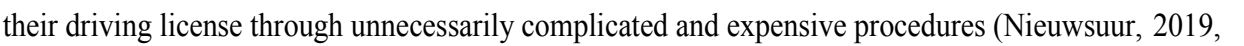

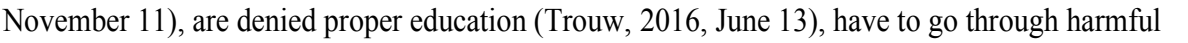

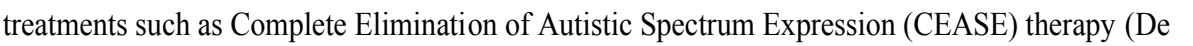

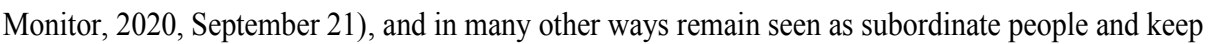

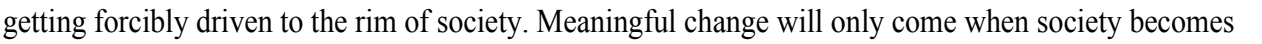

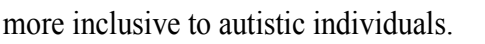

$\square$

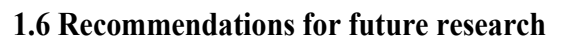

\begin{aligned} \hline \\ \hline\end{aligned}

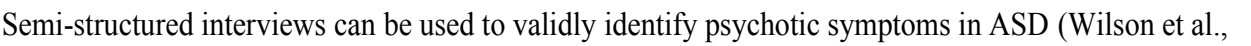




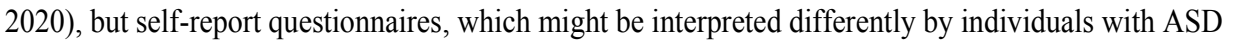

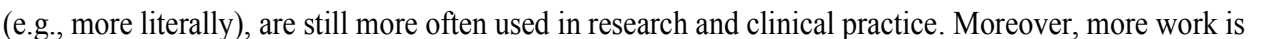

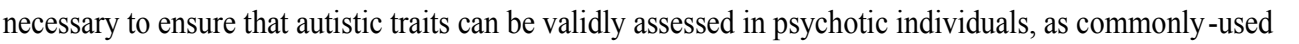

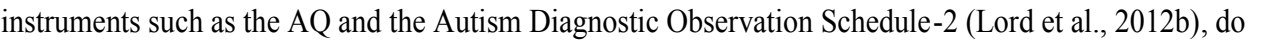

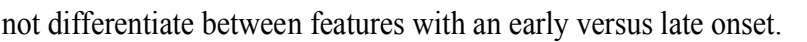

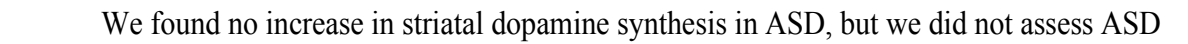

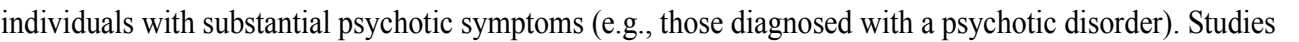

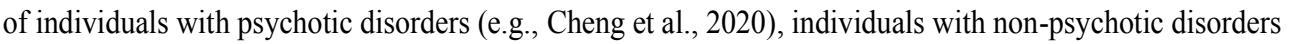

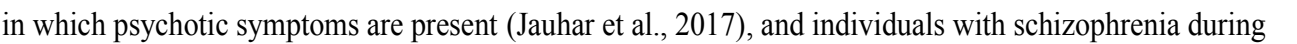

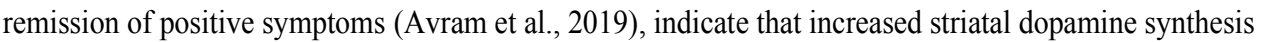

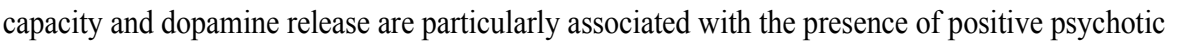

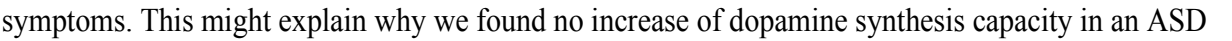

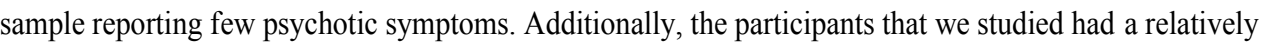

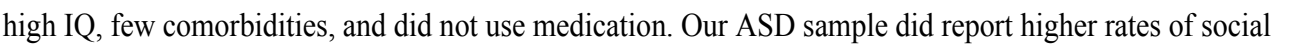

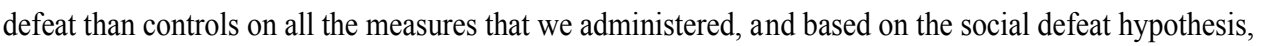

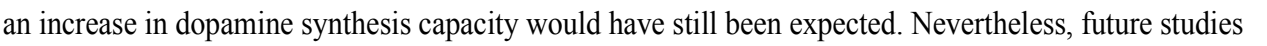

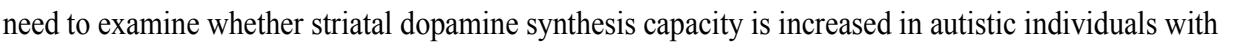

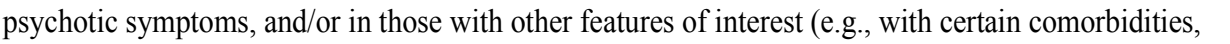

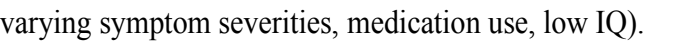

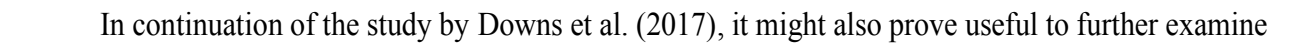

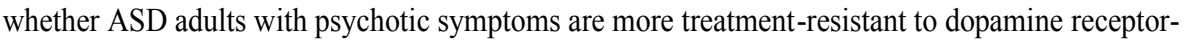

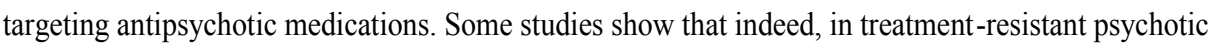

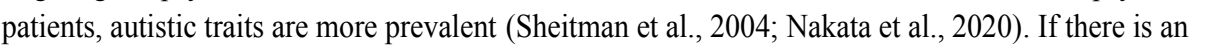

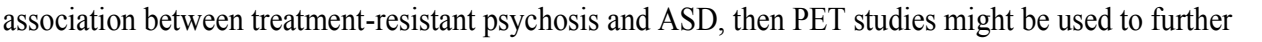

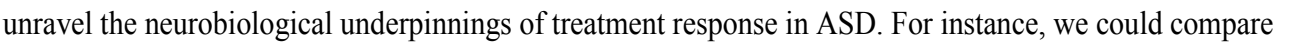

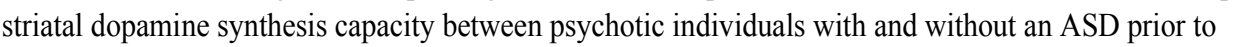

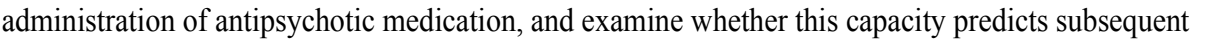

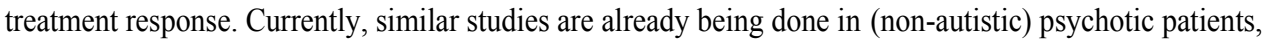

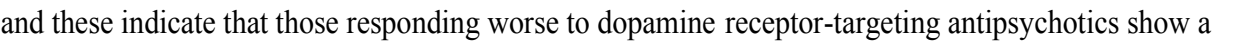

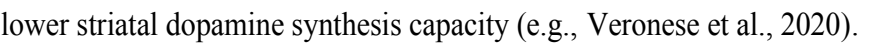

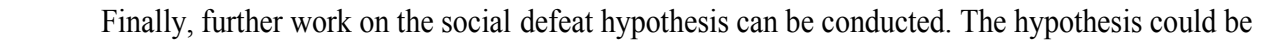

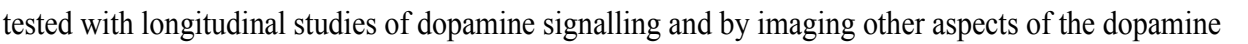

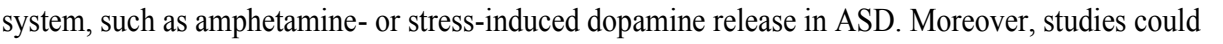

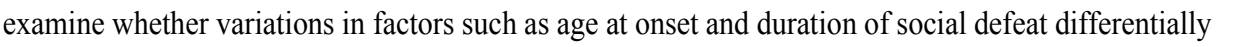

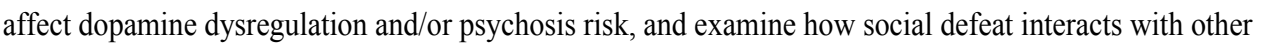

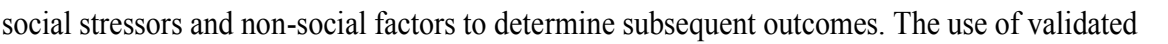

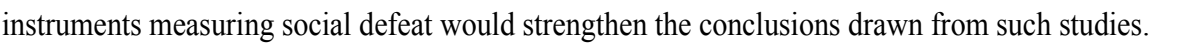
$\square$

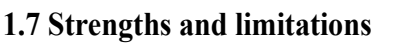

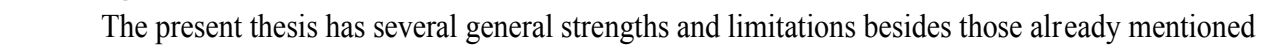

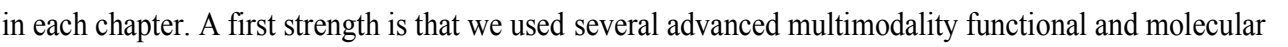

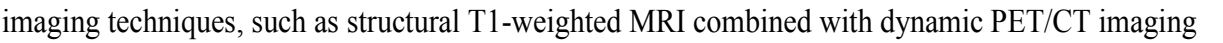
ए एव

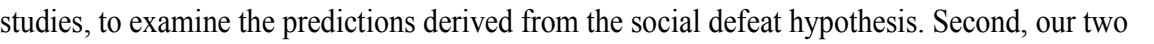




\section{General discussion}

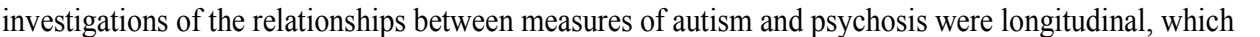

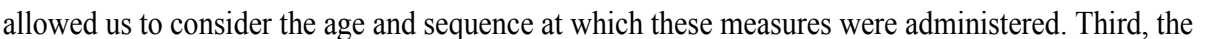

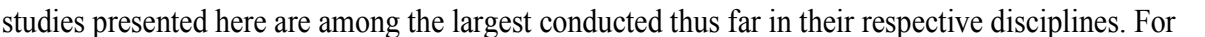

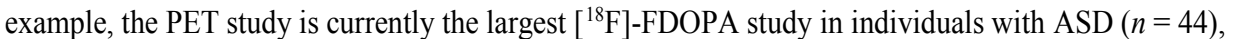

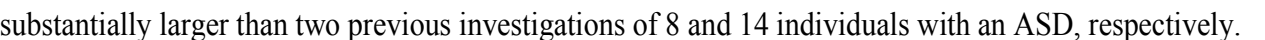
\begin{aligned} \hline \\ \hline\end{aligned}

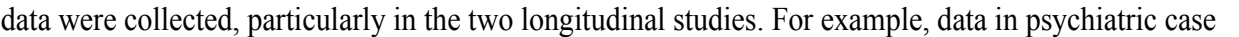

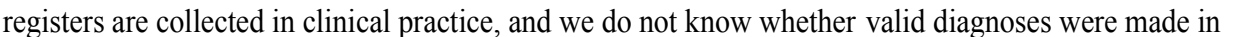

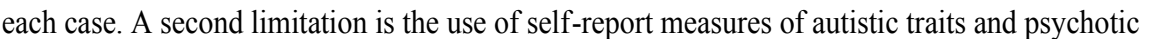
पा

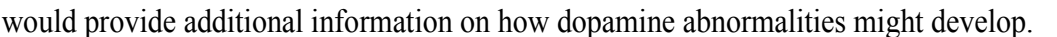
$\square$

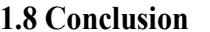

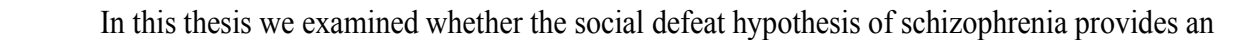

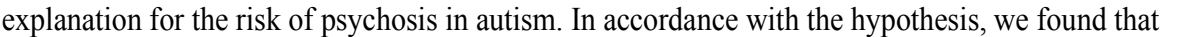

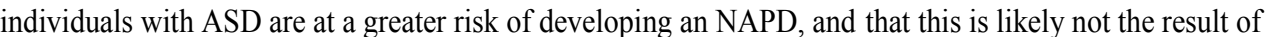

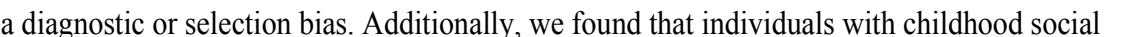

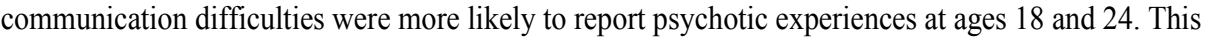

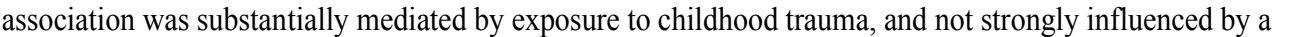

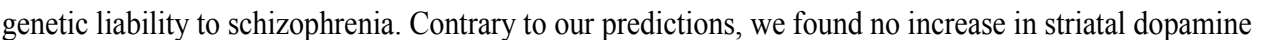

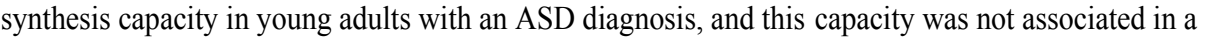

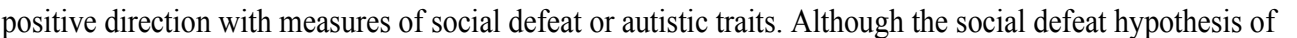

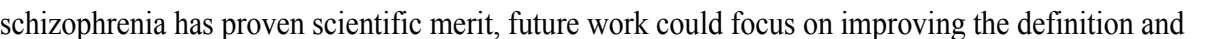

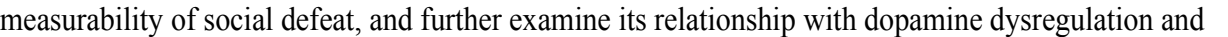
पा山ापा山ाण 


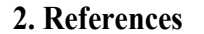

Abi-Dargham, A., Simpson, N., Kegeles, L., Parsey, R., Hwang, D. R., Anjilvel, S., Zea-Ponce, Y.,

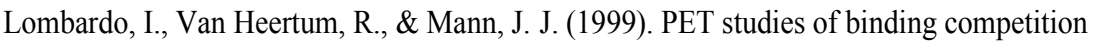

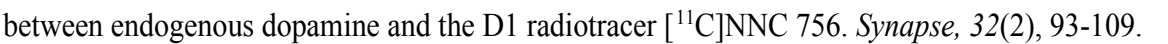

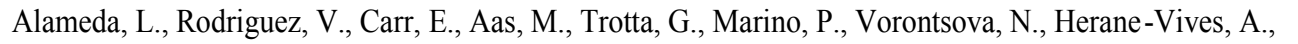

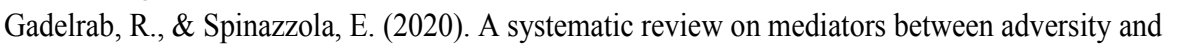

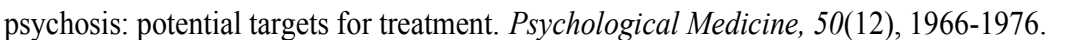

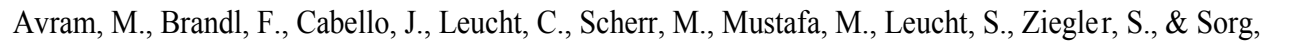

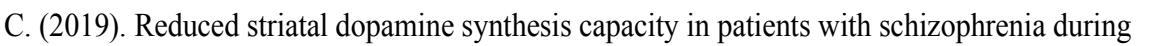

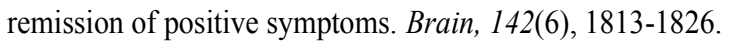

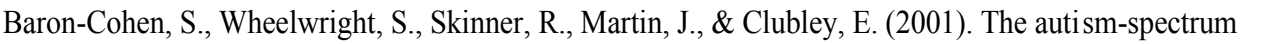

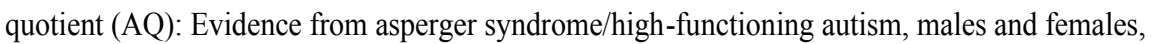

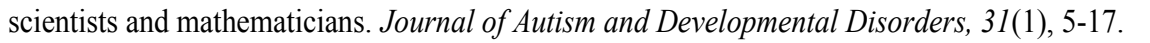

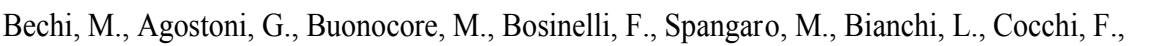

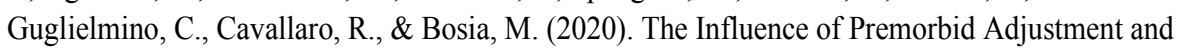

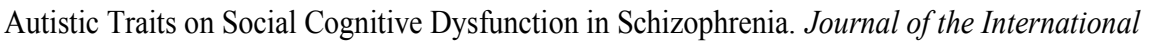

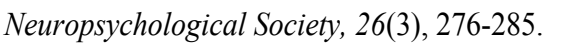

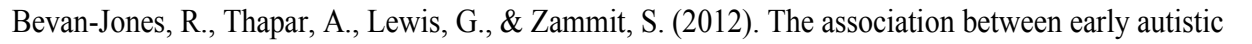

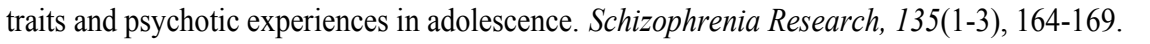

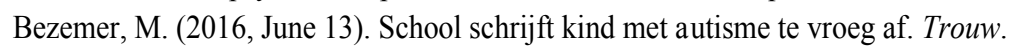

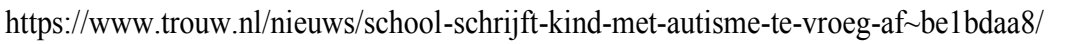

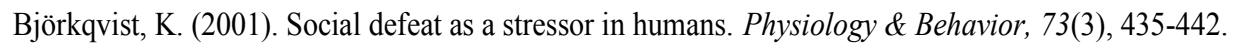

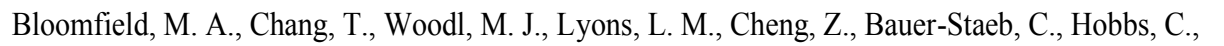

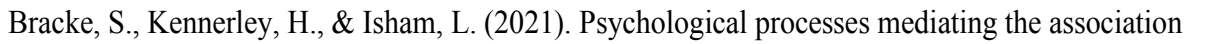

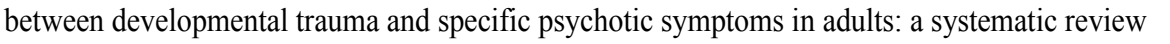

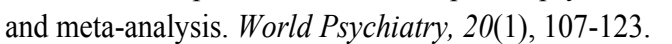

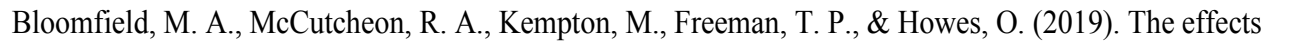

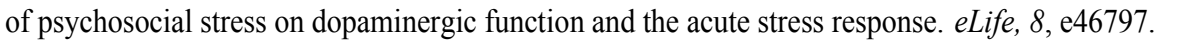

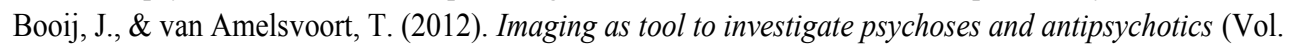

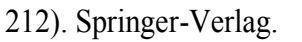

a

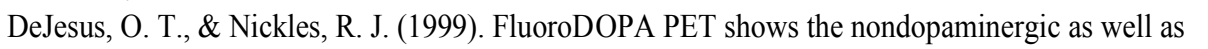

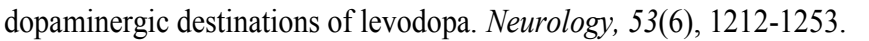

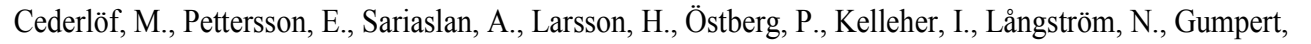

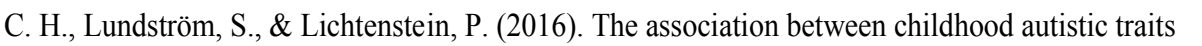

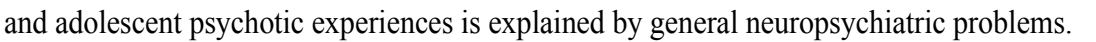

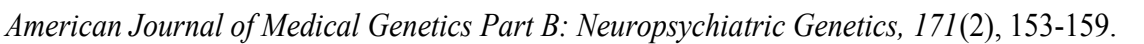

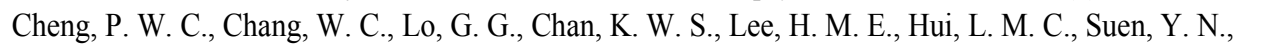

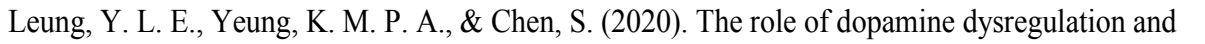

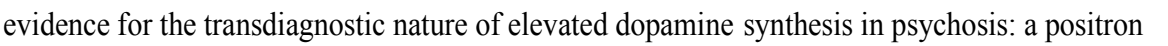

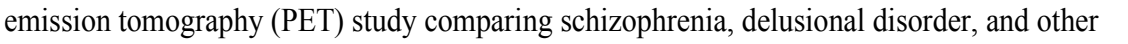

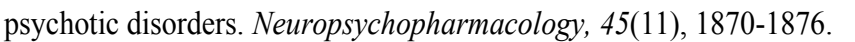

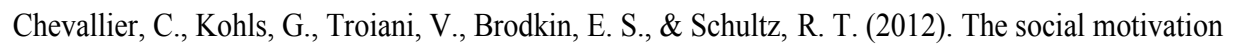

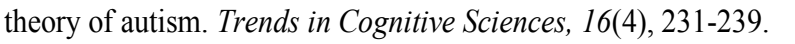




\section{General discussion}

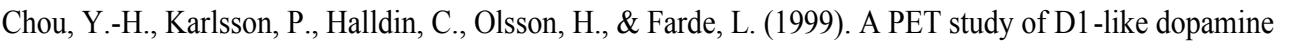

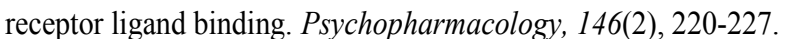

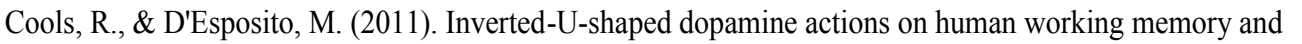

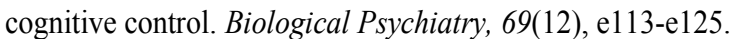

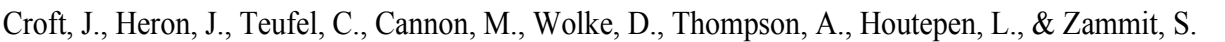

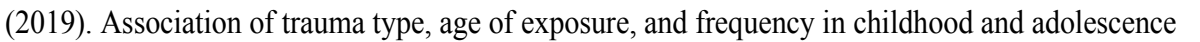

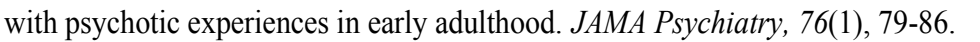

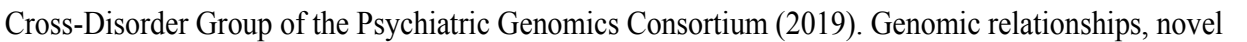

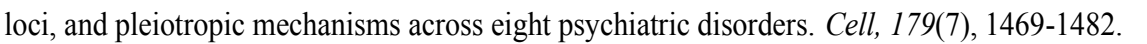

$\square 11 \mathrm{II}$

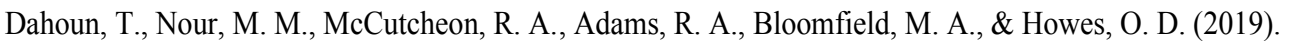

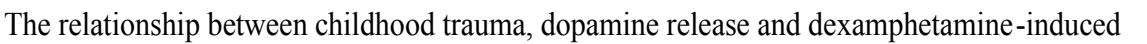

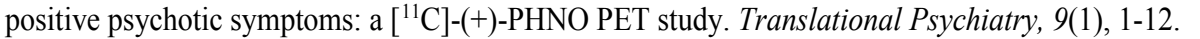

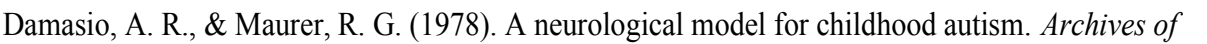

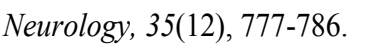

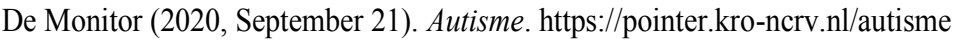

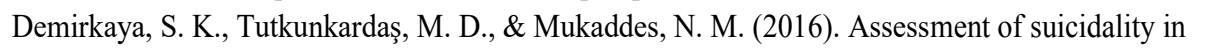

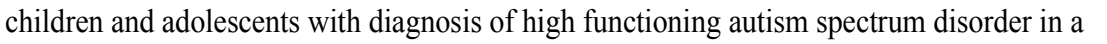

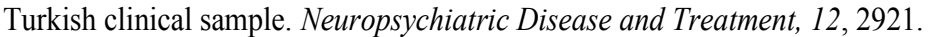

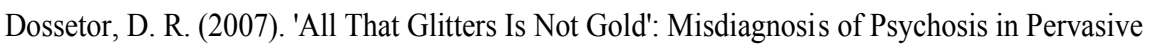

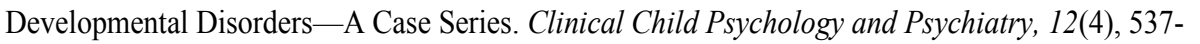
$\square \square \square$

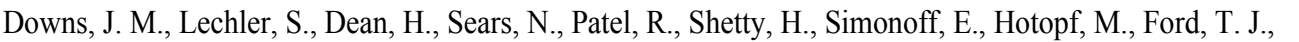
प

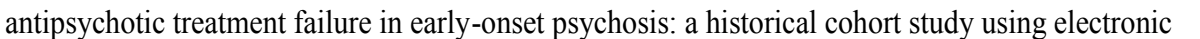

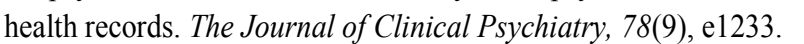

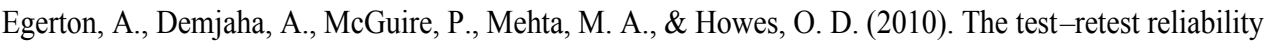

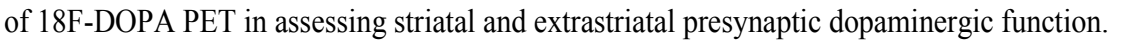

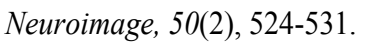

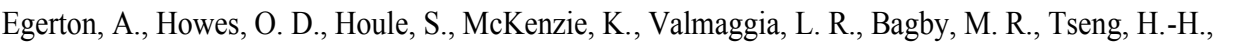

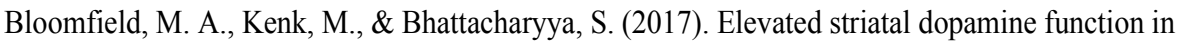

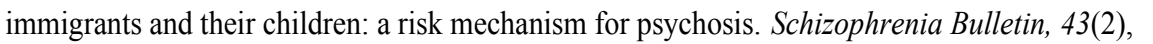

पाणाणा

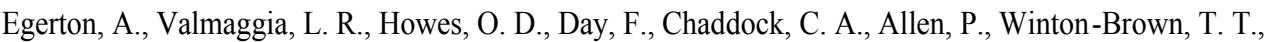

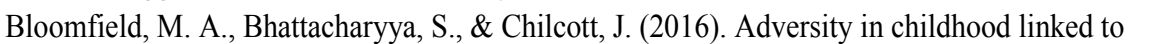

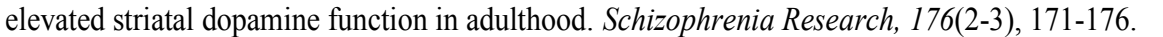

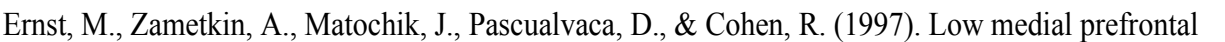

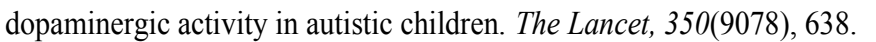

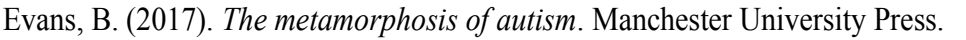

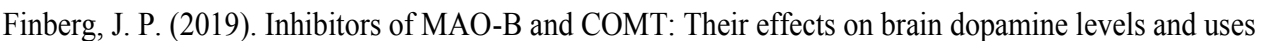

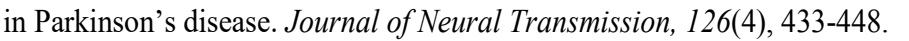

a

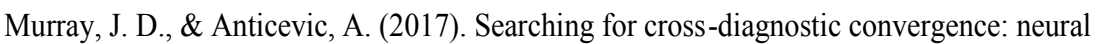




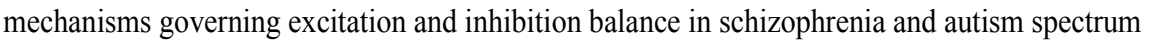

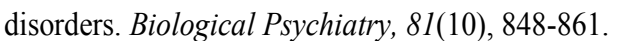

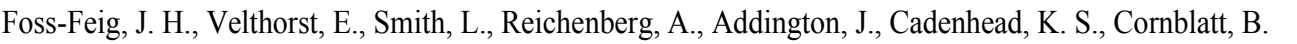

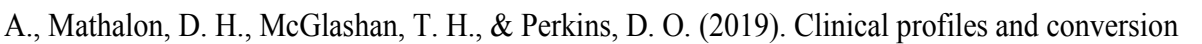

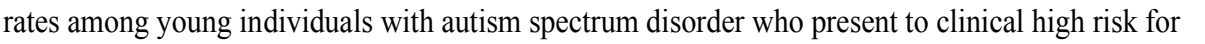

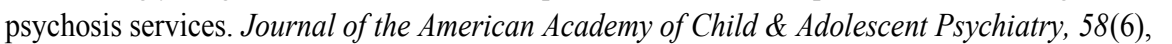
पाणाएा

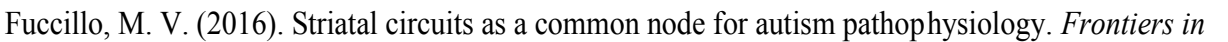

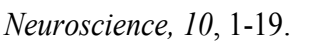

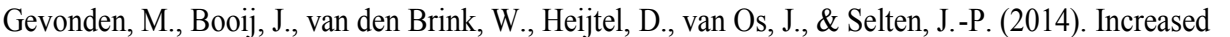

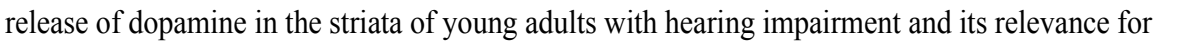

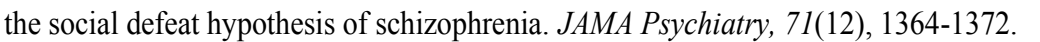

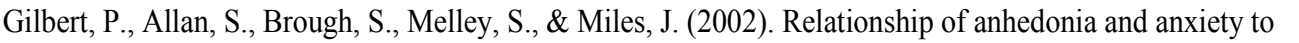

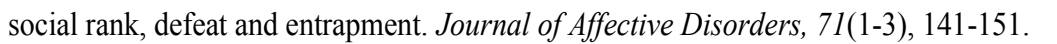

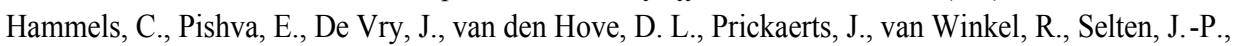

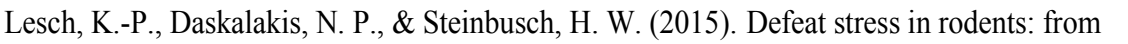

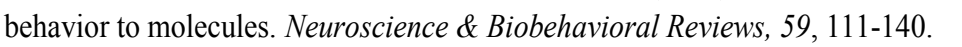

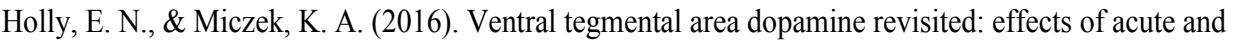

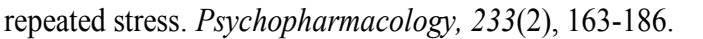

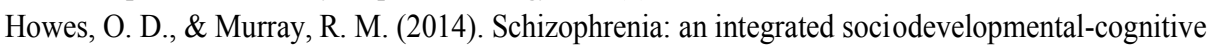

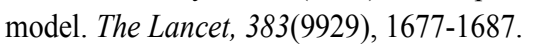

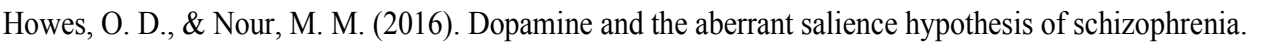

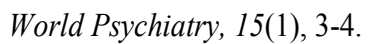

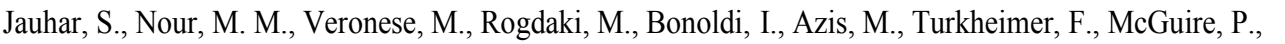

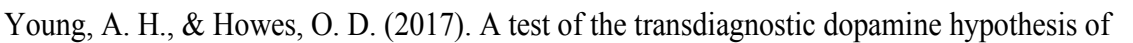

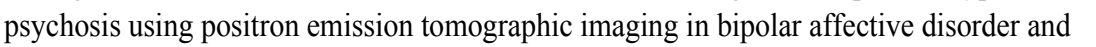

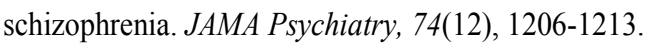

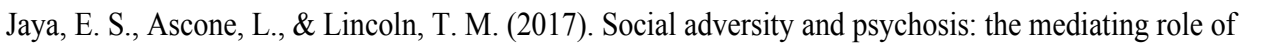

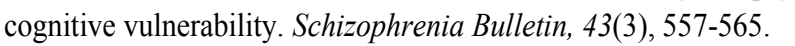

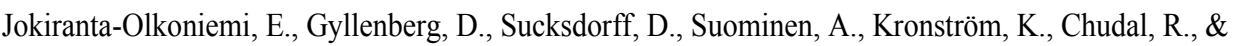

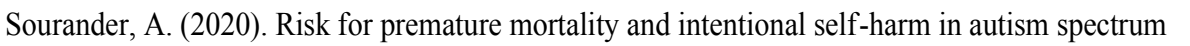

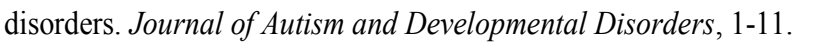

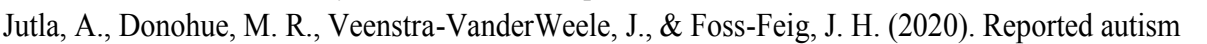

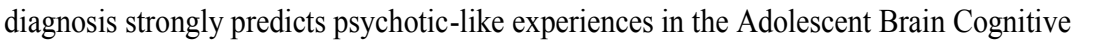

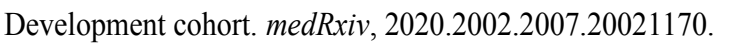

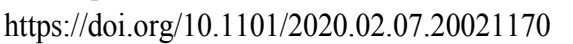

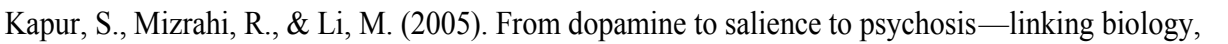

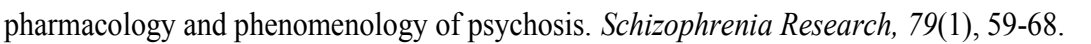

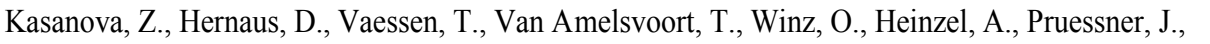

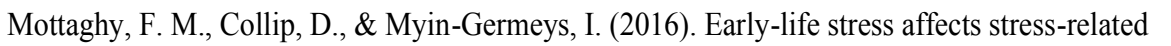

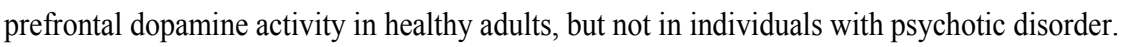

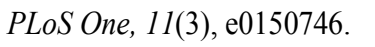




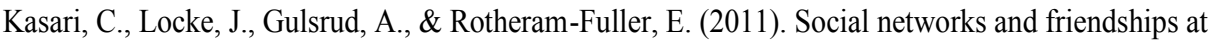

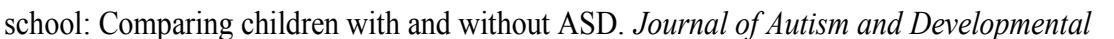

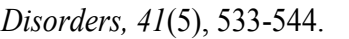

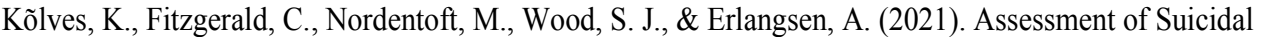

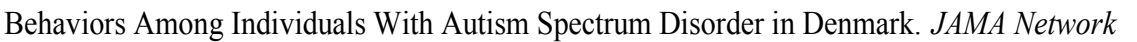

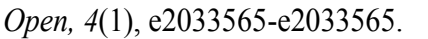

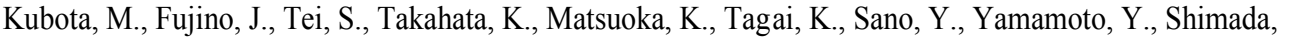

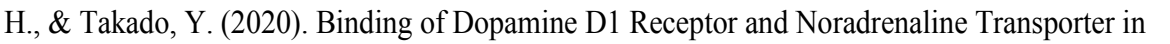

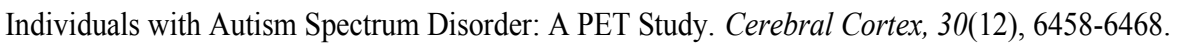

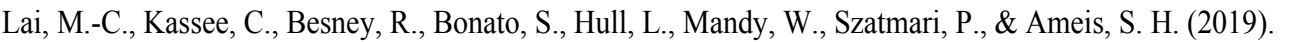

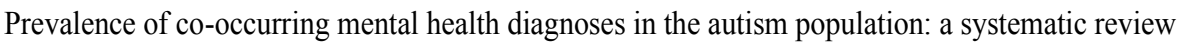

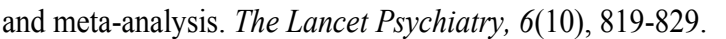

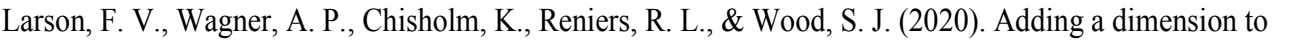

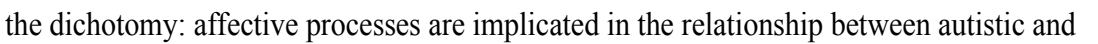

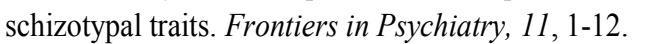

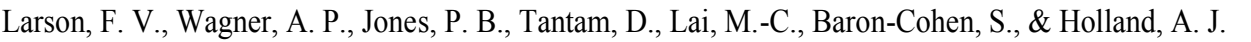

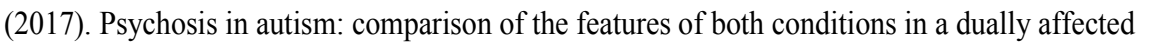

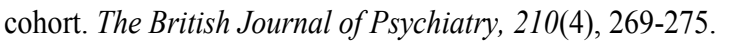

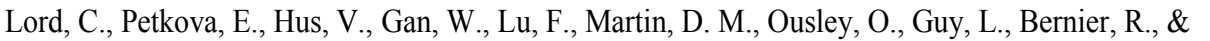

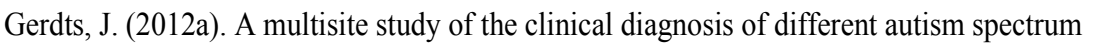

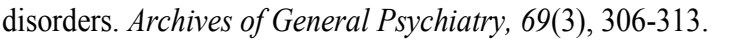

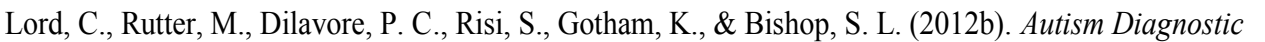

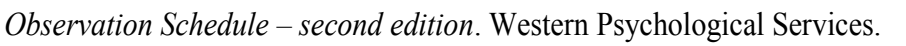

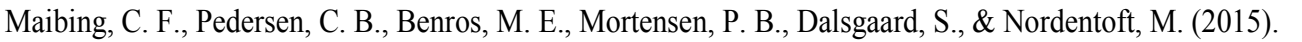

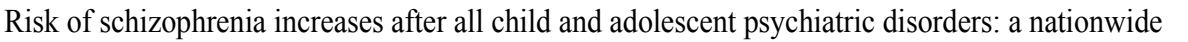

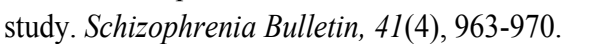

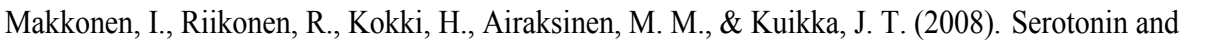

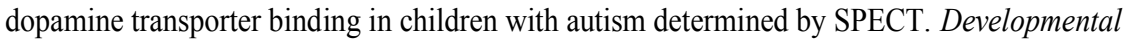

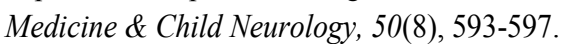

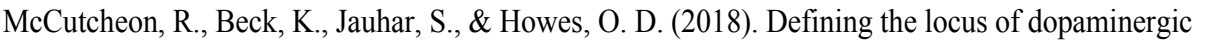

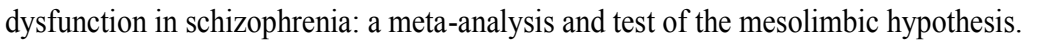

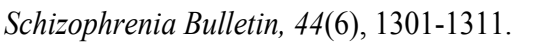

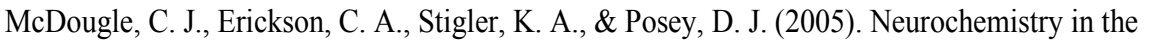

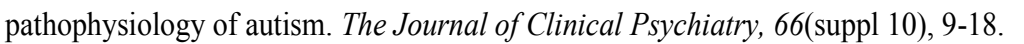

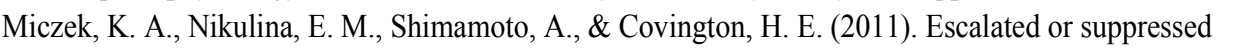

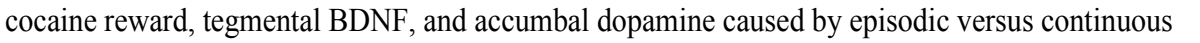

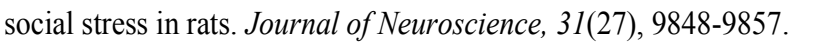

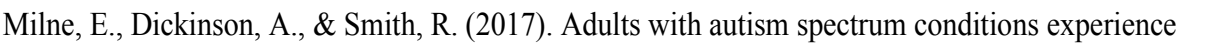

ए

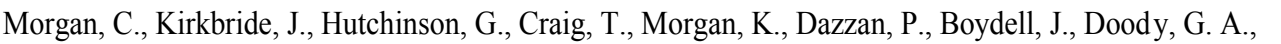

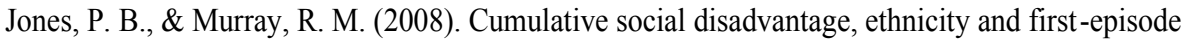

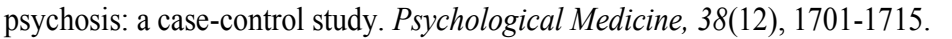

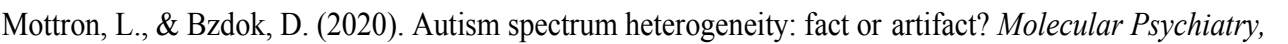

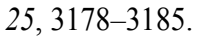




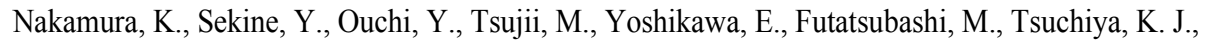

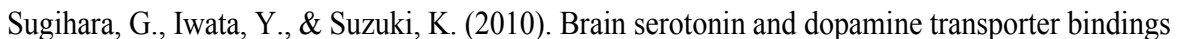

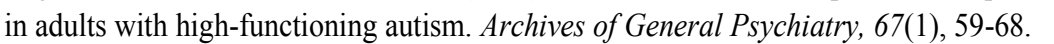

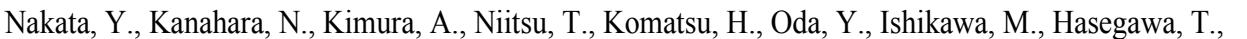

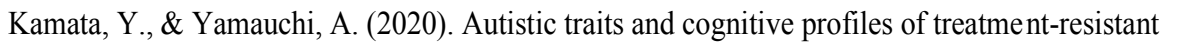

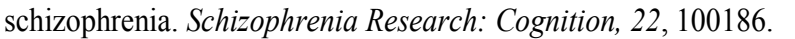

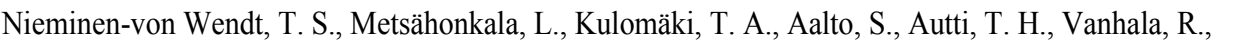

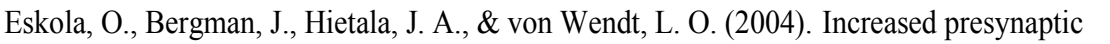

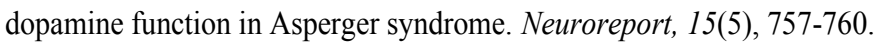

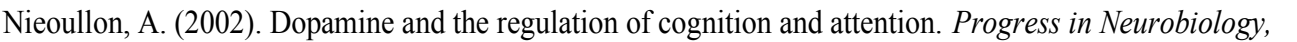

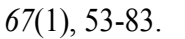

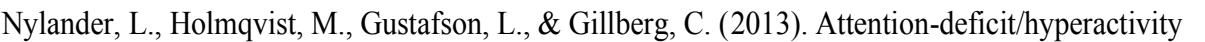

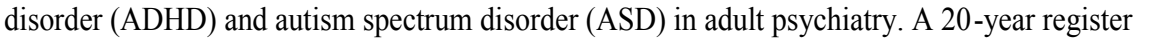

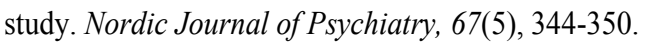

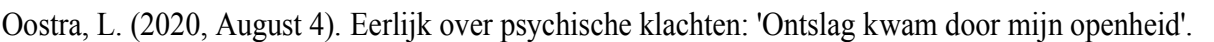

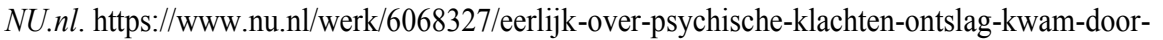

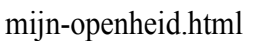

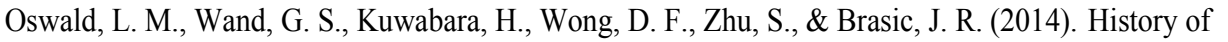

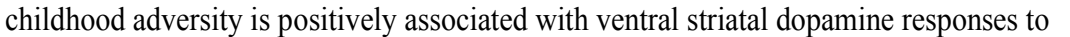

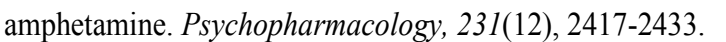

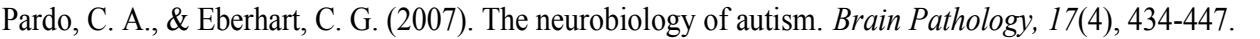

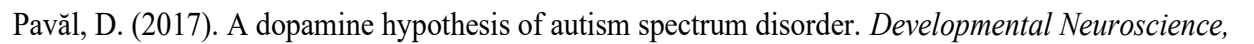

पाणाणमणाए

a

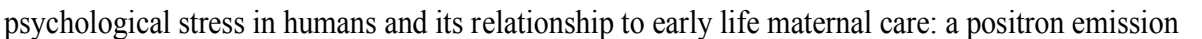

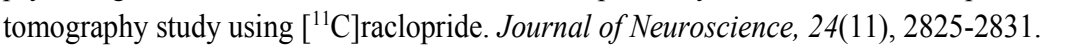

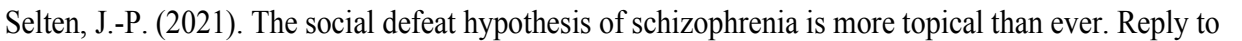

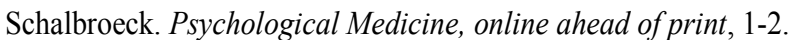

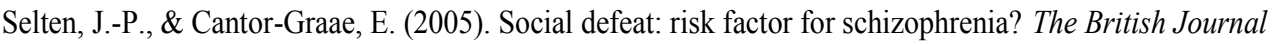

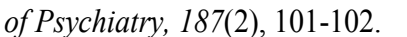

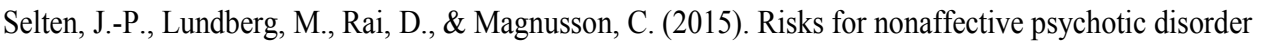

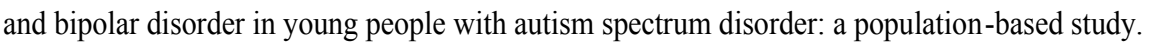

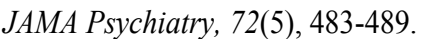

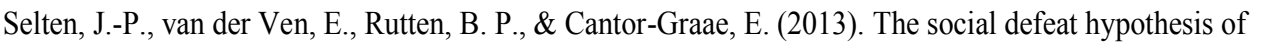

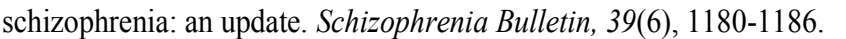

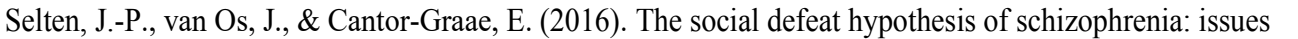

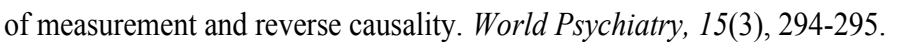

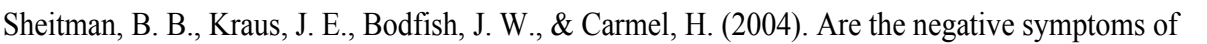

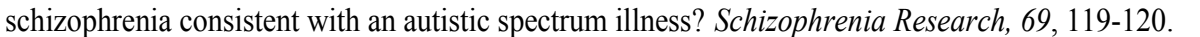

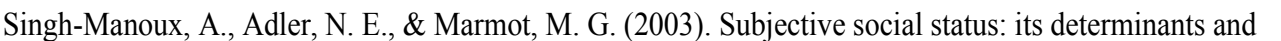

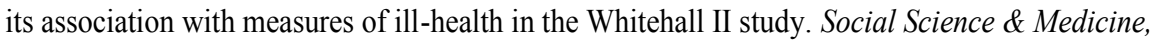

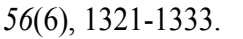

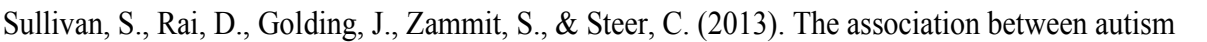

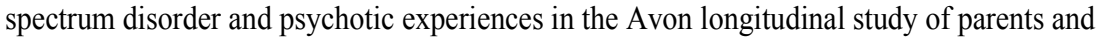




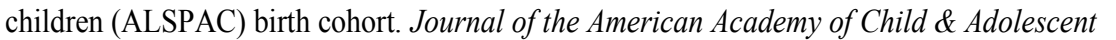

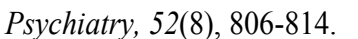

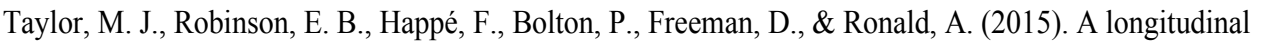

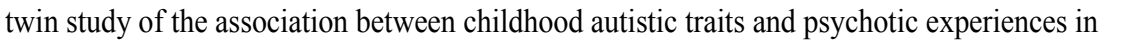

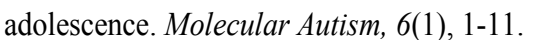

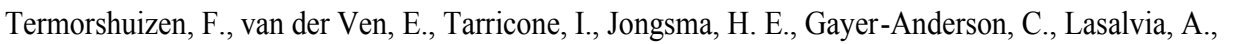

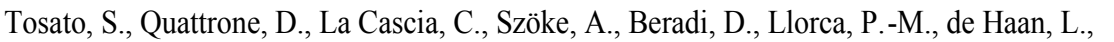

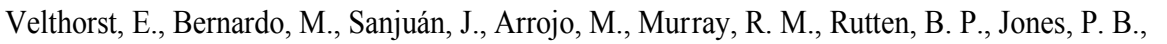

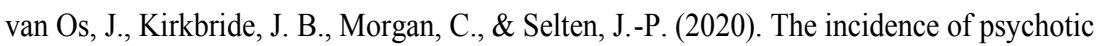

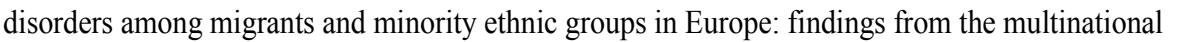

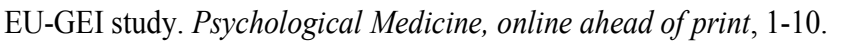

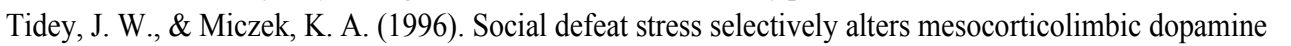

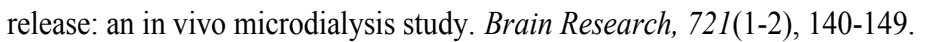

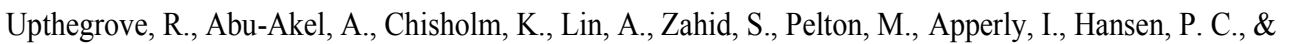

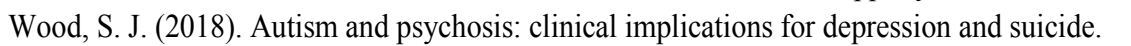

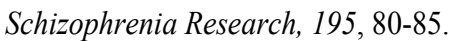

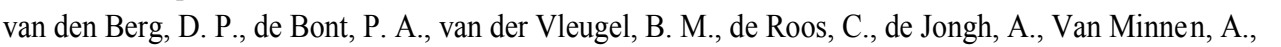

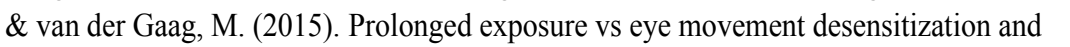

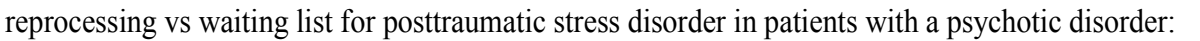

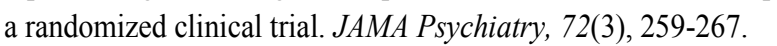

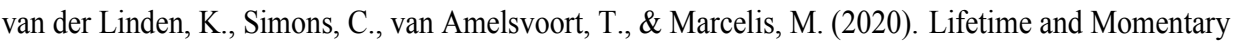

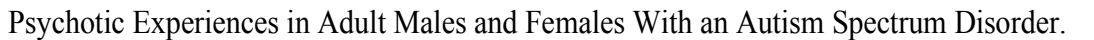

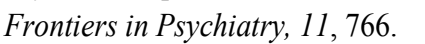

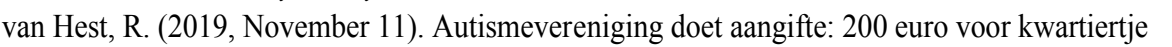

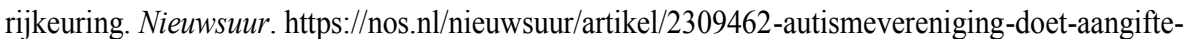

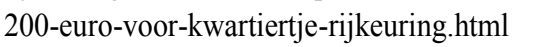

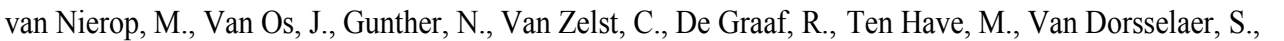

Bak, M., Myin-Germeys, I., \& van Winkel, R. (2014). between childhood trauma and psychosis? Evidence from the NEMESIS-2 S tudy. $\square \square \square$

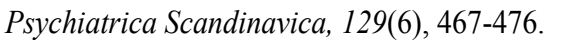

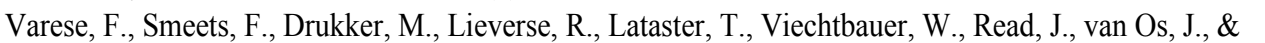

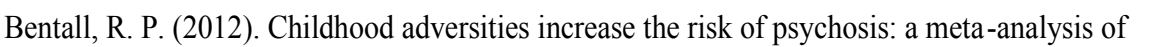

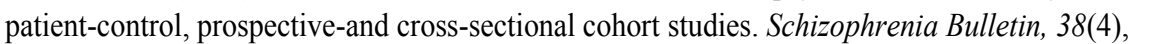

$\square 1 \| 1 \mathrm{~W}$

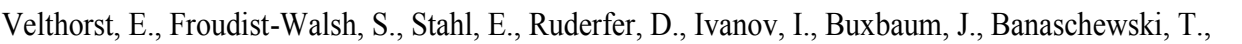

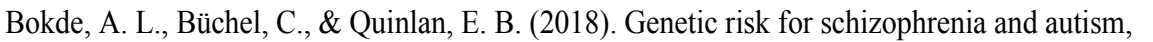

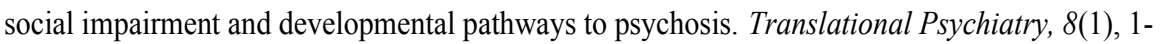

$\square \mathrm{III}$

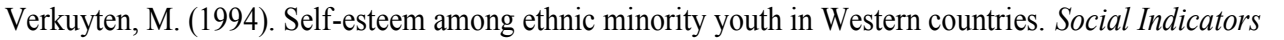

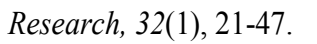

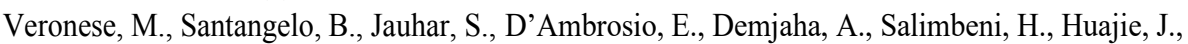

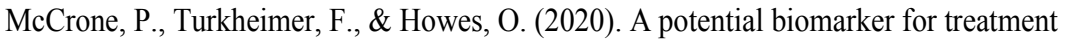

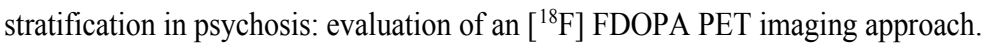

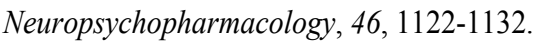




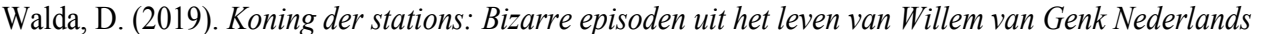

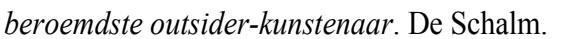

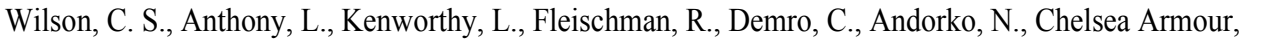

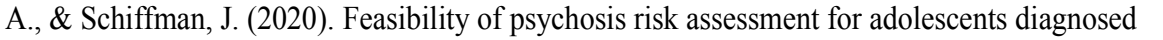

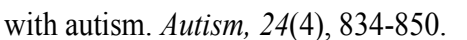

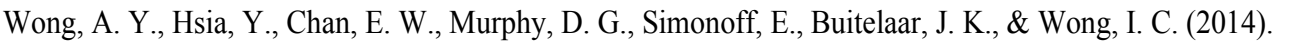

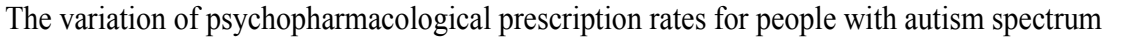

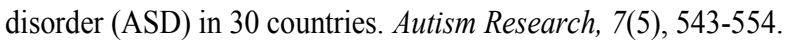

Wu, K., O’Keeffe, D., Politis, M., O’Keeffe, G. C., Robbins, T. W., Bose, S. K., Brooks, D. J., Piccini, P.,

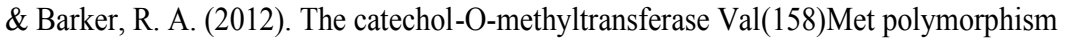

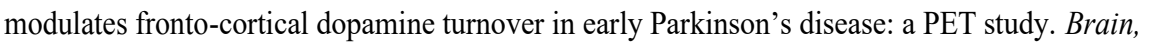

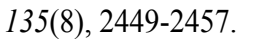

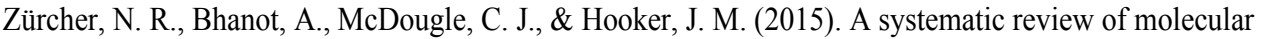

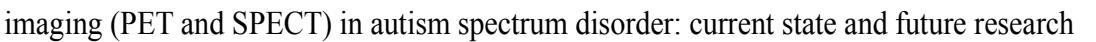

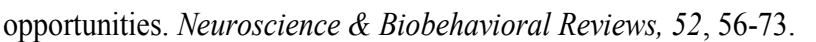

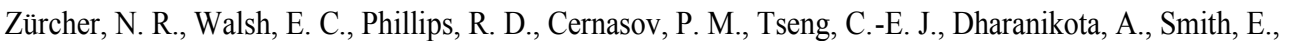

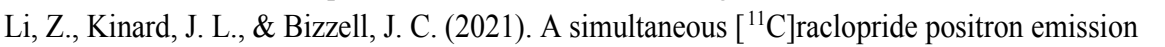
ए

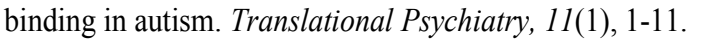

$\square$ 



\section{Appendices}

Nederlandse samenvatting

Impact paragraph

List of publications

Dankwoord

\section{Curriculum vitae}


Appendices

$\square$ 


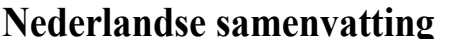

$\square$

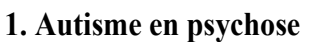

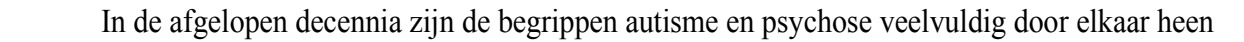

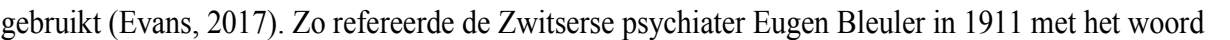

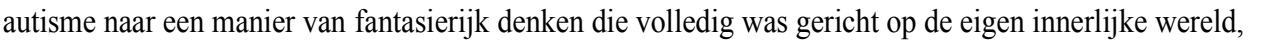

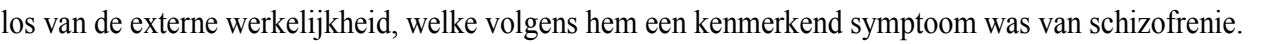

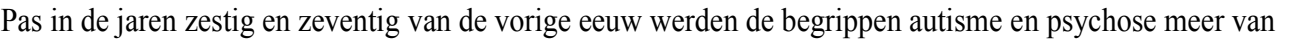

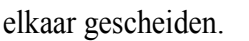

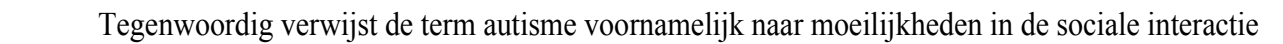

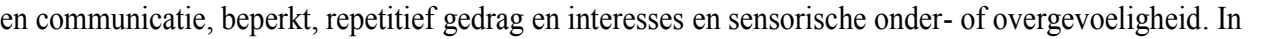

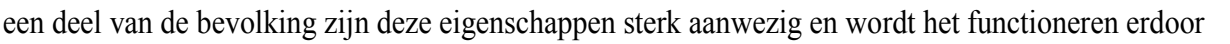

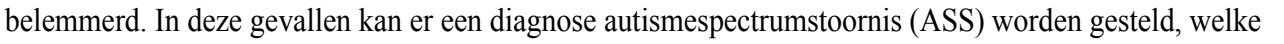

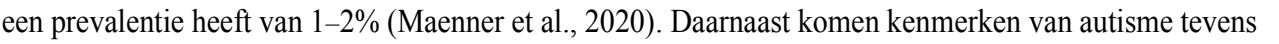

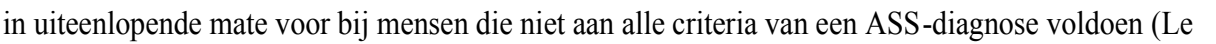

Couteur et al., 1996; Constantino et al., 2003) $\square$

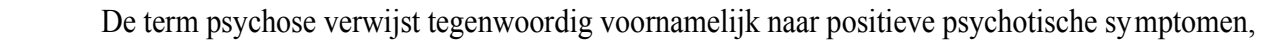

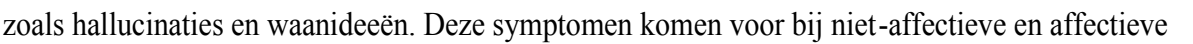

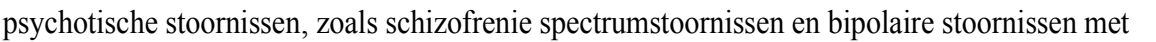

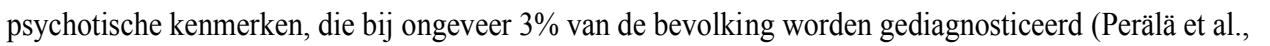

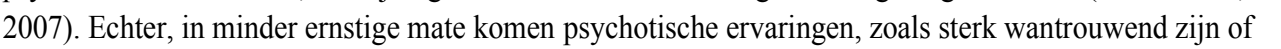

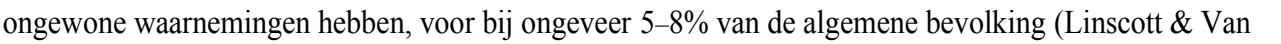

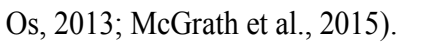

\begin{aligned} \hline \\ \hline\end{aligned}

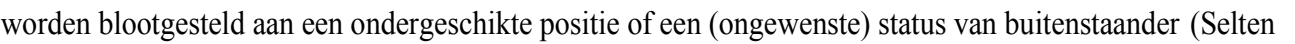

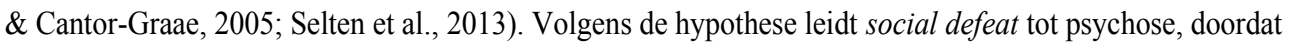

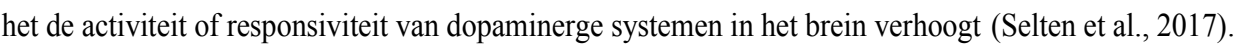

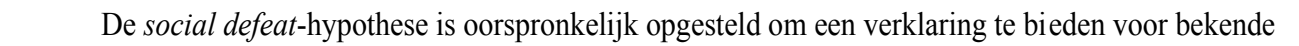

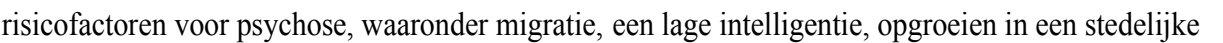

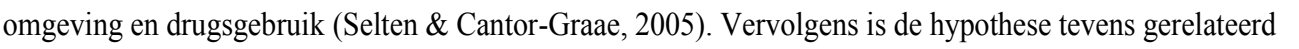

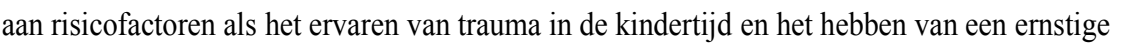

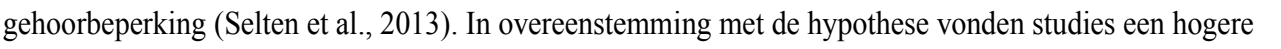

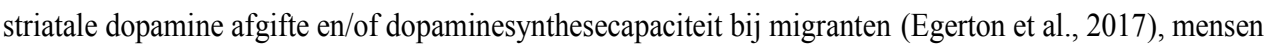

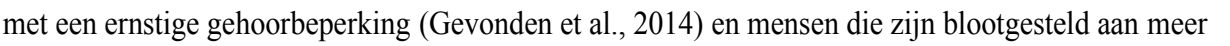

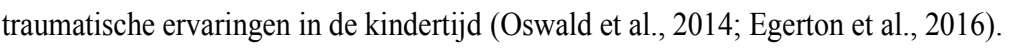

$\square$
$\square$

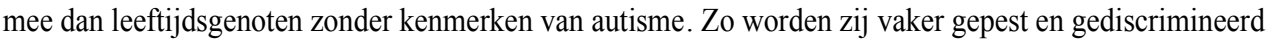

(Schroeder et al., 2014; Johnson \& Joshi, 2016)

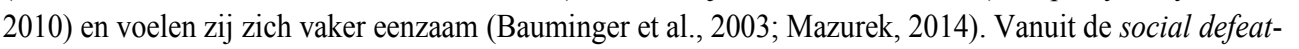

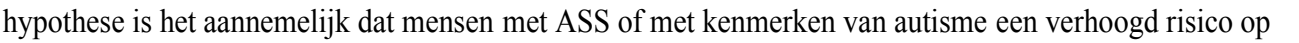

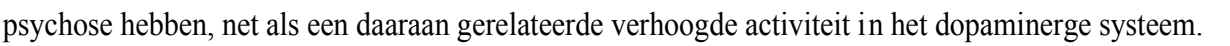

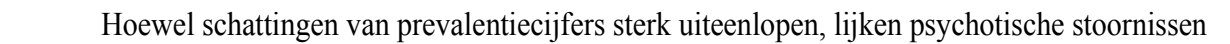

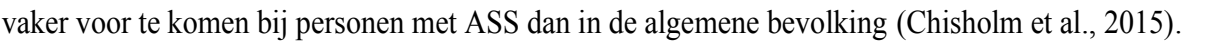

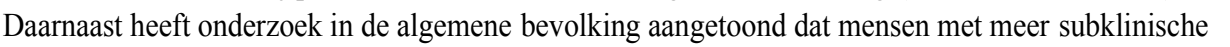




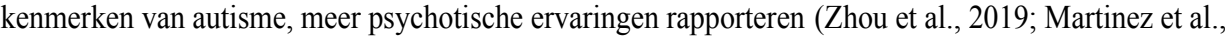
$\square \amalg$ Echter, deze resultaten zijn voornamelijk gebaseerd op cross Sectioneel onderzoek. Hierbij wo $\square \mid \square$ op één moment, meestal bij volwassenen, gekeken of kenmerken van autisme en psychose samengaan. Een belangrijk nadeel van dit soort onderzoek is dat deze kenmerken $\square \|$ Thetzelfde zijn. Zo zijn zowel bij ASS als bij psychose stoornissen in het contact, Katatonie, sociale teruggetrokkenheid en afvlakkingen in het affect te zien. Deze overlap in symptomen zou eraan bij kunnen dragen dat de twee stoornissen onterecht tegelijk gediagnosticeerd worden, waardoor schattingen van het samengaan van deze diagnose $\square$ te hoog zijn. Daarnaast is het mogelijk dat juist diegenen die op latere leeftijdworden gediagnosticeerd met ASS gezondheidsklachten. Deze zogenaamde selectiebias van mensen met meer gezondheidsklachten $\square$ zoals psychose, kan er wederom toe leiden dat het risico op psychose bij ASS overschat wordt. Meer onderzoek

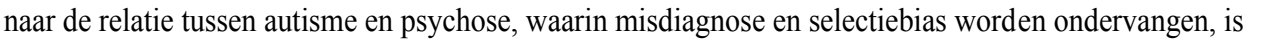
dus noodzakelijk. $\square$

Om de aanmaak en/of afgifte van de neurotransmitter dopamine in het brein te meten $1 \mathrm{Wl}$

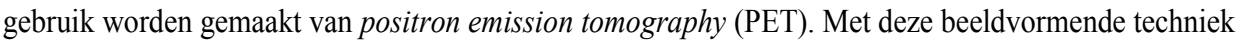
kunnen specifieke aspecten van neurotransmittersystemen in kaart worden gebracht bij levende

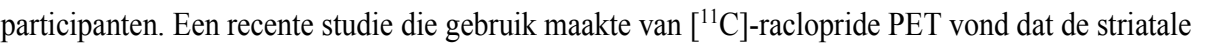
dopamine afgifte in reactie op beloning verlaagd was bij volwassenen met ASS

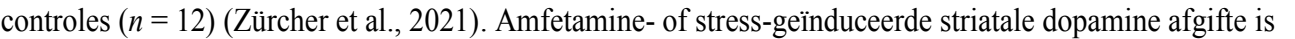
nog niet onderzocht (Zürcher et al., 2015) $₫$ Slechts twee studies onderzochten de striatale dopaminesynthesecapaciteit bij ASS $\square \square \square \square$ FFOPA PET $\square \square$ isteekproefgroottes waren erg klein $\square$

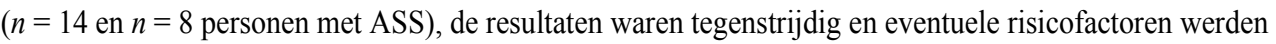

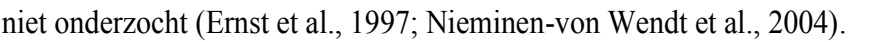

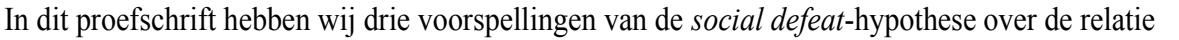

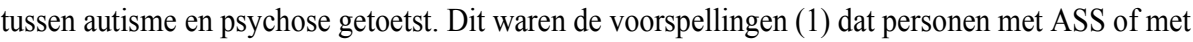
kenmerken van autisme verhoogde risico's hebben op het ontwikkelen van psychoses ten opzichte van

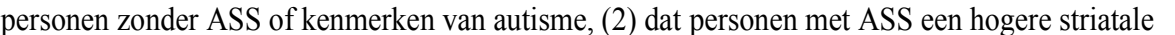

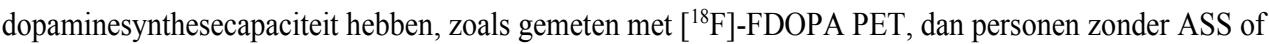

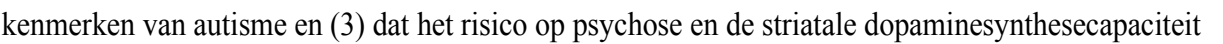

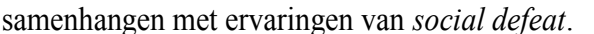

\section{$\square$}

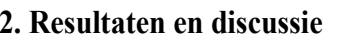

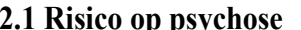

In hoofdstuk II gebruikten wij informatie uit de psychiatrische casusregisters Midden $\mathbb{N}$ ederland en Noord Nederland om het verband tussen ASS en niet affectieve psychotische stoornissen te onderzoeken. In hoofdstuk III bekeken wij de relatie tussen kenmerken van autisme en psychotische

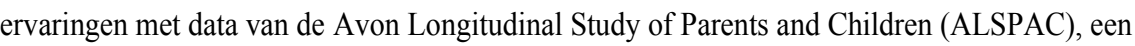
cohortstudie van personen die in 1991 en 1992 zijn geboren in de voormalige provincie Avon in het Verenigd Koninkrijk. Een aanname die wij binnen deze twee longitudinale studies deden, was dat ASS of kenmerken van autisme die op vroege leeftijd al aanwezig waren waarschijnlijk niet sterk beïnvloed

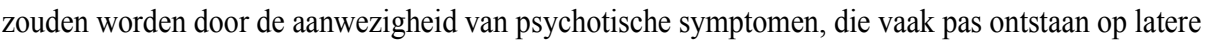
leeftijd. Door rekening te houden met de leeftijd waarop kenmerken van autisme aanwezig waren, verwachtten wij de kans op misdiagnose of selectiebias te verkleinen. $\square$ 


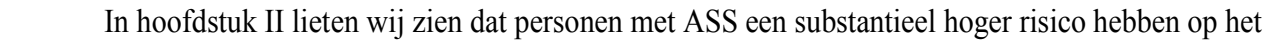

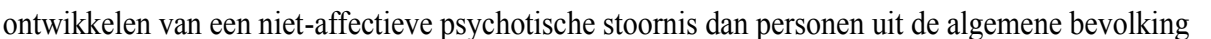

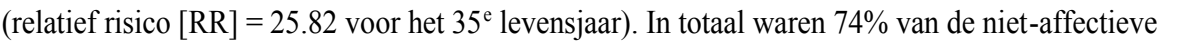

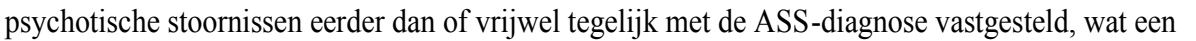

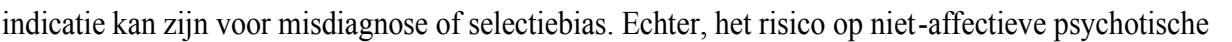

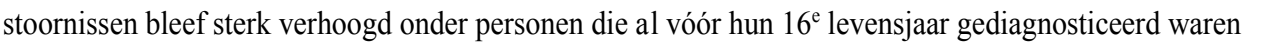

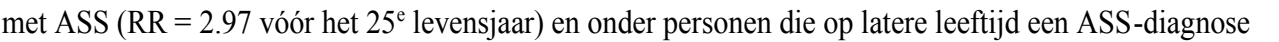

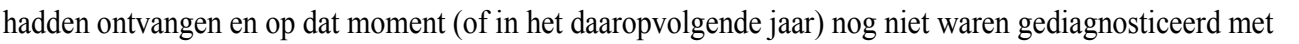

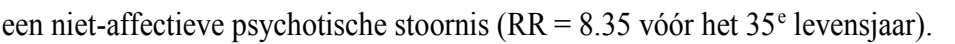

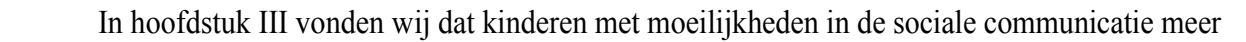

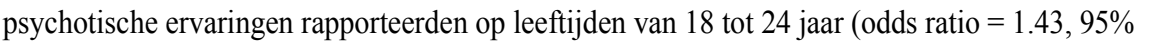

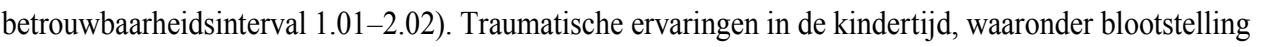

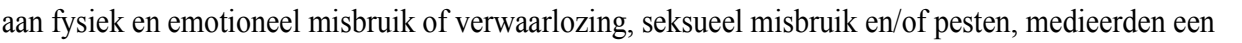

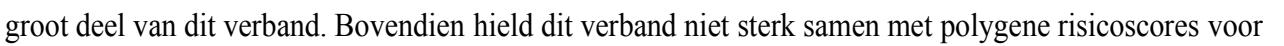

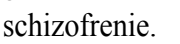

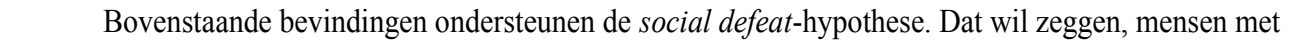

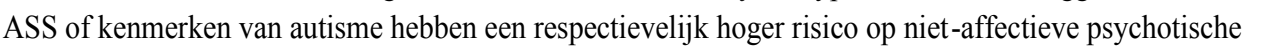

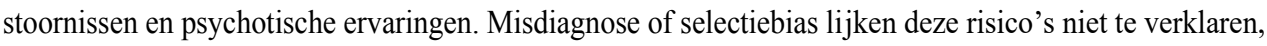

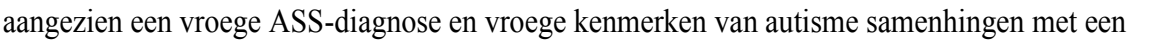

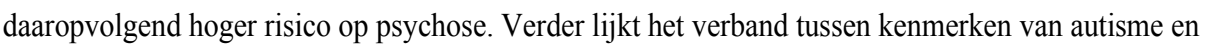

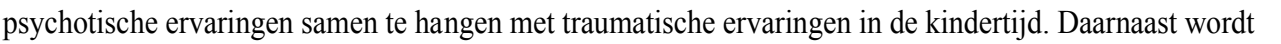

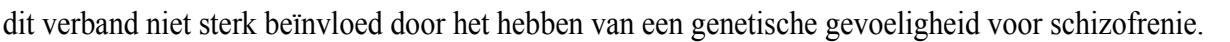
$\square$

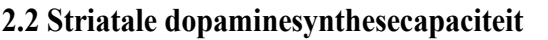

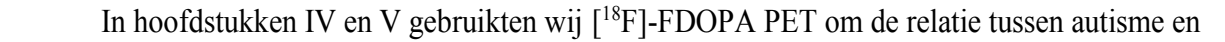

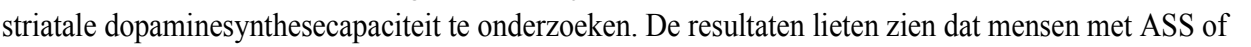

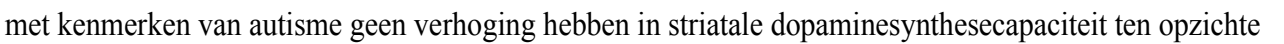

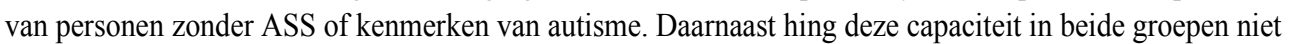

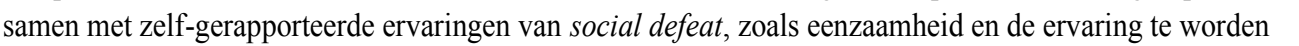

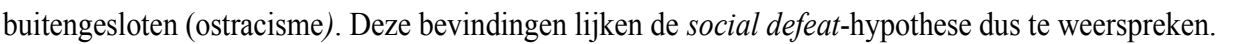

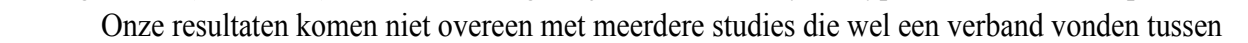

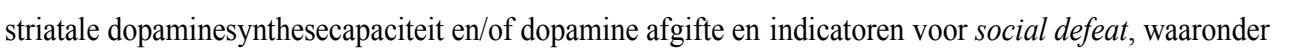

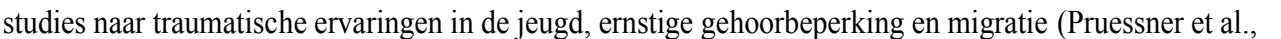

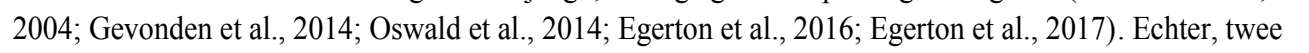

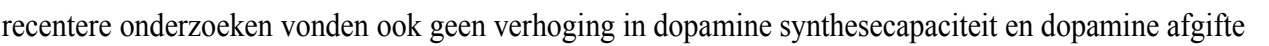

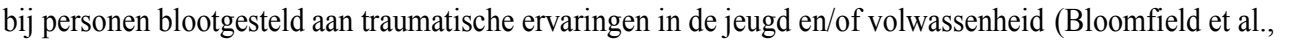
2019; Dahoun et al., 2019) $\square$

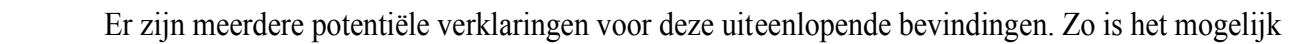

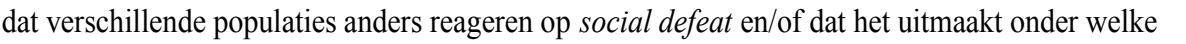

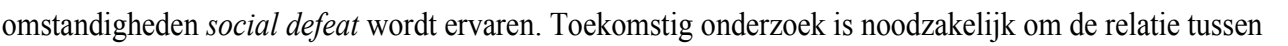

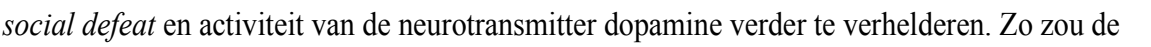

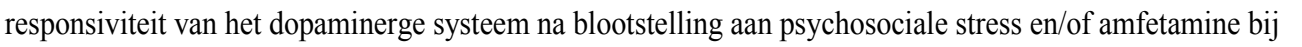

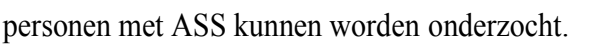




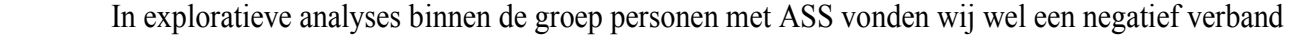

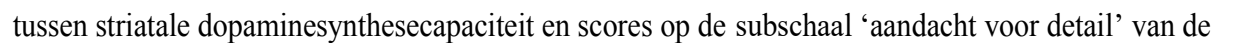

Autism Spectrum Quotient (AQ;

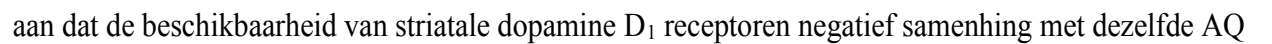

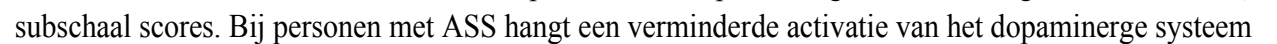

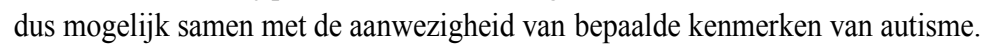
$\square$

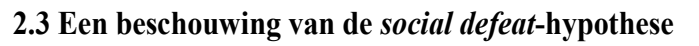

\begin{aligned} \hline \\ \hline\end{aligned}

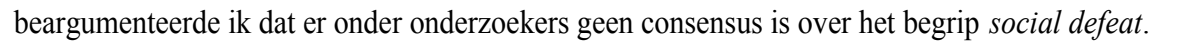

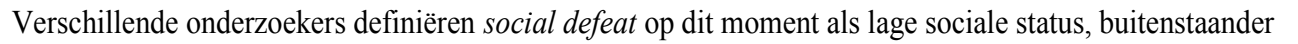

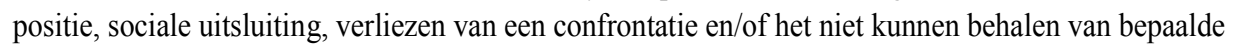
पा山(Björkqvist, 2001; Gilbert et al., 2002; Selten \& Cantor Graae, 2005)

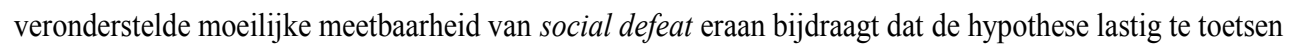
ए

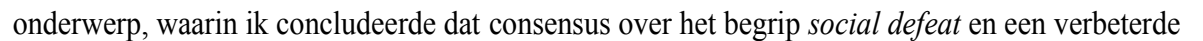

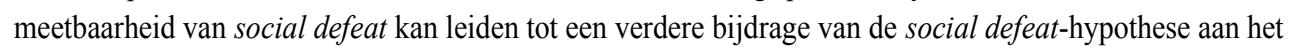

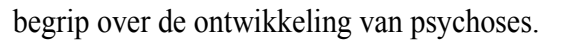

$\square$

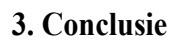

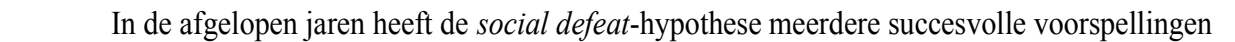

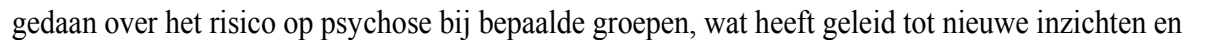

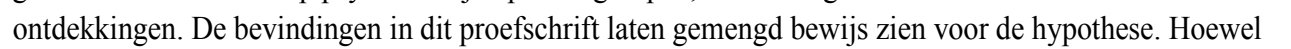
de risico's op psychotische stoornissen en psychotische ervaringen bij respectievelijk en personen met kenmerken van autisme verhoogd zijn en deze risico's samenhangen met blootstelling

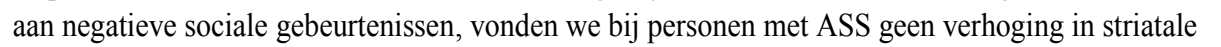

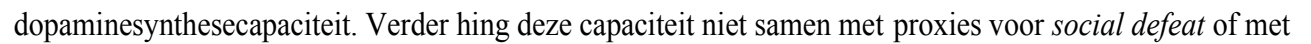
de aanwezigheid van meer kenmerken van autisme. Gezien het belang van de rol van de sociale omgeving

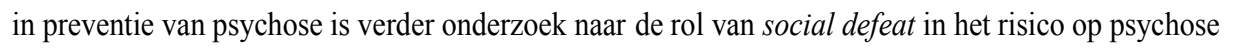
पाणापाणाप

$\square$ 


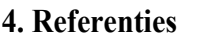

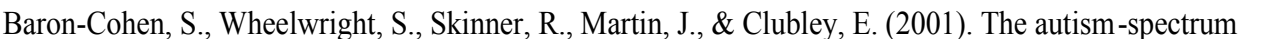

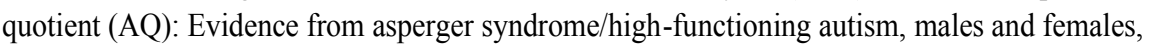

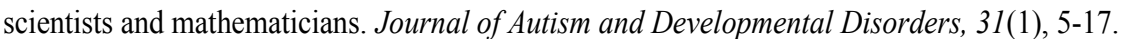

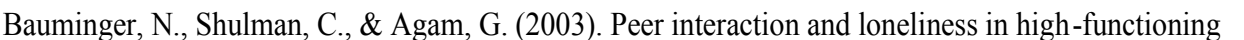

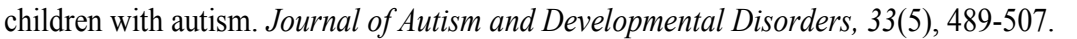

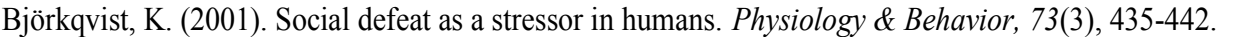

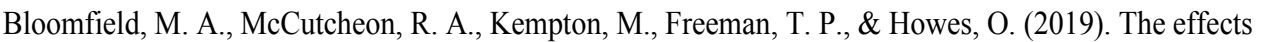

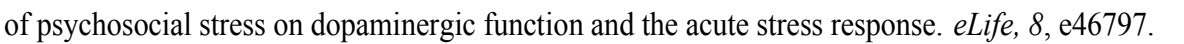

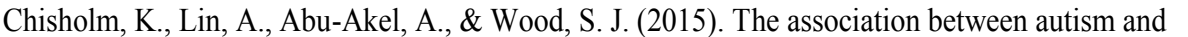

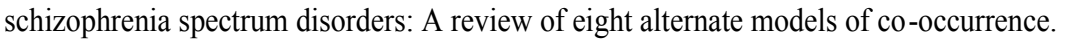

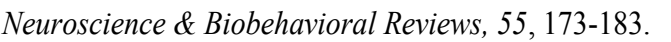

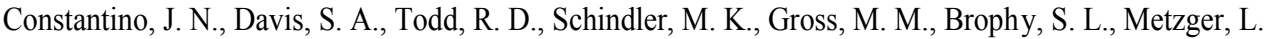

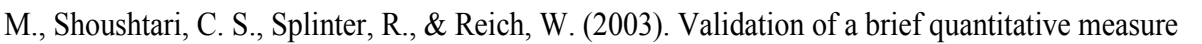

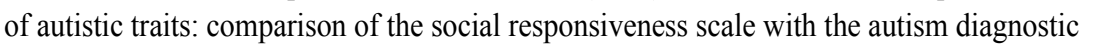

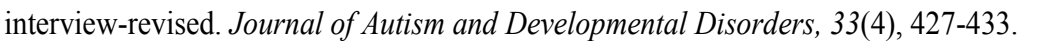

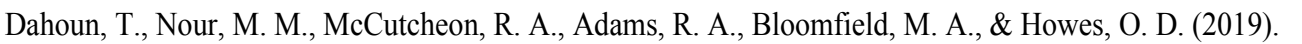

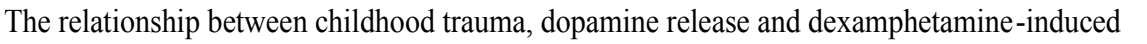

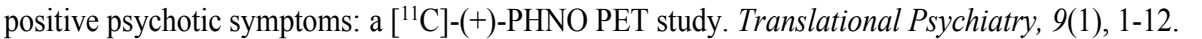

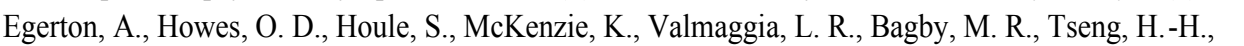

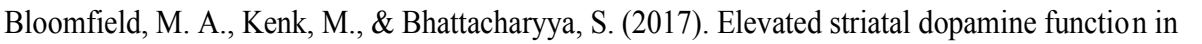

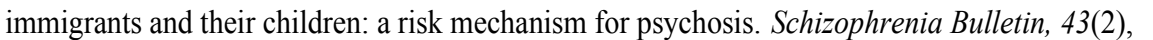
$\square|ण 1| \square$

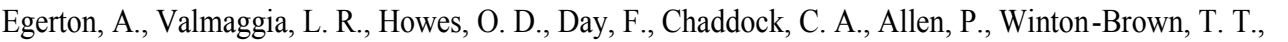

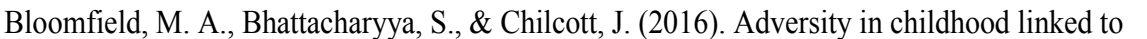

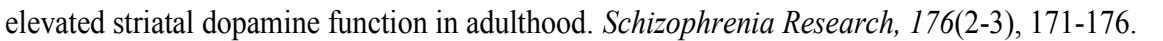

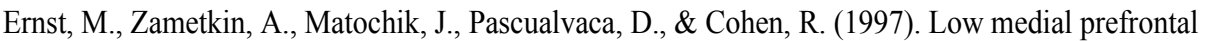

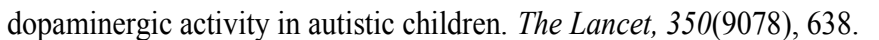

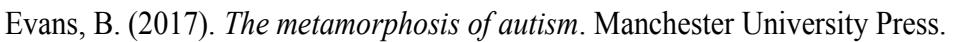

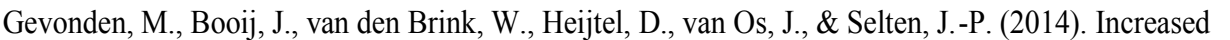

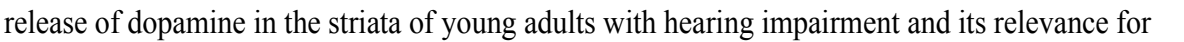

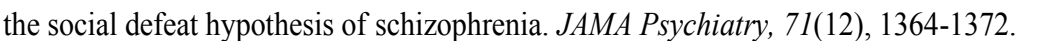

a

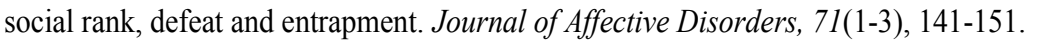

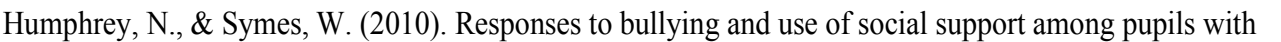

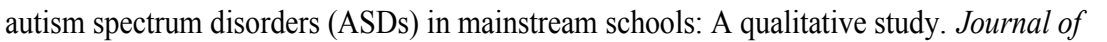

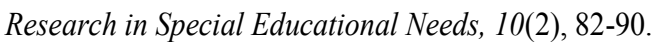

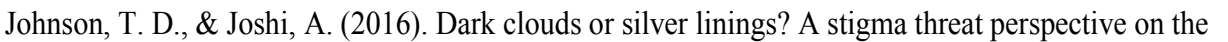

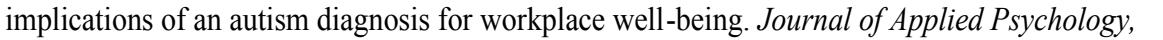
पाणा\|ापाणाण

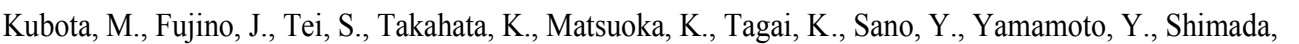

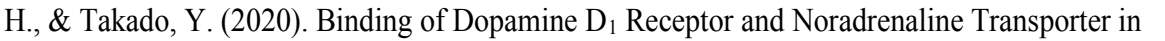

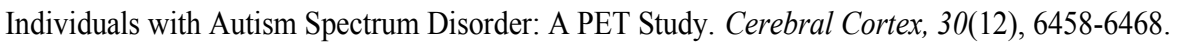




\section{Appendices}

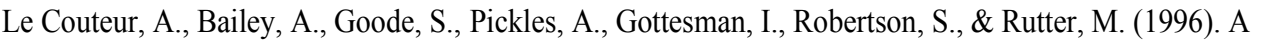

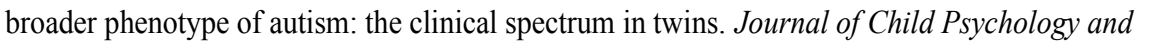

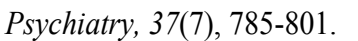

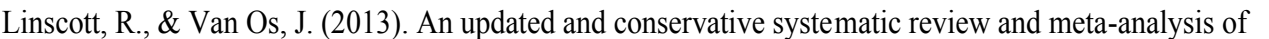

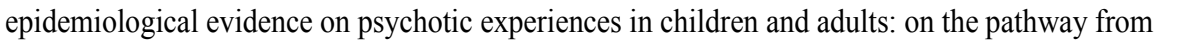

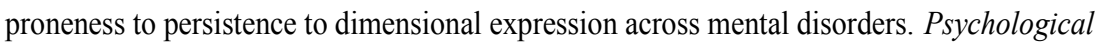

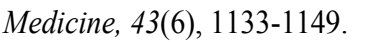

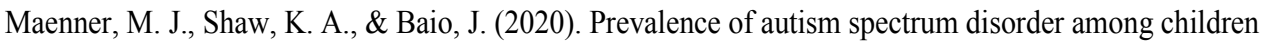

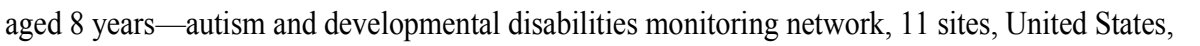

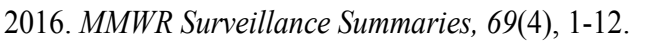

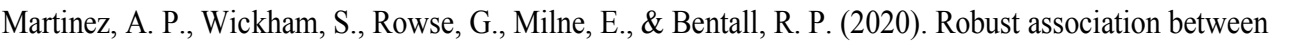

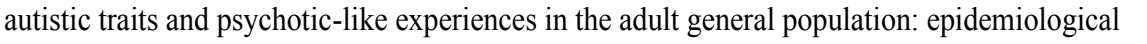

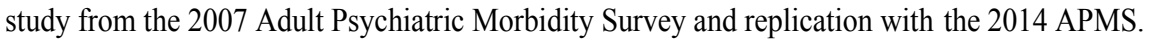

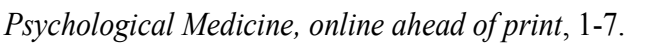

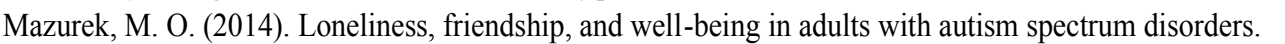

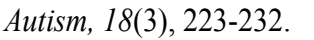

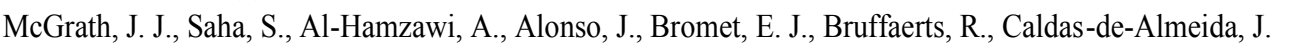

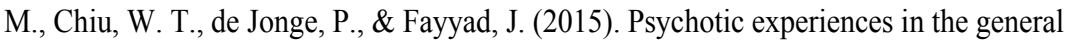

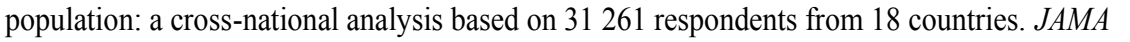

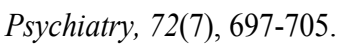

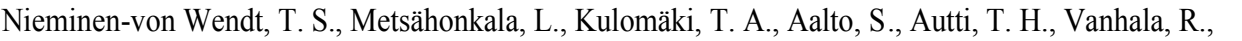

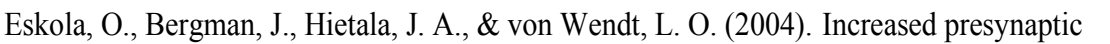

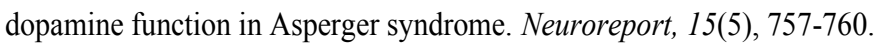

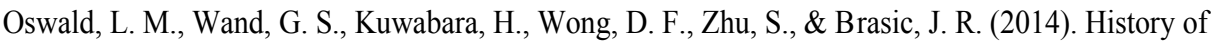

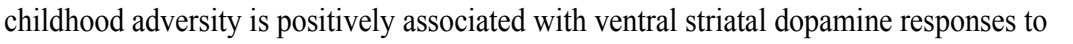

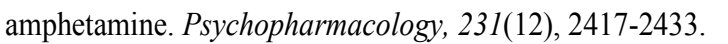

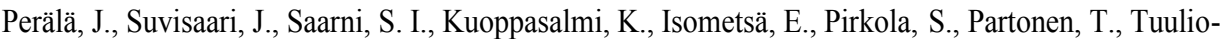

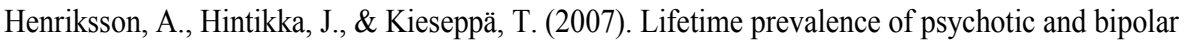

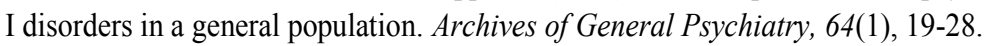

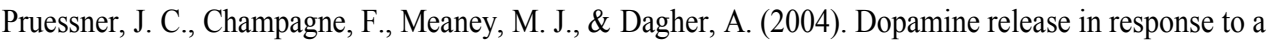

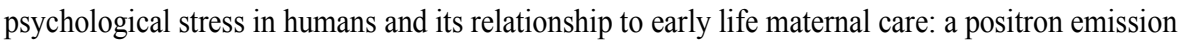

ए

a

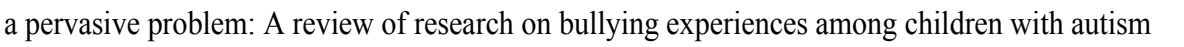

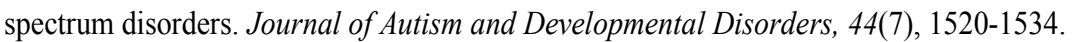

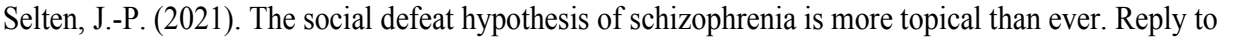

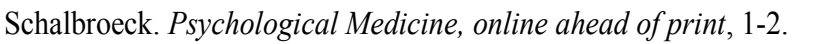

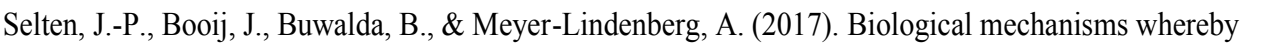

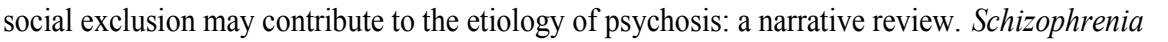

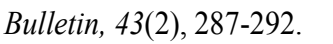

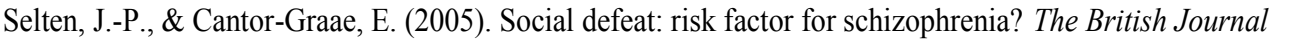

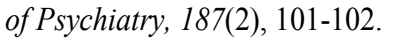

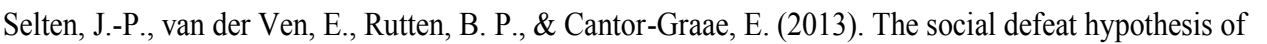

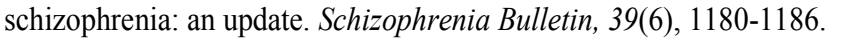




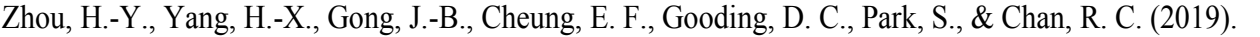

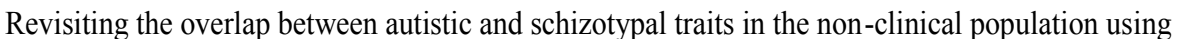

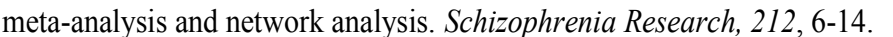

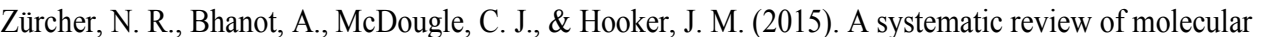

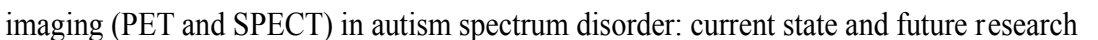

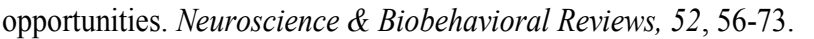

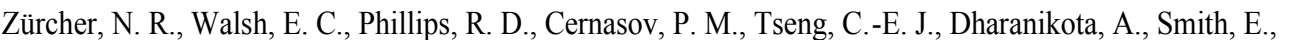

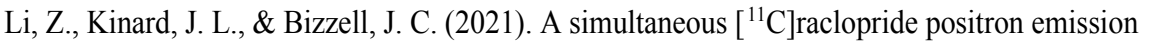

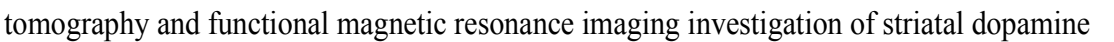

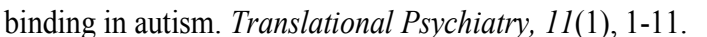

$\square$ 


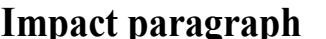

$\square$

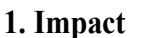

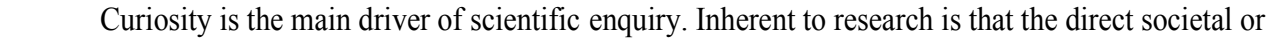

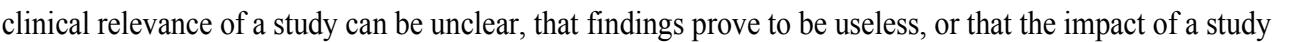

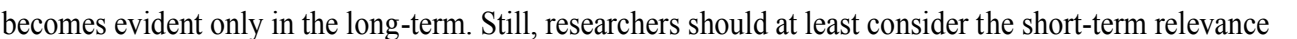

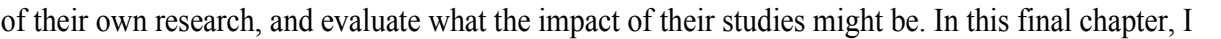

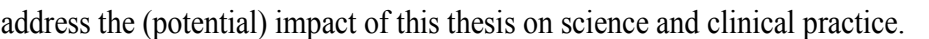

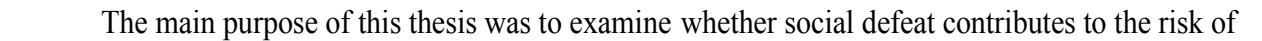

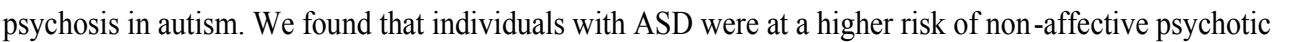

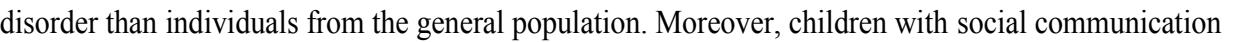

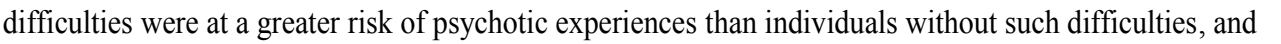

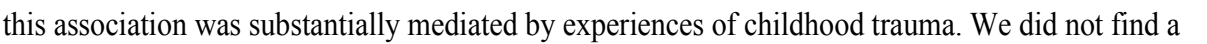

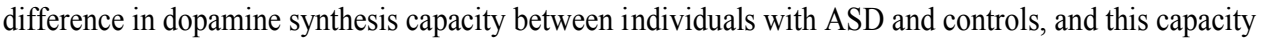

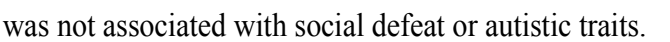

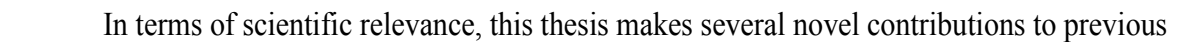
प

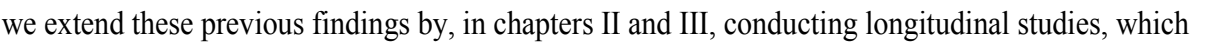

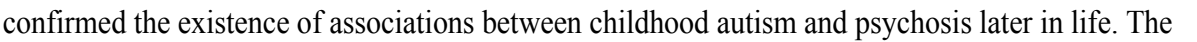

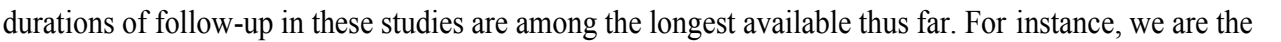

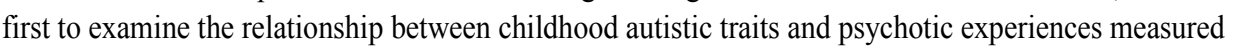

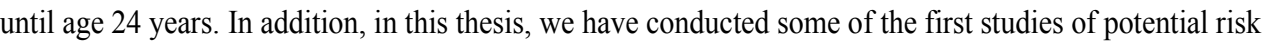
ए

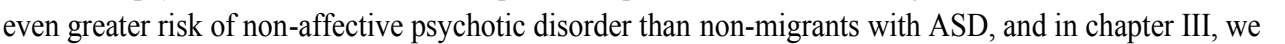
ए एाएणाएणाए

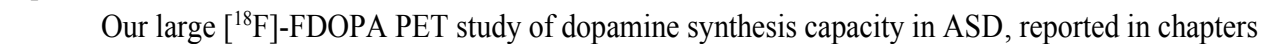

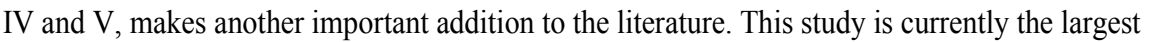

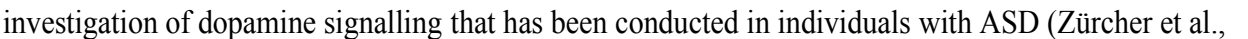

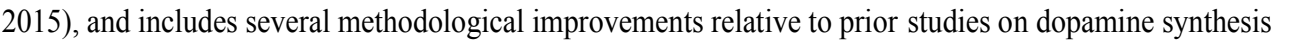

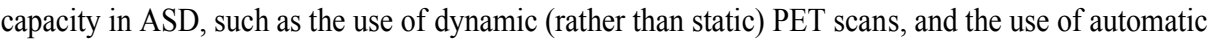

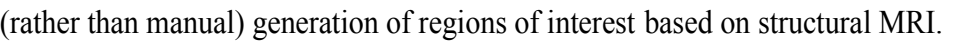

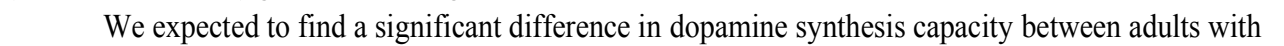

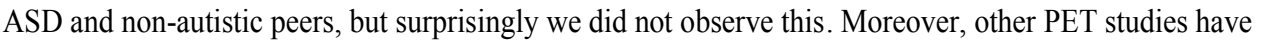

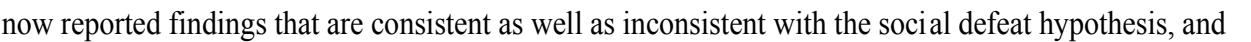

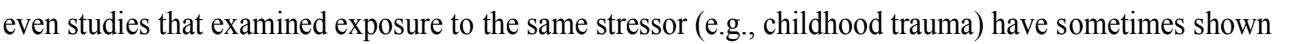

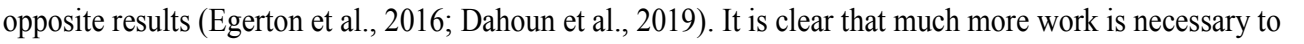

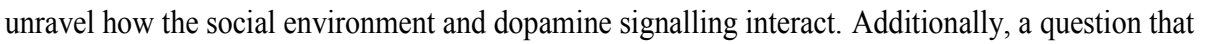

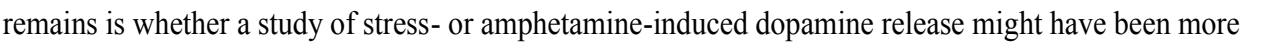

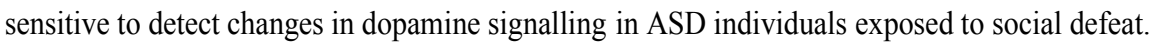

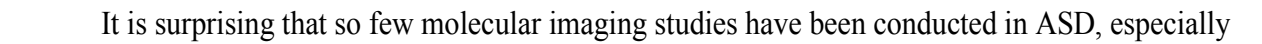

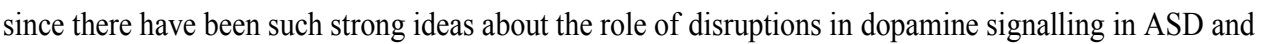

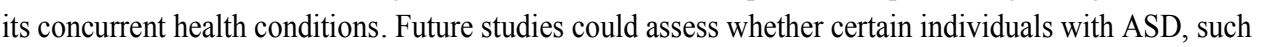

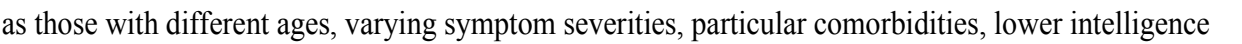




\section{Appendices}

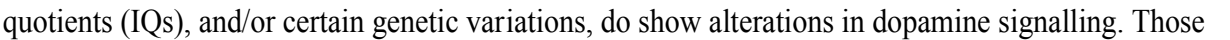

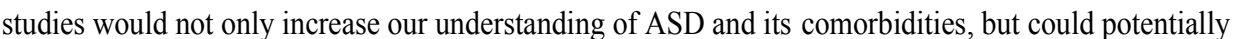

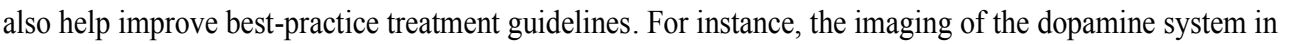

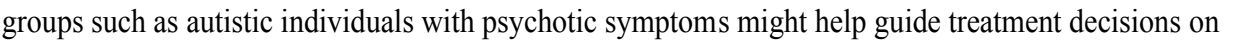

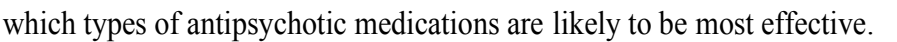

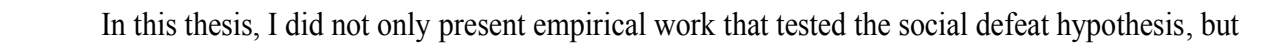

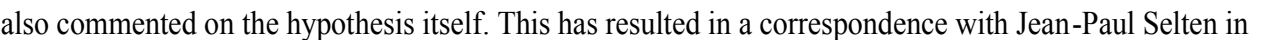

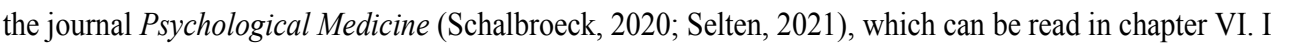

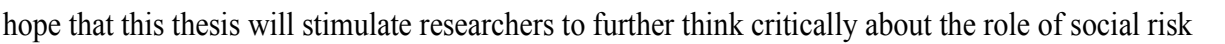

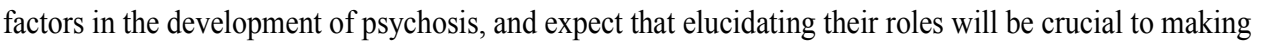

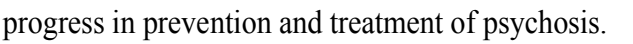

\begin{tabular}{c}
\hline \\
\hline
\end{tabular}

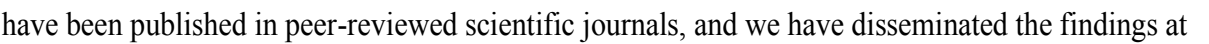

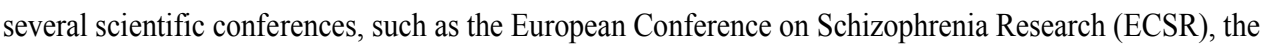

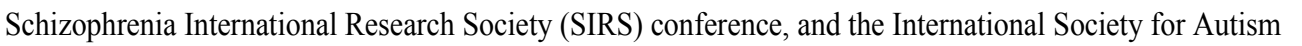

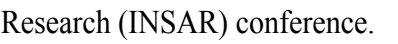

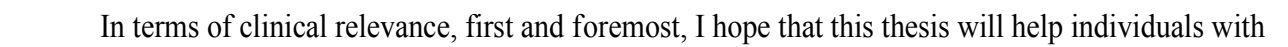

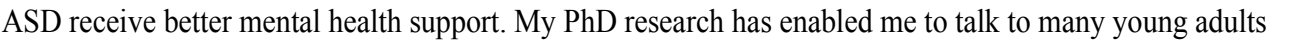

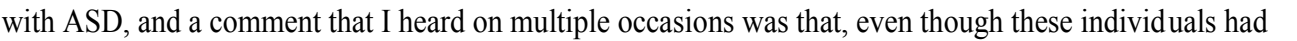

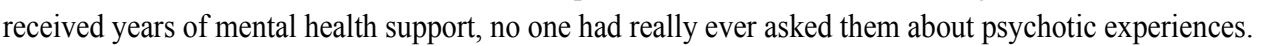
口 प

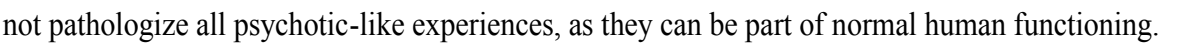

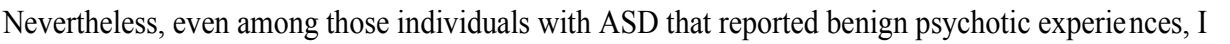

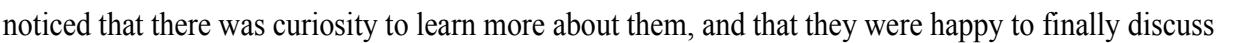

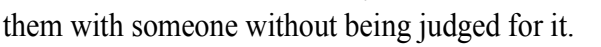

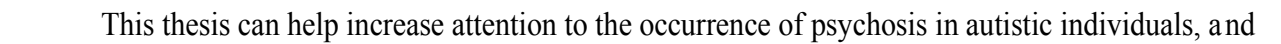

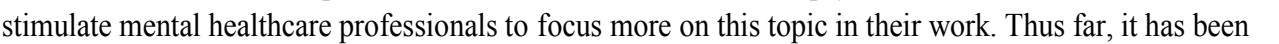

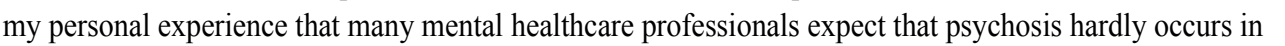

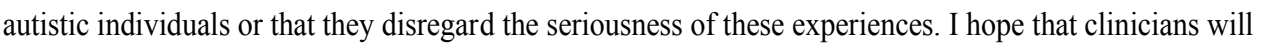
ए

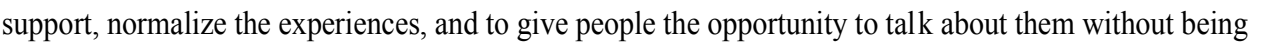

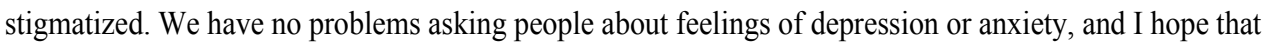

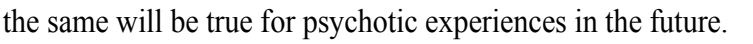

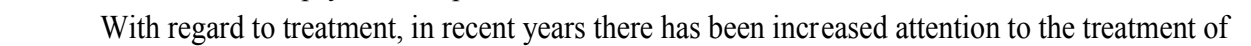

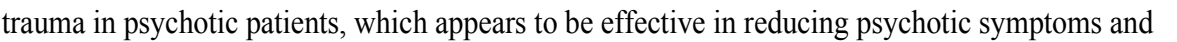

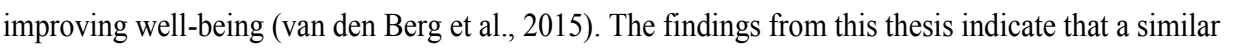

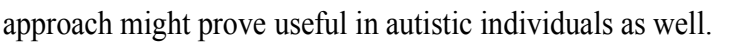

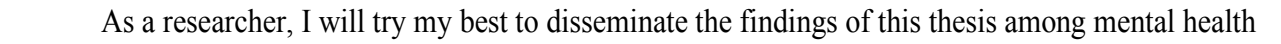

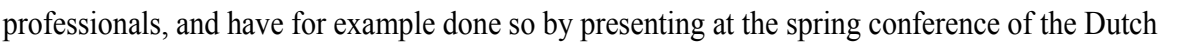

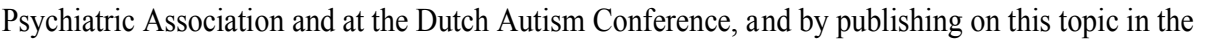

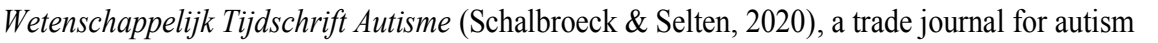

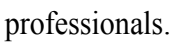




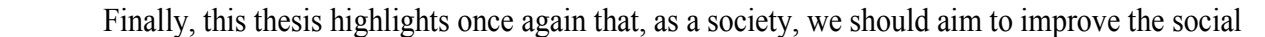

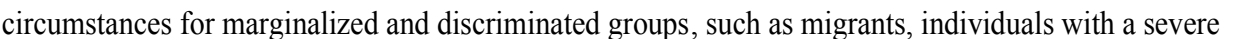

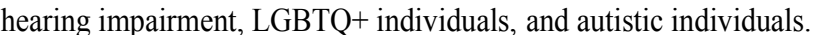




\section{Appendices}

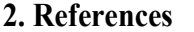

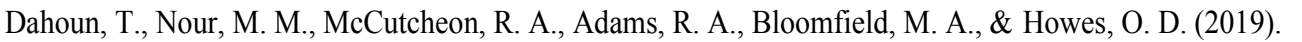

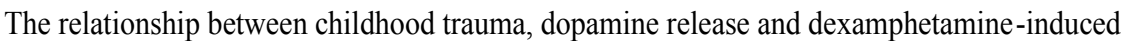

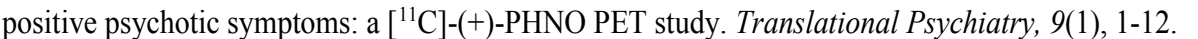

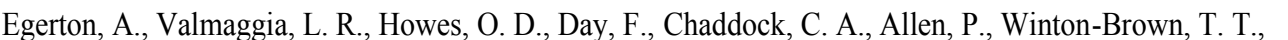

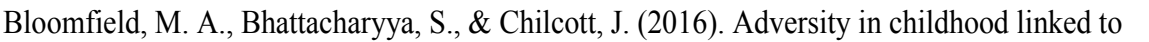

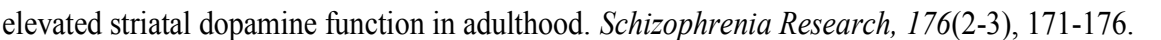

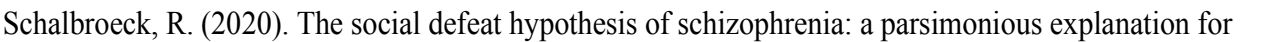

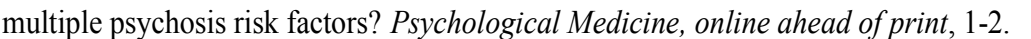

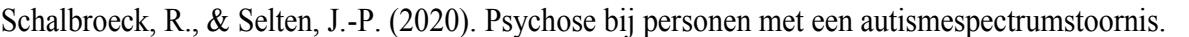

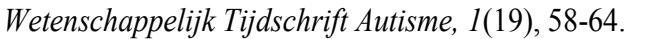

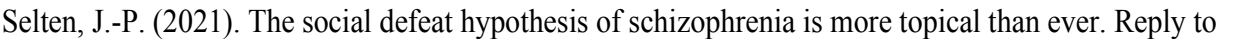

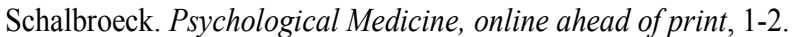

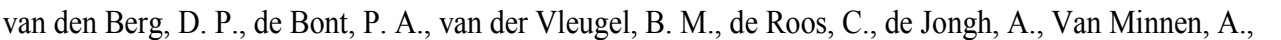

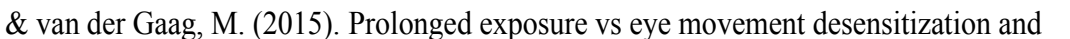

ए

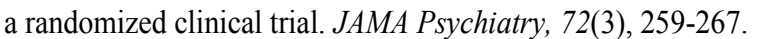

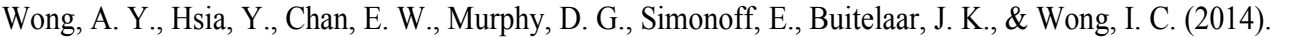

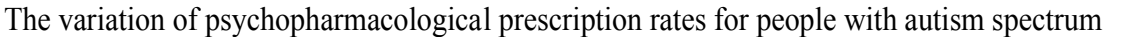

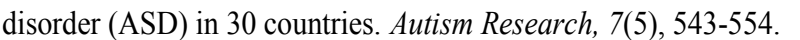

a

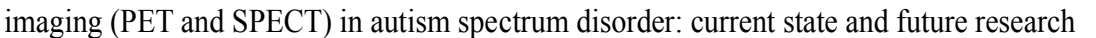

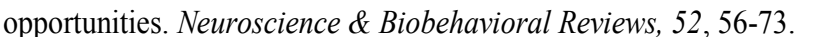

$\square$

$\square$ 


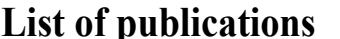

$\square$

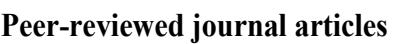

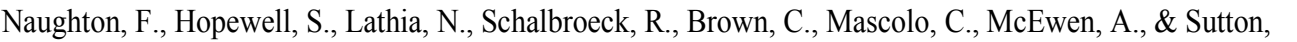

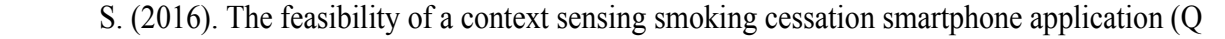

\begin{aligned} \hline \\ \hline\end{aligned}

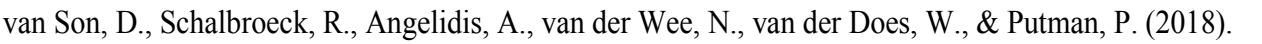

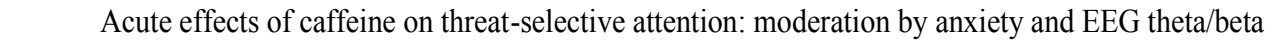

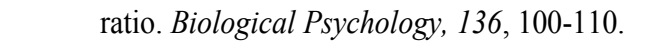

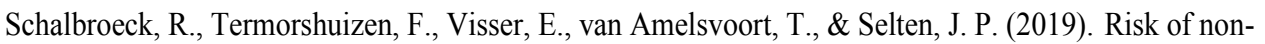

\begin{aligned} \hline \\ \hline\end{aligned}

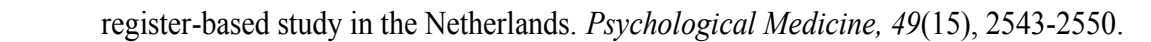

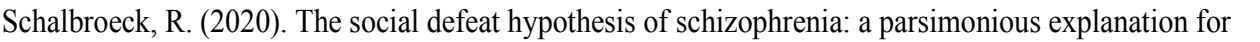

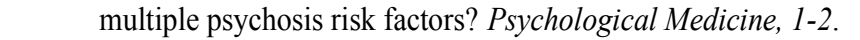

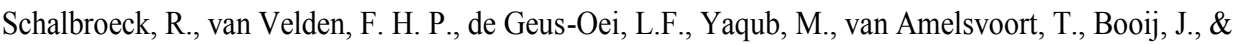

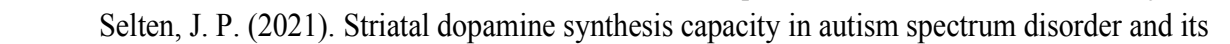

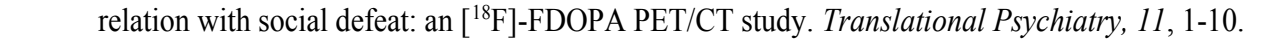

$\square$

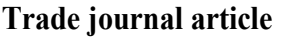

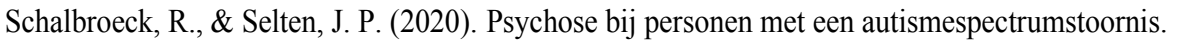

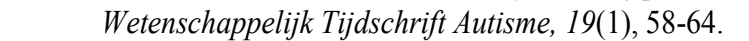


Appendices

$\square$ 


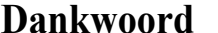

$\square$

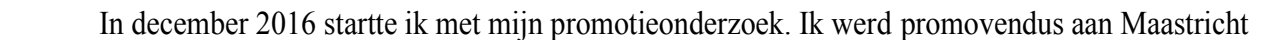

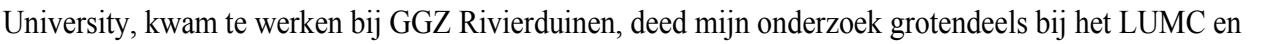

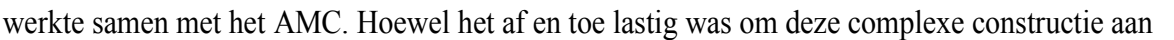

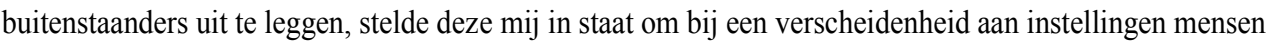

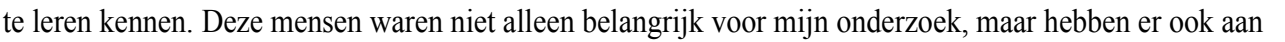

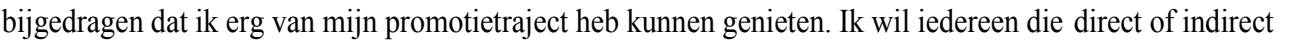

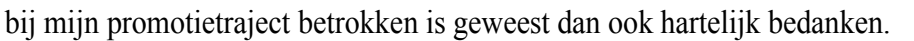

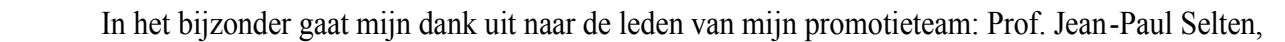

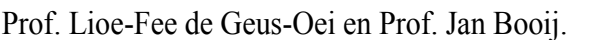

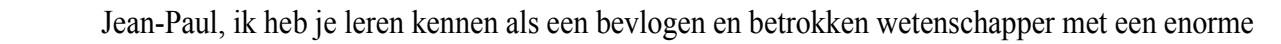

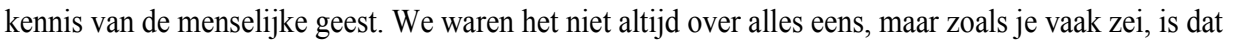
ए

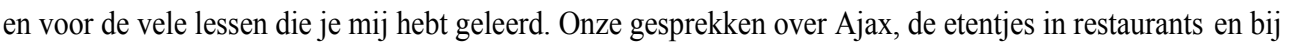

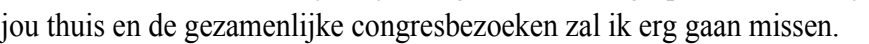

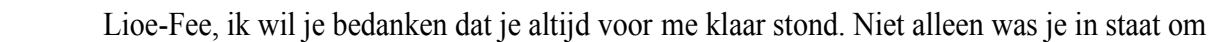

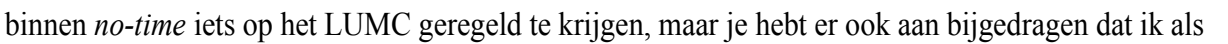

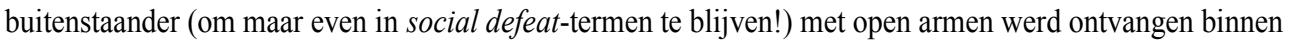

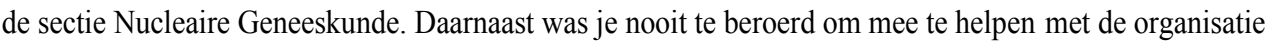

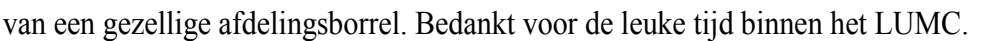

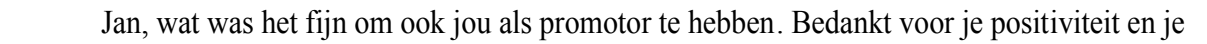

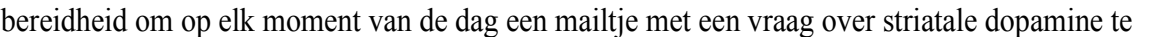

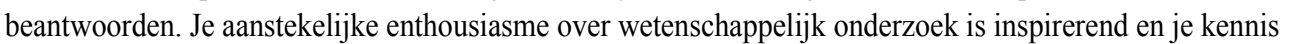

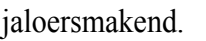

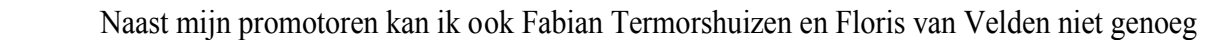

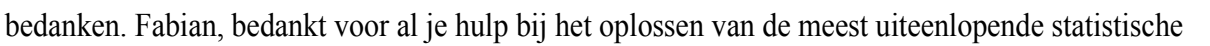
पण

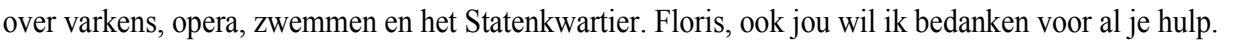

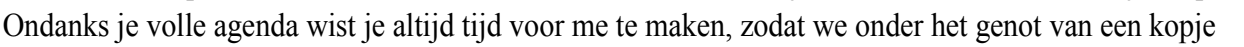

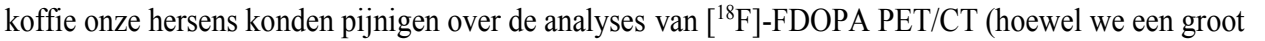

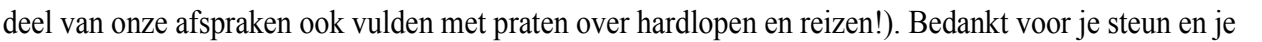

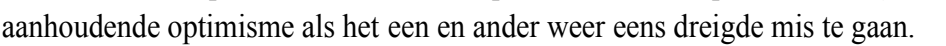

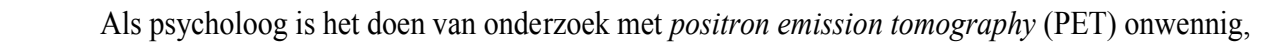

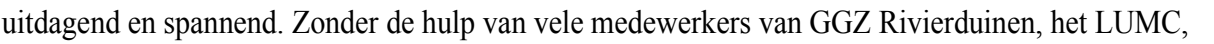

\section{Maastricht University, het AMC, het VUmc en King's College London was dit mij niet gelukt. Bedankt} $\square[\| 110$

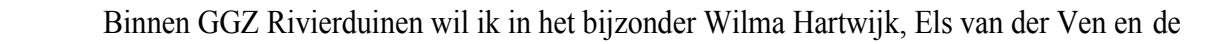

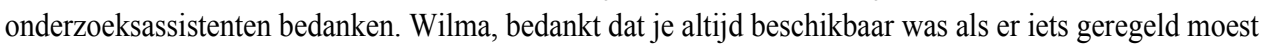

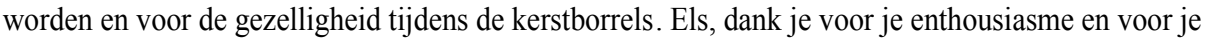

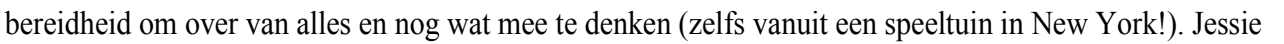

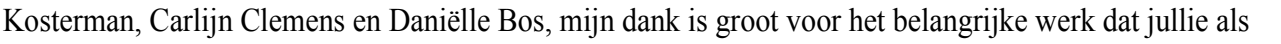

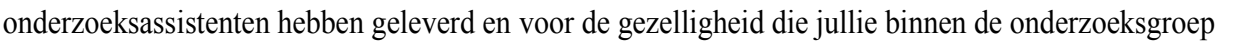
$\square \Pi\|\Pi\|\|\Pi\|$ 


\section{Appendices}

$\square \quad$ Ook bedank ik mijn collega's van het LUMC die betrokken waren bij het maken van de PET/CT $\square$

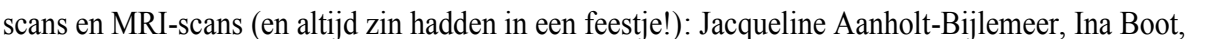

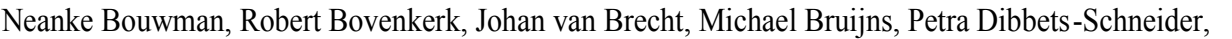

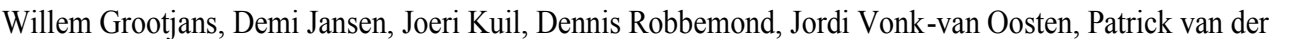

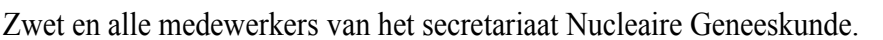

\begin{aligned} \hline \\ \hline\end{aligned}

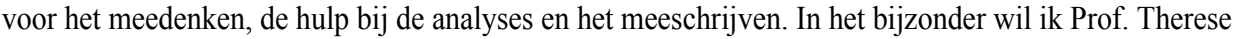
प

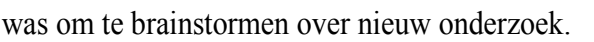

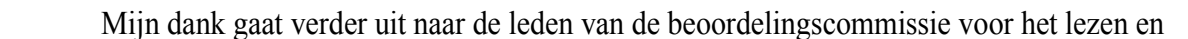

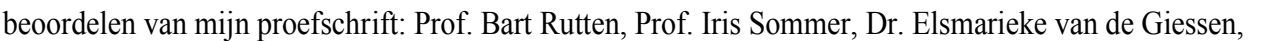

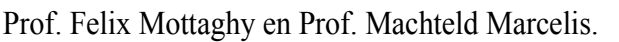

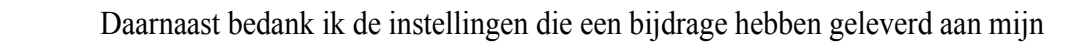

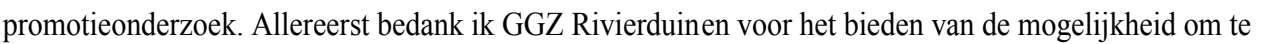

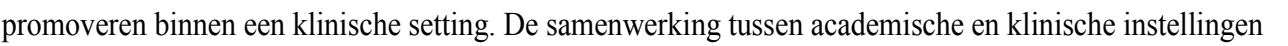

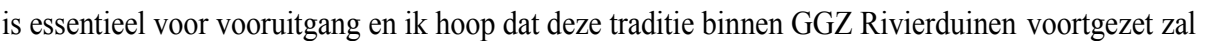

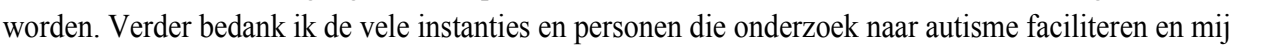

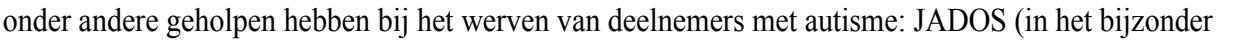

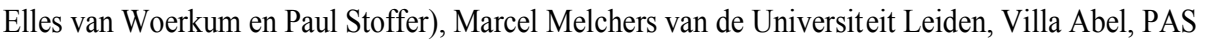

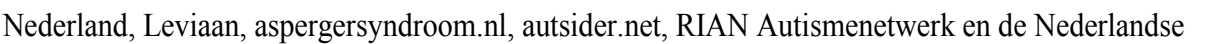

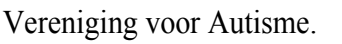

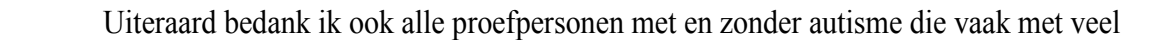

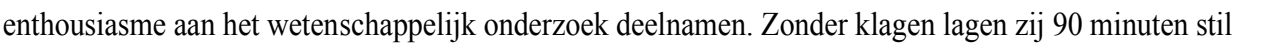

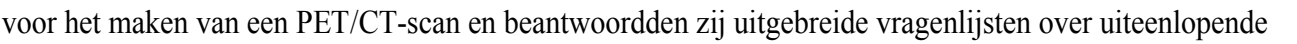

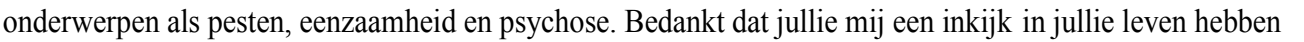

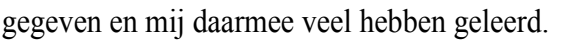

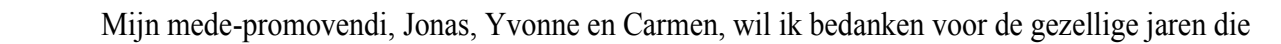

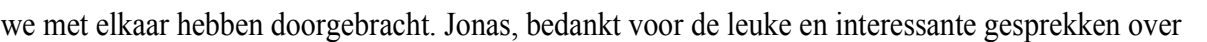

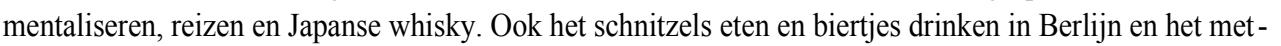

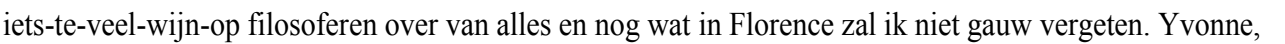

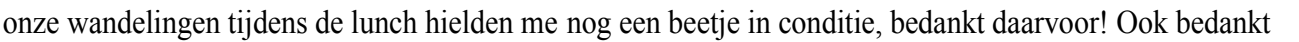

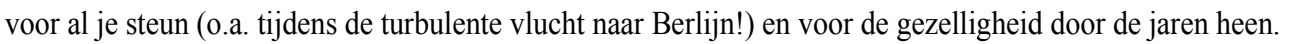

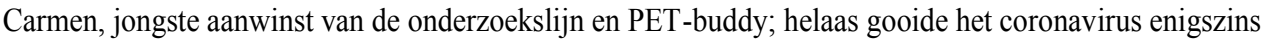

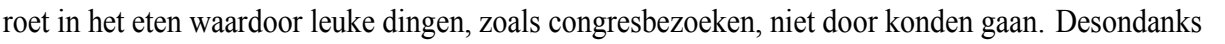

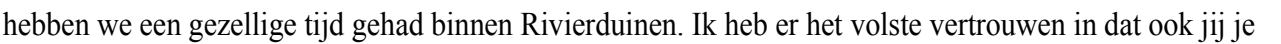

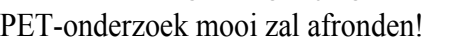

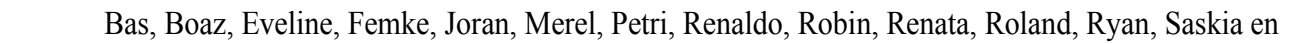

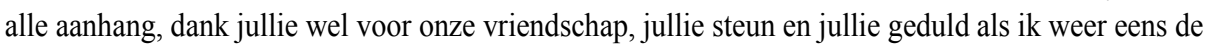

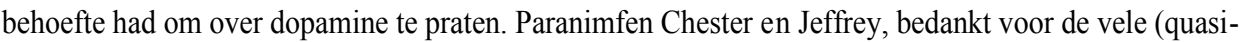

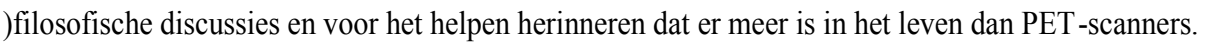

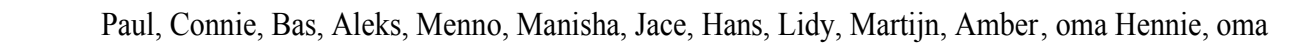

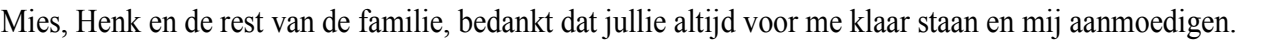

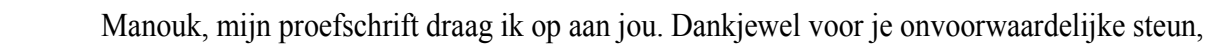

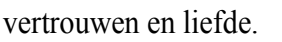




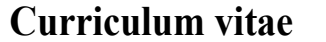

$\square$

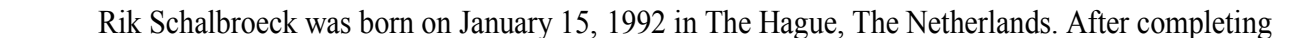
high school at the Alfrink College Zoetermeer, he obtained his bachelor's degree in Psychology at Leiden University. At the same university, he completed his research master's in Psychology, with a

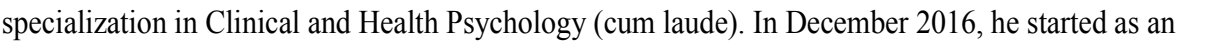

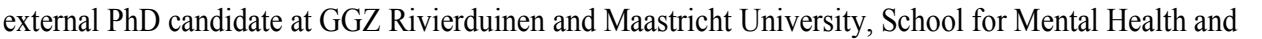

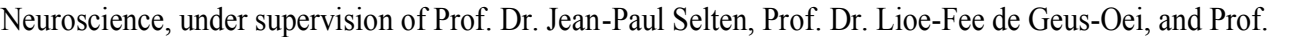
a $\square \square[\|ा\|$ 